\title{
Development of Screenable Pressure Sensitive Adhesives
}

Final Report for Project DE-FC07-00ID13881

\author{
By \\ Steven J. Severtson (Principal Investigator) \\ XinPing Wang, Michael J. Nowak and Jihui Guo \\ Department of Wood and Paper Science, University of Minnesota \\ 2004 Folwell Avenue, St. Paul, MN 55108 \\ Mark S. Kroll \\ H.B. Fuller Company, 1200 Willow Lake Boulevard, St. Paul, MN 55110 \\ Jennifer A. Lien \\ Boise Paper Solutions, 400 Second Street, International Falls, MN 56649 \\ Carl J. Houtman and Karen L. Scallon \\ USDA Forest Service, Forest Products Laboratory, One Gifford Pinchot Drive \\ Madison, WI 53705
}

November 28, 2003

\section{Executive Summary}

Several approaches were examined for meeting the project objective of developing pressure sensitive adhesive (PSA) products that are engineered for enhanced removal during the processing of recycled fiber, also known as environmentally benign PSAs. These included the 1.) design of environmentally benign PSA films, 2.) development of paper face stock with high screening removal efficiencies that retain attached PSA films and 3.) modification of face stock surface properties to enhance the removal of PSA films. All three approaches yielded promising laboratory results that were confirmed at the pilot scale and appear to be commercially viable. Most of this study focused on hot-melt formulations, which compose a smaller portion of the PSA label market than water-based formulations. However, hot-melt formulations are considerably less complex and allow great flexibility for property modifications. The results of this research have direct application to the study of water-based PSAs, which will be the focus of future work. 


\section{CONTENTS}

$\begin{array}{ll}\text { 1. INTRODUCTION } & 3\end{array}$

2. EXPERIMENTAL SECTION 4

2.1 Chemicals and Materials $\quad 4$

$\begin{array}{lll}2.2 & \text { Tensile Tests of Substrates } & 7\end{array}$

2.3 Dynamic Mechanical Spectroscopy 7

$\begin{array}{lll}2.4 & \text { PSA Loop Tack } & 7\end{array}$

$\begin{array}{lll}2.5 & \text { Peel Strength to Stainless Steel } & 8\end{array}$

2.6 Shear Adhesion Failure Measurements $\quad 8$

$\begin{array}{lll}2.7 & \text { Toluene Insolubles } & 8\end{array}$

$\begin{array}{lll}2.8 & \text { Acid Number } & 8\end{array}$

2.9 Sessile Drop Shape Analysis $\quad 9$

2.10 Procedure for Testing the Removal Efficiencies of PSAs at $46^{\circ} \mathrm{C} \quad 9$

2.11 Procedure for Testing the Removal Efficiencies of PSAs
at Various Temperatures

3. DEVELOPMENT OF SCREENABLE PSA FORMULATIONS 10

3.1 Temperature Dependence of Removal Efficiencies for Hot-Melt PSA Formulations $\quad 11$

3.2 Modeling the Fragmentation Behavior of Hot-Melt PSAs 14

$\begin{array}{llr}3.3 & \text { Pilot Trials } & 16\end{array}$

$\begin{array}{llr}3.4 & \text { Figures } & 17\end{array}$

4. ENHANCING PSA SCREENABILITY WITH TREATED SUBSTRATES 22

4.1 Influence of PET Face Stock on PSA Removal Efficiencies 22

4.2 Influence of Wet-Strength Paper Substrates on PSA Removal 25

4.3 Enhancing PSA Adhesion to Wet-Strength Paper Substrates 26

$\begin{array}{lll}4.4 & \text { Summaries and Conclusions } & 28\end{array}$

$\begin{array}{llr}4.5 & \text { Pilot Trials } & 28\end{array}$

$\begin{array}{llr}4.6 & \text { Figures } & 29\end{array}$

5. OPTIMIZING LAMINATE COMPONENTS TO INCREASE SCREENABILITY 38

5.1 Characterization of PSA Laminate Components 38

5.2 Influence of Commercial Face Stock on Removal Efficiencies 39

5.3 Influence of Substrate Wet-Strength on Removal Efficiencies 41

5.4 Influence of PSA-Face Stock Adhesion on Removal Efficiencies 42

$\begin{array}{lll}5.5 & \text { Polite Trials } & 44\end{array}$

$\begin{array}{lll}5.6 & \text { Figures } & 45\end{array}$ 
6. ACKNOWLEDGEMENTS 56

$\begin{array}{ll}\text { 7. LITERATURE CITED } & 57\end{array}$

8. PUBLICATIONS, PRESNTATIONS, PATENTS AND TECHNOLOGY TRANSFER

Appendix 1. Pilot Scale Testing of F-2004, 2005, 2008 and 2012

Appendix 2. Pilot Scale Testing of F-2001 and $2002 \quad 88$

Appendix 3. Pilot Scale Testing of F-2006 and $2007 \quad 115$

Appendix 4. Final Report Submitted by Dr. Yulin Deng of IPST (Subcontractor) 139 


\section{Introduction}

An industrial research area of high activity in recent years has been the development of pressure sensitive adhesive (PSA) products that do not interfere with the processing of post-consumer waste. $^{1-3}$ The problem of PSA contamination is arguably the most important technical challenge in expanding the use of recycled fiber. The presence of PSAs in recovered paper creates problems that reduce the efficiency of recycling and papermaking operations and diminish product quality. The widespread use of PSAs engineered to avoid these problems, often referred to as environmentally benign PSAs, could greatly increase the commercial viability of utilizing secondary fiber. Much of the research efforts in this area have focused on the development of PSAs that are designed for enhanced removal with cleaning equipment currently utilized by recycling plants. Most removal occurs at the pressure screens with the size and shape of residual contaminants in the process being the primary criteria for their separation. A viable approach for developing environmentally benign PSAs is their reformulation to inhibit fragmentation. ${ }^{4}$ The reduction of adhesives to small particles occurs almost exclusively during repulping; a process in which water and mechanical energy are used to swell and reduce paper products to their constituent fiber. Engineering PSA products to promote the formation of larger adhesive particles during repulping will greatly enhance their removal and reduce or eliminate their impact on the recycling process.

Formulating commercially viable environmentally benign PSA products requires the introduction of properties that enhance their removal from recycling operations without sacrificing adhesive performance or increasing manufacturing costs. The initial focus of this study was on hot-melt PSA products, which compose approximately $15 \%$ of the worldwide PSA market and is price competitive with water-based PSA. ${ }^{5}$ Hot-melt PSA can be described as thermoplastic viscoelastic solid mixtures, which upon heating become molten allowing for processing including their application to carriers to produce products such as PSA labels. ${ }^{6}$ Unlike water-based PSAs, hot-melt formulations are relatively simple systems consisting of only a few components. Most will contain a base polymer or polymer blend (20-50 wt.\%), tackifying resin (30-60 wt.\%), plasticizer (0-25 wt.\%) and stabilizer used to inhibit degradation (0.1-2 wt.\%). The base polymers typically utilized are styrenic block copolymers consisting of the higher glass transition temperature $\left(\mathrm{T}_{\mathrm{g}}\right)$ styrene segments in combination with lower $\mathrm{T}_{\mathrm{g}}$ (more rubbery) polymeric components such as ethylene-propylene, ethylene-butene, isoprene or butadiene. ${ }^{7,8}$ The styrene and rubbery blocks are incompatible, which provides opportunities for manipulation of mechanical properties through the use of tackifying resins and plasticizers specific to the different microphases that develop. The most common tackifying resins used in thermoplastic formulations are rosin acid and hydrocarbon derivatives. ${ }^{8}$ Rosin tackifiers are composed of rosin acids and derivatized rosin acids isolated primarily from kraft pulping spent cooking liquors. Hydrocarbon tackifiers are low molecular weight amorphous polymers synthesized from molecular species isolated from petroleum feedstreams. The role of plasticizers in hot-melt formulations is usually to reduce viscosity and lower cost, but plasticizers can also lower the $T_{g}$ of the rubbery phase extending the low temperature tack of an adhesive. Common plasticizers include low molecular weight liquid polyisobutene and mineral oils composed of complex molecular mixtures of aromatic, naphthenic and paraffinic species. The blending of various types of components at different concentrations provides for a broad range of bulk mechanical and surface properties. Use of these systems allows for an efficient iterative 
process involving reformulation, property characterization, and testing of removal efficiencies subsequent to repulping.

In this report, results are reviewed from a study of several approaches for producing benign hotmelt PSA products. A model series of hot-melt PSAs are examined, which consist of a styreneisoprene-styrene/styrene-isoprene (SIS/SI) linear triblock, diblock copolymer blend, tackifying resin, and naphthenic process oil. The PSAs were formulated with two types of tackifiers, a pentaerythritol ester of rosin and $\mathrm{a}_{5}$ petroleum hydrocarbon, to provide variation in the formulation composition. Components were blended in combinations to produce a broad range of properties and attached to paper substrates with bulk and surface properties that were manipulated using poly(amide epichlorohydrin) and alkenyl ketene dimer size providing variation in the strength and adhesion of PSA-substrate laminates. Screening removal efficiencies were gauged with laboratory repulping and screening and compared with properties of the laminate materials. Results indicate that environmentally benign PSA products can be achieved through modifications to the PSA, paper substrates or both. ${ }^{4,9}$ Also presented are data from pilot-scale testing demonstrating the application of findings in the design of commercially viable, benign PSA products.

Subsequent to the Experimental Section, this report is divided into three sections. Each will discuss a major approach to producing environmentally benign PSA products. The first, Development of Screenable PSA Formulations, examines the control of PSA film properties to inhibit fragmentation. A model that can accurately predict the removal efficiencies of hot-melt PSAs using commonly measured properties is presented. This work should allow adhesive manufacturers to develop benign PSAs without sacrificing performance or increasing costs. The second section, Enhancing PSA Screenability with Treated Substrates, describes research on what are referred to here as "self-sorting" label systems. For these systems, the properties of the PSA label face stock are manipulated to inhibit fiberization during repulping and enhance adhesion to attached PSAs. The face stock then acts as a reinforcing phase inhibiting the fragmentation of the PSA and retaining it during screening. The manipulation of face stock properties is achieved with inexpensive papermaking additives, which do not increase manufacturing costs. The third section, Optimizing Laminate Components to Increase Screenability, involves the manipulation of face stock surface properties. It is demonstrated that commonly utilized commercial face stock possess surface properties that enhance PSA fragmentation and reduce removal efficiencies. These properties can be manipulated with inexpensive coating materials to enhance the removal of attached PSAs.

\section{Experimental Section}

\subsection{Chemicals and Materials}

Copper(II)-ethylendiamine complex (1 M solution in water) and formic acid (reagent ACS, 88\%) were purchased from Acros Organics (Pittsburgh, PA). Naphthol Green B was purchased from Pylam Products Company, Inc. (Tempe, AZ ) and used to produce a 1.25\% aqueous solution containing 1\% formic acid. Hercules Corporation (Wilmington, Delaware) provided alkenyl ketene dimer size (Hercon 70). Wet-strength resins were supplied by Hercules (Kymene 557H, Kymene 450, Kymene 109LX and Kymene 557LX), Georgia-Pacific Resins, Inc. (Decatur, GA) (Amres 8855 and Amres 2747) and Cytec Industries Inc. (West Paterson, New Jersey) (Paramel 200 and Paramel HE-1). Starch (Penford Gum 260) was obtained from Penford Products 
Company (Cedar Rapids, IA). Boise Cascade Corporation (International Falls, MN) provided papermaking fiber and commercial face stocks. Laboratory produced paper face stock for PSA laminates contain a 50:50 w/w blend of hardwood and softwood bleached kraft fiber refined to levels similar to those used by the mill to produce paper. Poly(ethylene terphthalate) films (72 $\mathrm{g} / \mathrm{m}^{2}$ ) were provided by ChemInstruments (Fairfield, OH). H.B. Fuller Company (St. Paul, MN) formulated the hot-melt PSAs utilized in this project. Below a description of the PSAs studied is provided. All PSA samples were prepared in a laboratory batch mixer with sigma blades (Aaron Process Equipment, Bensenville, IL). The mixer temperature was set at $177^{\circ} \mathrm{C}$ and the mixing was performed under a nitrogen blanket. Coatings were made on a pilot coater via the slot die method. Films were coated on two-sided release paper and self wound. The film thickness was targeted at $1 \mathrm{mil}$ or $25.4 \mu \mathrm{m}$. Table 1 lists the available formulation information for the studied PSAs.

\section{N Series}

Description: The experimental or model PSAs consisted of a styrene-isoprene-styrene/styreneisoprene (SIS/SI) linear triblock, diblock copolymer blend (Vector 4114, Dexco, Houston, TX), a pentaerythritol ester of rosin tackifying resin (Sylvalite RE 100L, Arizona Chemical, Jacksonville, FL), and a naphthenic process oil (Viscosity $1200 \mathrm{sec}$ ). A second series of experimental hot-melts was formulated similarly using a $\mathrm{C}_{5}$ petroleum hydrocarbon tackifier (Wingtack 95, Goodyear Chemical, Akron, OH). The same composition as N1, N3, N4 and N12 was utilized, but with the hydrocarbon tackifier. These are denoted N1b, N3b, N4b and N12b.

\begin{tabular}{|c|c|c|c|}
\hline \multirow{2}{*}{ PSA } & \multicolumn{3}{|c|}{ Composition } \\
\cline { 2 - 4 } & polymer & plasticizer & tackifier \\
\hline N1 & 0.35 & 0.10 & 0.55 \\
\hline N2 & 0.35 & 0.10 & 0.55 \\
\hline N3 & 0.20 & 0.25 & 0.55 \\
\hline N4 & 0.35 & 0.15 & 0.50 \\
\hline N5 & 0.25 & 0.25 & 0.50 \\
\hline N6 & 0.35 & 0.13 & 0.52 \\
\hline N7 & 0.22 & 0.25 & 0.53 \\
\hline N8 & 0.23 & 0.25 & 0.52 \\
\hline N9 & 0.32 & 0.18 & 0.50 \\
\hline N10 & 0.25 & 0.20 & 0.55 \\
\hline N12 & 0.29 & 0.19 & 0.53 \\
\hline N14 & 0.29 & 0.19 & 0.53 \\
\hline N1b & 0.35 & 0.10 & 0.55 \\
\hline N3b & 0.20 & 0.25 & 0.55 \\
\hline N4b & 0.35 & 0.15 & 0.50 \\
\hline N12b & 0.29 & 0.19 & 0.53 \\
\hline
\end{tabular}




\section{Commercial PSAs:}

\begin{tabular}{|c|c|}
\hline Commercial Hot-Melt \& Reactive PSAs & Description \\
\hline NW-1043 & $\begin{array}{l}\text { No Crosslinking, Rubber Based, Medium Strength, } \\
\text { No Polarity }\end{array}$ \\
\hline HM-1597 & $\begin{array}{l}\text { No Crosslinking, Rubber Based, Medium Strength, } \\
\text { No Polarity }\end{array}$ \\
\hline HL-1713 & $\begin{array}{l}\text { No Crosslinking, Rubber Based, Medium Strength, } \\
\text { No Polarity }\end{array}$ \\
\hline HL-2053 & $\begin{array}{l}\text { No Crosslinking, Rubber Based, Medium Strength, } \\
\text { low polarity }\end{array}$ \\
\hline HL-2201 & $\begin{array}{l}\text { No Crosslinking, Rubber Based, Low Strength, } \\
\text { Medium Polarity }\end{array}$ \\
\hline HL-2203 & $\begin{array}{l}\text { No Crosslinking, Rubber Based, Low Strength, } \\
\text { Medium Polarity }\end{array}$ \\
\hline HL-2586 & $\begin{array}{l}\text { No Crosslinking, Rubber Based, Medium Strength, } \\
\text { low polarity }\end{array}$ \\
\hline HM-2713 & $\begin{array}{l}\text { No Crosslinking, Rubber Based, High Shear } \\
\text { Strength, No Polarity }\end{array}$ \\
\hline HL-2811 & $\begin{array}{l}\text { No Crosslinking, Rubber Based, Medium Strength, } \\
\text { low polarity }\end{array}$ \\
\hline WM-8000 Uncured & $\begin{array}{l}\text { Rubber Based, No Crosslink, Low Strength, } \\
\text { Medium Polarity }\end{array}$ \\
\hline WM-8000 Cured & $\begin{array}{l}\text { Rubber Based, Medium Crosslink, Medium } \\
\text { Strength, Medium Polarity }\end{array}$ \\
\hline HM-8326 & $\begin{array}{l}\text { No Crosslinking, Rubber Based, High Shear } \\
\text { Strength, No Polarity }\end{array}$ \\
\hline HL-8128x & $\begin{array}{l}\text { No Crosslinking, Rubber Based, Medium Strength, } \\
\text { No Polarity }\end{array}$ \\
\hline HM-9001 Uncured & $\begin{array}{l}\text { Rubber Based, No Crosslink, Low Strength, No } \\
\text { Polarity }\end{array}$ \\
\hline HM-9001 Cured & $\begin{array}{l}\text { Rubber Based, High Crosslink, High Strength, No } \\
\text { Polarity }\end{array}$ \\
\hline HM-9100 Uncured & $\begin{array}{l}\text { Acrylic Based, No Crosslink, Low Strength, } \\
\text { Medium Polarity }\end{array}$ \\
\hline HM-9100 Cured & $\begin{array}{l}\text { Acrylic Based, High Crosslink, High Strength, } \\
\text { Medium Polarity }\end{array}$ \\
\hline HM-9101 Uncured & $\begin{array}{l}\text { Acrylic Based, No Crosslink, Low Strength, } \\
\text { Medium Polarity }\end{array}$ \\
\hline HM-9101 Cured & $\begin{array}{l}\text { Acrylic Based, Medium Crosslink, Medium-Low } \\
\text { Strength, Medium Polarity }\end{array}$ \\
\hline HM-9102 Uncured & $\begin{array}{l}\text { Acrylic Based, No Crosslink, Low Strength, High } \\
\text { Polarity }\end{array}$ \\
\hline HM-9102 Cured & $\begin{array}{l}\text { Acrylic Based, Low Crosslink, Medium Low } \\
\text { Strength, High Polarity }\end{array}$ \\
\hline \multicolumn{2}{|l|}{ Experimental Water-Based PSAs } \\
\hline SE-5357-NA-7870-29B & Acrylic, no crosslink, low polarity \\
\hline SE-5235-NA-7784-80 & Acrylic, no crosslink, low polarity \\
\hline SE-5336-NA-7870-29A & Acrylic, no crosslink, low polarity \\
\hline SE-5269-NA-2820307 U11 & Acrylic, no crosslink, low polarity \\
\hline
\end{tabular}




\subsection{Tensile Tests of Substrates}

Paper substrates were standard $1.2 \mathrm{~g}, 200 \mathrm{~cm}^{2}$ handsheets produced using TAPPI Method T-205 om-88. When additives were incorporated into the paper, the chemicals were added from $1 \%$ $(\mathrm{w} / \mathrm{w})$ aqueous solutions to a heavily mixed $0.3 \%(\mathrm{w} / \mathrm{w})$ aqueous slurry of fiber. Handsheet curing was carried out as needed following procedures described by suppliers. All the handsheets were conditioned at $23^{\circ} \mathrm{C}$ and $50 \% \mathrm{RH}$ for more than one day before being subjected to testing. Dry and wet tensile strengths of handsheets were measured with an Instron (Canton, MA) Model 5542 Tensile Tester using TAPPI Methods T220 om-88 and T494 om-88, respectively. Wet tensile index $(\mathrm{Nm} / \mathrm{g})$ and tensile loss after wetting (fractional loss of strength after wetting) were used to characterize the influence of resins. The testing of filmic substrate tensile strengths was performed using the same technique as that used for paper.

\subsection{Dynamic Mechanical Spectroscopy}

The dynamic mechanical properties of the thermoplastic PSAs were measured using a Rheometrics (Piscataway, NJ), RDA-II dynamic mechanical spectrometer. Approximately 10 grams of the selected hot melt was deposited onto silicone release liner and transferred to 25-mm parallel plates. A temperature sweep was conducted from below the $\mathrm{T}_{\mathrm{g}}$ of the PSAs to above the crossover point at the melt stage of the adhesive. Experimental conditions included a scan rate of $5^{\circ} \mathrm{C} / \mathrm{min}$ and a frequency of $10 \mathrm{radians} /$ second $(\sim 1.6 \mathrm{~Hz}$, standard frequency used by most adhesive suppliers). DMS measurements were performed in shear mode and the strain rates were kept in the linear viscoelastic region.

The dynamic mechanical properties of the waterbased PSAs were determined using a PerkinElmer DMA 7e. A frequency of $1.0 \mathrm{~Hz}$, static stress of $1100 \mathrm{mN}$, and a dynamic stress of 1000 $\mathrm{mN}$ were programmed. Temperature calibration was performed with water, indium and zinc standards at a scan rate of $5^{\circ} \mathrm{C} / \mathrm{min}$. Pyris Series software was used to program the experiments and subsequently carry out data analysis. The method utilized for the DMS measurements involved a temperature scan from $10^{\circ} \mathrm{C}$ to $60^{\circ} \mathrm{C}$ at $5^{\circ} \mathrm{C} / \mathrm{min}$ using a parallel plate fixture in compression equipped with 10-mm plates. All experiments were normalized to the dimensions of the sample (rectangular bar, $\sim 6 \mathrm{~mm}$ long x $2 \mathrm{~mm}$ wide $\times 2 \mathrm{~mm}$ thick). Nitrogen was used to purge the system at a flow rate of $30 \mathrm{~mL} / \mathrm{min}$. DMA thermoscans for all of the PSAs tested in this project are considered proprietary information by H. B. Fuller Company and are not included.

\subsection{PSA Loop Tack}

The adhesion of thermoplastic PSAs to a stainless steel surface, which provides a measure of tack, was determined using the loop tack test method (ASTM D-6195). Prior to measurement, the stainless steel substrate (1/16" thick, Type 302 or 304 having a bright annealed finish) was cleaned with technical grade diacetone alcohol followed by several rinses of a 1:1 blend of methyl ethyl ketone and toluene. The selected PSA was coated to Mylar $\left(25 \pm 3 \mathrm{~g} / \mathrm{m}^{2}\right.$ coat weight) and cut into $1 " \pm 1 / 8^{\prime \prime}$ wide by approximately $5 "$ long sample dimensions. The two ends of the 5 " test strip were tapered together using masking tape such that the adhesive surface faced out. The sample was then inserted into the grips of a TLMI loop tack tester (ChemInstruments, Fairfield, $\mathrm{OH}$ ) and the cycle started. Subsequent to a one-minute dwell time, the loop tack for the PSA was measured and recorded in ounces. The advancing and 
receding rate of the PSA specimen during testing was $12 \mathrm{in} / \mathrm{min}$. The reported values are an average of at least five measurements.

\subsection{Peel Strength to Stainless Steel}

The 180-degree peel adhesion of PSA coated label stock to a stainless steel panel was measured as outlined by ASTM D-903. Prior to experiments, the stainless steel substrate was cleaned as described above for loop tack measurements. Sample preparation involved coating the selected PSA on Mylar ( $25 \pm 3 \mathrm{~g} / \mathrm{m}^{2}$ coat weight) and cutting the specimens into 1 " wide test strips. The PSA strips were applied to the clean stainless steel substrate using a rubber-covered roller, ensuring that no air bubbles were entrapped in the interfacial region. The sample was then secured in the test grips and base plate of a standard tensile tester (ChemInstruments), and peeled at an angle of 180 degrees with a constant peel rate of $12 \pm 1 \mathrm{in} / \mathrm{min}$. The high, low and average strength data were recorded. The reported peel adhesion values are an average of at least five measurements.

\subsection{Shear Adhesion Failure Measurements}

The temperature where thin films of hot melt PSAs fail in shear, or the SAFT, was determined in accordance with ASTM D-4498. Adhesive film specimens were prepared as laminates consisting of two 1" wide by 3 " long strips of the selected PSA ( 1 mil thick on Mylar) bonded at one end by a one-inch square area of the coated surfaces. Caution was used to ensure that air bubbles were not entrapped during the lamination process. The PSA laminate was then affixed to a specimen support located in a standard programmable forced air oven, and a 500-gram weight was suspended from the specimen to provide a constant interfacial shear force. The oven was programmed for a temperature ramp from ambient conditions to $175^{\circ} \mathrm{C}$ at a scan rate of $25^{\circ} \mathrm{C}$ /hour. The temperature at which the PSA sample delaminates is recorded as the SAFT. The reported SAFT values are an average of at least three measurements.

\subsection{Toluene Insolubles}

The level of crosslinking in PSA samples was determined using toluene solubility measurements via beaker extraction. Adhesive films were coated on Mylar and cut into 4" by 4" specimens that were pre-weighed. The adhesive strips were placed in a beaker, toluene was added to cover the samples, and then the PSA was left to soak overnight. Subsequent to the soaking process, the Mylar was removed from the solvent, dried and reweighed. The toluene solubles were filtered through a Whatman 41 filter paper, evaporated and weighed. Insoluble gel fractions were also collected for further analysis. The total sample weight was calculated by subtracting the mass of the Mylar from the initial mass of the PSA and Mylar. Toluene insolubles are reported as the percentage of PSA not solubalized by the solvent.

\subsection{Acid Number}

The amount of acid functionality present in thermoplastic PSAs was measured using a standard titration with known-normality base (ASTM D-1639). One gram of adhesive film or solids was combined with $100 \mathrm{~mL}$ of a 50/50 blend of toluene/isopropyl alcohol and a stir bar in a $250 \mathrm{~mL}$ Erlenmeyer flask. The flask was placed on a hot plate and connected to a water-cooled condenser. The sample was refluxed and stirred until the solids were completely dissolved. One $\mathrm{mL}$ of phenolphthalein indicator was added to the flask and the sample was titrated with $0.1 \mathrm{~N}$ alcoholic potassium hydroxide in a microburette to a pink endpoint. The volume titrated was 
recorded. A blank titration for the toluene/isopropyl alcohol mixture was performed and the acid number was calculated using,

$$
\text { Acid Number }=\frac{(\mathrm{A})(56.1)(\mathrm{N})}{\mathrm{W}}
$$

where $\mathrm{A}$ is the $\mathrm{mL}$ of potassium hydroxide (sample - blank), $\mathrm{W}$ equals the grams of solid, $\mathrm{N}$ is the normality of alcoholic potassium hydroxide, and 56.1 represents the molecular weight of $\mathrm{KOH}$.

\subsection{Sessile Drop Shape Analysis}

Contact angles were measured on adhesive and paper substrates utilizing sessile drop shape analysis. In this measurement, the profile of a sessile drop of the liquid located on a surface is acquired and the angle $(\theta)$ provided at the three-phase contact line is calculated from the extracted images. For this work, the contact angles of small sessile drops $(20 \mu \mathrm{L})$ of selected liquid deposited on various substrates were measured as a function of time using a Krüss (Hamburg, Germany) DSA 10 goniometer equipped with a Sony XC-77CE video camera. The DSA software was programmed in movie mode option and set up to ensure that the recording of contact angle measurements was triggered by the initial drop placement. The video images were captured at room temperature using a rate of 25 frames per second and the corresponding contact angle calculations were performed using the supplied software. Contact angles for water and diiodomethane were used to make estimates of solid surface energies for PSA films, bulk polymers, tackifying resins, and paper substrates using a technique described by Fowkes. ${ }^{10}$ The surface energies determined using the Fowkes approach were found to be in agreement with values obtained from the more labor intensive methods (e.g., Owens/Wendt theory and the three-component van Oss model). A consistent effort was made to extract contact angle values subsequent to liquid spreading and prior to the onset of absorption and evaporation.

\subsection{Procedure for Testing the Removal Efficiencies of PSAs at $46^{\circ} \mathrm{C}$}

A known amount of pressure sensitive adhesive film (approximately $4.5 \mathrm{~g}$ ) was transfer coated onto paper substrates (handsheets) using a heavy roller to produce labels. The release liner was then removed and the PSA and substrate (approximately $13.5 \mathrm{~g}$ ) were attached by hand to various sheets of a preweighed stack of $75 \mathrm{~g} / \mathrm{m}^{2}$, office copy paper $(886.5 \mathrm{~g})$, and the entire sample was cut into $0.25^{\prime \prime}$ wide strips using a commercial shredder. Tap water $(8.1 \mathrm{~L})$ that had been heated to $46^{\circ} \mathrm{C}$ with an immersion heater was combined with the shredded sample in an Adirondack 1800H Laboratory Pulper (Adirondack, NY) and mixed at $60 \mathrm{~Hz}$ for 20 minutes. The resulting fiber slurry was passed through a Valley Vibrating Flat Screen equipped with a 6cut slotted screen (i.e., slotted openings of $0.15 \mathrm{~mm}$ ). Screening rejects containing adhesive particles and fiber were removed from the screen plate. Rejected PSA particles were isolated from fibrous material for mass analysis by using solvent combined with an equal volume of water and copper(II)-ethylenediamine (CED) in an Erlenmeyer flask and mixed with a magnetic stir rod for approximately 8 hours to dissolve cellulose fiber. Adhesive particles were isolated via filtration and dried at $105^{\circ} \mathrm{C}$ to a constant weight. Rejected PSA mass was reported as a Removal Efficiency, denoted RE, which is the percentage of PSA added to the repulper sample that is rejected at the screen. Tested PSA films were soaked in water and CED and dried at $105^{\circ} \mathrm{C}$ for extended periods to determine the mass loss of PSA additives (e.g., 
plasticizers and tackifiers) during the analysis. Losses were found to be negligible. For rejects containing wet-strength paper, a pretreatment is required to aid in the break down of cellulose. This involved soaking of rejects for 1 hour at $70^{\circ} \mathrm{C}$ in a $\mathrm{pH} 11$ aqueous solution containing $1 \%$ $\mathrm{H}_{2} \mathrm{O}_{2}$ (base on paper) before CED dissolution was carried out. When this treatment was applied to PSA films no significant mass loss was detected.

\subsection{Procedure for Testing the Removal Efficiencies of PSAs at Various Temperatures}

For measurements examining the influence of PSA bulk properties on repulping behavior, a known amount of pressure sensitive adhesive film $(\sim 1.5 \mathrm{~g})$ was transfer coated onto paper substrates using a heavy roller to produce labels. The paper substrates consisted of standard 75 $\mathrm{g} / \mathrm{m}^{2}$, office copy paper that was conditioned at $23^{\circ} \mathrm{C}$ and $50 \% \mathrm{RH}$. Subsequent to the lamination process, the release liner was removed and the PSA/substrate system $(\sim 6.5 \mathrm{~g})$ was attached by hand to various sheets of a pre-weighed stack of copy paper $(255 \mathrm{~g})$. The entire sample was then cut into 0.25 " wide strips using a commercial shredder. Tap water $(3 \mathrm{~L})$ that had been heated to the selected temperature with an immersion heater was combined with the shredded sample in an Adirondack 450H laboratory pulper (Adirondack, NY) and mixed at $60 \mathrm{~Hz}$ for 30 minutes. The repulper was equipped with a heating/cooling jacket connected to a recirculating water bath to maintain temperature during testing. The temperature change of the contaminated fiber slurry for a 30-minute repulping experiment was determined to be $\pm 1^{\circ} \mathrm{C}$ over the range of temperatures investigated $\left(10^{\circ} \mathrm{C}\right.$ to $\left.100^{\circ} \mathrm{C}\right)$. The resulting fiber slurry was passed through a Valley Vibrating Flat Screen equipped with a 6-cut slotted screen (i.e., slotted openings of $0.15 \mathrm{~mm}$ ). Screening rejects containing adhesive particles and fiber were removed from the screen plate. Rejected PSA particles were isolated from fibrous material for mass analysis using copper(II)ethylenediamine (CED) mixed with a magnetic stir rod for approximately 8 hours to dissolve cellulose fiber. Adhesive particles were isolated via filtration and dried at $105^{\circ} \mathrm{C}$ to a constant weight. Rejected PSA mass was reported as a Removal Efficiency, which is the percentage of PSA added to the repulper that is rejected at the screen. Tested PSA films were soaked in water and CED and dried at $105^{\circ} \mathrm{C}$ for extended periods to determine the mass loss of PSA additives (e.g., plasticizers and tackifiers) during the analysis. Losses were found to be negligible. For experiments involving the modification of PSA laminate systems, paper substrates were produced in the laboratory as standard $1.2 \mathrm{~g}, 200 \mathrm{~cm}^{2}$ handsheets using TAPPI Method T-205 om-88. When additives were incorporated into the paper, the chemicals were added from $1 \%$ $(\mathrm{w} / \mathrm{w})$ aqueous solutions to a heavily mixed $0.3 \%(\mathrm{w} / \mathrm{w})$ aqueous slurry of fiber. Handsheet curing was carried out as needed following procedures described by suppliers. All of the handsheets were conditioned and then subjected to testing as outlined above.

\section{Development of Screenable PSA Formulations}

In recycled paper, PSAs exist as thin films that laminate various paper products together. These laminates are introduced into the repulping process and are broken down with the recovered paper they contaminate. Most commercial repulping operations are carried out at high consistency and the fragmentation of PSAs caught in the process is less due to contact with the rotor that drives the mixing and more due to the stresses induced in the films by the surrounding slurry. These stresses act to remove PSA films from paper surfaces and fragment them into smaller particles. It is clear that the adhesion between the PSA film and paper substrates plays a role in determining the extent of this reduction. However, unless paper substrates are treated to inhibit their break down, ${ }^{9}$ the removal of the PSA is determined primarily by its own physical 
properties. It is expected that cohesive strength will determine fragmentation tendency of adhesives. Cohesive strength of a material is commonly characterized by its tensile strength, ${ }^{11-13}$ but given the high fluidity of PSA films, tensile elongation properties are difficult to measure and the results tend to be dependent on sample preparation and strain rate. In addition, the stressstrain behavior of hot-melt PSAs is a strong function of temperature making the characterization of PSA-film tensile properties both cumbersome and tenuous. As will be shown, failure of these systems appears to be best characterized by the kinetics of relaxation mechanisms, which is directly related to the level of viscoelasticity of the films.

A technique commonly used to gauge viscoelastic properties is dynamic mechanical spectroscopy (DMS). ${ }^{14,15}$ DMS thermal scans identify temperature regions over which dynamic mechanical properties undergo significant changes such as phase transitions and gauge the relative ratio of fluid to elastic behavior. However, DMS measurements are restricted to the linear-elastic region of the material and information on cohesive strength is extrapolated. A measurement that does provide information on both failure and viscoelasticity is the shear adhesion failure temperature or SAFT. ${ }^{16,17}$ This is a performance response often cited by adhesive suppliers. The SAFT is the temperature where an adhesive laminate fails while being subjected to a constant shear force. For laminates produced from identical label systems, SAFT can be taken as a measure of the temperature at which relaxation kinetics of the PSA becomes rapid indicating a significant loss in cohesive strength and increase in fluid-like behavior. Here, SAFT was used in combination with DMS thermal analysis to develop a model that predicts the temperature dependence of the removal efficiency via screening from recycled fiber furnishes for thermoplastic-based PSAs. Results indicate that reformulation of PSAs to manipulate its SAFT and thermal separation of phase transitions provides a method for controlling PSA removal efficiencies and designing environmentally benign hot-melt PSAs. Efforts in this area produced several commercial PSA, which are currently being marketed by HBF.

\subsection{Temperature Dependence of Removal Efficiencies for Hot-Melt PSA Formulations}

Table 1 lists the composition of the experimental PSAs used in this study along with results for several commonly run performance tests including loop tack, peel adhesion and SAFT, as well as surface energies $(\gamma)$ estimated from contact angle measurements. PSAs $1 \mathrm{~b}, 2 \mathrm{~b}, 3 \mathrm{~b}$ and $10 \mathrm{~b}$ are identical in composition to PSAs 1, 2, 3 and 10 but differ in the type of tackifying resin used in the formulation. PSAs 1-10 are formulated with a rosin ester tackifier while PSAs $1 b, 2 b, 3 b$ and $10 \mathrm{~b}$ use $\mathrm{a}_{5}$ hydrocarbon tackifier. According to results from previous repulping studies, ${ }^{9}$ the interaction between filmic PSAs and the coating substrate is a significant factor in determining the removability of PSA formulations. For laminate systems in which the adhesion between the PSA and substrate in water is relatively weak, as is the case here, the release of the adhesive from the paper substrate occurs almost instantaneously and thus changes in removal efficiency are primarily attributed to the properties of separated PSA films. Figure 1 shows removal efficiency curves for PSAs 1 (solid line) and $1 \mathrm{~b}$ (dashed line) as a function of temperature. (The superimposed mechanical Tan $\delta$ curves from DMS measurements will be discussed later.) The results demonstrate a sigmoid shape, which was found for the entire set of model hot-melt PSAs. An empirical equation that effectively fits the sigmoidal character of the removal efficiency curves possesses the form, 


$$
\text { Removal Efficiency }=\frac{\exp \left(\frac{\mathrm{T}_{50}-\mathrm{T}_{\mathrm{R}}}{\alpha}\right)}{1+\exp \left(\frac{\mathrm{T}_{50}-\mathrm{T}_{\mathrm{R}}}{\alpha}\right)} \times 100 \%
$$

where $\mathrm{T}_{50}$ is the inflection temperature of the sigmoidal removal curve (i.e., temperature required for $50 \%$ removal efficiency), $\mathrm{T}_{\mathrm{R}}$ is the repulping temperature and $\alpha$ determines the temperature width over which removal drops from 100 to $0 \%$. It is important to note that the equation is an empirical fit of the data and not based on any existing theory of material comminution.

Table 1. Levels for additives present in the series of hot-melt PSA formulations, adhesive performance measures used to characterize the PSAs and their estimated surface energies.

\begin{tabular}{lccccccc} 
PSA & $\chi$ Base Polymer & $\chi$ Plasticizer & $\chi$ Tackifier & Peel to SS $(\mathrm{N} / 25 \mathrm{~mm})$ & Loop Tack $(\mathrm{N} / 25 \mathrm{~mm})$ & SAFT $\left({ }^{\circ} \mathrm{C}\right)$ & $\gamma\left(\mathrm{mJ} / \mathrm{m}^{2}\right)$ \\
\hline PSA 1 & 0.35 & 0.10 & 0.55 & 33.4 & 29.5 & 57 & 37.0 \\
PSA 2 & 0.20 & 0.25 & 0.55 & 33.4 & 30.9 & 47 & 42.6 \\
PSA 3 & 0.35 & 0.15 & 0.50 & 18.7 & 25.6 & 57 & 39.6 \\
PSA 4 & 0.25 & 0.25 & 0.50 & 24.9 & 24.2 & 51 & 36.6 \\
PSA 5 & 0.35 & 0.13 & 0.52 & 25.8 & 24.5 & 56 & 37.3 \\
PSA 6 & 0.22 & 0.25 & 0.53 & 21.8 & 28.1 & 49 & 37.8 \\
PSA 7 & 0.23 & 0.25 & 0.52 & 19.1 & 28.9 & 49 & 37.2 \\
PSA 8 & 0.32 & 0.18 & 0.50 & 20.0 & 29.8 & 54 & 37.3 \\
PSA 9 & 0.25 & 0.20 & 0.55 & 28.5 & 38.7 & 51 & 39.1 \\
PSA 10 & 0.29 & 0.19 & 0.52 & 26.3 & 33.4 & 53 & 42.2 \\
PSA 1b & 0.35 & 0.10 & 0.55 & 34.7 & 20.0 & 74 & 40.1 \\
PSA 2b & 0.20 & 0.25 & 0.55 & 27.6 & 43.2 & 58 & 42.0 \\
PSA 3b & 0.35 & 0.15 & 0.50 & 33.8 & 35.6 & 30.6 & 62 \\
PSA 10b & 0.29 & 0.19 & 0.52 & 25.4 & 31.4 \\
\hline
\end{tabular}

Regardless, Eq. 1 provides excellent fits of removal curves for all of the model PSAs (with all $\mathrm{R}^{2}$ values $>0.99$ ). The extracted parameters from nonlinear regression analysis (Datafit software, Oakdale Engineering, Oakdale, PA) are provided in Table 2 including the $T_{50}$ and $\alpha$ values. A model that could predict the removal efficiency of PSAs as a function of temperature without performing cumbersome repulping studies requiring specialized equipment would provide producers with a tool for obtaining environmental impact information that could be used in the formulation process. Attempts to provide a model for predicting the removal efficiency as a function of temperature a priori focused on obtaining relationships between $\alpha$ and $\mathrm{T}_{50}$ values from the fit of Eq. 1 and performance responses from standard adhesive tests. It was determined that DMS and SAFT data were the best predictors of model parameters.

DMS involves the introduction of an oscillatory deformation to a material within its linear-elastic region and measurement of its response. Three parameters are commonly used to characterize the results; storage modulus, loss modulus and Tan $\delta .{ }^{14,15}$ The loss modulus (G") measures the freedom of molecular motion in a material, the storage modulus $\left(\mathrm{G}^{\prime}\right)$ measures the ability of a material to store elastic energy, and Tan $\delta$ is the ratio of these quantities (i.e., Tan $\delta=\mathrm{G}^{\prime \prime} / \mathrm{G}^{\prime}$ ). Tan $\delta$ gauges the balance of viscous to elastic behavior and is used to identify phase changes, 
such as the glass-rubber transition for an amorphous polymer. ${ }^{7,12,15}$ Figure 2 shows a DMS thermal scan measured for the SIS/SI block copolymer system used to formulate all PSAs in Table 1. For the SIS/SI block copolymer system, maximums in Tan $\delta$ near -50 and $140{ }^{\circ} \mathrm{C}$ correspond to transitions for the polyisoprene and polystyrene domains, respectively. ${ }^{7,8}$ These transitions are associated with significant changes in mechanical properties and can best be described as the glass-rubber transitions for the separate microphases or domains that form. The addition of tackifiers and/or plasticizers to the SIS/SI block copolymer system modifies the thermal locations of transitions. The level of modification is dependent on the relative concentration of components and the affinity of additives for the different polymer blocks. Superimposed on the removal efficiency data in Fig. 1 are DMS thermal scans for PSA 1 and PSA $1 b$. The scans are representative of the Tan $\delta$ curves demonstrated by hot-melt PSAs. The two regions where Tan $\delta$ is maximized correspond to the $T_{g}$ of the tackified polyisoprene midblock domains (lower temperature) and a transition related to the $T_{g}$ of the polystyrene endblock segments (higher temperature). ${ }^{8}$ The figure demonstrates the influence additives such as tackifying resins have on the SIS/SI system. The rosin ester tackifier exhibits compatibility with both the polyisoprene and polystyrene domains and its use in PSA 1 shifts the $\mathrm{T}_{\mathrm{g}}$ for the polyisoprene domains to higher temperatures and reduces the thermal location of the transition related to the $\mathrm{T}_{\mathrm{g}}$ for the polystyrenic domains. The $\mathrm{C}_{5}$ hydrocarbon tackifier is predominantly compatible with the rubbery blocks. Its use increases the $\mathrm{T}_{\mathrm{g}}$ of the rubbery domains but has little impact on the location of the transition related to the $T_{g}$ for the polystyrenic domains in PSA $1 b$.

Table 2. Extracted parameters $T_{50}$ and $\alpha$ from fits of the experimental PSA removal curves with Eq. 1 as well as experimental SAFT values and $0.10 \Delta \mathrm{T}$ determined from DMS data.

\begin{tabular}{lcccc} 
PSA & $\mathrm{T}_{50}\left({ }^{\circ} \mathrm{C}\right)$ & $\alpha\left({ }^{\circ} \mathrm{C}\right)$ & $\mathrm{SAFT}\left({ }^{\circ} \mathrm{C}\right)$ & $0.10 \Delta \mathrm{T}\left({ }^{\circ} \mathrm{C}\right)$ \\
\hline PSA 1 & 58 & 3.6 & 57 & 4.7 \\
PSA 2 & 46 & 3.2 & 47 & 3.7 \\
PSA 3 & 61 & 3.8 & 57 & 3.9 \\
PSA 4 & 48 & 3.9 & 51 & 4.4 \\
PSA 5 & 55 & 3.0 & 56 & 4.0 \\
PSA 6 & 45 & 4.1 & 49 & 4.6 \\
PSA 7 & 46 & 2.3 & 49 & 3.8 \\
PSA 8 & 54 & 6.1 & 54 & 5.9 \\
PSA 9 & 52 & 1.9 & 51 & 4.2 \\
PSA 10 & 56 & 3.2 & 53 & 4.7 \\
PSA 1b & 78 & 5.7 & 74 & 7.1 \\
PSA 2b & 63 & 8.7 & 58 & 7.0 \\
PSA 3b & 78 & 11.7 & 72 & 7.3 \\
PSA 10b & 61 & 7.5 & 62 & 6.9 \\
\hline
\end{tabular}

SAFT is related to the phase behavior of PSAs and can be manipulated through changes in additive type and concentration. ${ }^{7,17}$ This is evident from comparisons of SAFT values for the PSAs formulated with the different tackifying resins (Table 1). It is also demonstrated in Fig. 3, which plots SAFT values as a function of base polymer content for PSAs with the rosin ester and 
hydrocarbon tackifying resin. In both cases, the relationship is linear, but the parameters of the fit are different demonstrating that these types of correlations are formulation specific. As discussed in the Introduction, the SAFT can be described as the temperature at which highly rapid deformation is found for the PSA producing a failure response. The SAFT reported here is measured by laminating identical PSA labels (films plus carriers) to produce an overlap region of one square inch. A constant load is applied to induce a shear stress parallel to the overlapping films, and the temperature is raised until the laminate fails. This is reported as the SAFT. Theoretically, cohesive failure in shear is being measured, but it is understood that there are potential contributions from adhesion. SAFT values for PSA 1 and $1 \mathrm{~b}$ are 57 and $74^{\circ} \mathrm{C}$, respectively. Comparing these values with Fig. 1 indicates that the SAFT occurs between the $\mathrm{T}_{\mathrm{g}}$ for the tackified polyisoprene phase and the transition related to the $\mathrm{T}_{\mathrm{g}}$ of the polystyrene phase. Subsequent to the $T_{g}$ of the tackified polyisoprene phase, the separated polystyrenic phase can be thought of as physical crosslinks that maintain the residual solid-like behavior of the PSA. ${ }^{7,17}$ As temperature is raised, viscoelasticity increases due to increasing fluid-like behavior of the rubbery phase and/or loss of the reinforcing contribution of the physical crosslinks as temperatures approach the $T_{g}$ of the polystyrenic domains. The result is a decrease in cohesive strength producing accelerated creep strain and failure. Table 3 provides the dynamic mechanical properties of the model PSAs measured at the SAFT. The data indicate that SAFTs do not correspond to threshold dynamic mechanical properties. Given that SAFT is based on adhesive failure and $\mathrm{G}^{\prime}, \mathrm{G}^{\prime \prime}$ and Tan $\delta$ are elastic properties this is not unexpected, but the results indicate that the information provided by DMS and SAFT are independent.

\subsection{Modeling the Fragmentation Behavior of Hot-Melt PSAs}

In this section, it is demonstrated how estimates of $\alpha$ and $\mathrm{T}_{50}$ can be obtained from Tan $\delta$ and SAFT data. To promote the use of Eq. 1 as a design tool, the goal was to provide relationships that can easily be used quantitatively or semi-quantitatively. From Table 2 it is evident that $\alpha$ values vary for the different adhesives. Returning to Fig. 1, it appears that the removal efficiencies for PSAs 1 and $1 \mathrm{~b}$ drop from 100 to $0 \%$ between the transitions for the rubbery and polystyrene phases. That is, $\alpha$ values are related to the thermal width of this plateau region. Further evidence for this can be found by noting the significant increase in $\alpha$ values for the PSAs containing a hydrocarbon tackifier (PSAs 1b, 2b, 3b, 10b) compared to the hot-melts formulated with a rosin ester tackifier (PSAs 1, 2, 3, 10), which were found to possess narrower plateau regions. Based on the description provided in the previous section of the plateau region as involving the onset of viscoelastic behavior and increasing loss of cohesive strength moving thermally towards the styrene transition, this connection to $\alpha$ would appear reasonable. To determine if $\alpha$ values correlate with the length of the plateau region, a method had to be determined for quantifying its thermal width. The approach used here involves linear fits of Tan $\delta$ data leading into the plateau region, the plateau region itself and data leading out of the region. The difference between the temperature intersections of these three lines was taken as the width of the plateau region, denoted $\Delta \mathrm{T}$. This is demonstrated in Fig. 4 for two commercial hot-melt PSAs. (These PSAs will be discussed in more detail below.) This was found to be the most objective and repeatable method for estimating the plateau thermal width. Fitting the $\alpha$ values from Table 2 versus $\Delta \mathrm{T}$ values extracted from the DMS data with a linear model passing through the origin produced a slope of 0.10 . 
Table 3. Dynamic mechanical properties measured at the shear adhesion failure temperature (SAFT) for the formulated PSAs.

\begin{tabular}{lccc} 
PSA & $\mathrm{G}^{\prime} @$ SAFT $(\mathrm{Pa})$ & $\mathrm{G} "$ @ $\mathrm{SAFT}(\mathrm{Pa})$ & $\mathrm{Tan} \delta @$ SAFT \\
\hline PSA 1 & 25259 & 14778 & 0.59 \\
PSA 2 & 5588 & 5026 & 0.90 \\
PSA 3 & 24467 & 13445 & 0.55 \\
PSA 4 & 10284 & 6660 & 0.65 \\
PSA 5 & 23497 & 13292 & 0.57 \\
PSA 6 & 7599 & 5778 & 0.76 \\
PSA 7 & 9768 & 6803 & 0.70 \\
PSA 8 & 18948 & 10113 & 0.53 \\
PSA 9 & 12739 & 8569 & 0.67 \\
PSA 10 & 15778 & 9221 & 0.58 \\
PSA 1b & 15642 & 7647 & 0.49 \\
PSA 2b & 5363 & 3107 & 0.58 \\
PSA 3b & 22423 & 7686 & 0.34 \\
PSA 10b & 9121 & 4667 & 0.51 \\
\hline
\end{tabular}

This provided an equation for estimating $\alpha$ values based on the DMS data analysis technique described (i.e., $\alpha=0.10 \Delta \mathrm{T}$ where temperature is in degrees Celsius). It should be stressed that the locations of transitions and likely the estimated width of the plateau region will be dependent on the frequency and scan rate of the DMS measurement.

In addition to $\alpha$ and $\mathrm{T}_{50}$ values, Table 2 lists $0.10 \Delta \mathrm{T}$ and SAFT quantities for the experimental hot-melt PSAs. It is evident from the results that the $\mathrm{T}_{50}$ and SAFT values are in good agreement and in fact, SAFTs appear to be an acceptable predictor of $\mathrm{T}_{50} \mathrm{~S}$ in Eq. 1 (i.e., $\mathrm{T}_{50} \approx \mathrm{SAFT}$ ). This is true for both the rosin ester and $\mathrm{C}_{5}$ aliphatic tackified formulations. This may be due to the sigmoid shape of the removal efficiency versus temperature curves in which removal drops sharply over a relatively narrow temperature region. With the presumption that this drop is due to the initial significant loss of cohesive strength in the PSA films, it would be expected that the SAFT would be in the region of sharpest decline, and thus near $\mathrm{T}_{50}$. Having outlined methods for predicting $\alpha$ and $T_{50}$, the removal efficiency curves can be predicted using Eq. 1. To validate the model, predicted removal efficiencies using $0.10 \Delta \mathrm{T}$ to predict $\alpha$ and SAFT to predict $\mathrm{T}_{50}$ were plotted against experimentally measured values (140 points in all) and fit with a linear model. The slope, intercept and $\mathrm{R}^{2}$ values were determined to be $0.99,0.07$ and 0.98 , respectively. It was found that estimates of both parameters were required to produce acceptable fits. In Fig. 5a, removal efficiency data for all of the experimental PSAs is plotted as a function of repulping temperature. In Fig. 5b, the measured removal efficiencies are plotted as a function of $\left[\left(\mathrm{SAFT}-\mathrm{T}_{\mathrm{R}}\right) / 0.10 \Delta \mathrm{T}\right]$ for each of the PSAs. Also shown is the theoretical removal efficiency (dashed line). It appears the model provides an accurate estimate of removal efficiencies for the PSAs and a useful means for describing the potential environmental impact of a hot-melt PSA. The results shown here indicate that the SAFT should be significantly greater than $T_{R}$ to produce a more benign PSA (i.e., produce a higher removal efficiency). It is possible that the magnitude of this difference could become the most useful predictor of PSA removal for formulators. 
Given that the data reported here contains two different thermoplastic formulations it is believed that this result is applicable to a wide range of hot-melt PSAs and possibly other systems (e.g., water-based).

As a test of the general applicability of the model for hot-melt PSAs developed here, it was used to predict the temperature dependence of the removal efficiency for two commercial hot-melt PSA formulations provided by H. B. Fuller Company. The first, identified as commercial PSA 1, contains an SIS linear triblock copolymer. The second, identified as commercial PSA 2, contains a styrene-butadiene-styrene (SBS) linear triblock copolymer. Both of these PSAs have different components and compositions and are formulated with a different tackifying resin and plasticizer than those used in the experimental PSAs. Figure 4 shows DMS data for commercial PSAs 1 and 2. Marked on the data are the SAFT and $\Delta \mathrm{T}$ values for the PSAs and the lines used to determine $\Delta \mathrm{T}$ from Tan $\delta$ curves. The values reported are in excellent agreement with the $\mathrm{T}_{50}$ and $\alpha$ values determined from nonlinear regression of the removal curves, which were 49 and $5.7^{\circ} \mathrm{C}$, respectively, for commercial PSA 1 and 79 and $6.4^{\circ} \mathrm{C}$, respectively, for commercial PSA 2. Figure 6 shows the removal efficiencies measured for the commercial PSAs as a function of temperature and the removal efficiency curves predicted using the model (solid curves). It is clear that the model accurately predicts the removal efficiency. The results indicate that hot-melt PSAs can be formulated that are removable via screening and are thus considered environmentally benign. The limitations placed on the performance properties of hot-melt formulations are difficult to determine at this point, but given that commercial PSA 2 would be considered a highly screenable formulation at repulping temperatures of $46^{\circ} \mathrm{C}$, typical of many mills, indicates that commercially feasible, environmentally benign formulations can be developed. It is hoped that this work will help promote the consideration of environmental impact when developing new PSA products.

\subsection{Pilot Trials}

Appendix 1 reviews the results of pilot scale testing for five PSAs that were identified via the model and or laboratory testing as being highly screenable. These include hot-melt PSAs HM2713 (F-2004), HM-8326 (F-2005), HL-8128x (F-2008) and HL-2586 (F-2012). These were tested for their impact on paper recycling at the Forest Products Laboratory (FPL) using their open-loop recycling procedure. All five adhesives were acceptably removed, primarily by screening with cleaning and flotation acting as polishing steps. All exceeded the USPS specifications for particle size after pulping (greater than $0.32 \mathrm{sq} . \mathrm{mm}$ ) and final pulp adhesive content (20 ppm or less). All of the hot-melt PSA products will be marketed as environmentally benign formulations by H. B. Fuller Company. 


\subsection{Figures}

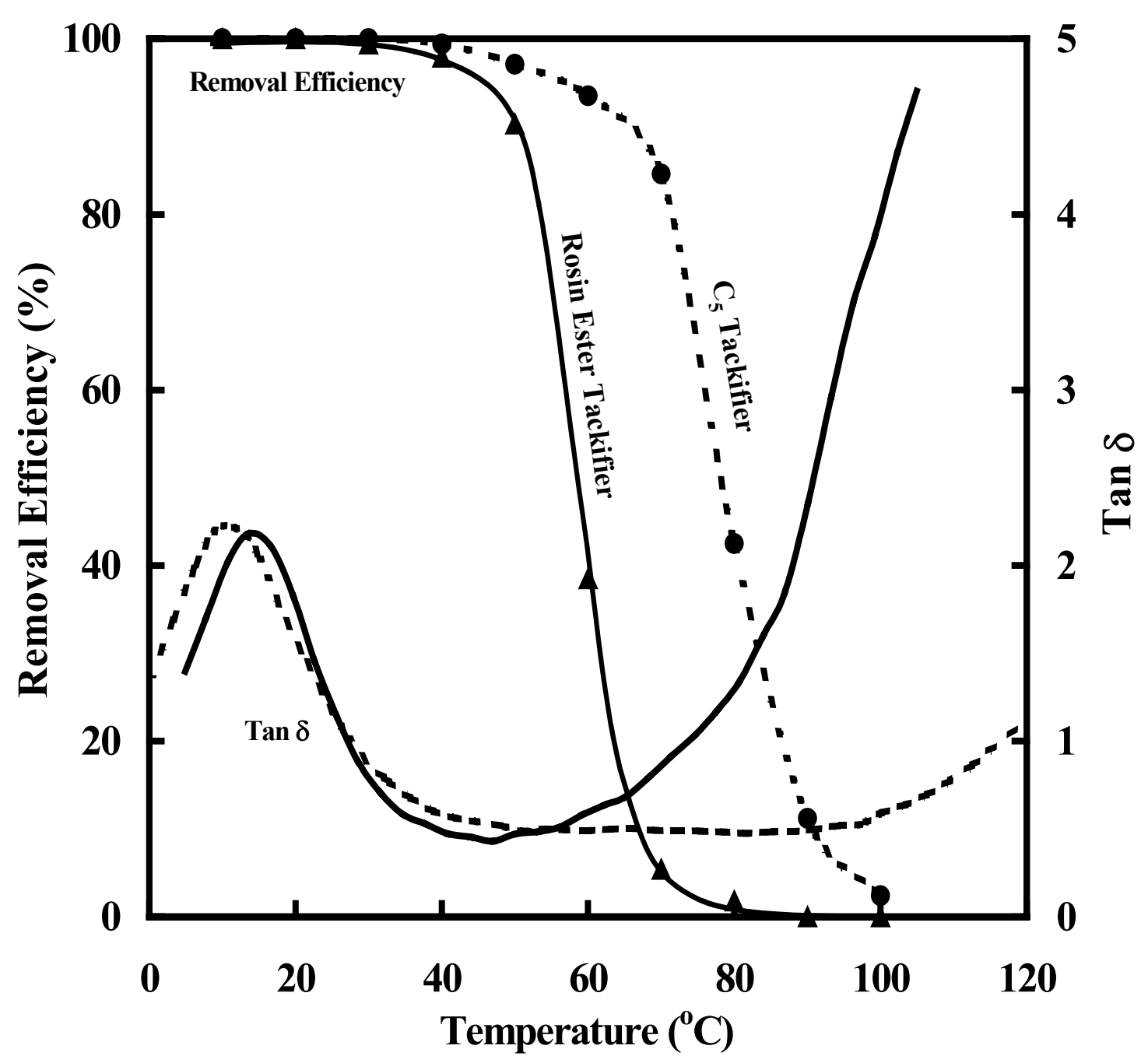

Figure 1. Removal efficiency and PSA Tan $\delta$ values as a function of temperature for PSAs 1 (rosin ester tackifier) and $1 \mathrm{~b}\left(\mathrm{C}_{5}\right.$ tackifier), the solid and dashed lines, respectively. 


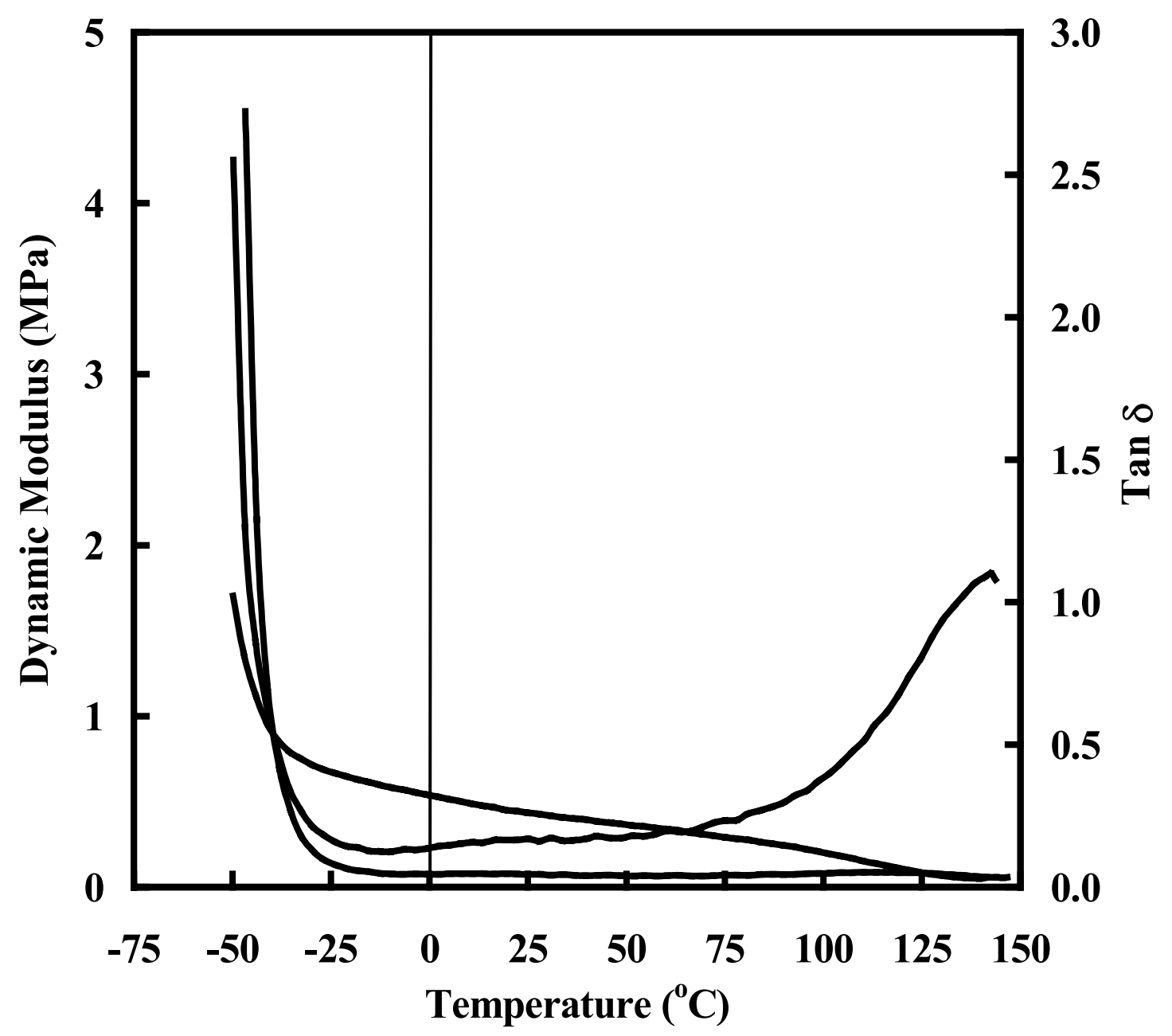

Figure 2. Dynamic mechanical heating curves for the SIS/SI base polymer system used to formulate the experimental series of hot-melt PSAs. 


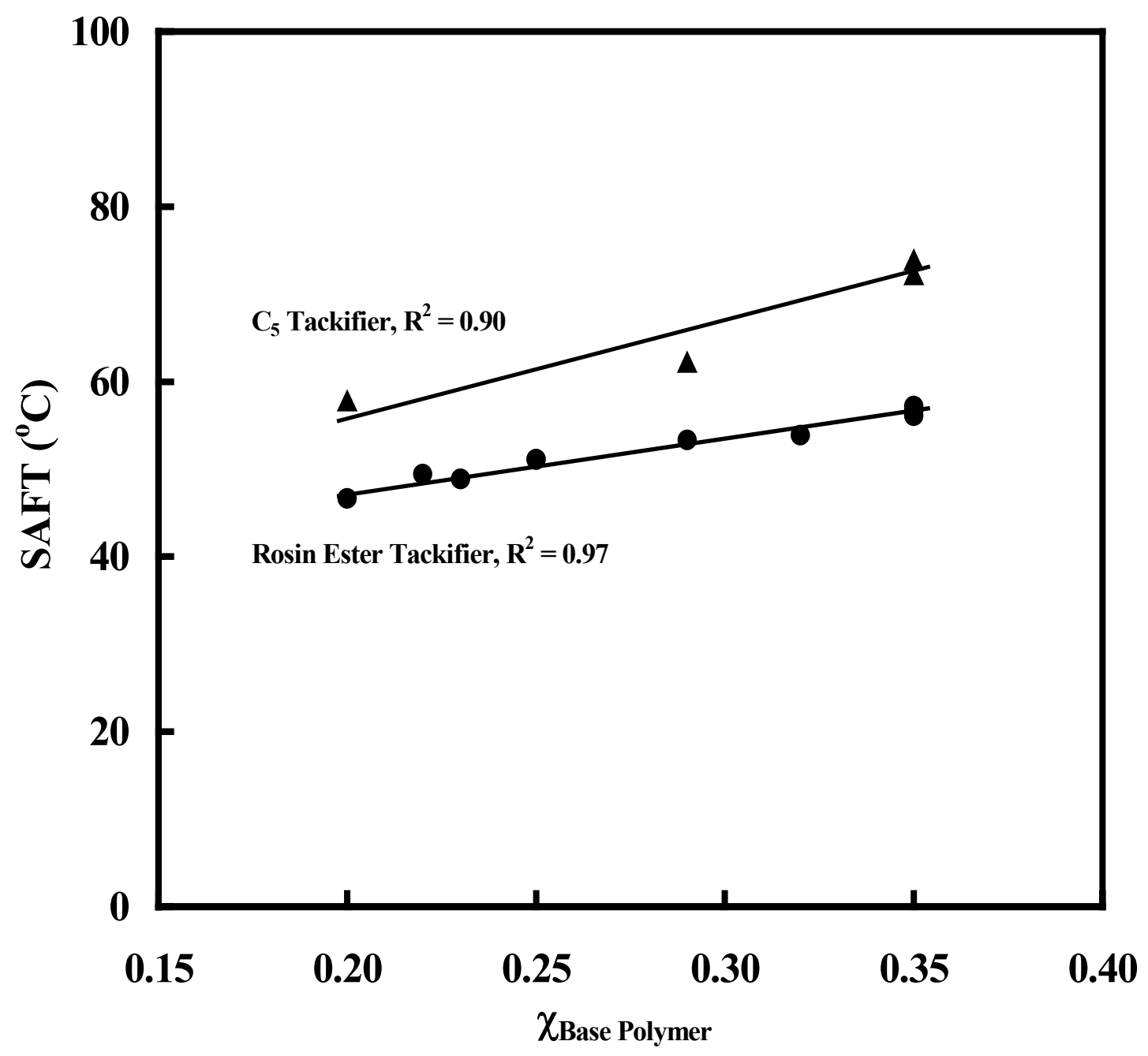

Figure 3. Shear adhesion failure temperature for the hot-melt PSAs possessing rosin ester and hydrocarbon tackifier as a function of base polymer content in the formulation. 


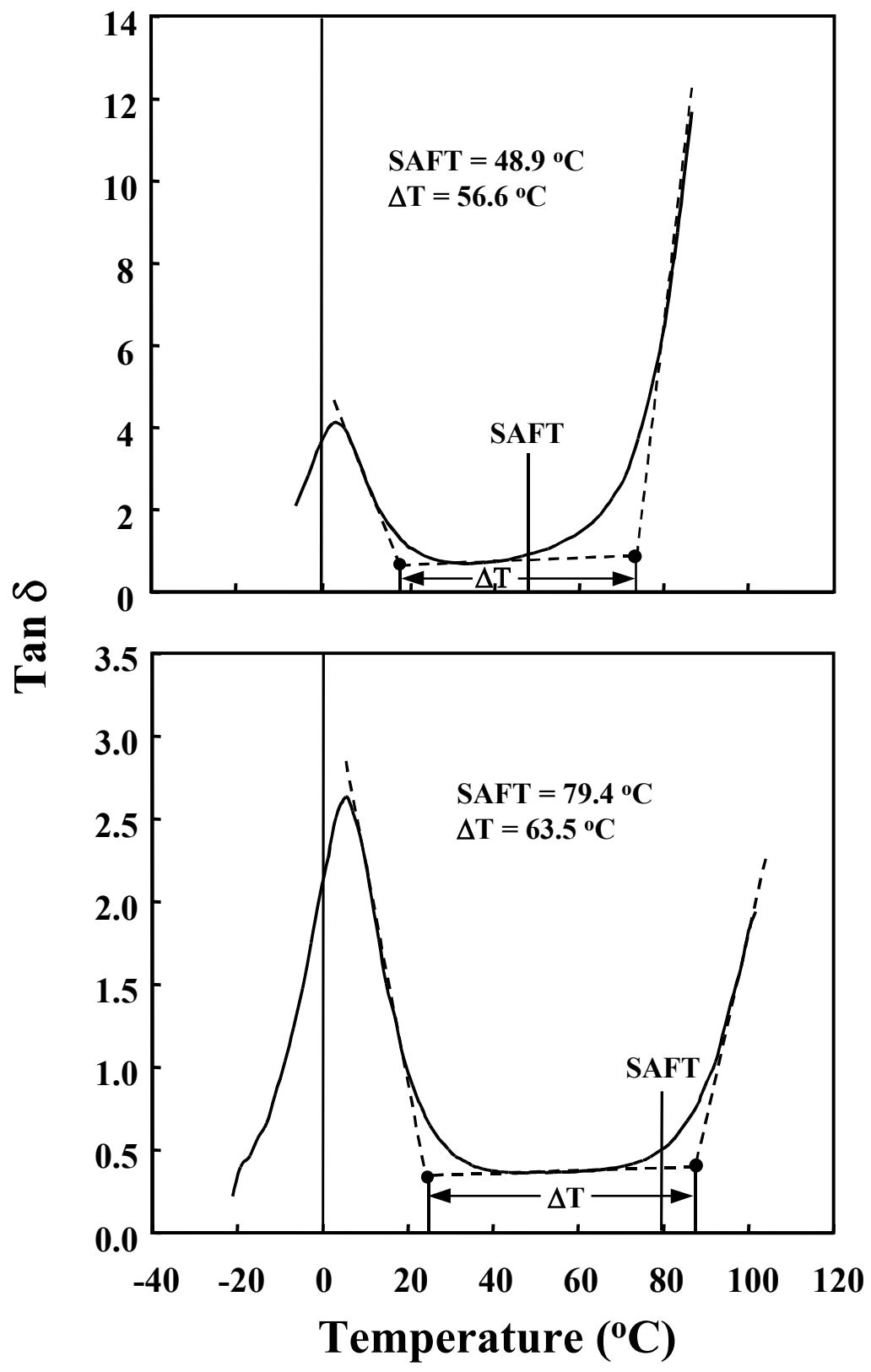

Figure 4. Tan $\delta$ values measured for commercial PSAs 1 and 2 as a function of DMS measurement temperature. Also included in the figure are the experimental SAFT and $\Delta \mathrm{T}$ quantities as well as the method utilized to determine $\Delta \mathrm{T}$ of the plateau region. 


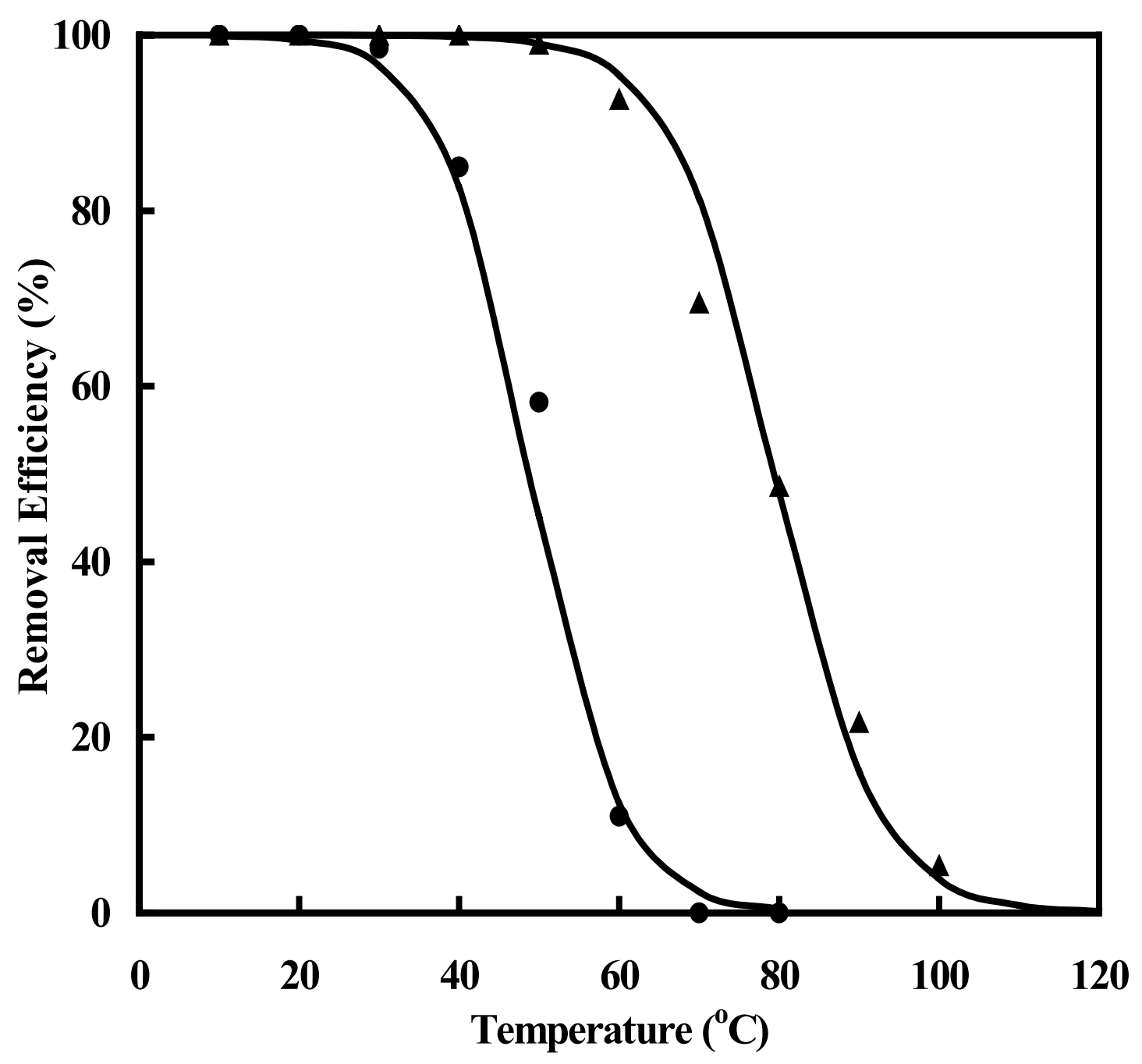

Figure 5. Summary of temperature-dependent repulping results for 14 hot-melt PSA formulations. Solid and dashed lines represent systems possessing rosin ester and $\mathrm{C}_{5}$ aliphatic tackifier, respectively. Part (b) of the figure provides removal curves as a function of [(SAFT $\left.\left.\mathrm{T}_{\mathrm{R}}\right) / 0.10 \Delta \mathrm{T}\right]$ (see text). 


\section{Enhancing PSA Screenability with Treated Substrates}

In addition to the development of screenable formulations, another avenue explored for producing benign PSA products was the use of label stock treated to resist fiberization in water. The theory is that a label resistant to disintegration during repulping can be easily removed either right at the repulper or through screening. If the label is designed to retain its adhesive, the contamination problem is diminished. It is common practice to use chemical additives to protect paper against the effects of water. Untreated papermaking fibers readily swell with water delaminating fiber-fiber bonds and significantly reducing paper strength. Common wet-end chemicals that protect paper against water include internal sizing agents and wet-strength resins. Sizing agents work primarily by increasing the contact angle of water on fiber surfaces. This evokes capillary forces to counter the flow of water into the pores produced in paper by overlapping fibers, generating resistance to water penetration into the sheet. It should be emphasized that this is not a moisture barrier. The resistance to water penetration provided through sizing will be fairly easy to overcome during the repulping of a PSA label, and the size will not provide the wet label with much resistance to mechanical forces. Wet-strength resins on the other hand are designed to provide water-saturated paper with increased strength. ${ }^{18-20}$ These resins are typically reactive polymeric materials that crosslink both with themselves and with fiber surfaces to produce a complex network in and around fiber-fiber bonded regions. This network prevents these bonded regions from swelling, and may also provide the fibers with reinforcing bonds that are not affected by water. ${ }^{21-23}$ There are a number of wet-strength resins commercially available such as polyaminoamide epichlorohydrin and polyethylene imine. ${ }^{24,25}$

\subsection{Influence of PET Face Stock on PSA Removal Efficiencies}

Table 4 provides composition and performance data on the experimental hot melt PSA formulations as well as removal efficiencies (via screening) for these films when coated on paper substrates. These values range from 21 to $95 \%$. When paper becomes wet, there is a substantial reduction in its strength due to the wetting of cellulose surfaces and a delamination of fiber-fiber bonds. For example, the paper substrates used to produce Table 1 have an average dry tensile strength of $3702 \mathrm{~N} / \mathrm{m}(61.7 \mathrm{Nm} / \mathrm{g}$ tensile index $)$, while their wet tensile strength is $84.0 \mathrm{~N} / \mathrm{m}$ $(1.40 \mathrm{Nm} / \mathrm{g}$ tensile index). This nearly $98 \%$ loss in strength is common for paper not treated with wet-strength additives. During repulping, it is likely that PSA films quickly shed their paper carriers and are broken down at a rate determined primarily by the PSA's mechanical properties. When the experimental PSA formulations were coated on poly(ethylene terephthalate) (PET) thin-film substrates, all were found to have a removal efficiency of nearly $100 \%$. PET does not swell in water, so its measured dry and wet tensile strength were found to be the same, $6,000 \mathrm{~N} / \mathrm{m}(100 \mathrm{Nm} / \mathrm{g}$ tensile index $)$. When PSA films were attached to PET and repulped, the size and shape of the laminate appears unaffected and the adhesive is completely retained by the PET. This indicates that attaching the PSA film to a carrier that does not break down during repulping can prevent its fragmentation. 
Table 4. Composition of experimental PSAs, results from standard performance tests and measured removal efficiencies (RE).

\begin{tabular}{|c|c|c|c|c|c|c|c|}
\hline \multirow{2}{*}{ PSA } & \multicolumn{2}{|c|}{ Composition (mass fraction) } & \multicolumn{3}{c|}{ PSA Properties } & RE (\%) \\
\cline { 2 - 7 } & $\begin{array}{c}\text { SIS/SI } \\
\text { Polymer }\end{array}$ & Plasticizer & Tackifier & $\begin{array}{c}\text { Peel to SS } \\
(\mathbf{N} / 25 m m)\end{array}$ & $\begin{array}{c}\text { Loop tack } \\
(\mathbf{N} / 25 m m)\end{array}$ & $\begin{array}{c}\text { SAFT } \\
\left({ }^{\mathbf{0}} \mathbf{F}\right)\end{array}$ & $\begin{array}{c}\text { Untreated } \\
\text { Paper Substrate }\end{array}$ \\
\hline PSA1 & 0.20 & 0.25 & 0.55 & 33.4 & 30.9 & 116 & 21 \\
\hline PSA2 & 0.22 & 0.25 & 0.53 & 21.8 & 28.1 & 121 & 42 \\
\hline PSA3 & 0.23 & 0.25 & 0.52 & 19.1 & 28.9 & 120 & 54 \\
\hline PSA4 & 0.25 & 0.25 & 0.50 & 24.9 & 24.2 & 124 & 64 \\
\hline PSA5 & 0.29 & 0.19 & 0.52 & 28.0 & 35.6 & 128 & 78 \\
\hline PSA6 & 0.32 & 0.18 & 0.52 & 20.0 & 29.8 & 129 & 88 \\
\hline PSA7 & 0.35 & 0.10 & 0.55 & 21.8 & 28.1 & 135 & 95 \\
\hline
\end{tabular}

In addition to the mechanical properties of the paper substrate, the adhesion of the attached PSA in water likely plays a significant role in determining its removal. The strong retention of PSA films by PET can be explained partly in terms of the reversible or thermodynamic work of adhesion $\left(\mathrm{W}_{\mathrm{A}}\right)$ required for their separation in water, i.e., ${ }^{9}$

$$
\mathrm{W}_{\mathrm{A}}=\gamma_{\mathrm{sub}-\mathrm{w}}+\gamma_{\mathrm{psa-w}}-\gamma_{\mathrm{psa}-\text { sub }}
$$

Here $\gamma_{\text {sub-w }}, \gamma_{\text {psa-w }}$ and $\gamma_{\text {psa-sub }}$ are the substrate-water, PSA-water and PSA-substrate interfacial energies, respectively. These values are not readily available, but can be estimated using various predictive equations. The simplest has the form, ${ }^{10}$

$$
\gamma_{12}=\gamma_{1}+\gamma_{2}-2\left[\left(\gamma_{1}^{\mathrm{d}} \gamma_{2}^{\mathrm{d}}\right)^{1 / 2}+\left(\gamma_{1}^{\mathrm{p}} \gamma_{2}^{\mathrm{p}}\right)^{1 / 2}\right]
$$

where the subscripts 1 and 2 indicate the phases that form an interface, $\gamma_{12}$ is the interfacial energy and $\gamma_{1}$ and $\gamma_{2}$ are the surface energies for phases 1 and 2, respectively, and $\gamma^{\mathrm{d}}$ and $\gamma^{\mathrm{p}}$ denote dispersive and polar components of the surface energy, respectively. Surface energies of PSAs and paper substrates used in this study were estimated from contact angle measurements using a technique described by Fowkes. ${ }^{11}$ Table 5 shows the surface properties of the liquids used in these measurements as well as estimated surface energies for the experimental PSAs, their components, PET and paper treated with various additives. Surface energies of the PSAs are similar to what would be predicted assuming an additive relationship for their components. Values for the PET film and the untreated paper were similar to previously reported values for PET $^{10}$ and cellulose. ${ }^{12}$ Although the sessile drop technique for measuring contact angle is not advisable for porous substrates, our measurements as well as previously reported results indicate that meaningful values can be extracted if care is taken to deconvolute the influence of absorption and swelling. ${ }^{13}$ For paper labels, this becomes significantly easier the higher the size response of the paper. 
Table 5. Estimated surface energies and their dispersive and polar components for the various materials used in the study.

\begin{tabular}{|c|c|c|c|}
\hline & $\gamma^{d}\left(\mathbf{m J} / \mathbf{m}^{2}\right)$ & $\gamma^{\mathbf{p}}\left(\mathbf{m J} / \mathbf{m}^{2}\right)$ & $\gamma\left(\mathrm{mJ} / \mathrm{m}^{2}\right)$ \\
\hline Diiodomethane* & 49.5 & 1.3 & 50.8 \\
\hline Water* & 21.8 & 51.0 & 72.8 \\
\hline SIS/SI Polymer & 39.5 & 0.6 & 40.1 \\
\hline Plasticizer & $\mathrm{NA}$ & NA & 30.3 \\
\hline Tackifier & 44.0 & 0.5 & 44.5 \\
\hline PSA1 & 41.1 & 1.5 & 42.6 \\
\hline PSA2 & 37.7 & 0.03 & 37.7 \\
\hline PSA3 & 37.2 & 0.05 & 37.2 \\
\hline PSA4 & 36.6 & 0.03 & 36.6 \\
\hline PSA5 & 40.8 & 0.2 & 41.0 \\
\hline PSA6 & 37.3 & 0.0 & 37.3 \\
\hline PSA7 & 37.0 & 0.0 & 37.0 \\
\hline PET & 45.3 & 1.3 & 46.6 \\
\hline $\begin{array}{c}\text { Untreated Paper } \\
\text { Substrate }\end{array}$ & 37.1 & 32.4 & 69.5 \\
\hline $\begin{array}{c}\text { Wet-Strength } \\
\text { Paper Substrate }\end{array}$ & 32.7 & 21.3 & 54.0 \\
\hline $\begin{array}{l}\text { Sized Wet- } \\
\text { Strength Paper } \\
\text { Substrate }\end{array}$ & 30.8 & 0.6 & 31.4 \\
\hline
\end{tabular}

* from reference 10

Table 6 lists PSA-substrate thermodynamic work of adhesion values for dry and aqueous environments estimated using Eqs. 1 and 2 and values from Table 2. These values indicate that the work of adhesion between PSA and PET in an aqueous environment is slightly higher than those calculated for PET in air. Calculated work of adhesion values for the PSA films on untreated paper substrates in air are almost the same as those for the PSAs on PET in air, but the calculated work of adhesion values for the PSAs on untreated paper substrates in an aqueous environment are significantly lower. Values calculated in an aqueous medium are about 1/3 of values for cellulose in air. This difference results from the strong interaction between water and the polyhydroxyl structure of cellulose to produce a low interfacial energy, significantly reducing the energy required for the removal of the PSA. It should be noted that the aqueous medium $\mathrm{W}_{\mathrm{A}}$ calculations assume an interface between the PSAs and dry cellulose. Given the hygroscopic nature of cellulose fibers, this is unlikely, and a more accurate estimate of $\mathrm{W}_{\mathrm{A}}$ (Eq. 2) may be the $\gamma_{\text {sub-w }}$ value alone, which would decrease estimated $\mathrm{W}_{\mathrm{A}}$ values for the separation of PSAs from wet cellulose. Using any estimate, it appears work must be done to remove the PSA from its substrate in an aqueous environment. Significantly more work is required when the PSAs are attached to PET. 
Table 6. Estimated thermodynamic work of adhesion values for the removal of PSAs from PET and paper substrates.

\begin{tabular}{|c|c|c|c|c|c|c|c|c|}
\hline \multirow[t]{2}{*}{ PSA } & \multicolumn{2}{|c|}{$\begin{array}{c}\mathrm{W}_{\mathrm{A}} \text { for PET } \\
\left(\mathrm{mJ} / \mathrm{m}^{2}\right)\end{array}$} & \multicolumn{2}{|c|}{$\begin{array}{c}W_{A} \text { for } \\
\text { Untreated } \\
\text { Paper }\left(\mathbf{m J} / \mathbf{m}^{2}\right) \\
\end{array}$} & \multicolumn{2}{|c|}{$\begin{array}{c}\mathrm{W}_{\mathrm{A}} \text { for Wet- } \\
\text { Strength Paper } \\
\left(\mathrm{mJ} / \mathrm{m}^{2}\right)\end{array}$} & \multicolumn{2}{|c|}{$\begin{array}{l}W_{A} \text { for Sized } \\
\text { Wet-Strength } \\
\text { Paper }\left(\mathrm{mJ} / \mathrm{m}^{2}\right) \\
\end{array}$} \\
\hline & Dry & Wet & Dry & Wet & Dry & Wet & Dry & Wet \\
\hline PSA1 & 89.0 & 78.5 & 92.0 & 22.2 & 84.6 & 33.7 & 73.1 & 78.6 \\
\hline PSA2 & 83.1 & 90.0 & 76.8 & 24.4 & 71.8 & 38.3 & 68.4 & 91.3 \\
\hline PSA3 & 82.6 & 89.2 & 76.8 & 24.1 & 71.8 & 38.0 & 68.0 & 90.6 \\
\hline PSA4 & 81.9 & 89.7 & 75.7 & 24.2 & 70.8 & 38.2 & 67.4 & 91.2 \\
\hline PSA5 & 87.1 & 87.8 & 82.9 & 24.3 & 78.1 & 38.4 & 71.6 & 88.3 \\
\hline PSA6 & 82.2 & 92.0 & 74.4 & 24.8 & 69.9 & 39.2 & 67.8 & 93.6 \\
\hline PSA7 & 82.2 & 91.2 & 74.1 & 24.7 & 69.6 & 39.1 & 67.5 & 93.4 \\
\hline
\end{tabular}

\subsection{Influence of Wet-Strength Paper Substrates on PSA Removal}

From the above discussion, it would appear that producing paper substrates that will resist fiberization and retain the attached PSA film will require both a manipulation of its bulk mechanical properties as well as its surface properties. The mechanical properties of wet paper can be modified through the use of wet-strength resins. These additives allow paper products to retain a higher fraction of their dry strength when wet. The most common wet-strength resins utilized by the paper industry are the poly(amido-amine) epichlorohydrins or PAEs. ${ }^{14}$ These treatments are believed to work by adsorbing at fiber surfaces and polymerizing with both each other to form highly crosslinked networks that inhibit swelling and with cellulose providing water-insensitive linkages between fibers. ${ }^{15-17}$ Figure 6 shows the influence of 3 different commercial PAE resins on wet tensile strength of paper as percent active chemical added to dry fiber solids. As can be seen, the resins produce a 7- to 10-fold increase in the wet tensile strength of the paper. In Figure 7, the removal of the paper via screening as a function of tensile loss after wetting is plotted. In these experiments, no PSAs were attached to the paper substrate and the repulping was carried out on a small scale using a procedure described by Fischer. ${ }^{18}$ The objective of these tests was to determine the best variables for characterizing the influence of resins on the fiberization of the paper substrates. As shown, the points with nonzero reject values linearly correlate with tensile loss after wetting for 7 different commercial wet-strength resins including various PAEs as well as urea and melamine formaldehyde resins. No such relationship was found between reject levels and the wet tensile strength of the paper.

The influence of wet strength paper substrates on the removal efficiencies of various attached experimental PSAs is shown in Figure 8. Results indicate that the wet strength of the paper substrate has a strong influence on the removal of some PSAs and little influence on others. This is likely due to differences in adhesion (e.g., PSA6 separated from its face stock completely and the others still were at least partly attached following repulping). The mass fraction of a PSA that is retained by a treated paper substrate during repulping $\left(\mathrm{x}_{\mathrm{s}}\right)$ can be estimated from its removal efficiencies when coated on treated $\left(\mathrm{RE}_{\text {treated }}\right)$ and untreated paper labels $\left(R E_{\text {untreated }}\right)$ as, 


$$
\mathrm{x}_{\mathrm{s}}=\frac{\mathrm{RE}_{\text {treated }}-\mathrm{RE}_{\text {untreated }}}{100 \%-\mathrm{RE}}
$$

This is obtained from a mass balance for the removed PSA assuming that the substrate is not broken down, the mass of PSA retained by treated paper substrates during repulping is completely removed and that the mass of PSA not retained by the paper substrate during

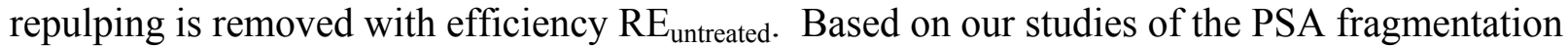
mechanism during repulping, these assumptions appear reasonable for the adhesives tested here. It is likely that $\mathrm{x}_{\mathrm{S}}$ is related to the apparent energy of adhesion. However, the complex nature of the process involving the removal of a viscoelastic film from a hygroscopic substrate with complex dynamic stresses precludes a rigorous treatment. Here, we take a more qualitative approach to produce a semi-empirical relationship.

The strength of an adhesive bond has been described as being composed of 3 contributions. ${ }^{19-21}$ One contribution is the ability of the PSA to physically deform and wet out the substrate. Another is from the surface interactions that develop, which are characterized by the thermodynamic work of adhesion $\left(\mathrm{W}_{\mathrm{A}}\right)$. This is the work required to separate the PSA from its substrate in the absence of viscoelastic losses. A final contributor is the ability of the PSA to dissipate energy upon deformation or debonding. It was found that attaching PSA films to paper substrates using various pressures $(200$ to $600 \mathrm{kPa})$, temperatures $\left(15\right.$ to $\left.105^{\circ} \mathrm{C}\right)$ and contact times had no impact on the measured removal efficiencies. This indicates that differences in the transfer coating process and likely initial bonding do not produce significant differences in the PSA-paper substrate adhesion between samples. Thus, the thermodynamic work of adhesion and dissipative mechanisms are more likely responsible for these differences. As summarized in Table 3, estimated $\mathrm{W}_{\mathrm{A}}$ values for the removal of experimental PSAs from wet strength paper substrates in an aqueous medium are all similar. The small differences that do exist between PSAs 1,2 and 6 are not consistent with the order found in Figure 8. Another difference between these PSAs is their mechanical loss tangents. The mechanical loss tangent is equal to the ratio of the loss and storage moduli of a material, i.e., $\tan \delta=\mathrm{G}^{\prime \prime} / \mathrm{G}^{\prime}$, where $\mathrm{G}^{\prime \prime}$ and $\mathrm{G}^{\prime}$ are the loss and storage moduli, respectively. Figure 9 shows $\tan \delta$ measured at $10 \mathrm{rad} . / \mathrm{s}$ as a function of temperature for PSA1, PSA2 and PSA6. As can be seen from the figure, at the repulping temperatures used in measuring the removal efficiencies of the PSAs, they possess slightly different loss tangent values. Figure 10 is a plot of $\mathrm{x}_{\mathrm{s}}$ versus the mechanical loss tangent or $\tan \delta$ of the attached PSA films for the experimental PSAs. The results indicate that for $\tan \delta$ values of less than about 0.45 , using the treated paper has little or no influence on the removal of the PSAs. Above this value there is a linear relationship between retention and the $\tan \delta$ of the PSAs. Given that $\tan \delta$ gauges the ability of a material to dissipate deformation energy, ${ }^{22}$ we assume here it gauges nonequilibrium or dissipative contributions to the apparent adhesion of the PSA to the paper substrate. The results indicate that these interactions can exert a significant influence on the retention of the adhesive film during repulping.

\subsection{Enhancing PSA Adhesion to Wet-Strength Paper Substrates}

From Figure 10, it appears that retention of the PSA film can be increased through the use of a PSA with a higher mechanical loss tangent, but this restricts the adhesives that can be removed using this technique. An approach that removes restrictions on the PSA is the enhancement of 
the thermodynamic work of adhesion, $\mathrm{W}_{\mathrm{A}}$, between the PSA and paper substrate by modifying the surface properties of the paper. From Eq. 3, it appears that this can be achieved by increasing the paper substrate-water interfacial energy $\left(\gamma_{\text {sub-w }}\right)$, reducing the PSA-paper substrate interfacial energy $\left(\gamma_{\text {psa- sub }}\right)$ or both. Both can be achieved by lowering the surface energy of papermaking fibers through the application of chemical sizing agents. ${ }^{13}$ The most common sizing agents used in alkaline papermaking are alkyl ketene dimers (AKD) and alkenyl succinic anhydrides (ASA). These species possess amphiphilic structures with large aliphatic components and cellulosereactive head groups. They are water-insoluble and are introduced into the papermaking process as a colloid, which heterocoagulates with fiber used to produce paper. In the process of drying the paper and with storage, sizing agents react and orient on cellulose to provide fibers with nonpolar surfaces. Our measurements show that the advancing contact angle for water on paper increased from 22.3 to $111^{\circ}$ with the application of AKD to a level of $0.6 \%$ of dry fiber solids. This is consistent with contact angle changes measured for single sized papermaking fiber. ${ }^{23}$ The increased contact angle for aqueous solutions on treated cellulose produce capillary forces that inhibit solution penetration and to a certain extent, provide protection of fiber-fiber bonds to maintain paper strength. ${ }^{24}$ Here, the desired effect is the expected increase in $\gamma_{\text {sub-w }}$ and reduction in $\gamma_{\text {psa- sub. }}$.

Figure 11 shows the influence of a commercial AKD sizing agent on the size response and wet tensile strength of paper containing a wet-strength resin. Here, size response is measured using the Hercule's Size Test (HST) and the level of sizing or size response is measured as HST seconds. Simply stated, this test measures how quickly an aqueous dye solution penetrates through a sheet of paper. Thus, for paper of a similar basis weight and fiber type, an increase in penetration time is a measure of the degree of sizing for the sheet. As demonstrated in the figure, the sizing degree increases sharply with the dosage of sizing agent, while the wet tensile strength increases only slightly. Figure 12 shows the influence of increasing sizing response for wetstrength paper substrates on the removal efficiency of the attached PSAs. The results indicate a sharp increase in the removal efficiencies for small increases in HST penetration times. These initial sharp increases were produced with size addition of about $0.25 \%$ on dry fiber. Following this initial rise, the removal efficiency levels off at $92 \%, 95 \%, 96 \%$ for PSA1, PSA 2 and PSA6, respectively. Comparing this with their removal efficiencies when attached to untreated paper of $21 \%, 42 \%$ and $88 \%$, respectively, demonstrates the significant improvement obtained. The influence of the sizing agent on removal efficiencies is further demonstrated in Figure 13, which shows removal efficiencies for PSA2 as a function of tensile loss for sized and unsized paper.

The higher removal efficiencies observed for sized, wet strength, paper substrates are believed to be a direct result of increased adhesion. From Table 6, it can be seen that the sizing agent significantly increases the estimated thermodynamic work of adhesion between the PSA and paper substrate. In fact, it is estimated that $\mathrm{W}_{\mathrm{A}}$ for the dry paper substrate is affected little by the presence of the sizing agent, while $\mathrm{W}_{\mathrm{A}}$ for the wet paper substrate is more than doubled to where it is actually higher than that for the dry paper substrate. The strong influence of the sizing agent on adhesion is also seen in peel tests where very small increases in size response are found to dramatically increase the peel force between the PSA film and wet paper. These increases are such that it becomes difficult to separate the PSA film from the paper without delamination at sizing levels well below that used here in the sized, wet strength paper substrates. Figure 14 shows $\mathrm{x}_{\mathrm{s}}$ plotted as a function of the $\tan \delta$ for PSAs attached to PET, wet-strength paper, and 
sized wet-strength paper, which indicate a linear relationship between substrate retention and tan $\delta$ is also found when the paper substrate is sized. The results for PET are shown to demonstrate the trend for the slope and intercept. It appears that the intercept increases and the slope decreases as the thermodynamic work of adhesion is increased. The estimates in Table 3 indicate that the work of adhesion to sized, wet strength paper is similar to its adhesion to PET. However, it should be stressed that these are simply estimates based on the assumption that the swelling of the paper substrate does not influence the PSA-paper substrate interfacial energy.

\subsection{Summary and Conclusions}

An alternative approach to current efforts on the development of environmentally benign PSAs has been presented. Rather than engineering PSA films to enhance their removal from recycling operations, this approach involves the manipulation of paper substrate properties to produce paper that resists fiberization and retains attached PSAs. It was found that the addition of poly(amide epichlorohydrin) wet strength resin to paper substrates effectively inhibited their fiberization during repulping operations and that the influence of this treatment was best characterized as the fractional loss in tensile strength after wetting rather than the wet tensile strength of the paper. The ability of wet strength paper to enhance the removal of attached PSAs appears limited by adhesion, which was found to be dependent on the mechanical loss tangent of the PSA. Adhesion was increased through the use of an alkyl ketene dimer sizing agent, which reduces the paper substrate-PSA and raises the paper substrate-water interfacial energies increasing the thermodynamic work of adhesion. Use of the sizing agent in combination with the wet strength resin significantly increased the removal of PSAs via screening in laboratory testing. All of the PSAs tested had removal efficiencies greater than $90 \%$. The control of PSA contaminants is arguably the most important technical issue for paper recycling. Here we have demonstrated the potential of a new contaminant control approach. Future work will explore the impact of treated substrates on the recycling process and further refinements of the approach such as surface treatments.

\subsection{Pilot Trials}

Appendix 2 reviews the results of pilot scale testing for hot-melt PSA HL-2201. This PSA was identified via the developed model above and through laboratory testing of having a low removal efficiency (approximately 2\% when coated on untreated paper and repulped using procedure 2.10). (In fact, this PSA gave the lowest removal efficiencies of those tested as part of this project.) For pilot testing, the PSA was coated on C1S $\left(92 \mathrm{~g} / \mathrm{m}^{2}\right.$, tensile loss $=95.4 \%$, base sheet HST time $=3.5 \mathrm{~s}$ ) produced commercially by Boise Solutions (International Falls, MN) and sized, wet-strength coated paper $\left(92 \mathrm{~g} / \mathrm{m}^{2}\right.$, tensile loss $=75.8 \%$, base sheet HST time $\left.=128 \mathrm{~s}\right)$ produced at the Western Michigan Pilot facilities (Kalamazoo, MI). Pilot production was funded by Boise Solutions and wet-end chemicals were provided by Hercules Incorporated (Wilmington, DE). The sample coated on the commercial face stock is denoted F-2001, and the sample produced at the pilot scale is denoted F-2002. As expected, the F-2001 sample performed poorly and was identified by the FPL as possibly the worst performing PSA tested at their facilities. When the PSA was then attached to the coated face stock containing high wetstrength and a high degree of sizing, the removal efficiency was significantly improved. A patent application has been filed for this technology. 


\subsection{Figures}

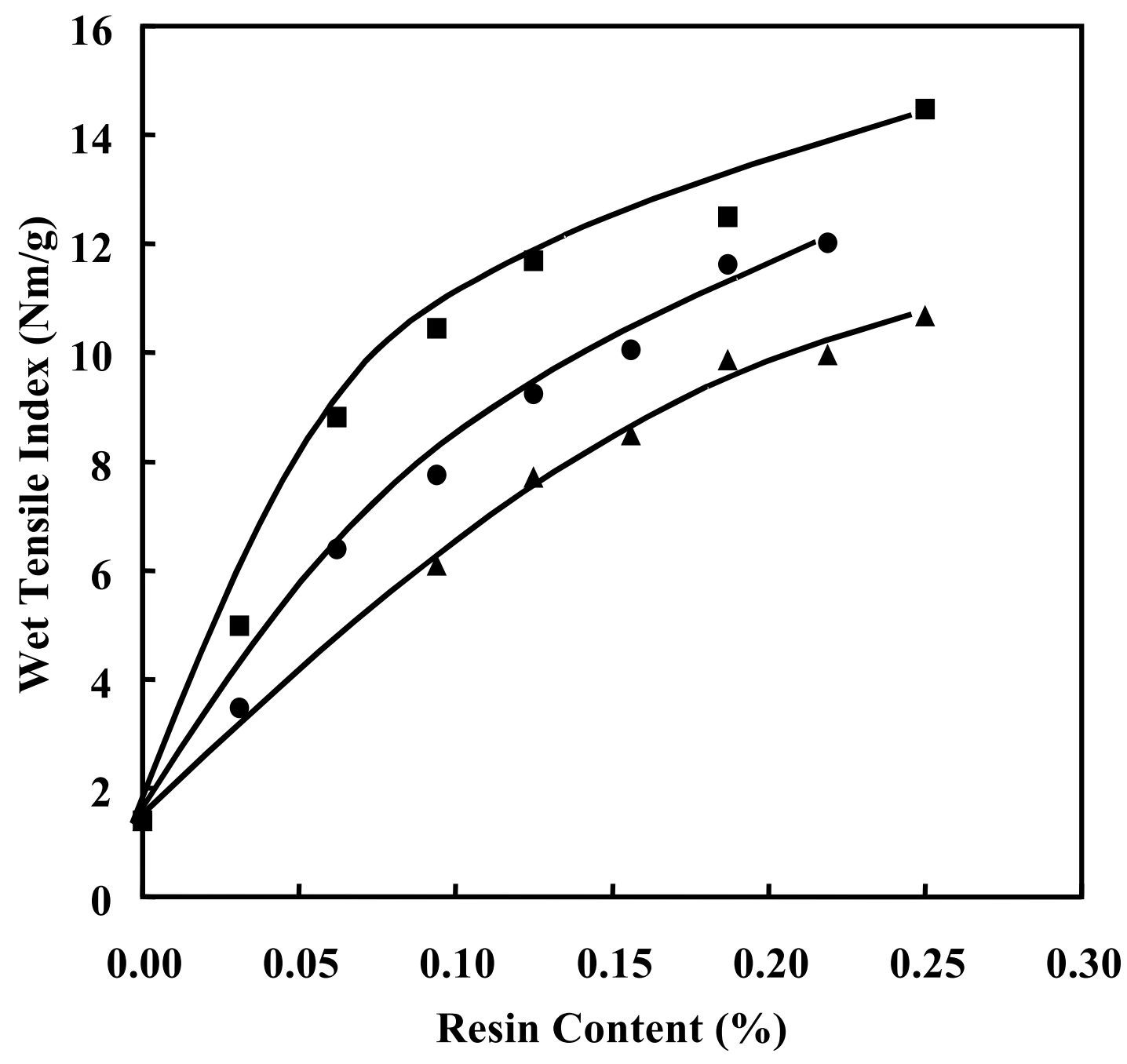

Figure 6. Wet tensile index of paper as a function of resin content on a dry fiber basis for several commercial wet-strength resins. “ם " Kymene 557H; “” Kymene 557LX; “ ” Amres 2747. 


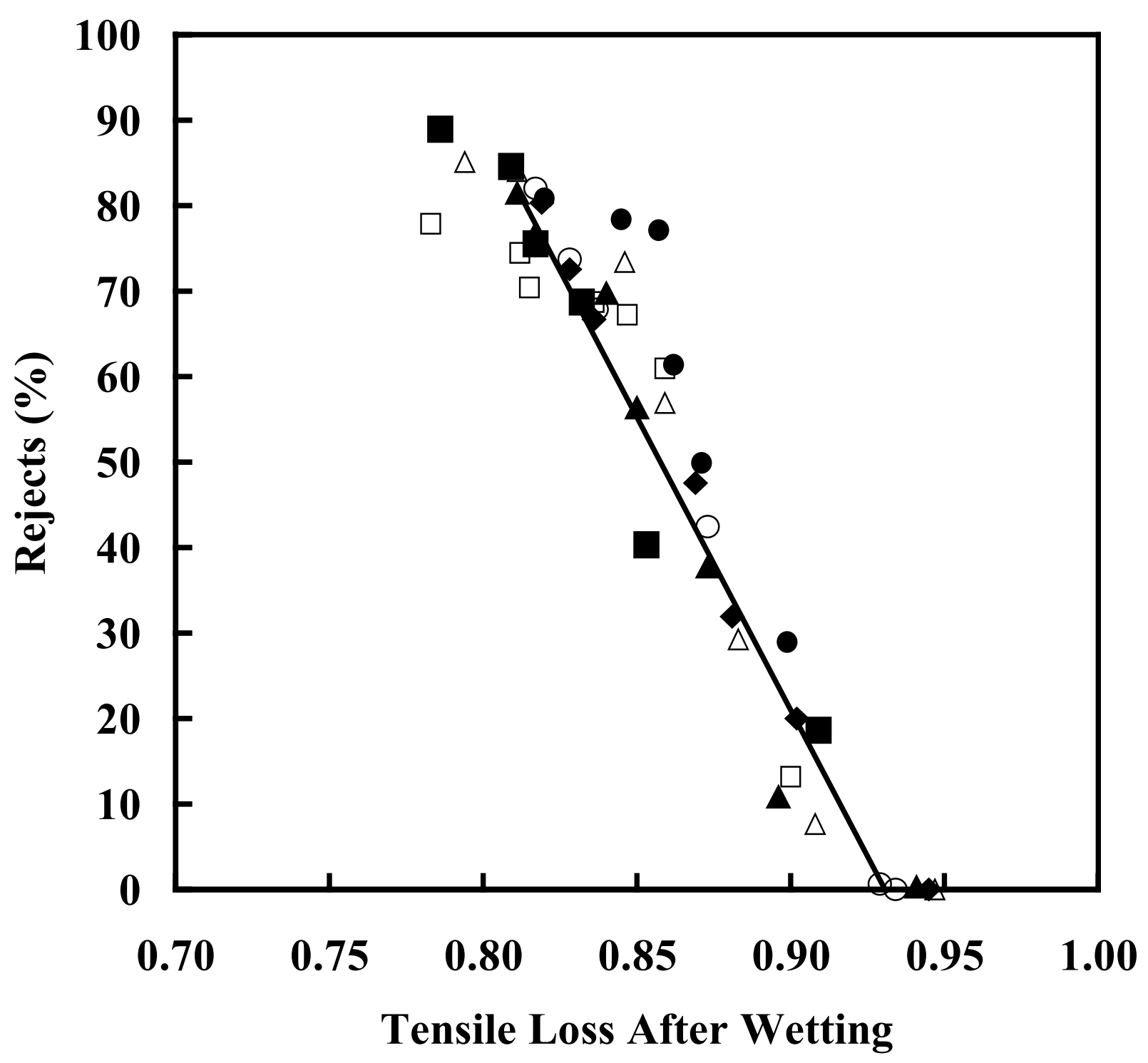

Figure 7. Screening efficiencies as a function of tensile loss after wetting for paper treated with a

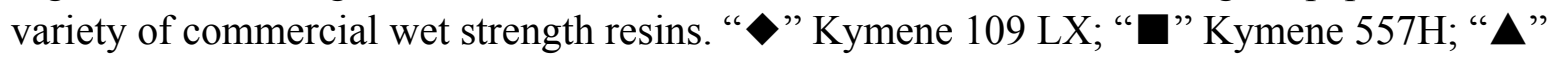
Kymene 557LX; “ ○” Kymene 450; “ $\triangle$ ” Ameres 8855; “○” Ameres 2727; “ $\square$ ” Paramel 200. 


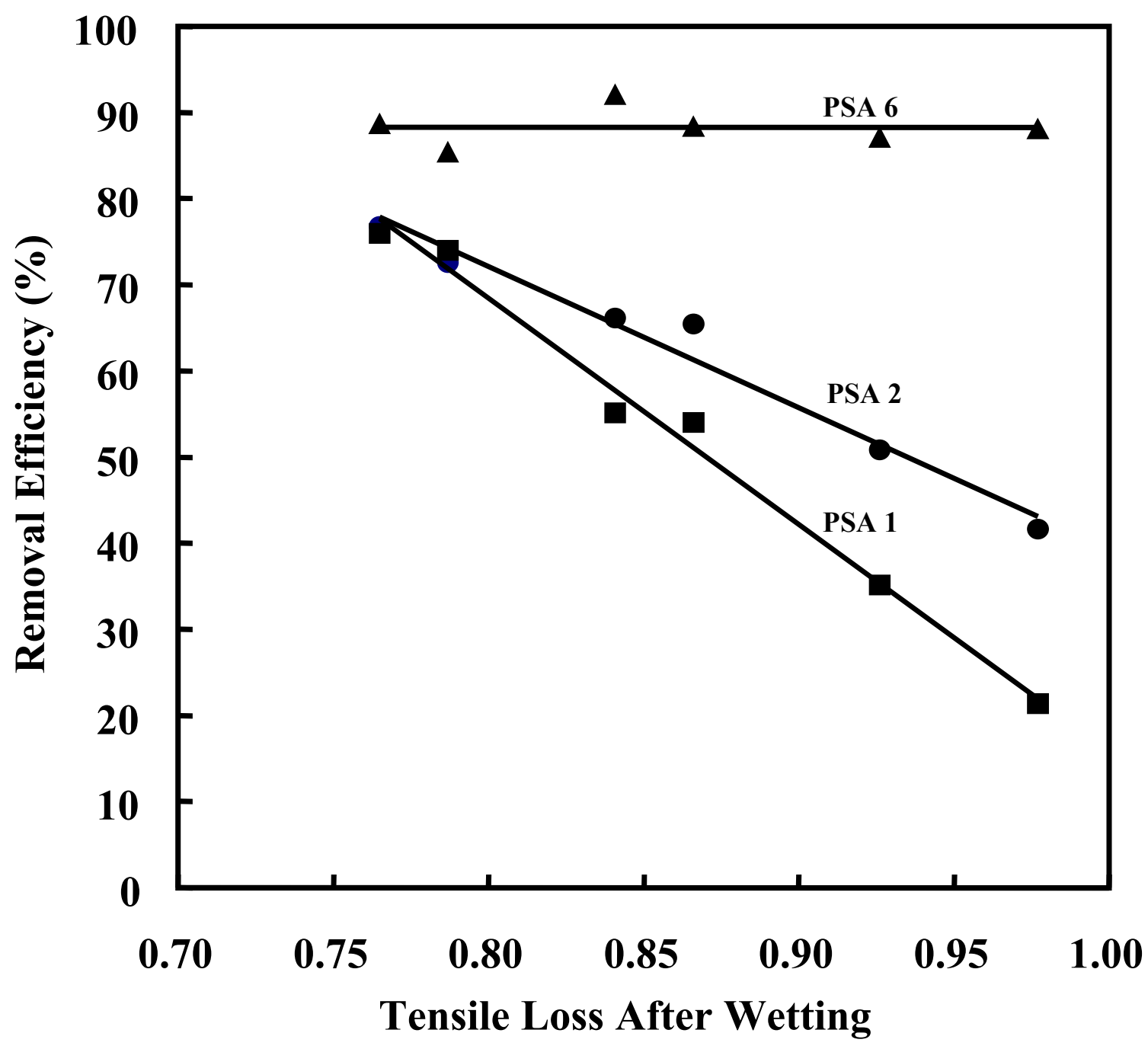

Figure 8. Removal efficiencies for PSA1, PSA 2 and PSA6 as a function of tensile loss after wetting for paper substrates treated with a commercial wet-strength resin (Kymene 557H). 


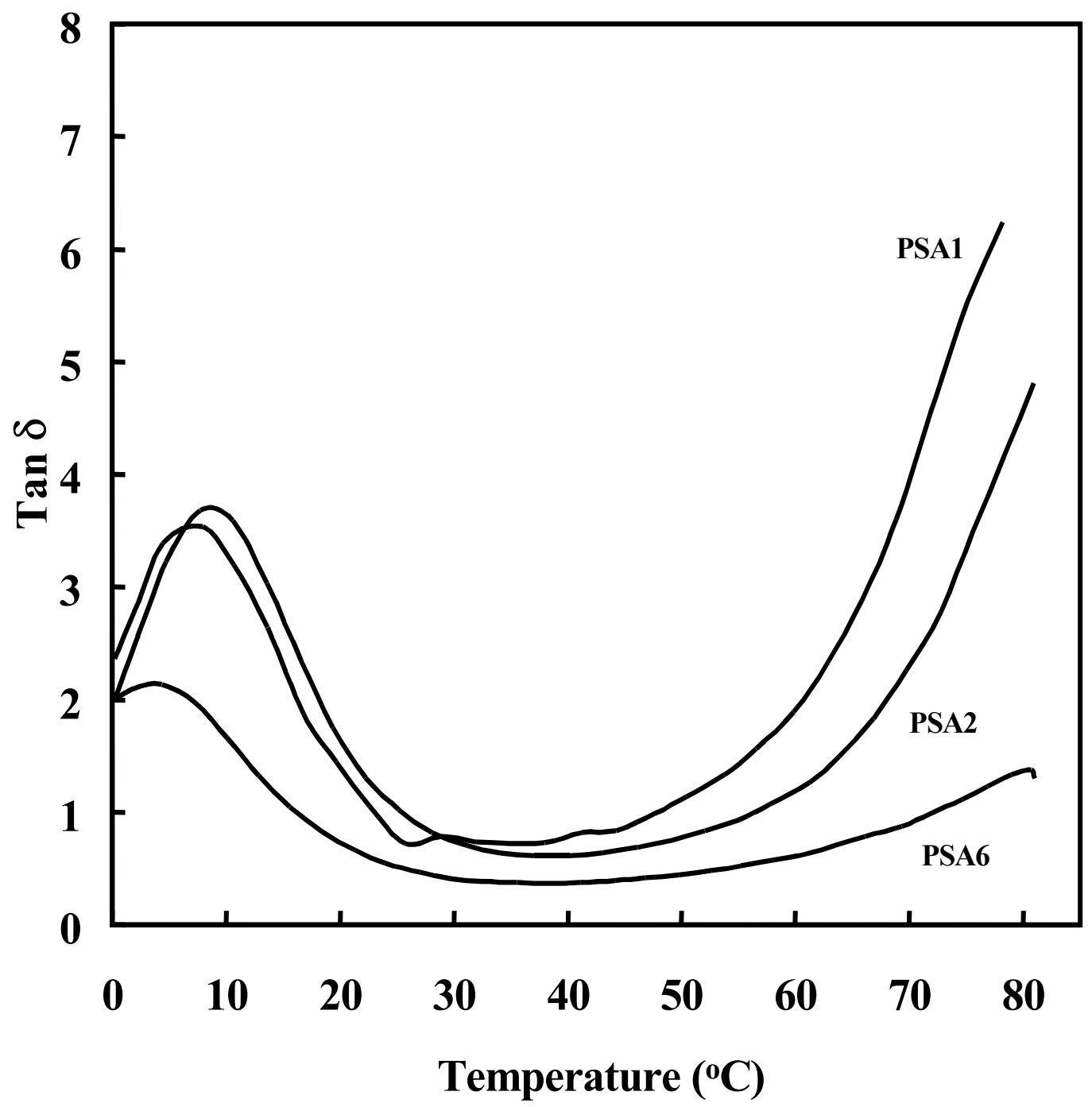

Figure 9. Tan $\delta$ measured at $10 \mathrm{rad} . / \mathrm{s}$ as a function of temperature for PSA1, PSA2 and PSA6. 


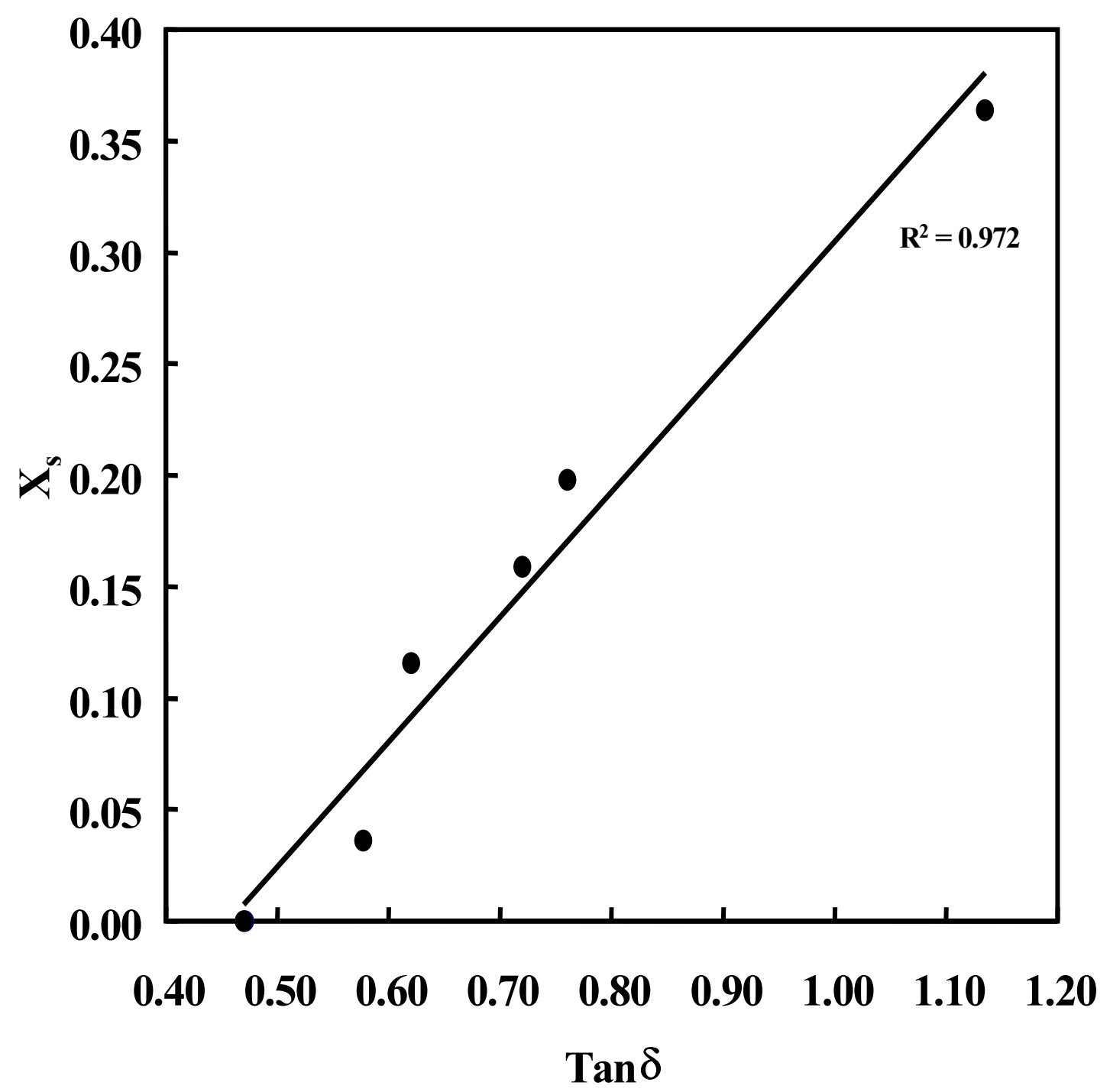

Figure 10. The mass fraction of PSA retained by the paper substrate during repulping $\left(\mathrm{x}_{\mathrm{s}}\right)$ as a function of $\tan \delta\left(50^{\circ} \mathrm{C}, 10 \mathrm{rad} . / \mathrm{s}\right)$ for experimental PSAs. The paper substrate was treated with $0.25 \%$ of Kymene $557 \mathrm{H}$ and has a tensile loss after wetting of 0.827 . 


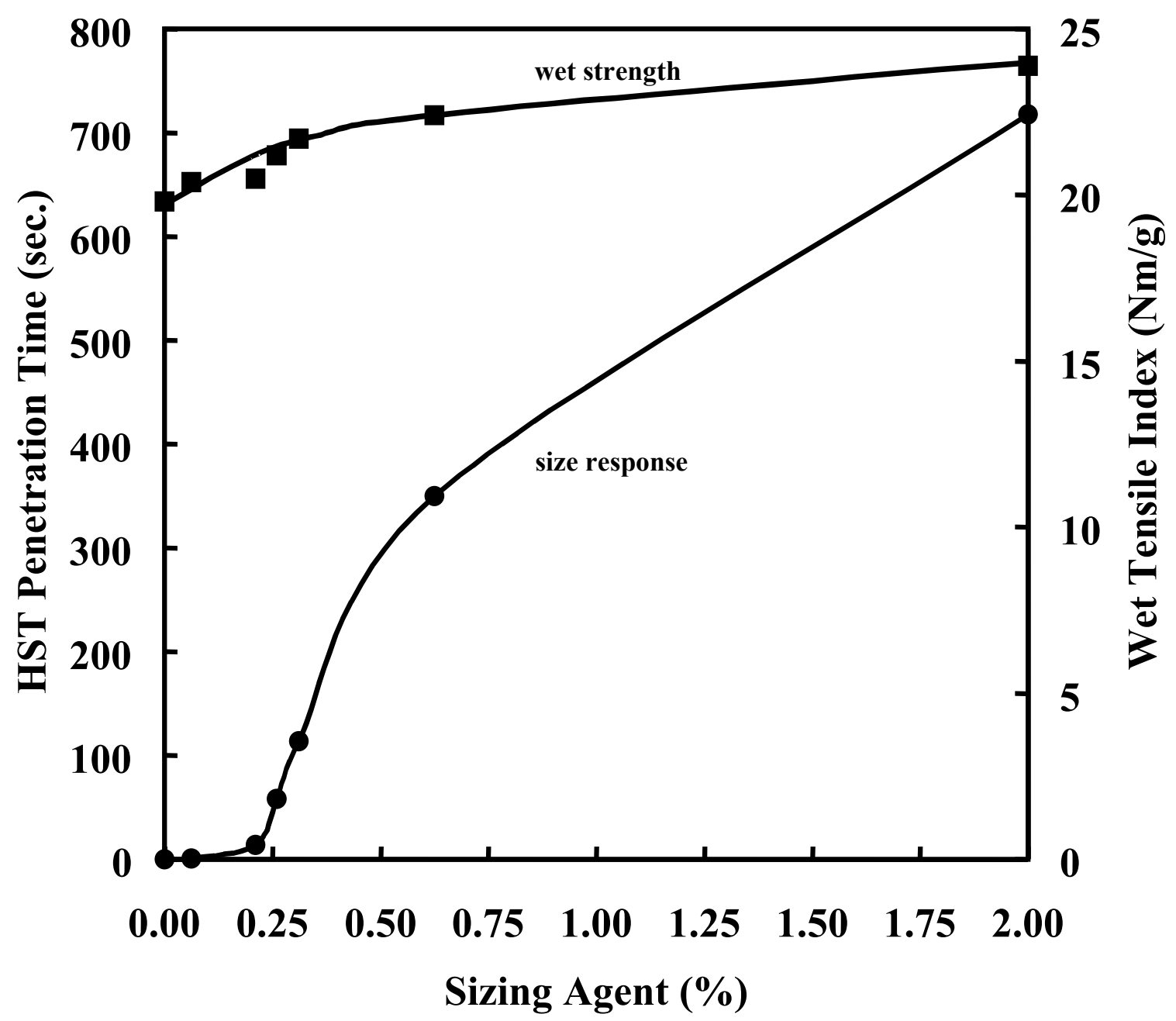

Figure 11. The size response (HST penetration times) and wet tensile index as a function of the apparent sizing agent (Hercon 70 ) concentration for paper substrates treated with $0.5 \%$ of Kymene $557 \mathrm{H}$. 


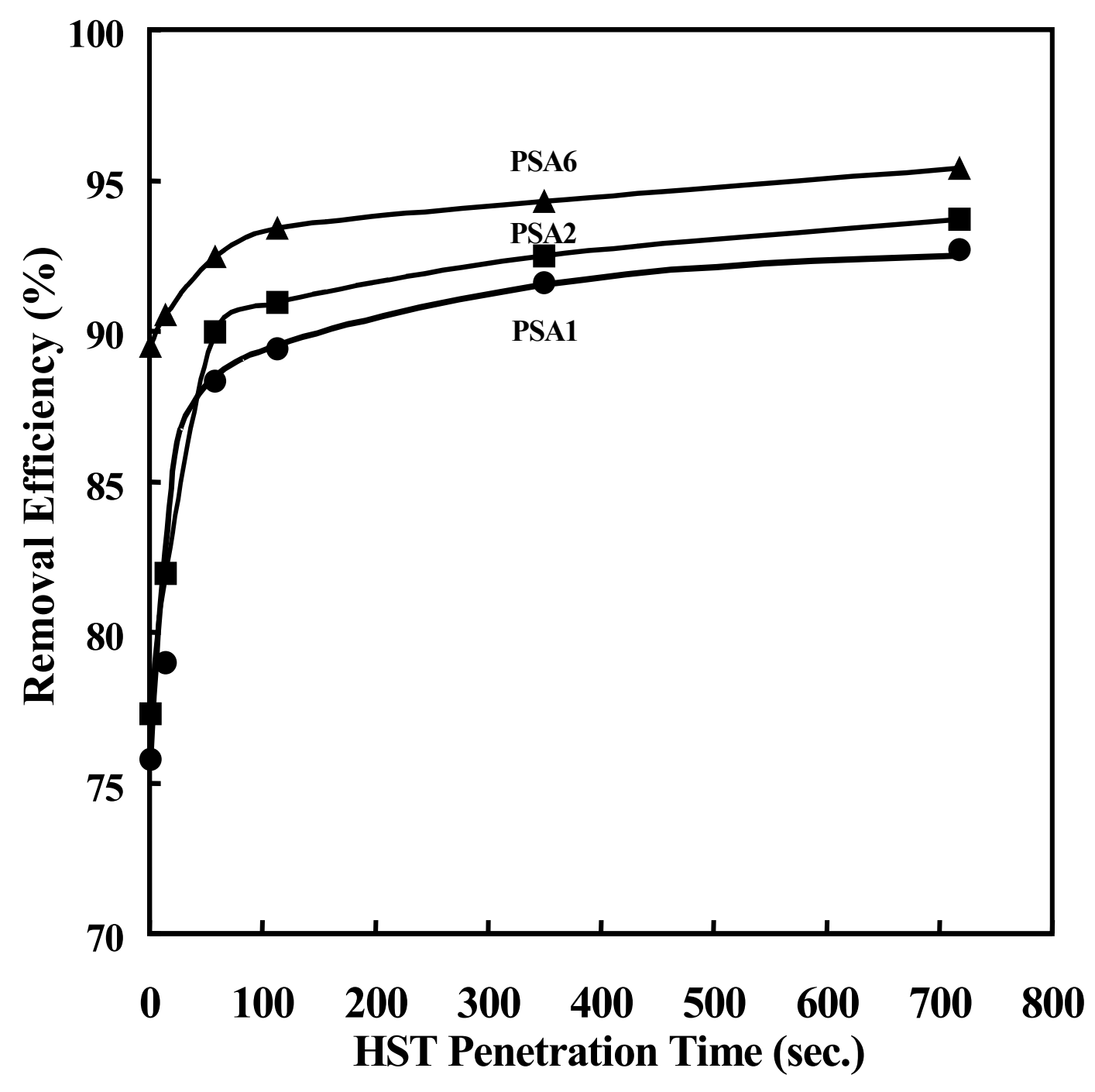

Figure 12. Effect of HST penetration times of sized, wet-strength paper substrates treated with various levels of Hercon 70 and $0.5 \%$ Kymene $557 \mathrm{H}$ on the removal efficiency of PSA1, PSA2 and PSA6. 


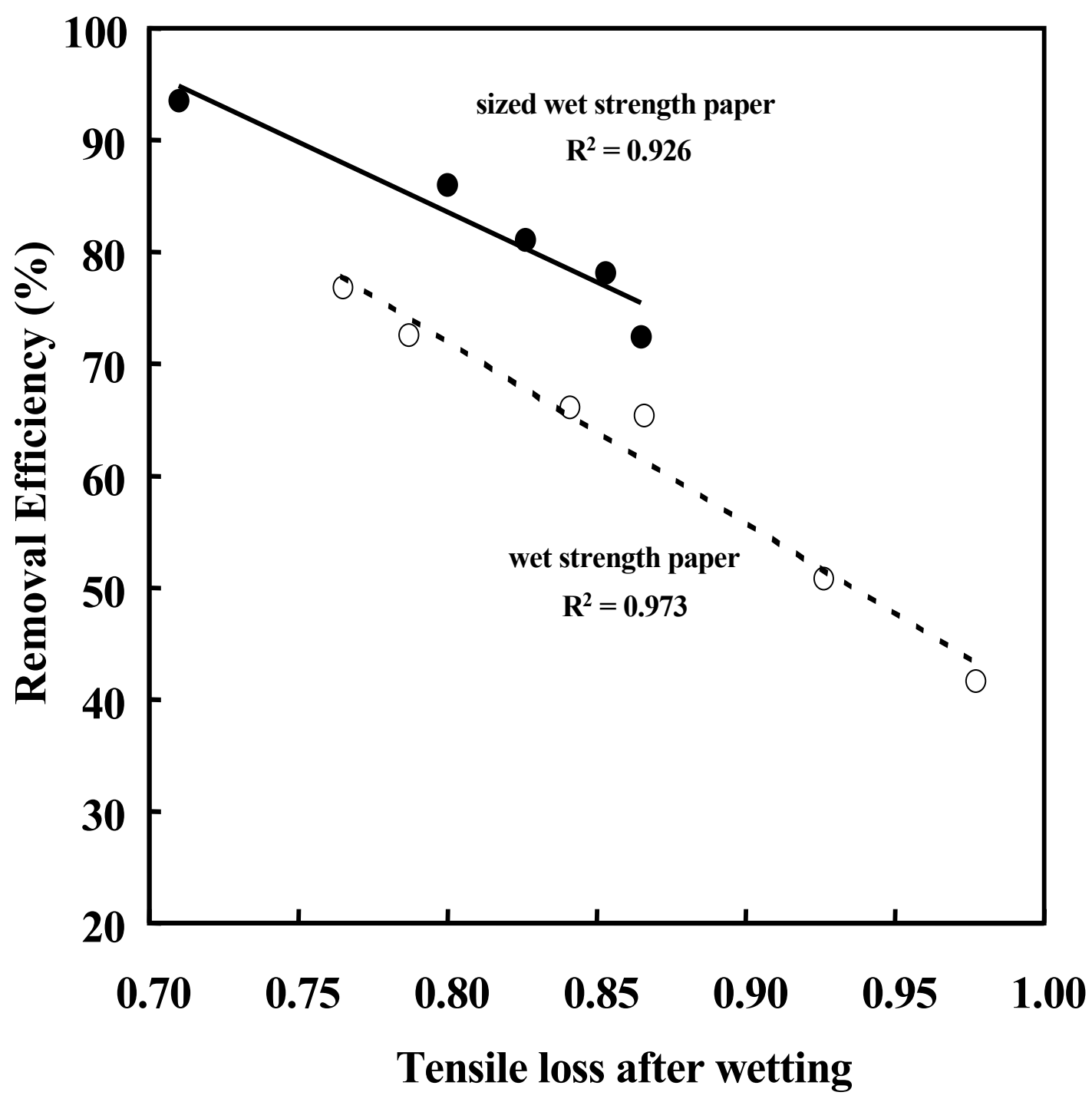

Figure 13. The removal efficiency of PSA 2 as a function of tensile loss after wetting for wetstrength paper substrates and sized, wet-strength paper substrates. 


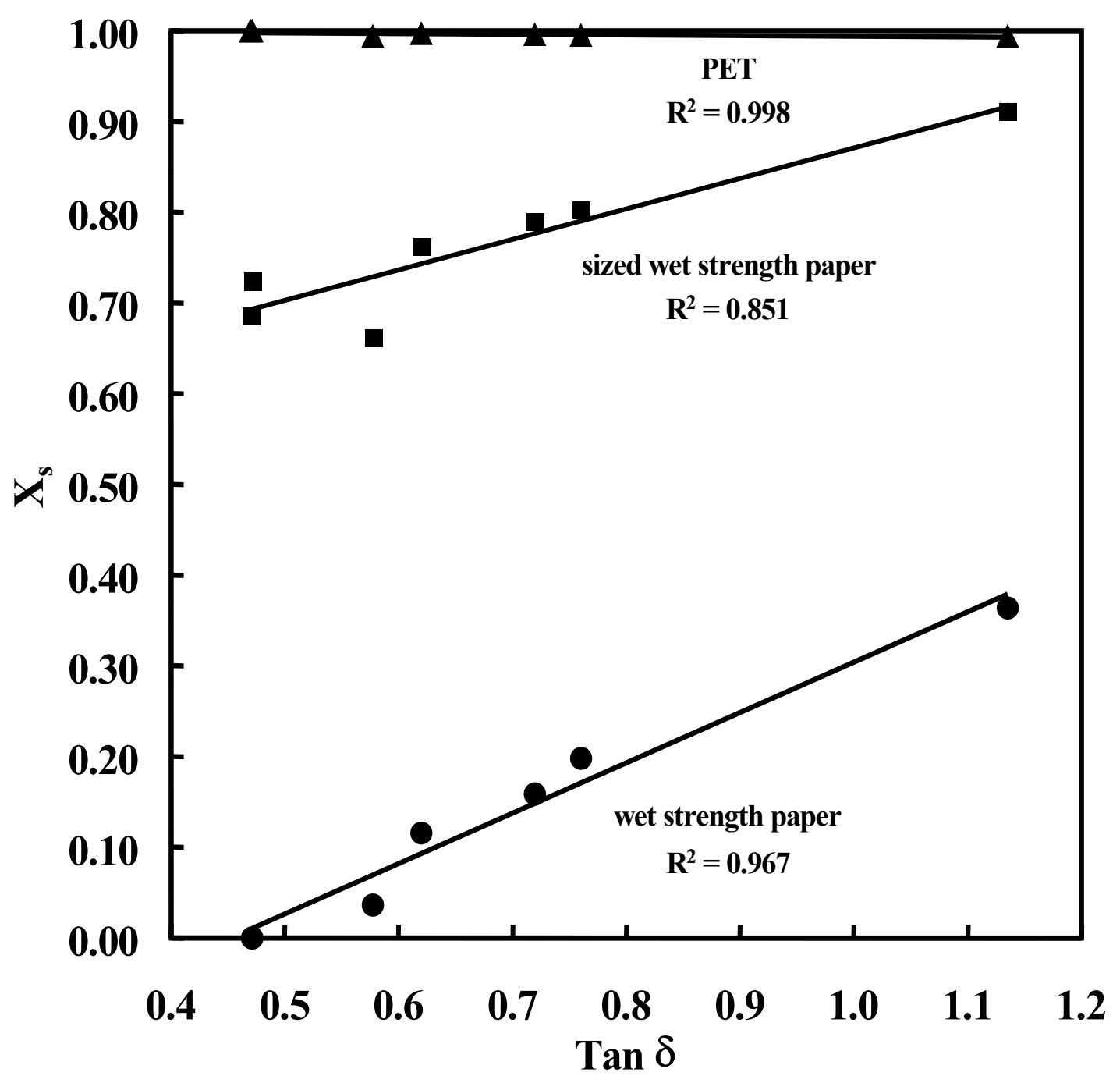

Figure 14. The mass fraction of PSA retained by the paper substrate during repulping $\left(\mathrm{x}_{\mathrm{s}}\right)$ as a function of $\tan \delta\left(50^{\circ} \mathrm{C}, 10 \mathrm{rad} . / \mathrm{s}\right)$ for experimental PSAs attached to wet-strength paper substrates $(0.5 \%$ Kymene $557 \mathrm{H})$, sized, wet-strength paper $(0.625 \%$ Hercon $70,350 \mathrm{HST}$,s) and PET. 


\section{Optimizing Laminate Components to Increase Screenability}

Most commercial face stock utilized in PSA laminates are not treated with wet-strength resin and readily break down during repulping. Increasing the adhesion between PSA and face stock in a label enhances PSA removal efficiencies if the paper does not disperse into its constituent fibers, but the influence of this interaction when fiberization does occur is not known. Here it will be shown that under these circumstances, increasing the PSA-substrate adhesion can greatly diminish PSA removal. It is also shown that increasing the wet strength of label face stock that subsequently fiberizes during repulping further diminishes removal efficiencies of attached PSAs. Results are consistent with the observation that PSA films fragment more readily when in their open geometry likely due to the film surface area dependency of the induced stresses. ${ }^{26}$ It is proposed that the collapse of PSA films during repulping is inhibited by the presence of residual fiber from laminate paper layers. Once these layers are removed, films collapse reducing their surface area and the extent of induced stresses. Delamination of PSA labels is controlled by the tendency of wet paper layers to fiberize or debond from film surfaces rather than transfer the induced loads. Thus the extent to which a face stock will diminish the removal efficiency of an attached PSA is expected to be dependent on the wet paper strength and the strength of the paper-PSA bonding in an aqueous environment. In this paper, we review a study on the influence of both of these. The results indicate that in their current form, commercial face stocks promote the fragmentation of attached PSAs limiting their removal efficiencies. It is hoped that the information presented here will allow label producers to develop new laminates possessing higher screening removal efficiencies, thus limiting their impact on paper recycling operations.

\subsection{Characterization of PSA Laminate Components}

All experiments utilized a laminate structure consisting of the experimental hot-melt PSA sandwiched between various face stocks and envelope paper. Table 7 lists bulk mechanical and surface properties of tested commercial face stocks, untreated paper and envelope paper. Properties of the face stocks were measured for both the final products as well as the uncoated base sheets. The coated label stock, referred to as C1S (coated 1 side), consists of a $61 \mathrm{~g} / \mathrm{m}^{2}$ (37 lbs. $/ 3000 \mathrm{ft}^{2}$ ) base sheet containing approximately $10 \%$ clay filler. C1S is produced from a $50: 50$ hardwood:softwood fiber blend and is pigment coated on a single side at a level of approximately $16 \mathrm{~g} / \mathrm{m}^{2}\left(10 \mathrm{lbs} . / 3000 \mathrm{ft}^{2}\right)$. This grade is commonly used as a face stock in PSA laminates. The EDP (electronic data processing), base sheet has a basis weight of $70 \mathrm{~g} / \mathrm{m}^{2}(43$ lbs. $\left./ 3000 \mathrm{ft}^{2}\right)$ and contains a $60: 40$ hardwood:softwood fiber and approximately $10 \%$ clay filler. It is coated on both sides $\left(7 \mathrm{~g} / \mathrm{m}^{2}\right.$ or $\left.4.3 \mathrm{lbs} . / 3000 \mathrm{ft}^{2}\right)$ at a size press with a styrenic-acrylic random copolymer treatment used to enhance toner adhesion. The EDP is commonly used as face stock for laser printed, bulk-mailing PSA labels (e.g., bar codes). Untreated paper samples are $60 \mathrm{~g} / \mathrm{m}^{2}\left(37 \mathrm{lbs} . / 3000 \mathrm{ft}^{2}\right)$ basis weight handsheets produced in the laboratory from a refined $(400 \mathrm{~mL}) 50: 50$ hardwood:softwood fiber blend. The envelope grade is a standard white wove envelope paper with a basis weight of $90 \mathrm{~g} / \mathrm{m}^{2}\left(55 \mathrm{lbs} . / 3000 \mathrm{ft}^{2}\right)$ containing $10 \%$ ash and $70: 30$ hardwood:softwood fiber blend.

Dry and wet tensile strengths are listed for both the machine (MD) and cross (CD) directions, except in the case of the untreated paper, which is isotropic in the MD-CD plane. It was reported previously that fiberization of paper treated with polymeric additives to increase wet strength correlates with tensile loss subsequent to wetting. ${ }^{9}$ From Table 7 it can be seen that although the 
dry and wet tensile strengths are higher in the MD, the tensile loss after wetting is similar for the two directions. The Hercules Sizing Test was used to gauge the sizing level of the uncoated paper. This test measures how quickly an aqueous dye solution penetrates through a sheet of paper. For paper of a similar basis weight and fiber type, an increase in penetration time is an indication of the degree of sizing for the sheet. As can be seen from Table 7, the C1S and EDP base sheets have the highest sizing levels. High sizing levels are typically used with the base sheets of coated grades. Also shown are surface energies $(\gamma)$ estimated from contact angle measurements. ${ }^{10}$

Table 7. Mechanical and Surface Properties of Paper Face Stocks and Substrate.

\begin{tabular}{|c|c|c|c|c|c|c|c|c|c|}
\hline \multirow{3}{*}{$\begin{array}{c}\text { Face Stock } \\
\begin{array}{c}\text { Untreated } \\
\text { Handsheets }\end{array} \\
\end{array}$} & \multirow{2}{*}{$\begin{array}{c}\text { Basis } \\
\text { Weight } \\
\left(\mathbf{g} / \mathbf{m}^{2}\right)\end{array}$} & \multicolumn{2}{|c|}{$\begin{array}{c}\text { Dry Tensile Index } \\
(\mathrm{Nm} / \mathrm{g})\end{array}$} & \multicolumn{2}{|c|}{$\begin{array}{l}\text { Wet Tensile Index } \\
(\mathrm{Nm} / \mathrm{g})\end{array}$} & \multicolumn{2}{|c|}{$\begin{array}{c}\text { Tensile Loss } \\
(\%)\end{array}$} & \multirow{2}{*}{$\begin{array}{l}\text { HST Time } \\
\text { (s) }\end{array}$} & \multirow{2}{*}{$\begin{array}{c}\text { Surface } \\
\text { Energy } \\
\left(\mathrm{mJ} / \mathrm{m}^{2}\right)\end{array}$} \\
\hline & & $\begin{array}{l}\text { Machine } \\
\text { Direction }\end{array}$ & $\begin{array}{c}\text { Cross } \\
\text { Direction } \\
\end{array}$ & $\begin{array}{l}\text { Machine } \\
\text { Direction }\end{array}$ & $\begin{array}{c}\text { Cross } \\
\text { Direction } \\
\end{array}$ & $\begin{array}{l}\text { Machine } \\
\text { Direction }\end{array}$ & $\begin{array}{c}\text { Cross } \\
\text { Direction } \\
\end{array}$ & & \\
\hline & 60 & \multicolumn{2}{|c|}{65.98} & \multicolumn{2}{|c|}{1.36} & \multicolumn{2}{|c|}{97.94} & 0.3 & 71.1 \\
\hline $\begin{array}{c}\text { Envelope } \\
\text { Paper }\end{array}$ & 90 & 85.25 & 35.19 & 2.28 & 1.04 & 97.32 & 97.04 & 93.8 & 43.4 \\
\hline $\begin{array}{c}\text { EDP } \\
\text { (Base Sheet) }\end{array}$ & 71 & 95.82 & 42.46 & 3.767 & 1.67 & 96.07 & 96.06 & 125.8 & 35.6 \\
\hline EDP & 77 & 100.2 & 42.33 & 4.23 & 1.52 & 95.77 & 96.40 & - & 39.7 \\
\hline $\begin{array}{c}\text { C1S } \\
\text { (Base sheet) }\end{array}$ & 60 & 96.23 & 36.45 & 5.42 & 2.62 & 94.37 & 92.81 & 103 & 33.0 \\
\hline C1S & 77 & 66.5 & 34.35 & 3.89 & 2.24 & 94.15 & 93.48 & - & 39.7 \\
\hline
\end{tabular}

Figure 15 shows the DMA thermal scan for the two commercial hot-melt PSAs. Both Commercial PSA 1 and Commercial PSA 2 are label grade products. The scan is representative of the $\tan \delta$ curves demonstrated by thermoplastic products, which are typically formulated with styrenic block copolymers consisting of the higher glass transition temperature $\left(\mathrm{T}_{\mathrm{g}}\right)$ styrene segments in combination with lower $\mathrm{T}_{\mathrm{g}}$ (more rubbery) polymeric components such as ethylenepropylene, ethylene-butene, isoprene or butadiene. ${ }^{7,8}$ The two regions where $\tan \delta$ is maximized corresponds to the $\mathrm{T}_{\mathrm{g}}$ of the tackified rubbery domains (lower temperature) and a transition related to the $T_{g}$ of the polystyrene segments (higher temperature). ${ }^{8}$ The inset of the figure contains the SAFT and $\Delta \mathrm{T}$ values, which are used to predict the $\mathrm{T}_{50}$ and $\alpha(=0.1 \Delta \mathrm{T}$ in Celsius) parameters in Eq. 1. Figure 16 shows the predicted removal efficiency versus temperature curve, as well as PSA removal efficiency data collected between 10 and $100^{\circ} \mathrm{C}$ for laminates containing untreated paper face stock. As was reported previously, the model provides an accurate estimate of removal efficiencies. Given that the repulping operation during paper recycling is carried out in the vicinity of $46^{\circ} \mathrm{C}$, it can be seen that Commercial PSA 2 is the more benign formulation, i.e., it has high removal efficiencies at typical repulping temperatures.

\subsection{Influence of Commercial Face Stock on Removal Efficiencies.}

For laminates produced from untreated paper face stock and envelope paper, fragmentation behavior of the PSA is likely determined primarily by the bulk mechanical properties of the PSA. These paper adherends have relatively high surface energies and low wet-strengths (Table 7) and likely contribute little to laminates resistance to fragmentation. In Figure 17, removal 
efficiencies of Commercial PSA 1 and Commercial PSA 2 for laminates consisting of the PSA sandwiched between envelope paper and C1S, EDP and untreated paper face stock are shown. The results indicate that lower removal efficiencies are found for the same PSA when attached to the commercial face stocks. In the case of Commercial PSA 1, the difference is close to $35 \%$ at $46^{\circ} \mathrm{C} . \mathrm{T}_{50}$ values when attached to the untreated paper, EDP and $\mathrm{C} 1 \mathrm{~S}$ were 57,49 and $47^{\circ} \mathrm{C}$, respectively, for Commercial PSA 1 and 80,70 and $68^{\circ} \mathrm{C}$, respectively, for Commercial PSA 2. $\alpha$ values were $6.4,6.2$ and $6.5^{\circ} \mathrm{C}$, respectively, for Commercial PSA 1 and $9.2,8.0$ and $8.3^{\circ} \mathrm{C}$, respectively, for Commercial PSA 2 . The shift in $\mathrm{T}_{50}$ values with relatively minor changes in measured $\alpha$ values indicates that adjusting the predictive model described above to account for the affect of the face stock may be accomplished with adjustments to predictions for $\mathrm{T}_{50}$, but as will be demonstrated below, this is not strictly correct. Results indicate its plateau region fixes the region over which the PSA is fragmented and a simple temperature shift in the sigmoid function does not account for the changing curve shape. However, the shifts in the sigmoid inflection points encountered here are small enough that Eq. 1 can be used to reasonably account for the influence of face stock properties.

For laminates involving face stock and substrates that possess minimal wet-strength and adhesion to the PSA (e.g., untreated paper and the envelope substrate) SAFTs of PSAs provide an accurate estimate of the inflection point temperature for removal efficiency curves. The SAFT values reported here are measured by laminating identical PSA labels (films plus carriers) to produce an overlap region of one square inch. A constant load is applied to induce a shear stress parallel to the overlapping films, and the temperature is raised until the laminate fails. This is reported as the SAFT, which theoretically is a measure of cohesive failure in shear. Previously it was discussed that for styrenic block copolymer based hot-melt formulations, which account for most commercial hot-melt PSAs, SAFTs occur near the transition related to the $T_{g}$ of the polystyrene phase. It was proposed that as temperatures increase from the $T_{g}$ of the rubbery phase towards a transition associated with the $T_{\mathrm{g}}$ of the polystryrene phase, the PSA loses strength due to increased fluidity of the rubbery phase and/or loss of the reinforcing contribution from the physical crosslinks contributed by the polystyrenic phase. ${ }^{4}$ SAFT is the temperature where the adhesive demonstrates a decrease in cohesive strength and accelerated creep strain sufficient to produce failure under the test conditions. The fact that under standard test conditions SAFTs for PSAs are in close agreement with $\mathrm{T}_{50}$ values may be fortuitous to a certain extent given the dependency of viscoelastic behavior on induced stress and temperature. Figure 18a demonstrates the influence of relatively small changes in film stress on SAFT values for overlapping 1-mil films. Loads are given in relation to that used in the standard SAFT test of $500 \mathrm{~g}$. The failure temperature decreases as the load is increased, and over this load range, the relationship is linear. If SAFT is a good indicator of PSA fragmentation behavior, these results demonstrate a strong dependency on increased film stress. This is also indicated in Fig. 18b, which shows removal efficiency measured at $50^{\circ} \mathrm{C}$ as a function of film weight for the commercial PSAs. The measured SAFTs for the different film weights are constant $\left(56 \pm 2^{\circ} \mathrm{C}\right.$ for Commercial PSA 1 and $80 \pm 3^{\circ} \mathrm{C}$ for Commercial PSA 2), and the removal efficiencies climb with film thickness. The effect is less pronounced for Commercial PSA 2 due to its high removal at $50^{\circ} \mathrm{C}$. Commercial PSAs will have film weights in the 0.5 to 1 mil range where this relationship appears to be the strongest. 


\subsection{Influence of Substrate Wet-Strength on Removal Efficiencies.}

Intra-film adhesion is likely inhibited by the presence of residual face stock and it has previously been reported that the extent to which PSA films are fragmented during repulping is governed in great part by their geometry (open films versus collapsed) ${ }^{26}$ The removal of face stock from a PSA film during repulping is controlled to great extent by the strength of the wet paper. To examine the role of face stock wet-strength on PSA screening removal, removal efficiencytemperature curves were measured for both Commercial PSA 1 and Commercial PSA 2 when coated on face stock containing various wet-strength resin concentrations. Properties for these model face stock samples are shown in Table 8. Figure 19 plots the removal efficiencies for Commercial PSA 1 (Fig. 19a) and Commercial PSA 2 (Fig. 19b) measured at various temperatures as a function of face stock percent tensile loss after wetting (tensile loss). The parabolic shape of these curves can be explained by examining Fig. 20, which shows the screening removal of the paper plotted as a function of tensile loss. For these measurements, a procedure was used in which only the face stock was repulped in a small scale. ${ }^{27}$ The points with nonzero reject values correlate in a linear fashion with tensile loss, and the leveling of the curve at a tensile loss value at approximately $95 \%$ indicates the value where paper is no longer removed from the repulping slurry with screening. This is the same region where the curves in Fig. 19 are minimized. The climb in removal efficiency values for decreasing tensile loss values below this point can be attributed to the increasing levels of rejected paper that carry the PSA with it. The increase in removal efficiencies with increasing tensile loss above this point corresponding to a decrease in face stock wet strength. This region contains face stocks that are fiberized during repulping, but the process is likely inhibited by the higher wet strength. It can be seen that an increase in the tensile loss, corresponding to a reduction in wet strength, produces an increase in the removal efficiency for both PSAs. For example, in the case of Commercial PSA 1 at $50^{\circ} \mathrm{C}$ (near typical repulping temperatures) this increase is more than $25 \%$ for the tensile loss range of about 95 to $98 \%$.

Table 8. Mechanical and Surface Properties of wet-strength face stock.

\begin{tabular}{|c|c|c|c|c|c|}
\hline \multirow{2}{*}{$\begin{array}{c}\text { PAE Resin } \\
\text { Concentration } \\
(\%)\end{array}$} & \multicolumn{2}{|c|}{$\begin{array}{c}\text { Tensile Index } \\
\mathbf{( N m} / \mathbf{g})\end{array}$} & \multirow{2}{*}{$\begin{array}{c}\text { Tensile Loss } \\
\mathbf{( \% )}\end{array}$} & \multirow{2}{*}{$\begin{array}{c}\text { HST Time } \\
\mathbf{( s )}\end{array}$} & $\begin{array}{c}\text { Surface Energy } \\
\left(\mathbf{m J} / \mathbf{m}^{\mathbf{2}}\right)\end{array}$ \\
\cline { 2 - 3 } & Dry & Wet & & 0.3 & 71.1 \\
\hline 0.000 & 65.98 & 1.36 & 97.94 & 0.3 & 60.4 \\
\hline 0.005 & 53.22 & 1.56 & 97.07 & 0.3 & 57.4 \\
\hline 0.010 & 63.39 & 1.92 & 96.96 & 0.3 & 54.8 \\
\hline 0.019 & 71.94 & 2.90 & 95.97 & 0.3 & 53.1 \\
\hline 0.031 & 69.39 & 3.81 & 94.51 & 0.4 & 51.4 \\
\hline 0.06 & 63.25 & 5.18 & 91.81 & 0.4 & 50.5 \\
\hline 0.101 & 68.88 & 9.04 & 86.87 & 0.5 & 48.7 \\
\hline 0.200 & 60.39 & 9.84 & 83.70 & 0.6 & \\
\hline
\end{tabular}


The data from Fig. 19 indicate a temperature dependency for the influence of the wet-strength resin on measured removal efficiencies. For Commercial PSA 1 removal efficiencies are not dependent on tensile loss at temperatures of approximately $30^{\circ} \mathrm{C}$ and lower and $70^{\circ} \mathrm{C}$ and higher. In these temperature regions removal efficiencies were near 100 and $0 \%$, respectively. For Commercial PSA 2 the temperature regions where the maximum and minimum removal efficiencies are found are approximately $40^{\circ} \mathrm{C}$ and lower and $90^{\circ} \mathrm{C}$ and higher, respectively. Comparing these temperatures with the DMA data for the PSAs provided in Fig. 15 it can be seen that the region over which the influence of the face stock wet-strength is found corresponds to the plateau regions for the adhesives. As discussed previously, the temperature region over which hot-melt PSAs are prone to fragmentation is subsequent to the rubbery phase $T_{g}$ and prior to the transition associated with $\mathrm{T}_{\mathrm{g}}$ for the styrenic phase, i.e., the plateau region. ${ }^{4,7,17}$ This is also the region in which the hot-melt formulations provide adhesive properties. Prior to the rubbery phase $T_{g}$, the PSA is strong enough to resist fragmentation during repulping, but the modulus of the PSA is too high to provide sufficient wetting of intended substrates. Subsequent to the disruption of the styrenic phase marked by the SAFT for a hot-melt PSA, the PSA retains little of its cohesive strength. With regard to adhesion, it should point out that the wet-strength resin does lower the surface energy of treated paper. However, it will be become apparent from the discussion of the next section that these changes cannot account for magnitude of change in removal efficiencies observed.

Figure 21 shows removal efficiencies for both model PSAs for various face stock tensile loss values. The solid curves are the predicted removal efficiencies (Eq. 1) using the SAFT and DMA data for predictions of $\mathrm{T}_{50}$ and $\alpha$ values, respectively. It can be seen that prior to the plateau region and subsequent to the SAFT, values for the various tensile losses are similar. Within the plateau region there is an obvious reduction in removal efficiencies with increasing tensile loss. Differences in removal efficiency between the different tensile losses for the temperatures within the plateau region are small but do appear to increase slightly as SAFTs are approached. This may be a result of the small increase in viscolelasticity in this region enhancing the PSA-face stock adhesion. Figure 22 shows $\mathrm{T}_{50}$ values obtained from fits of the data shown in Fig. 21 as a function of face stock tensile loss. Results are shown for both Commercial PSA 1 and Commercial PSA 2. It can be seen that these relationships are linear with relatively small slopes. $\alpha$ values ranged from 6.4 to $7.4^{\circ} \mathrm{C}$ and 9.1 to $9.9^{\circ} \mathrm{C}$ with average values of $7.1 \pm 0.4^{\circ} \mathrm{C}$ and $9.6 \pm 0.3^{\circ} \mathrm{C}$, respectively for Commercial PSA 1 and Commercial PSA 2 , and $\mathrm{R}^{2}$ values were all above 0.99 .

\subsection{Influence of PSA-Face Stock Adhesion on Removal Efficiencies.}

Sizing agents such as alkyl ketene dimers (AKD) and alkenyl succinic anhydrides (ASA) possess amphiphilic structures with large aliphatic components and cellulose-reactive head groups. These chemicals are introduced during the production of paper to provide fibers with nonpolar surfaces. Lowering the surface energy of the cellulose fiber enhances the thermodynamic work of adhesion for the removal of attached PSAs in an aqueous medium. ${ }^{9}$ This can be demonstrated with the expression for the thermodynamic work of adhesion $\left(\mathrm{W}_{\mathrm{A}}\right)$ required for the separation of a PSA from its paper substrate in water, i.e., ${ }^{28}$

$$
\mathrm{W}_{\mathrm{A}}=\gamma_{\text {sub-w }}+\gamma_{\mathrm{psa}-\mathrm{w}}-\gamma_{\text {psa-sub }}
$$


Here $\gamma_{\text {sub-w }}, \gamma_{\text {psa-w }}$ and $\gamma_{\text {psa-sub }}$ are the substrate-water, PSA-water and PSA-substrate interfacial energies, respectively. The addition of these species to fibers used in paper substrates produces nonpolar surfaces increasing $\mathrm{W}_{\mathrm{A}}$ by both increasing the paper substrate-water interfacial energy $\left(\gamma_{\text {sub-w }}\right)$ and reducing the PSA-paper substrate interfacial energy $\left(\gamma_{\text {psa-sub }}\right)$. Estimates of changes in $\mathrm{W}_{\mathrm{A}}$ due to the presence of a sizing agent were made with Eq. 1 using interfacial energies estimated from, ${ }^{29}$

$$
\gamma_{12}=\gamma_{1}+\gamma_{2}-2\left[\left(\gamma_{1}{ }^{\mathrm{d}} \gamma_{2}{ }^{\mathrm{d}}\right)^{1 / 2}+\left(\gamma_{1}{ }^{\mathrm{p}} \gamma_{2}{ }^{\mathrm{p}}\right)^{1 / 2}\right]
$$

where 1 and 2 indicate the phases that form an interface, $\gamma_{12}$ is the interfacial energy and $\gamma_{1}$ and $\gamma_{2}$ are the surface energies for phases 1 and 2, respectively, and $\gamma^{\mathrm{d}}$ and $\gamma^{\mathrm{p}}$ denote dispersive and polar components of the surface energy, respectively. Paper and PSA surface energies were estimated from contact angle measurements. ${ }^{10}$

Table 9. Mechanical and Surface Properties of sized face stock.

\begin{tabular}{|c|c|c|c|c|c|}
\hline \multirow{2}{*}{$\begin{array}{c}\text { Concentration } \\
(\%)\end{array}$} & \multicolumn{2}{|c|}{$\begin{array}{c}\text { Tensile Index } \\
(\mathrm{Nm} / \mathrm{g})\end{array}$} & \multirow{2}{*}{$\begin{array}{c}\text { Tensile Loss } \\
\text { (\%) }\end{array}$} & \multirow{2}{*}{$\begin{array}{c}\text { HST Time } \\
\text { (s) }\end{array}$} & \multirow{2}{*}{$\begin{array}{l}\text { Surface Energy } \\
\qquad\left(\mathrm{mJ} / \mathrm{m}^{2}\right)\end{array}$} \\
\hline & Dry & Wet & & & \\
\hline 0 & 61.78 & 1.17 & 98.11 & 0.3 & 71.1 \\
\hline 0.008 & 60.66 & 1.28 & 97.89 & 0.3 & 51.4 \\
\hline 0.016 & 59.83 & 1.42 & 97.63 & 0.5 & 45.2 \\
\hline 0.026 & 60.27 & 1.19 & 98.02 & 0.6 & 46.4 \\
\hline 0.039 & 58.28 & 1.37 & 97.65 & 0.7 & 41.3 \\
\hline 0.047 & 59.31 & 1.56 & 97.37 & 0.7 & 40.7 \\
\hline 0.065 & 65.39 & 1.15 & 98.23 & 2.5 & 38.5 \\
\hline 0.078 & 62.78 & 1.31 & 97.91 & 3.5 & 38.0 \\
\hline 0.117 & 64.25 & 1.39 & 97.84 & 85.2 & 29.2 \\
\hline 0.156 & 65.03 & 1.92 & 97.04 & 211.6 & 26.3 \\
\hline 0.182 & 62.21 & 1.68 & 97.30 & 293.1 & 24.8 \\
\hline
\end{tabular}

It was found that low dosages of commercially available sizing agents significantly enhanced the removal of PSAs when attached to paper treated with wet-strength additives to inhibit fiberization. The effect appears to be just the opposite when the sizing agent is used with face stock that readily fiberizes. This is demonstrated in Fig. 23a and b, which shows the removal efficiency measured at $50^{\circ} \mathrm{C}$ for Commercial PSA 1 and Commercial PSA 2 respectively as a function of sizing agent concentration used in the model face stock in percent solids. Properties for the sized, model face stock are shown in Table 9. The removal efficiency drops with 
increasing apparent sizing agent concentration (concentration added) and levels at approximately $0.05 \%$ size. For sizing concentrations above about $0.2 \%$, a slight second drop in removal efficiency was often found. This drop in the curves was eliminated by soaking the labels in water prior to repulping indicating a water penetration effect for the higher sizing levels. Because the commercial face stock base sheets had HST times that corresponded to sizing concentrations lower than $0.2 \%$, only data for these lower concentrations are shown. Also plotted on the figure are the thermodynamic work of adhesion values for the two PSAs and the sized face stocks calculated with Eqs. 2 and 3. Commercial PSA 1 and Commercial PSA 2 had similar surface energies of 32.6 and $33.0 \mathrm{~mJ} / \mathrm{m}^{2}$, respectively, with dispersive and polar components of 31.3 and $1.3 \mathrm{~mJ} / \mathrm{m}^{2}$ and 32.3 and $0.7 \mathrm{~mJ} / \mathrm{m}^{2}$, respectively. It can be seen that as the removal efficiencies decrease with increasing size concentration, the thermodynamic work of adhesion for the removal of the PSAs from paper in an aqueous environment increase. These two measurements appear to mirror each other for the two PSAs leveling at approximately the same concentration. The thermodynamic work of adhesion accounts for only a fraction of the work of adhesion but was previously found to provide a qualitative indication of changes in adhesion. ${ }^{9}$ The removal efficiency for the sized model face stock was found to correlate linearly with the inverse of the apparent sizing agent concentration $\left(r^{2}=0.98\right)$.

The extent to which the sizing influences removal efficiencies demonstrates a temperature dependency. The curves indicate that the PSA removal efficiency only drops over the plateau region for the PSA. This is demonstrated in Fig. 24 for Commercial PSA 1. Figure 24a shows the removal efficiency as a function of apparent sizing concentration measured over a range of temperatures. Dependency on sizing levels is found only subsequent to the $\mathrm{T}_{\mathrm{g}}$ for the modified rubbery phase of the PSA and up to temperatures at or near the transition related to the $T_{g}$ of the styrenic phase. As with the wet-strength paper, the drop in removal efficiency becomes more significant as the temperature moves towards the SAFT of the adhesive. Figure $24 \mathrm{~b}$ shows this effect in relation to the sigmoidal drop in removal efficiency. Fits of this data with Eq. 1 produced values that ranged from 6.4 to $7.4^{\circ} \mathrm{C}$ with an average value of $7.1 \pm 0.4^{\circ} \mathrm{C}$ and $\mathrm{R}^{2}$ values were all above 0.99 . The shift in the $\mathrm{T}_{50}$ values varied linearly with the inverse of calculated thermodynamic work of adhesion values and with face stock surface energies. This latter correlation is shown in Fig. 25. It can be understood qualitatively from Eq. 2. Raising the polarity of the paper surface will decrease the substrate-water interfacial energy $\left(\gamma_{\text {sub-w }}\right)$ and increase the PSA-substrate surface energy $\left(\gamma_{\text {psa-sub }}\right)$ lower the work of adhesion for the removal of the PSA film from the paper in an aqueous environment.

\subsection{Pilot Trials}

Appendix 3 reviews the results of pilot scale testing for a water-based PSA. The PSA was coated on EDP produced commercially by Boise Solutions (International Falls, MN) and EDP that was treated with a hydrophilic polymer coating that was applied at the size press. The EDP sample with no surface treatment is denoted F-2001, and the treated sample is denoted F-2002. Little difference was found between the samples in pilot testing. Future trials, funded by H. B. Fuller Company and Boise Cascade Corporation, are planned for early 2004. 


\subsection{Figures}
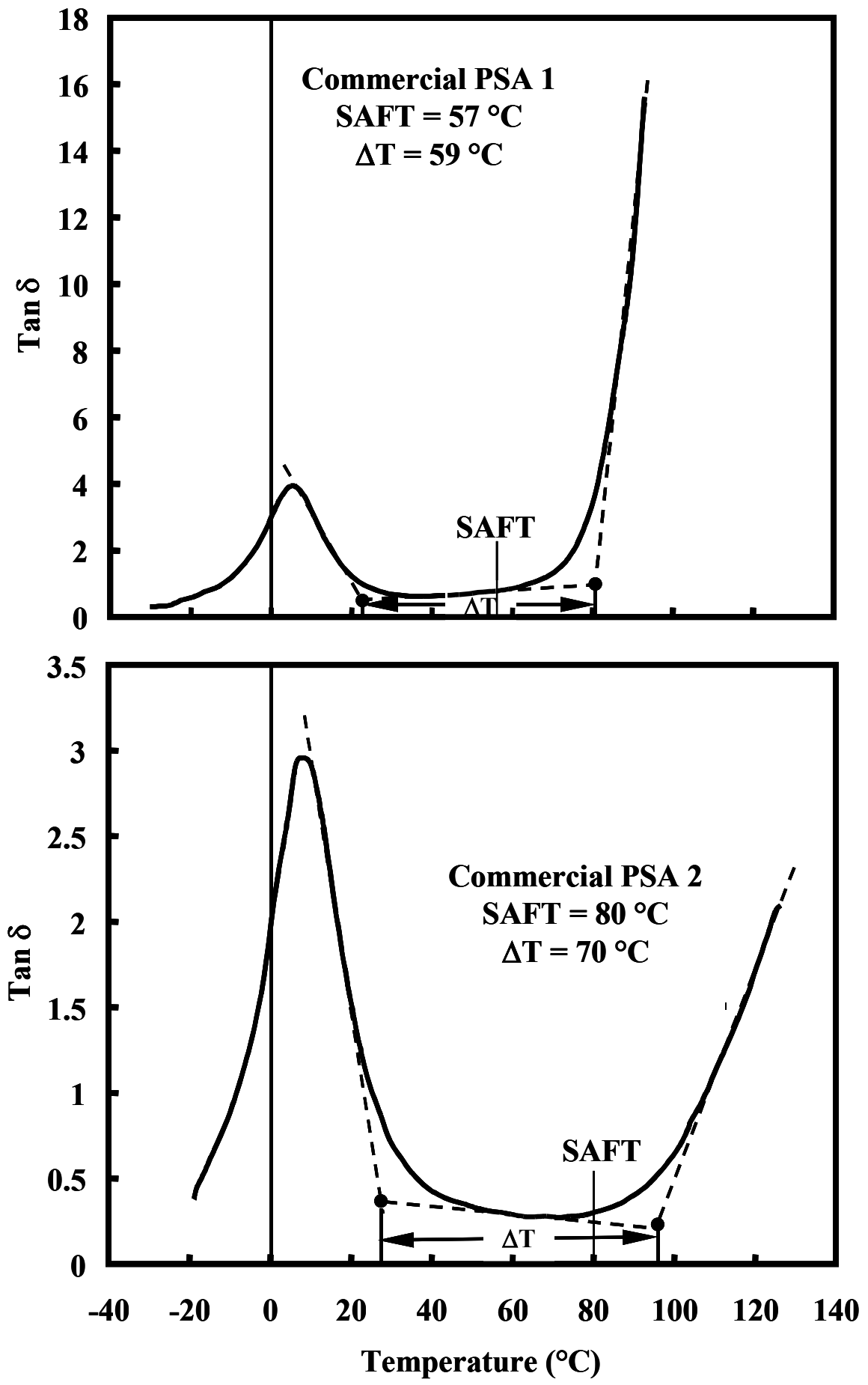

Figure 15. Mechanical tan $\delta$ values measured for Commercial PSA 1 and Commercial PSA 2 as a function of temperature. Also shown are the experimental SAFT and the $\Delta \mathrm{T}$ determination method. 


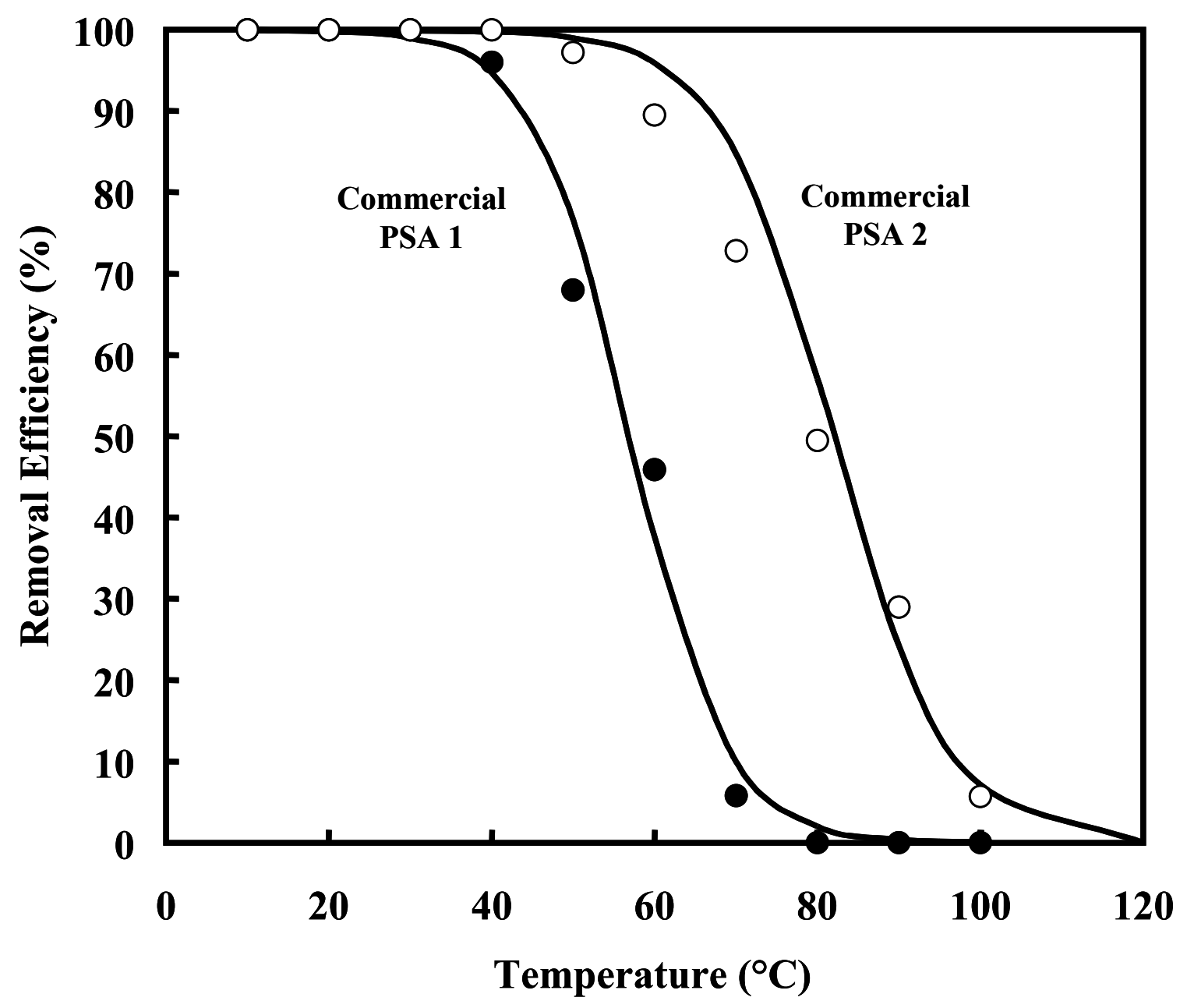

Figure 16. Removal efficiencies as a function of temperature for Commercial PSA 1 (solid circles) and Commercial PSA 2 (open circles) with untreated paper. The solid lines are the predicted removal curves calculated using Eq. 1. 


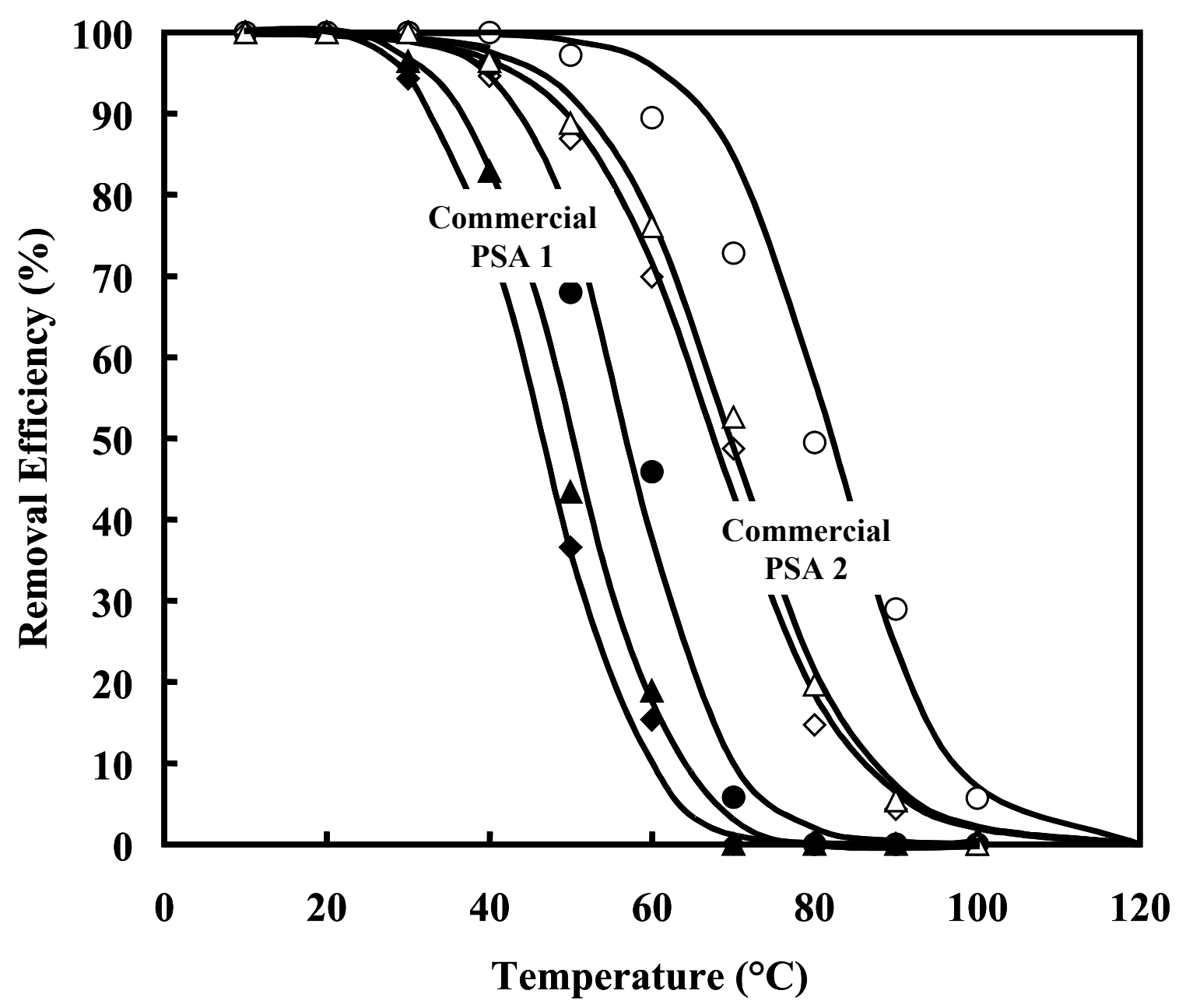

Figure 17. Removal efficiencies as a function of temperature for Commercial PSA 1 (solid symbols) and Commercial PSA 2 (open symbols) for laminates produced with C1S, EDP and untreated paper face stock. The curves are the sigmoid fit of the data points. 

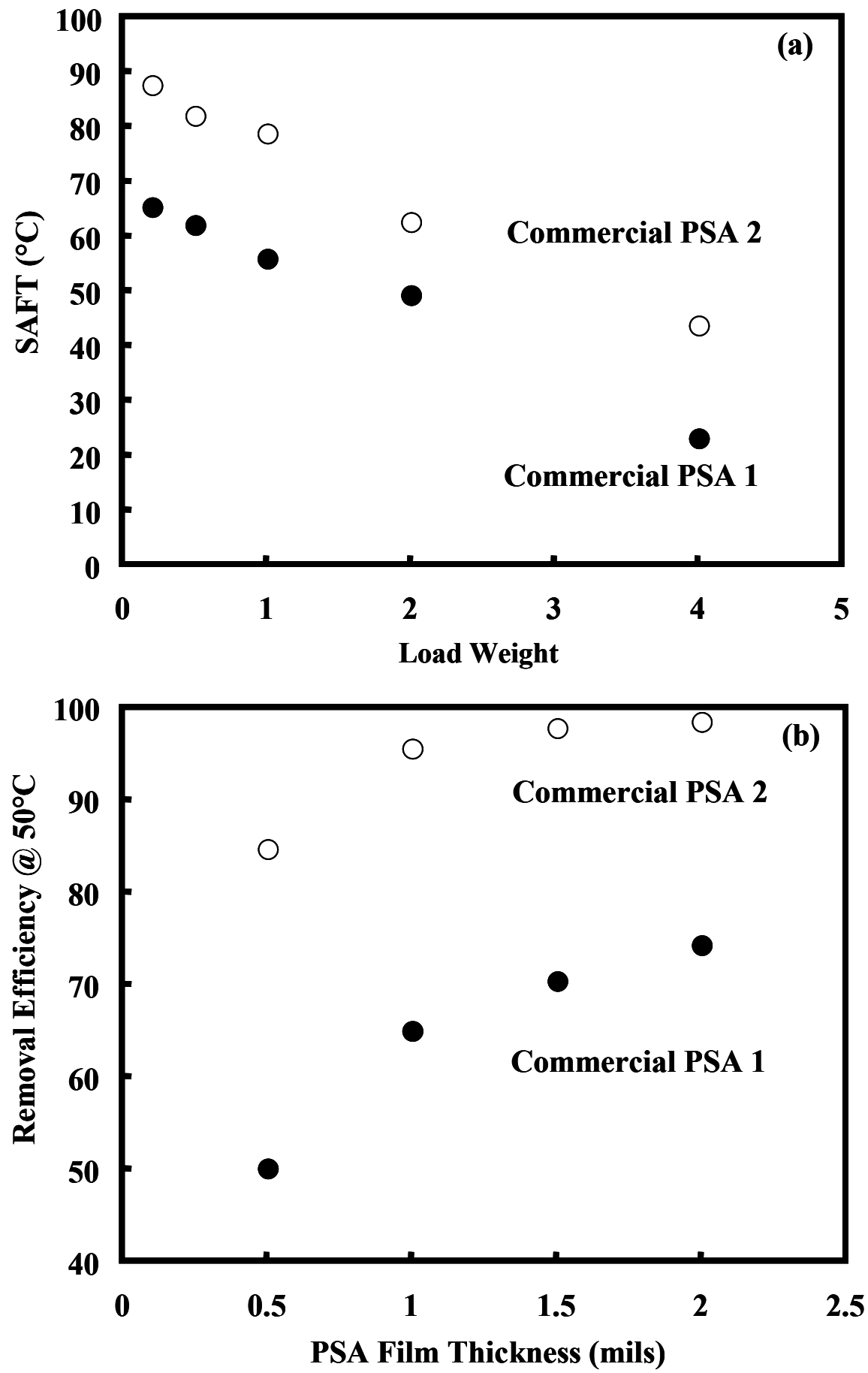

Figure 18. (a). SAFTs of Commercial PSA 1 and Commercial PSA 2 as a function of applied load in terms of the standard test load (i.e., $500 \mathrm{~g}$ ). (b). Removal efficiency measured at $50^{\circ} \mathrm{C}$ as a function of film thickness for Commercial PSA 1 and Commercial PSA 2. 

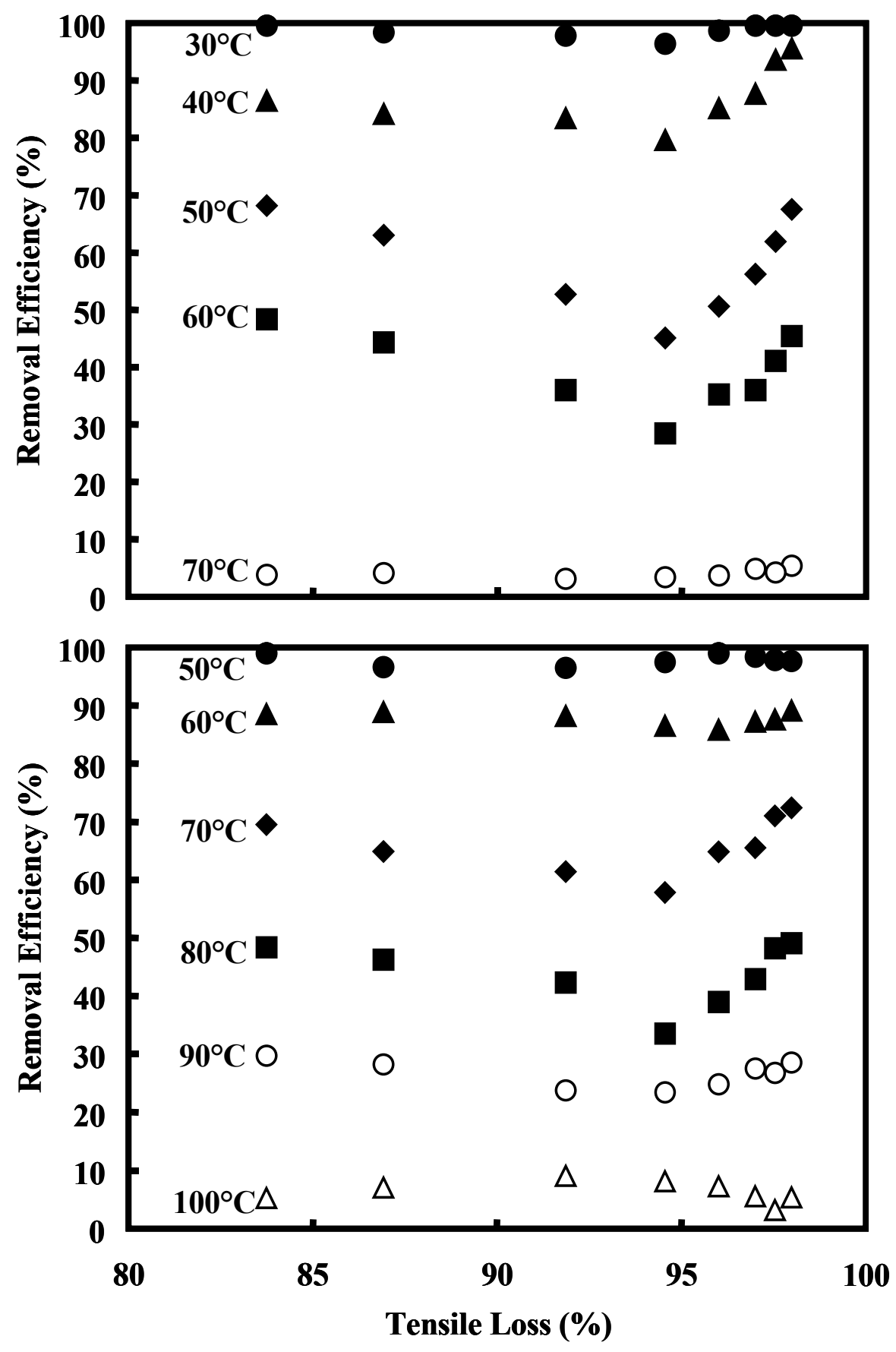

Figure 19. (a). Removal efficiency of Commercial PSA 1 as a function of percent decrease in tensile strength of face stock subsequent to saturation with water (i.e., tensile loss) for a range of temperatures. (b). Removal efficiency of Commercial PSA 2 as a function of tensile loss for a range of temperatures. 


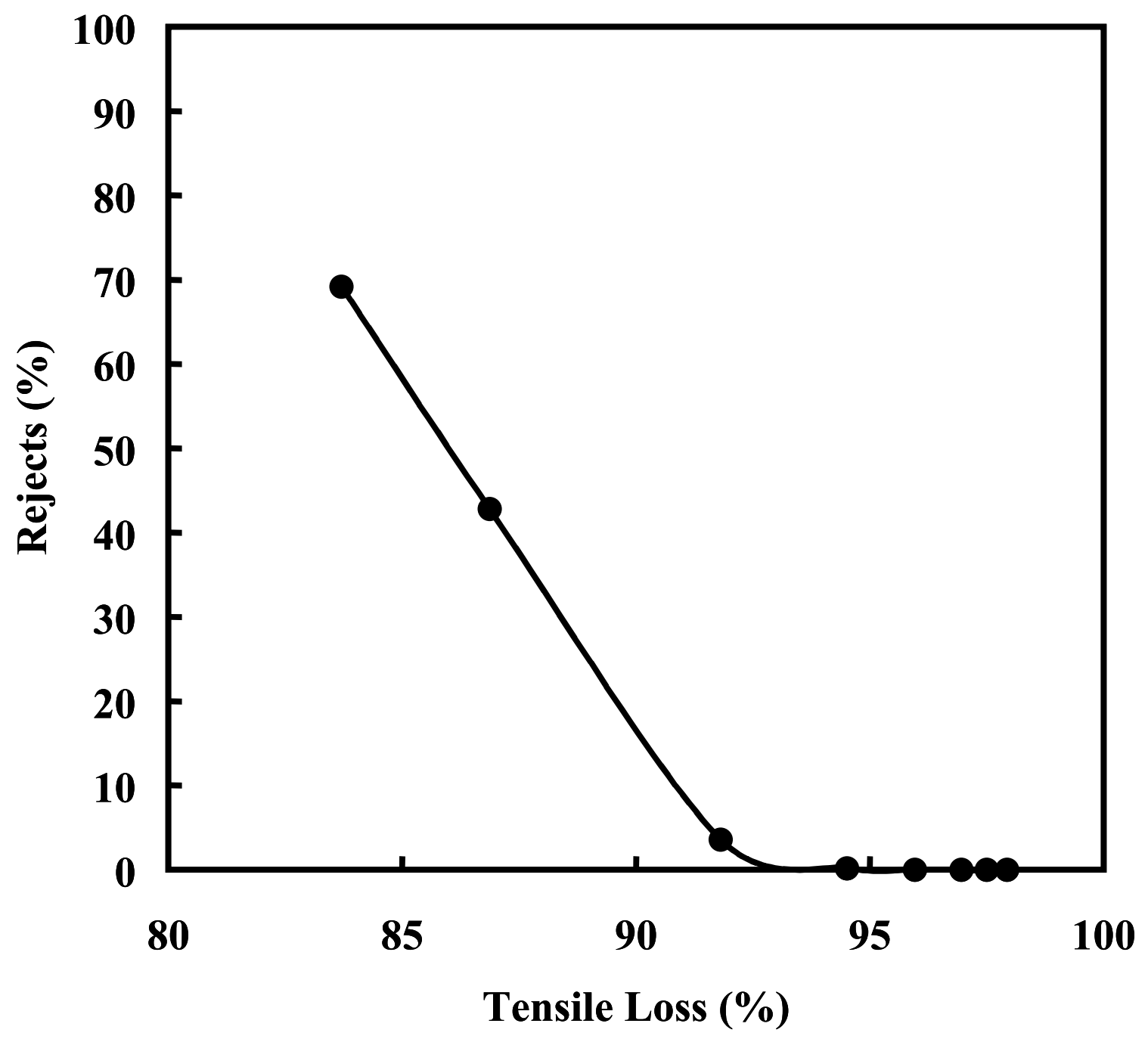

Figure 20. Screening removal of the wet-strength face stock as a function of its tensile loss. 


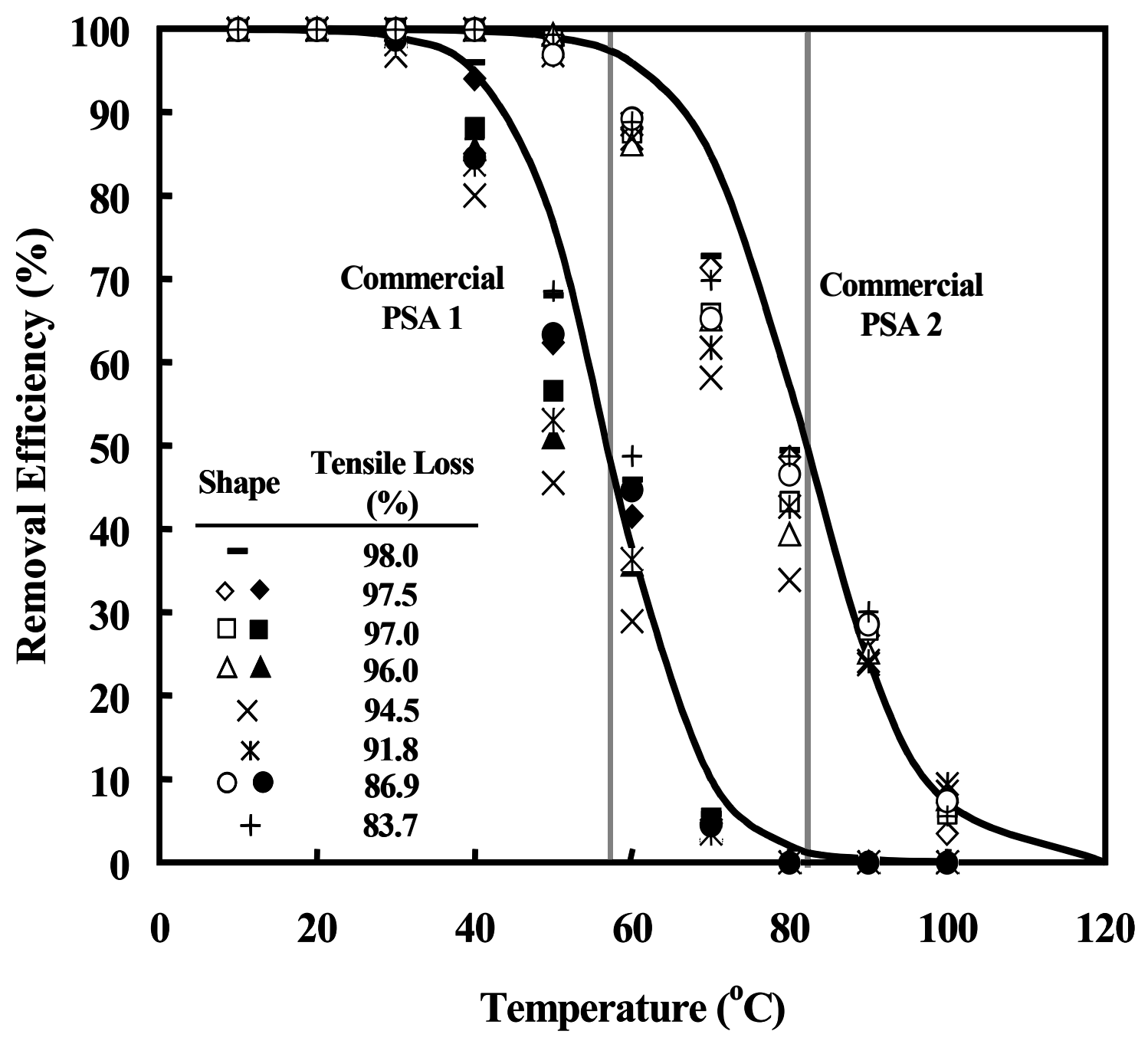

Figure 21. Removal efficiency as a function of temperature for Commercial PSA 1 (solid symbols) and Commercial PSA 2 (open symbols) for various face stock tensile loss values. The solid curves are the predicted removal efficiencies of the adhesives using Eq. 1. 


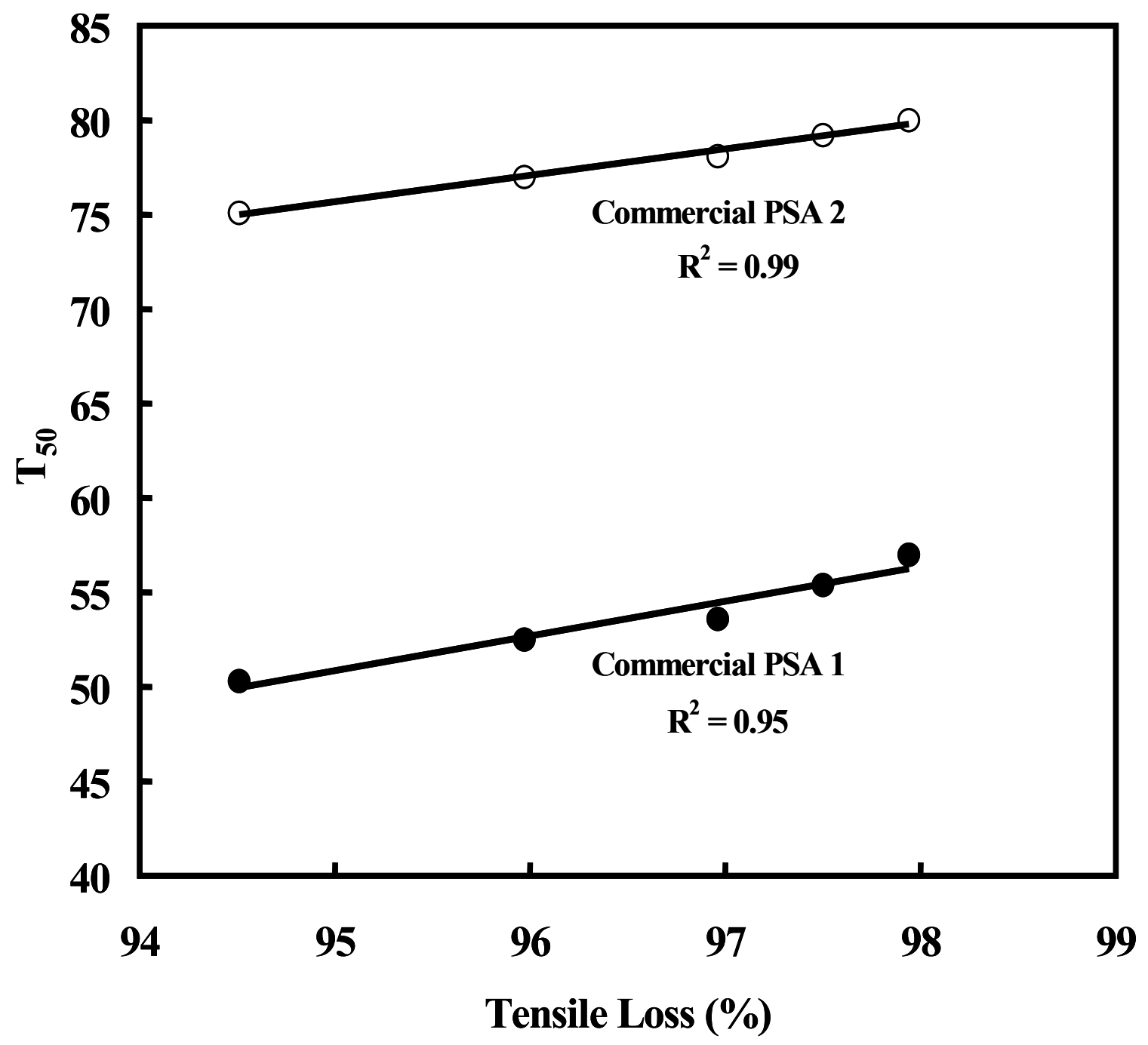

Figure 22. $\mathrm{T}_{50}$ values obtained from fits of the data shown in Fig. 7 using Eq. 1 as a function of face stock tensile loss. 


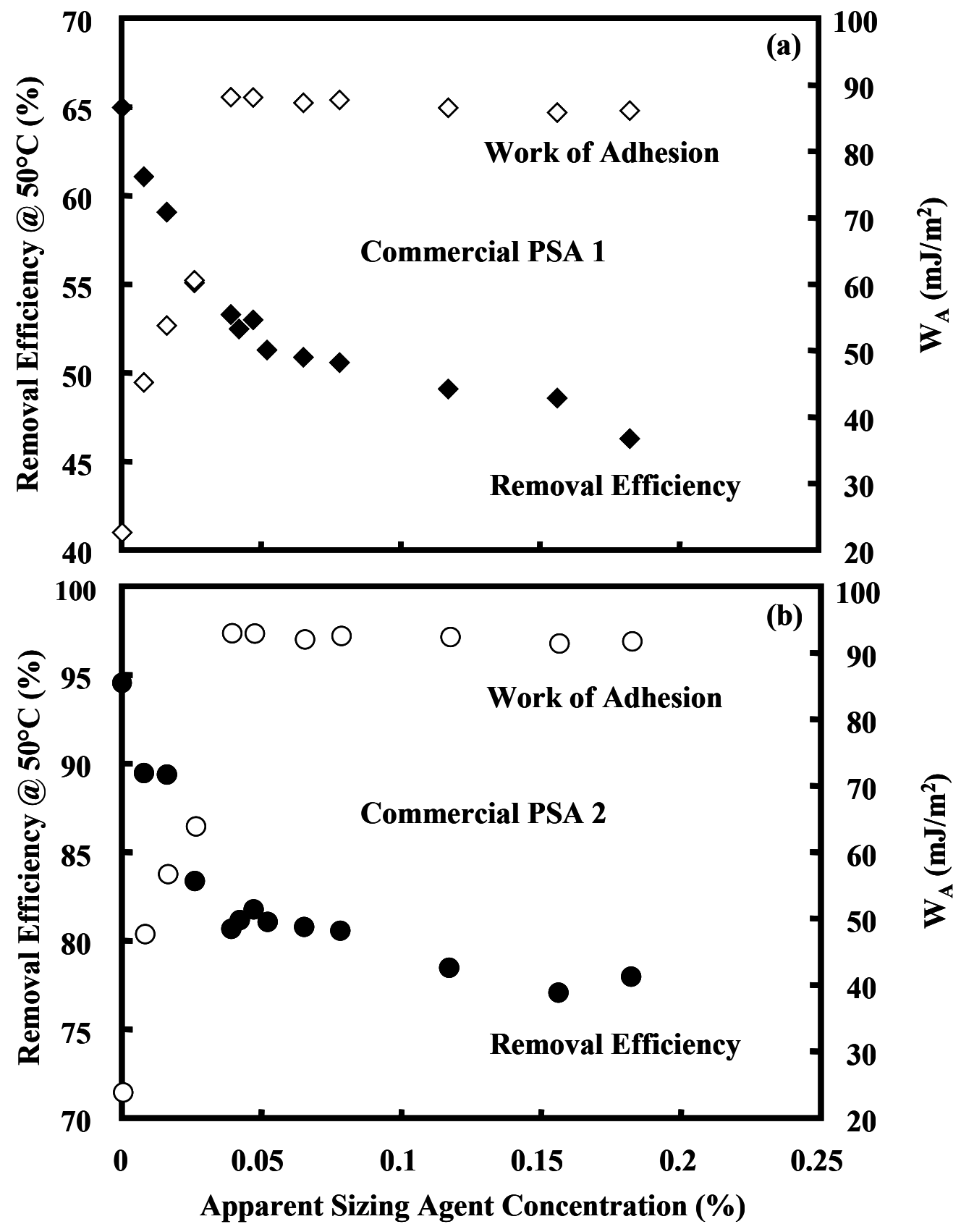

Figure 23. (a). Removal efficiency measured at $50^{\circ} \mathrm{C}$ (solid circles) and the thermodynamic work of adhesion (open circles) for Commercial PSA 1 as a function of sizing agent concentration. (b) Removal efficiency measured at $50^{\circ} \mathrm{C}$ (solid circles) and the thermodynamic work of adhesion (open circles) for Commercial PSA 2 as a function of sizing agent concentration. 

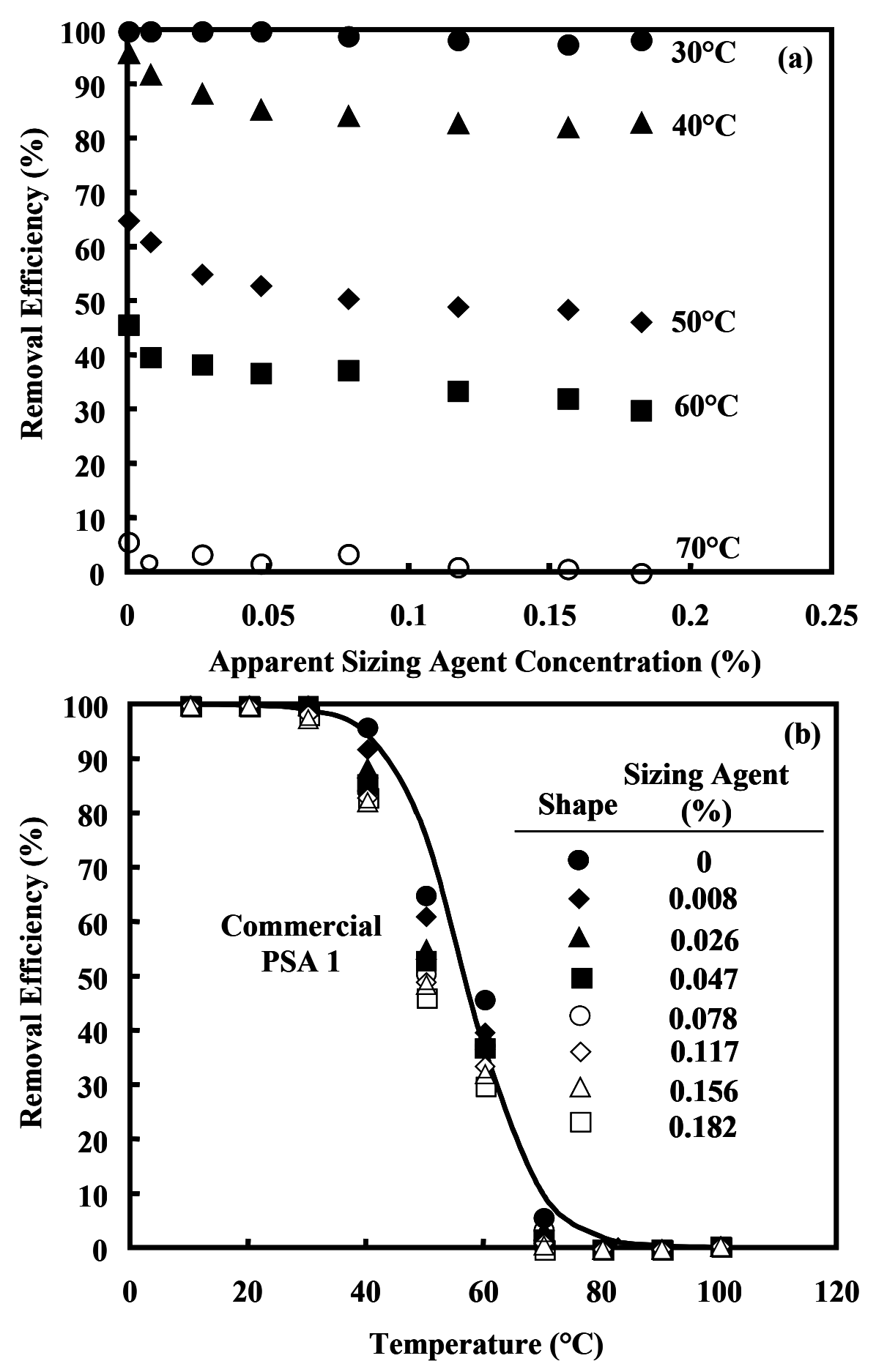

Figure 24. (a). Removal efficiencies as a function of apparent sizing agent concentration for Commercial PSA 1 over a range of temperatures. (b). Removal efficiency of Commercial PSA 1 as a function of temperature for various apparent sizing agent concentrations. The solid curves are the predicted removal efficiencies using Eq. 1. 


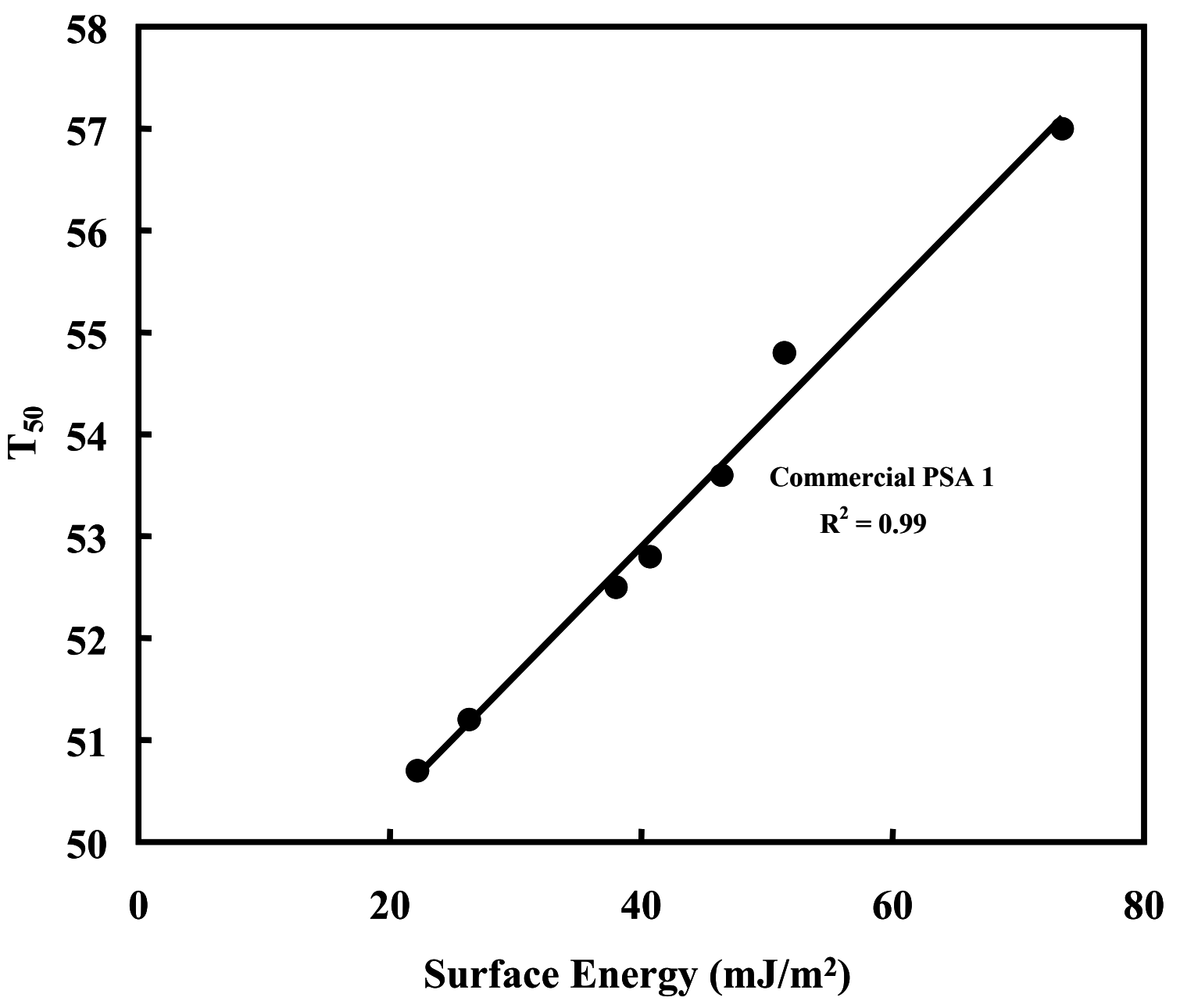

Figure 25. $\mathrm{T}_{50}$ values obtained from fits of the data shown in Fig. 10b using Eq. 1 as a function of face stock surface energy. 


\section{Acknowledgements}

The authors wish to thank Leslie Clapp and Robert Polance of H. B. Fuller Company for their help in formulating and characterizing the experimental PSAs, Ryan Verhulst of the University of Minnesota for his help in collecting removal efficiency data and members of the Recycling Task Group for their guidance throughout this project. 


\section{Literature Cited}

1. Guo, J. S.; Ojunga-Andrew, M.; Chen, A. T.; Trembley, S. D. Development of Environmentally Benign Pressure Sensitive Adhesives. Adhesives \& Sealants Industry 2002, $9,36$.

2. Peng, J. Y. United States Postal Service Efforts to Develop an Environmentally Benign Pressure-Sensitive Adhesive for Postage Stamp Applications. 2000 TAPPI Recycling Symposium, Washington, D.C., March 2000; TAPPI Press: Atlanta, 2000; Vol. 1, p 3.

3. Bloembergen, S.; McLennan, I.; Cassar, S.; Narayan, R. Polymer Resins Designed for Environmental Sustainability. Adhesives Age, 1998, 41, 20.

4. Nowak, M. J.; Severtson, S. J.; Wang, X. P.; Kroll, M. S. Properties Controlling the Impact of Styrenic Block Copolymer Based Pressure Sensitive Adhesives on Paper Recycling. Ind. Eng. Chem. Res., 2003, 42, 1681.

5. Severtson, S. J.; Kroll, M. S. Development of Environmentally Benign Pressure Sensitive Adhesives. ASC International Convention and Exposition, Los Angeles, April 2002.

6. Benedek, I. Development and Manufacture of Pressure-Sensitive Products; Marcel Dekker, Inc.: New York, 1999.

7. Tse, M. Studies of Triblock Copolymer-Tackifying Resin Interactions by Viscoelasticity Resins Interactions by Viscoelasticity and Adhesive Performance. J. Adhesion Sci. Technol., 1989, 3, 551.

8. Chu, S. G. Viscoelastic Properties of Pressure Sensitive Adhesives. In Handbook of Pressure Sensitive Adhesive Technology; Statas, D., Ed.; Van Nostrand-Rheinhold Co., New York, 1988.

9. Severtson, S. J.; Wang, X. P.; Kroll, M. S. Development of Environmentally Benign Pressure-Sensitive Adhesive Systems via Modification of Substrate Properties. Ind. Eng. Chem. Res., 2002, 41, 5668.

10. Fowkes, F. M. Attractive Forces at Interface. Ind. Engr. Chem. 1964, 56, 40.

11. Park, Y. J.; Kim, J. H. Effects of Surface Functional Groups on Film Formation and Tensile Strength Development in Reactive Latex Systems. Polymer Engineering and Science, 1998, 38,884 .

12. Zhao, C. L.; Roser, J.; Heckmann, W.; Zosel, A.; Wistuba, E. Structured Latex Particles with Improved Mechanical Properties. Progress in Organic Coatings, 1999, 35, 265.

13. Pandya, K. C.; Williams, J. G. Cohesive Zone Modeling of Crack Growth in Polymers - Part I - Experimental Measurement of Cohesive Law. Plastics Rubber and Composites, 2000, $29,439$.

14. Sperling, L. H. Introduction to Physical Polymer Science; John Wiley \& Sons: New York, 1992.

15. Menard, K. P. Dynamic Mechanical Analysis: A Practical Introduction; CRC Press: Boca Raton, 1999.

16. Tse, M. F. Fundamental Understanding in Rolling Ball Tack of Tackified Block Copolymer Adhesives. J. Adhesion, 1999, 70, 95.

17. Tse, M. F. Pressure Sensitive Adhesives Based on Vector ${ }^{\circledR}$ SIS Polymers I. Rheological Model and Adhesive Design Pathways. J. Adhesion, 1996, 56, 79.

18. Caulfield, D. F., Ester Crosslinking to Improve Wet Performance of Paper Using Multifunctional Carboxylic Acids, Butanetetracarboxylic and Citric Acid, Tappi J., 1994, 77 (3), 205. 
19. Espy, H. H. and Geist, G. W., Using Neutral/Alkaline-Curing Resins to Produce WetStrength Grades from Recycled Pulp, Tappi J., 1992, 75 (7), 192,.

20. Fredholm, B., Samuelsson, B., Westfelt, A., Westfelt, L., The Chemistry of Paper WetStrength. II. Design and Synthesis of Model Polymers, Cellulose Chem. Technol., 1981, 15, 247.

21. Espy, H. H., The Mechanism of Wet-Strength Development in Paper: A Review, Tappi J., 1995, 78 (4), 90.

22. Espy, H. H., Rave, T. W., The Mechanism of Wet-Strength Developed by Alkaline-Curing Amino Polymer-Epichlorohydrin Resins, Tappi J. 1988, 71 (5), 133.

23. Westfelt, L., Chemistry of Paper Wet-Strength. 1. A Survey of Mechanisms of Wet Strength Development, Cellulose Chem. and Technol., 1979, 13, 813.

24. Fischer, S. A., Structure and Wet Strength Activity of Polyaminoamide Epichlorohydrin Resins Having Azetidinium Functionality, Tappi J., 1996, 79 (11), 179.

25. Merrett, K. J., Factors Affecting the Performance of Polyamide Type Wet Strength Resins, Appita, 1983, 37 (3), 233.

26. Venditti, R. A.; Chang, H.; Jameel, H. Overview of Stickies Research at North Carolina State University. Paper Age, 1999, 115 (11), 18.

27. Fischer, S.A. Repulping wet strength paper. Tappi J. 1997, 80(11), 141.

28. Owens, D.K. Some Thermodynamic Aspects of Polymer Adhesion, J.Appl.Polym.Sci., 1970,14,1725.

29. Owens, D.K. Estimation of the Surface Free Energy of Polymers, J.Appl.Polm.Sci., 1969, 13, 1741. 


\section{Publications, Presentations, Patents and Technology Transfer \\ Publications:}

1. Severtson, S. J.; Wang, X. P.; Kroll, M. S. Development of Environmentally Benign Pressure-Sensitive Adhesive Systems via Modification of Substrate Properties. Ind. Eng. Chem. Res. 2002, 41, 5668.

2. Nowak, M. J.; Severtson, S. J.; Wang, X. Properties Controlling the Impact of Styrenic Block Copolymer Based Pressure-Sensitive Adhesives on Paper Recycling. Ind. Eng. Chem. Res. 2003, 42, 1681.

3. Guo, J,; Severtson, S. J.; Kroll, M. S. Role of Paper Face Stock Properties in Determining Removal Efficiencies of Pressure Sensitive Adhesive Films from Recycling Operations. Ind. Eng. Chem. Res. Submitted.

\section{Presentations:}

1. Severtson, S. J. and Kroll, M. S., "Development of Environmentally Benign Pressure Sensitive Adhesives," Presented at the 2002 ASC International Convention and Exposition held in Los Angeles (April 14-16, 2002).

2. Severtson, S. J. and Kroll, M. S. Redesigning Laminate Components to Reduce the Environmental Impact of Hot Melt Pressure Sensitive Adhesive Products. Presented at the 7th Annual Green Chemistry and Engineering Conference (ACS/AIChE) held at the National Academies, Washington, DC, June 23-26, 2003.

\section{Patents:}

1. Severtson, Steven J.; Wang, Xinping; Nowak, Michael J. Sortable adhesive-coated paper articles and keeping paper intact in recycling process. US Patent Pending.

2. One provisional patent application jointly filed by the University of Minnesota and H. B. Fuller Company.

\section{Technology Transfer:}

To date, five commercial screenable hot-melt PSAs have been developed by H. B. Fuller Company. These include hot-melt PSAs HM-2713, HM-8326, HL-8128x and HL-2586. These were tested for their impact on paper recycling at the USDA Forest Service, Forest Products Laboratory (FPL) using their recycling procedure. All five adhesives were acceptably removed, primarily by screening with cleaning and flotation acting as polishing steps. All exceeded the USPS specifications for particle size after pulping (greater than 0.32 sq. $\mathrm{mm}$ ) and final pulp adhesive content (20 ppm or less). These products will be marketed as environmentally benign formulations.

It should be stressed that the research started by this project will be pursued by H. B. Fuller Company and Boise Cascade Corporation. For example, pilot scale trials are planned for early 2004, and data are being reviewed to determine if patent protection should be sought. Also, several publication summarizing laboratory and pilot scale results are currently being prepared for submission to scientific and trade journals. Thus, it is expected that much could be added to this section over the next 12-18 months. 


\section{Forest Products Laboratory Pilot Plant Recycling Trials with \\ Hot Melt Adhesives F-2004, F-2005, F-2008, F-2012}

Prepared by: Karen Scallon

Reviewed by: Carl Houtman

USDA Forest Service

Forest Products Laboratory

One Gifford Pinchot Drive

Madison, WI 53705

In partial fulfillment of Subcontract No. V4046084002

between University of Minnesota

Department of Wood and Paper Science and

USDA Forest Service

Forest Products Laboratory

October 16, 2003 


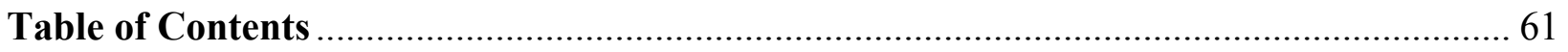

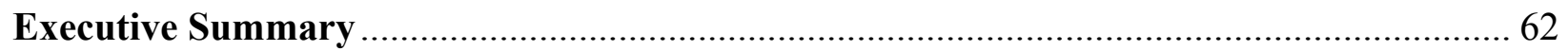

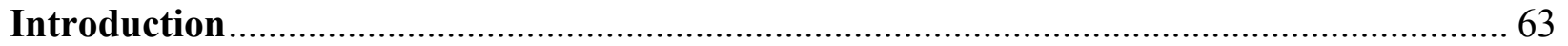

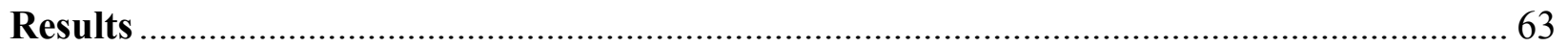

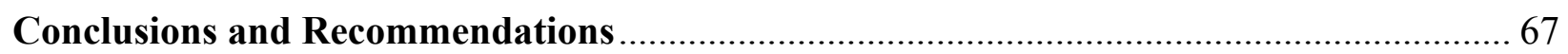

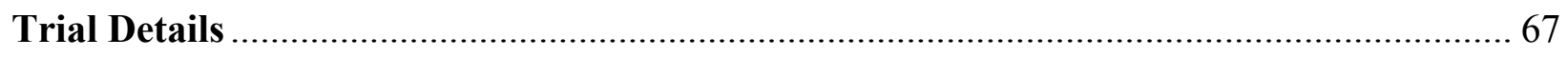

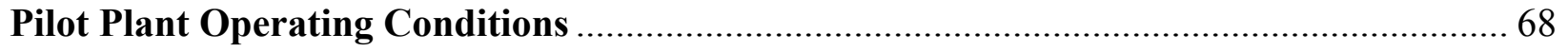

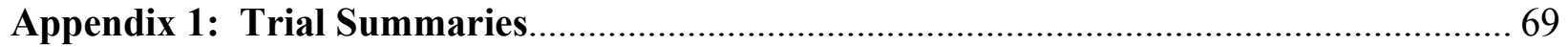

Appendix 2: Phase IV Pilot Plant Recycling Procedure ................................................ 77

Appendix 3: Hydrophobic Contaminant Identification Method ..................................... 85

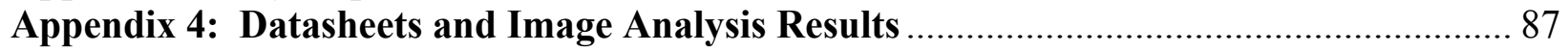




\section{Executive Summary}

Four open-loop recycling trials were conducted at the Forest Products Laboratory, Madison, Wisconsin for the University of Minnesota Department of Wood and Paper Science. In each trial, a different hot melt pressure sensitive adhesive (PSA) on Boise Cascade facepaper was tested. Each PSA sample had an identification number: F-2004, F-2005, F-2008, or F-2012. Trial results were used to investigate the PSA removability/recyclability of each sample.

Each of the four PSAs tested was acceptably removed (20 ppm or less), primarily by screening with cleaning and flotation acting as polishing steps. The final pulp adhesive content averaged:

- $5 \pm 5$ ppm for F-2004

- $3 \pm 1$ ppm for F-2005

- $6 \pm 1$ ppm for F-2008

- $6 \pm 1$ ppm for F-2012

The PSA pulper particle size for each sample was also acceptable ( 0.32 sq. $\mathrm{mm}$ or greater):

- 1.16 sq. $\mathrm{mm}$ for F-2004

- 1.40 sq. $\mathrm{mm}$ for F-2005

- 2.04 sq. $\mathrm{mm}$ for F-2008

- 1.96 sq. mm for F-2012 
Introduction

This report contains information and results obtained for four open-loop recycling trials conducted for the University of Minnesota Department of Wood and Paper Science. The trials and samples are identified as follows:

- Trial \#349, sample F-2004, conducted on October 1, 2002

- Trial \#350, sample F-2005, conducted on October 9, 2002

- Trial \#371, sample F-2008, conducted on September 9, 2003

- Trial \#372, sample F-2012, conducted on September 23, 2003

In each trial, a different hot melt pressure sensitive adhesive (PSA) on Boise Cascade facepaper was tested. Trial summaries are provided in Appendix 1.

Results

Image analysis (IA) adhesive levels and particle sizes are presented in Tables 1 and 2, respectively, for both trials. These tables present values after statistical analysis of raw data.

Table 1: Adhesive levels for hot melt PSA samples.

\begin{tabular}{|c|c|c|c|c|c|c|c|c|}
\hline \multirow{2}{*}{$\begin{array}{l} \\
\text { Sample Point } \\
\text { (ID No.) }\end{array}$} & \multicolumn{2}{|c|}{$\begin{array}{c}\text { TRIAL \#349 } \\
\text { SAMPLE F-2004 }\end{array}$} & \multicolumn{2}{|c|}{$\begin{array}{c}\text { TRIAL \#350 } \\
\text { SAMPLE F-2005 }\end{array}$} & \multicolumn{2}{|c|}{$\begin{array}{c}\text { TRIAL \#371 } \\
\text { SAMPLE F-2008 }\end{array}$} & \multicolumn{2}{|c|}{$\begin{array}{c}\text { TRIAL \#374 } \\
\text { SAMPLE } \\
\text { F-2012 }\end{array}$} \\
\hline & ppm & $\begin{array}{c}95 \% \\
\text { CI }\end{array}$ & ppm & $\begin{array}{l}95 \% \\
\text { CI }\end{array}$ & ppm & $\begin{array}{c}95 \% \\
\text { CI }\end{array}$ & ppm & $\begin{array}{c}95 \% \\
\text { CI }\end{array}$ \\
\hline $\begin{array}{l}\text { Screening Feed } \\
\text { (1) }\end{array}$ & 8,400 & 958 & 5,261 & 781 & 3,872 & 1,148 & 5,262 & 1,062 \\
\hline $\begin{array}{l}0.3 \mathrm{~mm} \text { Screen } \\
\text { A Accepts (3) }\end{array}$ & 1,434 & 191 & 558 & 54 & 85 & 30 & 96 & 25 \\
\hline $\begin{array}{l}0.1 \mathrm{~mm} \text { Screen } \\
\text { B Accepts }(5)\end{array}$ & 95 & 15 & 47 & 12 & 5 & 1 & 17 & 4 \\
\hline $\begin{array}{l}1^{\text {st }} \text { Forward } \\
\text { Cleaner Feed } \\
\text { (8) }\end{array}$ & 70 & 10 & 40 & 8 & 18 & 4 & 8 & 2 \\
\hline $\begin{array}{l}1^{\text {st }} \text { Thru-Flow } \\
\text { Cleaner Feed } \\
\text { (11) }\end{array}$ & 48 & 10 & 29 & 7 & 18 & 7 & 13 & 3 \\
\hline $\begin{array}{l}\text { Flotation Feed } \\
\text { (18) }\end{array}$ & 13 & 5 & 12 & 4 & 10 & 2 & 8 & 2 \\
\hline $\begin{array}{l}\text { Flotation } \\
\text { Accepts (20) }\end{array}$ & 1 & 1 & 3 & 1 & 8 & 1 & 5 & 1 \\
\hline Final Pulp (22) & 5 & 5 & 3 & 1 & 6 & 1 & 6 & 1 \\
\hline
\end{tabular}


Table 2: Particle sizes for hot melt PSA samples.

\begin{tabular}{|c|c|c|c|c|c|c|c|c|}
\hline \multirow{2}{*}{$\begin{array}{l}\text { Sample Point } \\
\text { (ID No.) }\end{array}$} & \multicolumn{2}{|c|}{$\begin{array}{c}\text { TRIAL \#349 } \\
\text { SAMPLE F-2004 }\end{array}$} & \multicolumn{2}{|c|}{$\begin{array}{c}\text { TRIAL \#350 } \\
\text { SAMPLE F-2005 }\end{array}$} & \multicolumn{2}{|c|}{$\begin{array}{c}\text { TRIAL \#371 } \\
\text { SAMPLE } \text { F-2008 }\end{array}$} & \multicolumn{2}{|c|}{$\begin{array}{c}\text { TRIAL } \# 374 \\
\text { SAMPLE } \\
\text { F-2012 }\end{array}$} \\
\hline & sq. $\mathrm{mm}$ & $\begin{array}{c}95 \% \\
\text { CI }\end{array}$ & sq. $\mathrm{mm}$ & $\begin{array}{c}95 \% \\
\text { CI }\end{array}$ & sq. $\mathrm{mm}$ & $\begin{array}{c}95 \% \\
\text { CI }\end{array}$ & sq. $\mathbf{m m}$ & $\begin{array}{c}95 \% \\
\text { CI }\end{array}$ \\
\hline $\begin{array}{l}\text { Screening Feed } \\
\text { (1) }\end{array}$ & 1.1556 & 0.1161 & 1.3975 & 0.2074 & 2.0369 & 0.5745 & 1.9606 & 0.3442 \\
\hline $\begin{array}{l}0.3 \mathrm{~mm} \text { Screen } \\
\text { A Accepts (3) }\end{array}$ & 0.3234 & 0.0281 & 0.2702 & 0.0143 & 0.2254 & 0.0731 & 0.2011 & 0.0428 \\
\hline $\begin{array}{l}0.1 \mathrm{~mm} \text { Screen } \\
\text { B Accepts }(5)\end{array}$ & 0.0953 & 0.0075 & 0.0847 & 0.0080 & 0.0725 & 0.0103 & 0.0650 & 0.0077 \\
\hline $\begin{array}{l}1^{\text {st }} \text { Forward } \\
\text { Cleaner Feed } \\
(8)\end{array}$ & 0.0882 & 0.0082 & 0.0851 & 0.0130 & 0.0741 & 0.0066 & 0.0559 & 0.0062 \\
\hline $\begin{array}{l}1^{\text {st }} \text { Thru-Flow } \\
\text { Cleaner Feed } \\
\text { (11) }\end{array}$ & 0.0795 & 0.0115 & 0.0858 & 0.0175 & 0.0887 & 0.0348 & 0.0752 & 0.0043 \\
\hline $\begin{array}{l}\text { Flotation Feed } \\
\text { (18) }\end{array}$ & 0.0816 & 0.0139 & 0.0769 & 0.0230 & 0.0693 & 0.0065 & 0.0625 & 0.0064 \\
\hline $\begin{array}{l}\text { Flotation } \\
\text { Accepts (20) }\end{array}$ & 0.0127 & 0.0111 & 0.0323 & 0.0085 & 0.0719 & 0.0101 & 0.0670 & 0.0053 \\
\hline Final Pulp (22) & 0.0710 & 0.0801 & 0.0303 & 0.0110 & 0.0647 & 0.0191 & 0.0668 & 0.0023 \\
\hline
\end{tabular}

The raw handsheet adhesive level and particle size values were subjected to normality plotting analysis. This analysis identifies handsheets that appear to be inconsistent with the rest of the handsheets in that group and also allows identification of sets of handsheets that display inconsistencies in processing. Typically, IA results can be normalized with the omission of one or two outlier points - or handsheets - out of a total of 16 points or sheets. In certain cases, up to a maximum of 4 points or sheets can be omitted; otherwise the data is left "as is." Fewer sheets, if any, are omitted for the final pulp, which typically (for a removable PSA) has a non-gaussian distribution due to zero/near-zero ppm levels. The IA method is presented in Appendix 3. Raw IA datasheets and results are presented in Appendix 4.

Based on the IA results in Table 1, the PSA of all four samples was removed to acceptable levels (20 ppm or less) in the recycling system. The final pulp adhesive content averaged:

- $5 \pm 5$ ppm for F-2004

- $3 \pm 1$ ppm for F-2005

- $6 \pm 1$ ppm for F-2008

- $6 \pm 1$ ppm for F-2012 
The PSA pulper particle size, shown in Table 2, for all four samples was also acceptable $(0.32$ sq. $\mathrm{mm}$ or greater):

- 1.16 sq. $\mathrm{mm}$ for F-2004

- 1.40 sq. mm for F-2005

- 2.04 sq. mm for F-2008

- 1.96 sq. mm for F-2012

Screening removal efficiencies could be calculated at various stages of screening based on ppm values in Table 1 and are shown in Table 3 below.

Table 3: Screening removal efficiencies for hot melt PSA samples.

\begin{tabular}{|c|c|c|}
\hline Sample ID & $\begin{array}{c}\text { 12 cut (0.3 mm) Screening } \\
\text { Removal Efficiency }\end{array}$ & $\begin{array}{c}\text { Overall Screening Removal } \\
\text { Efficiency }\end{array}$ \\
\hline F-2004 & $82.9 \%$ & $98.9 \%$ \\
\hline F-2005 & $89.4 \%$ & $99.1 \%$ \\
\hline F-2008 & $97.8 \%$ & $99.9 \%$ \\
\hline F-2012 & $98.2 \%$ & $99.7 \%$ \\
\hline
\end{tabular}

Figure 1 shows the $0.3 \mathrm{~mm}$ (12 cut) screening efficiency versus PSA pulper particle size for samples F-2004, F-2005, F-2008, and F-2012 and other PSAs tested in Phase IV of the USPS project for comparison. All of the samples appear in the upper range of the data set. 


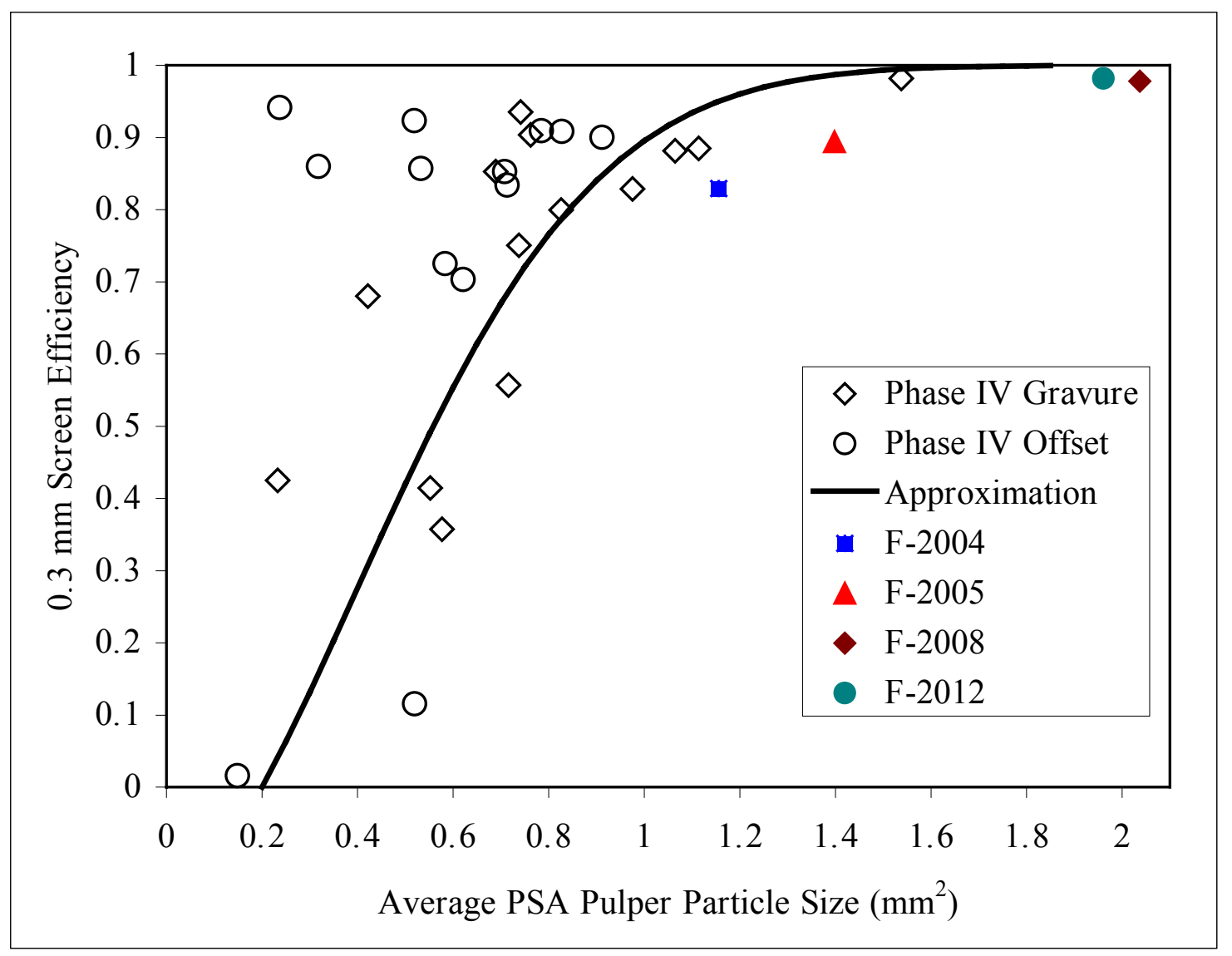

Figure 1. Plot of $0.3 \mathrm{~mm}$ screen efficiency versus average PSA pulper particle size for adhesives in the Phase IV database and for samples F-2004, F-2005, F-2008, and F-2012.

PSA rejects collected on the $0.2 \mathrm{~mm}$ ( 8 cut) flatscreen for each trial were oven dried and weighed. The PSA rejects collected on the 8 cut $(0.2 \mathrm{~mm})$ flatscreen for each trial was as follows:

- $534 \mathrm{~g}$ OD for F-2004;

- $632 \mathrm{~g}$ OD for F-2005;

- $1,300 \mathrm{~g}$ OD for F-2008;

- $941 \mathrm{~g}$ OD for F-2012 (note that $719 \mathrm{~g}$ OD was lodged in the 12 cut $(0.3 \mathrm{~mm}$ ) pressure screen in addition).

Note that for Trial \#371 and \#374 the weight of PSA rejects collected is greater than the theoretical $1.125 \mathrm{~kg}$ (or $1 \%$ of the total stock weight of $112.5 \mathrm{~kg}$ ), which is based on a PSA coating of 1 mil thickness. It is thought that the PSA of samples F-2008 and F-2012 was not consistently coated to 1 mil thickness and might have been coated thicker than 1 mil. 
Conclusions and Recommendations

Each of the four PSAs tested was acceptably removed (20 ppm or less) and had an acceptable pulper particle size ( 0.32 sq. $\mathrm{mm}$ or greater).

Trial Details

The trials were conducted at the USDA Forest Service, Forest Products Laboratory (FPL) Recycling Pilot Plant in Madison, Wisconsin USA. The open-loop recycling procedure is presented in Appendix 2.

The stock materials for each trial weighed a total of 112.5 oven-dried (OD) $\mathrm{kg}$ and are identified in Table 4.

Table 4: Pulper mass loadings of stock materials for hot melt PSA recycling trials.

\begin{tabular}{|c|c|c|}
\hline \multicolumn{3}{|l|}{ TRIAL \#349 } \\
\hline $\begin{array}{l}47.5 \% \text { copy paper } \\
53.44 \mathrm{~kg} \mathrm{OD} \\
56.85 \mathrm{~kg} \text { weighed out }\end{array}$ & $\begin{array}{l}47.5 \% \text { envelope paper } \\
53.44 \mathrm{~kg} \text { OD } \\
56.85 \text { weighed out }\end{array}$ & $\begin{array}{l}5 \% \text { F-2004 facepaper }(\sim 1 \% \\
\text { adhesive content by weight }) \\
5.625 \mathrm{~kg} \text { OD } \\
5.625 \mathrm{~kg} \text { weighed out }\end{array}$ \\
\hline \multicolumn{3}{|l|}{ TRIAL \#350 } \\
\hline $\begin{array}{l}47.5 \% \text { copy paper } \\
53.44 \mathrm{~kg} \text { OD } \\
56.85 \mathrm{~kg} \text { weighed out }\end{array}$ & $\begin{array}{l}47.5 \% \text { envelope paper } \\
53.44 \mathrm{~kg} \text { OD } \\
56.85 \text { weighed out }\end{array}$ & $\begin{array}{l}5 \% \text { F-2005 facepaper }(\sim 1 \% \\
\text { adhesive content by weight }) \\
5.625 \mathrm{~kg} \text { OD } \\
5.625 \mathrm{~kg} \text { weighed out }\end{array}$ \\
\hline \multicolumn{3}{|l|}{ TRIAL \#371 } \\
\hline $\begin{array}{l}47.5 \% \text { copy paper } \\
53.44 \mathrm{~kg} \mathrm{OD} \\
56.85 \mathrm{~kg} \text { weighed out }\end{array}$ & $\begin{array}{l}\text { 47.5\% envelope paper } \\
51.49 \mathrm{~kg} \text { OD } \\
54.78 \text { weighed out }\end{array}$ & $\begin{array}{l}5 \% \text { F-2008 facepaper }(\sim 1 \% \\
\text { adhesive content by weight }) \\
5.625 \mathrm{~kg} \text { OD } \\
5.984 \mathrm{~kg} \text { weighed out }\end{array}$ \\
\hline \multicolumn{3}{|l|}{ TRIAL \#374 } \\
\hline $\begin{array}{l}47.5 \% \text { copy paper } \\
53.44 \mathrm{~kg} \text { OD } \\
56.85 \mathrm{~kg} \text { weighed out }\end{array}$ & $\begin{array}{l}47.5 \% \text { envelope paper } \\
51.42 \mathrm{~kg} \text { OD } \\
54.70 \text { weighed out }\end{array}$ & $\begin{array}{l}5 \% \text { F-2007 facepaper }(\sim 1 \% \\
\text { adhesive content by weight }) \\
5.625 \mathrm{~kg} \text { OD } \\
6.048 \mathrm{~kg} \text { weighed out }\end{array}$ \\
\hline
\end{tabular}

The facepaper of samples F-2008 and F-2012 had edges that were not coated with adhesive, which was accounted for in the reduced weight of envelope paper. For each trial, FPL personnel manually fixed the PSA facepaper to envelope paper and allowed a minimum of 72 hours before testing for development of adhesive permanence.

The stock materials were pulped at approximately $12.5 \% \mathrm{csc}$ in alkaline conditions for 20 minutes in $46 \pm 2{ }^{\circ} \mathrm{C}$ soft water. Following pulping, the pulper contents were transferred to the 
dumpchest and diluted to approximately $2.2 \% \csc$ with $46 \pm 2{ }^{\circ} \mathrm{C}$ soft water. The dumpchest contents, after inline dilution to approximately $1 \% \mathrm{csc}$, were delivered to a screening stage consisting of a $0.3 \mathrm{~mm}$ (12 cut) pressure screen, $0.2 \mathrm{~mm}$ ( 8 cut) flat screen, and a $0.1 \mathrm{~mm}$ (4 cut) pressure screen. The screening accepts were collected in a tank and diluted with $46 \pm 2{ }^{\circ} \mathrm{C}$ soft water to an approximate consistency of $0.65 \%$. The screening accepts were then sent through cleaning, flotation and drum washing/dewatering stages.

Pilot Plant Operating Conditions

Table 4 shows the important pilot plant operating conditions for Trials \#349, \#350, \#371 and \#374. Also shown, for reference only and not direct comparison to these trials, are averages and standard deviations of these parameters for 45 other post-consumer recycling trials in the Phase IV database.

Table 4: Operating conditions for hot melt PSA recycling trials.

\begin{tabular}{|c|c|c|c|c|c|c|c|}
\hline & $\begin{array}{r}\text { Trial } \\
\# 349\end{array}$ & $\begin{array}{l}\text { Trial } \\
\# 350\end{array}$ & $\begin{array}{l}\text { Trial } \\
\# 371\end{array}$ & $\begin{array}{l}\text { Trial } \\
\# 374\end{array}$ & \multicolumn{2}{|c|}{$\begin{array}{l}\text { Phase IV } \\
\text { Database }\end{array}$} & \\
\hline Parameter & Value & Value & Value & Value & Ave & StDev & Unit \\
\hline Temperature after Pulping & 48.3 & 47.1 & 44.5 & 44.3 & 46.6 & 1.3 & ${ }^{\circ} \mathrm{C}$ \\
\hline Consistency in Pulper & 12.79 & 12.95 & 12.72 & 12.65 & 12.4 & 0.2 & $\%$ \\
\hline $\mathrm{pH}$ after Pulping & 9.4 & 9.8 & 9.2 & 9.5 & 9.8 & 0.2 & $\mathrm{pH}$ \\
\hline Pulper Energy & 56.2 & 55.4 & 52.3 & 52.0 & 56.3 & 2.4 & $\mathrm{~kW} \mathrm{hr/MT}$ \\
\hline $0.3 \mathrm{~mm}$ Screen Feed Consistency & 1.08 & 1.12 & 1.06 & 1.09 & 1.15 & 0.04 & $\%$ \\
\hline $0.3 \mathrm{~mm}$ Screen Reject Rate & 12.7 & 14.4 & 15.4 & 15.1 & 14.6 & 1.1 & $\%$ \\
\hline $0.3 \mathrm{~mm}$ Screen Passing Speed & 0.43 & 0.41 & 0.41 & 0.41 & 0.42 & 0.003 & $\mathrm{~m} / \mathrm{s}$ \\
\hline $0.1 \mathrm{~mm}$ Screen Feed Consistency & 0.94 & 0.95 & 0.91 & 0.91 & 1.03 & 0.07 & $\%$ \\
\hline $0.1 \mathrm{~mm}$ Screen Reject Rate & 22.8 & 19.1 & 20.3 & 21.0 & 21 & 1 & $\%$ \\
\hline $0.1 \mathrm{~mm}$ Screen Passing Speed & 0.35 & 0.35 & 0.35 & 0.35 & 0.35 & 0.003 & $\mathrm{~m} / \mathrm{s}$ \\
\hline Forward Cleaner Feed Consistency & 0.59 & 0.66 & 0.65 & 0.66 & 0.64 & 0.04 & $\%$ \\
\hline Forward Cleaner Reject Rate & 8.5 & 3.0 & 9.8 & 9.9 & 10.3 & 0.7 & $\%$ \\
\hline $\begin{array}{l}\text { Thru-flow Cleaner Feed } \\
\text { Consistency }\end{array}$ & 0.49 & 0.49 & 0.51 & 0.49 & 0.50 & 0.03 & $\%$ \\
\hline Thru-flow Cleaner Reject Rate & 9.4 & 8.6 & 9.8 & 9.3 & 11.6 & 3.4 & $\%$ \\
\hline Flotation Feed Consistency & 0.51 & 0.53 & 0.53 & 0.51 & 0.61 & 0.03 & $\%$ \\
\hline Flotation Residence Time & 11.2 & 11.1 & 11.1 & 10.8 & 11.7 & 0.2 & $\min$. \\
\hline Flotation Reject Rate & 0.5 & 0.3 & 3.9 & --- & 2.0 & 1.0 & $\%$ \\
\hline Total Yield & 57.5 & 55.1 & 56.7 & 50.9 & 56 & 4 & $\%$ \\
\hline
\end{tabular}

One main goal in conducting each trial was to maintain the operating conditions as consistent as possible between the trials. 


\section{Appendix 1: Trial Summaries \\ Trial \#349 Summary}

Date: October 1, 2002

Purpose: Phase IV configuration testing of Univ. of MN sample F-2004 (a rubber-based thermoplastic PSA on Boise Cascade facepaper).

Materials: Required Mass Loadings: $47.5 \%$ copy paper, $47.5 \%$ envelope paper, $5 \%$ facepaper with adhesive material ( $\sim 1 \%$ adhesive).

Used $56.85 \mathrm{~kg}$ (53.44 kg OD) copy paper (OLD), $56.85 \mathrm{~kg}$ (53.44 kg OD) envelope paper, and $5.625 \mathrm{~kg} \mathrm{~F}-2004$ material (weight of facestock only). Total weight of all materials $=119.3 \mathrm{~kg}$ (112.5 kg OD). Adhesive material was adhered the week of September 9, 2002.

\section{Notes:}

- Feed to pressure screen started at 8:10 am. End screening 8:53 am. Cleaning stage began at 9:40 am. Overall, the trial ran smoothly.

- Pulping: Dumped some water before pulping due to low temp $\left(43.2^{\circ} \mathrm{C}\right)$. Temperature after pulping $=48.3^{\circ} \mathrm{C}$. The F-2004 test material pulped completely. Pulper consistency $=12.79 \%$ average. Average pulper particle size $=1.1556 \mathrm{sq} . \mathrm{mm}$.

- Screening: Screen A (12 cut), flat screen (8 cut) and Screen B (4 cut) were used. Nothing out the ordinary to report.

- Flat Screen: Adhesive was visible in flat screen accepts as small short segments $(\sim 1 / 3$ the size of the benchmark STR 34355 adhesive), yellowish-white in color and rubberlike. Some adhesive was collected in flat screen rejects. Adhesive agglomerated into a rubbery mass that is pale yellow in color. Adhesive sticks tenaciously to clothing, skin, hair, copper, red rubber. There were a few black specs in flat screen rejects (bugs???). Collected flat screen rejects weighed $534 \mathrm{~g}$ OD.

- Cleaning: Nothing out the ordinary to report.

- Flotation: 63 grams of DI-700 surfactant were dissolved in $60 \mathrm{~L}$ of water. The overall average surfactant pump rate from start to finish was $1.18 \mathrm{Lpm}(57 \mathrm{~L}$ used in 48 minutes 20 seconds; target pump rate $=1 \mathrm{Lpm}$ ). Flotation feed was $\sim 182 \mathrm{Lpm}$, rejects rate was 5-7 Lpm, airflow rate was $10 \mathrm{scfm}$.

- Drumwasher: Nothing out of the ordinary to report. Ran well. Final pulp averaged $24.18 \%$ csc.

- Data Acquisition: Nothing out of the ordinary to report. 
- Sample Analysis: From alternate method (Verity) image analysis results (@20\% contrast $)$, the 12 cut $(0.3 \mathrm{~mm})$ screening efficiency was $82.9 \%$ and the overall screening efficiency (4 cut $(0.1 \mathrm{~mm})$ screen accepts) was $98.9 \%$. Final pulp adhesive content was 5 \pm 5 ppm (average of values from two bags after statistical analysis of individual handsheet values).

- Cleaning Run: First cleaning run was $11 \pm 1 \mathrm{w} / 20 \%$ contrast. This was thought to be too high so another cleaning run was performed. Second cleaning run was $8 \pm 2 \mathrm{w} / 20 \%$ contrast; acceptable. 


\section{Trial \#350 Summary}

Date: October 9, 2002

Purpose: Phase IV configuration testing of Univ. of MN sample F-2005 (a rubber-based thermoplastic (hot melt) PSA on Boise Cascade facepaper).

Materials: Required Mass Loadings: $47.5 \%$ copy paper, $47.5 \%$ envelope paper, $5 \%$ facepaper with adhesive material ( $\sim 1 \%$ adhesive).

Used $56.85 \mathrm{~kg}$ (53.44 kg OD) copy paper (OLD), $56.85 \mathrm{~kg}$ (53.44 kg OD) envelope paper, and $5.625 \mathrm{~kg} \mathrm{~F}-2005$ material (weight of facestock only). Total weight of all materials $=119.3 \mathrm{~kg}$ (112.5 kg OD). Adhesive material was adhered on October 4, 2002.

\section{Notes:}

- Feed to pressure screen started at 7:40 am. End screening $\sim 8: 25 \mathrm{am}$. Cleaning stage began at $\sim 9: 15 \mathrm{am}$. Overall, the trial ran smoothly.

- Pulping: Temperature after pulping $=47.1{ }^{\circ} \mathrm{C}$. The F-2005 test material pulped completely. Pulper consistency $=12.95 \%$ average. Average pulper particle size $=$ 1.3975 sq. $\mathrm{mm}$.

- Screening: Screen A (12 cut), flat screen (8 cut) and Screen B (4 cut) were used. Nothing out the ordinary to report.

- Flat Screen: Adhesive was visible in flat screen rejects as small short segments, yellowtan in color and rubber-like. Compared to that in the accepts, most was collected in the rejects; some was in the accepts. Adhesive agglomerated into a rubbery mass but is not sticky or tacky (like F-2004) and could easily be pulled apart. It did not stick to skin or equipment and seemed to clean up well. Collected flat screen rejects weighed $632 \mathrm{~g}$ OD.

- Cleaning: Nothing out the ordinary to report.

- Flotation: 63 grams of DI-700 surfactant were dissolved in $60 \mathrm{~L}$ of water. The overall average surfactant pump rate from start to finish was $1.09 \mathrm{Lpm}(50.2 \mathrm{~L}$ used in 46 minutes 10 seconds; target pump rate $=1 \mathrm{Lpm}$ ). Flotation feed was $\sim 180 \mathrm{Lpm}$, rejects rate was $\sim 5-8 \mathrm{Lpm}$, airflow rate was $10 \mathrm{scfm}$. Accepts are white; no yellow color is visible.

- Drumwasher: Nothing out of the ordinary to report. Ran well. Final pulp averaged $24.91 \%$ csc.

- Data Acquisition: Nothing out of the ordinary to report. 
- Sample Analysis: From alternate method (Verity) image analysis results (@ 20\% contrast), the 12 cut $(0.3 \mathrm{~mm})$ screening efficiency was $89.4 \%$ and the overall screening efficiency ( 4 cut $(0.1 \mathrm{~mm})$ screen accepts) was $99.1 \%$. Final pulp adhesive content was 3 $\pm 1 \mathrm{ppm}$ (average of values from two bags after statistical analysis of individual handsheet values).

- Cleaning Run: $6 \pm 3 \mathrm{w} / 20 \%$ contrast; acceptable. 


\section{Trial \#371 Summary}

Date: September 10, 2003

Purpose: Phase IV configuration testing of Univ. of MN sample F-2008 (hot melt adhesive on Boise Cascade facepaper).

Materials: Required Mass Loadings: $47.5 \%$ copy paper, $47.5 \%$ envelope paper, $5 \%$ facepaper with adhesive material ( $\sim 1 \%$ adhesive).

Used $56.85 \mathrm{~kg}(53.44 \mathrm{~kg}$ OD) copy paper, $54.78 \mathrm{~kg}(51.49 \mathrm{~kg}$ OD) envelope paper, and $5.984 \mathrm{~kg}$ (5.625 kg OD) F-2008 facepaper. The F-2008 facepaper has edges that are not coated with adhesive, which is accounted for in the reduced weight of envelope paper. Total weight of all pulper materials $=117.61 \mathrm{~kg}(112.5 \mathrm{~kg}$ OD) . Adhesive material was adhered on envelope paper a minimum of 72 hours prior to the trial.

\section{Notes:}

- Feed to pressure screening stage started at 7:41 am and stopped at 8:25 am. Cleaning stage began at 9:13 am. Overall, the trial ran smoothly.

- Pulping: Temperature before pulping $=40.4^{\circ} \mathrm{C}$. Temperature after pulping $=44.5^{\circ} \mathrm{C}$. Pulper consistency $=12.7 \%$. Pulper particle size $=2.0369$ sq. $\mathrm{mm}$ (large). PSA pulping time was 20.6 minutes and pulper energy consumption during this time was 52.3 $\mathrm{kWhr} / \mathrm{MT}$.

- Screening: Screen A (12 cut), flat screen (8 cut) and Screen B (4 cut) were used. Nothing out the ordinary to report.

- Flat Screen: Adhesive is visible in the flat screen rejects as large rubbery masses, grayish-white in color. Also visible are thin, white worms that look like acrylic adhesive contamination from previous trial(s). There a some of these white worms in the accepts weir as well; however, they did not appear to be accumulating over time that much in the flat screen accepts/rejects, suggesting that these white worms are indeed contamination from previous trial(s). Check pulper image analysis to verify. The flat screen rejects highly agglomerate into a strong, rubbery mass that is very difficult to pull apart. Flat screen rejects $=1.300 \mathrm{~kg}$ OD. This is higher than the theoretical maximum of $1 \%$ of $112.5 \mathrm{~kg}$ or $1.125 \mathrm{~kg}$ due to the acrylic PSA contamination.

- Cleaning: Nothing out of the ordinary to report.

- Flotation: 63 grams of DI-700 surfactant were dissolved in $60 \mathrm{~L}$ of water. The overall average pump rate was $0.985 \mathrm{Lpm}(45 \mathrm{~L}$ used in $45.67 \mathrm{~min}$; target pump rate $=1 \mathrm{Lpm})$.

The flotation rejects line to the drain was plugged initially. The plug was cleared within 5 minutes after startup with minor rejects flow volume lost. 
- Drumwasher: Ran well. Final pulp averaged $23.8 \%$ csc.

- Data Acquisition: Nothing out of the ordinary to report.

- Sample Analysis: Handsheet ppm levels are reported using 20\% contrast in scanning software. From alternate method (Verity) image analysis results, the 12 cut $(0.3 \mathrm{~mm})$ screening efficiency was $97.8 \%$ and the overall screening efficiency $(4$ cut $(0.1 \mathrm{~mm})$ screen accepts) was $99.9 \%$. Final pulp adhesive content was $6 \pm 1 \mathrm{ppm}$ (average of values from two bags after statistical analysis of individual handsheet values). Acrylic worms are not present is handsheets for sample points after screening. These acrylic worms are residual contamination from previous Trial \#370. Handsheets for pulper sample point were dried at a lower temperature $\left(\sim 80^{\circ} \mathrm{C}\right)$ to prevent melting of the adhesive in the sheet. This was not necessary for other sample points.

- Cleaning Run: $1 \pm 1 \mathrm{w} / 20 \%$ contrast; acceptable. 


\section{Trial \#374 Summary}

Date: September 23, 2003

Purpose: Phase IV configuration testing of Univ. of MN sample F-2012 (hot melt adhesive on Boise Cascade facepaper).

Materials: Required Mass Loadings: 47.5\% copy paper, $47.5 \%$ envelope paper, $5 \%$ facepaper with adhesive material ( $\sim 1 \%$ adhesive).

Used $56.85 \mathrm{~kg}(53.44 \mathrm{~kg}$ OD) copy paper, $54.70 \mathrm{~kg}(51.42 \mathrm{~kg}$ OD) envelope paper, and $6.048 \mathrm{~kg}$ (5.625 kg OD) F-2012 facepaper. The F-2012 facepaper has edges that are not coated with adhesive, which is accounted for in the reduced weight of envelope paper. Total weight of all pulper materials $=117.60 \mathrm{~kg}(112.5 \mathrm{~kg} \mathrm{OD})$. Adhesive material was adhered on envelope paper a minimum of 72 hours prior to the trial.

\section{Notes:}

- Feed to pressure screening stage started at 8:26 am and stopped at $\sim 9: 11$ am. Cleaning stage began at $\sim 10: 05 \mathrm{am}$. Overall, the trial ran smoothly.

- Pulping: Temperature before pulping $=40.2^{\circ} \mathrm{C}$. Temperature after pulping $=44.3^{\circ} \mathrm{C}$. Pulper consistency $=12.65 \%$. Pulper particle size $=1.9606$ sq. $\mathrm{mm}$ (large). PSA pulping time was 20.5 minutes and pulper energy consumption during this time was 52.0 $\mathrm{kWhr} / \mathrm{MT}$.

- Screening: Screen A (12 cut), flat screen (8 cut) and Screen B (4 cut) were used. Jerry discovered a huge mass (944 g "as is", $718 \mathrm{~g}$ OD) of PSA in the rejects area of the $12 \mathrm{cut}$ screen after the trial. The mass was a grayish-off-white color (not pale yellow as the flat screen rejects were) and resembled bread dough. Screen A was making a repeated knocking noise during the trial, but seemed to still operate properly. Sample ports for accepts and rejects were checked and were not blocked and flows were still consistent with Phase IV trials.

- Flat Screen: Adhesive is visible in the flat screen rejects as large, agglomerated masses, pale yellow in color. Very tacky. A very small amount of tiny bits of adhesive is visible in the flat screen accepts. (No acrylic PSA contamination is visible, but there are other darker foreign objects and white unpulped paper strips (wet-strength material???) that accumulated in the flat screen along with the rejects. It appears this material has cleaned out the pipes.) Flat screen rejects $=941 \mathrm{~g} \mathrm{OD}$. Note that the weight of the flatscreen rejects plus the rejects discovered in the 12 cut screen (see above) exceeds the theoretical maximum of $1 \%$ of $112.5 \mathrm{~kg}$ or $1.125 \mathrm{~kg}$. It is possible that the coating thickness of the PSA on the facepaper is not consistently 1 mil thick.

- Cleaning: Nothing out of the ordinary to report. 
- Flotation: 63 grams of DI-700 surfactant were dissolved in $60 \mathrm{~L}$ of water. The overall average pump rate was $1.026 \mathrm{Lpm}(47 \mathrm{~L}$ used in $45.82 \mathrm{~min}$; target pump rate $=1 \mathrm{Lpm})$.

- Drumwasher: Ran well. Final pulp averaged $22.4 \%$ csc.

- Data Acquisition: Nothing out of the ordinary to report.

- Sample Analysis: Handsheet ppm levels are reported using 20\% contrast in scanning software. From alternate method (Verity) image analysis results, the 12 cut $(0.3 \mathrm{~mm})$ screening efficiency was $98.2 \%$ and the overall screening efficiency $(4$ cut $(0.1 \mathrm{~mm})$ screen accepts) was $99.7 \%$. Final pulp adhesive content was $6 \pm 1 \mathrm{ppm}$ (average of values from two bags after statistical analysis of individual handsheet values). Handsheets for pulper sample point were dried at a lower temperature $\left(\sim 80^{\circ} \mathrm{C}\right)$ to prevent melting of the adhesive in the sheet. This was not necessary for other sample points.

- Cleaning Run: $5 \pm 5 \mathrm{w} / 20 \%$ contrast; acceptable. 


\section{Appendix 2: Phase IV Pilot Plant Recycling Procedure}

These procedures are developed for evaluating the recyclability of environmentally benign postage stamp materials using those conventional unit operations located in the USDA Forest Products Laboratory pilot laboratory paper recycling facility. The process involves high consistency repulping, slot screening, centricleaning with both forward and thru-flow cleaners, flotation, washing, and papermaking using a pilot laboratory machine. Screening and forward cleaning include secondary fiber recovery.

\section{A. Equipment \& Materials}

I. Equipment

1. VOITH high consistency pulper model HC-1.5, $2500 \mathrm{~L}$ total volume, $1500 \mathrm{~L}$ maximum working volume, equipped with OHIO SEMITRONICS model CTX-500S current transducers feeding an OHIO SEMITRONICS model WH3-11195 AC watt-hr meter.

2. VOITH MULTIFRACTOR pressure screen model 00 equipped with a 0.30 $\mathrm{mm}(0.012$ ") slotted basket (1st primary stage). Voith VPS-05 pressure screen equipped with a $0.10 \mathrm{~mm}(0.004$ ") C-bar slotted basket (2nd primary stage).

3. AMINCO 6-plate vat flatscreen w/ $0.2 \mathrm{~mm}(0.008$ ") slotted plates 600 -liter tank plus transfer pump (fiber recovery and adhesive collection stage).

4. Beloit POSIFLOW 60 forward centricleaner (1st primary stage); Celleco CLEANPAC 270 forward centricleaner (2nd primary stage); Voith KSP 60 forward centricleaner with primary reject collection tank and stock pump (secondary fiber recovery stage).

5. Black-Clawson X-clone thru-flow centricleaner, $100 \mathrm{~mm}$ (4") nominal diameter; two primary cleaners in series.

6. LaMort 5000-L, 2-stage laboratory flotation cell.

7. Scales and 200-Liter drums to collect secondary forward cleaner rejects and flotation cell rejects.

8. Stock tanks and pumps, sufficient to store and transfer stock being processed.

9. Foxboro 8000A Magnetic flow tubes and IMT25 Magnetic flow transmitters installed throughout the system. These are the primary units for rate and volume measurements.

10. NALGENE, HDPE containers, or equivalent: 1-L, 4-L, 10-L, and 20-L capacities in sufficient numbers for sample collection. 
11. Self-sealing plastic bags, for sample collection: 4-L plus others as needed.

12. Assorted plastic bags ( $30 \times 60 \mathrm{~cm}, 45 \times 90 \mathrm{~cm}$ minimum sizes) for sample storage. Scales, $150-\mathrm{kg}$ minimum capacity, minimum resolution $0.1 \mathrm{~kg}$. Thermometers, utility knives, glassware, $\mathrm{pH}$ meter, etc. as required.

13. Screen carts, 1 x 1 x 1.5 meter, with 100 - mesh bottom wire (6 needed).

14. Balance, $1-\mathrm{kg}$ capacity, minimum accuracy $0.1 \mathrm{gm}$.

15. Vacuum drum washer, laboratory unit with 100-mesh wire; equipped with press roll and shredder.

16. Barrels, 200-Liter (or equivalent) for storage of cleaned pulp.

17. TAPPI handsheet former and auxiliary equipment

II. Materials

Definitions

Standard (Linered) Pressure Sensitive Adhesive (PSA) Stamp Laminate:

Face Paper/PSA/Release Liner, with or without printing.

Face paper: base paper sheet only, as used to prepare the Standard (Linered) Pressure Sensitive Adhesive Stamp Stock described above.

Linerless Pressure Sensitive Adhesive (PSA) Stamp Stock: Release coating/Printing/Face Paper/PSA.

Papers

Copy paper: single supply for all work; procured by USPS/FPL as a $31,000 \mathrm{lb}$. shipment derived from 2 consecutive master rolls from a commercial paper machine, slit into 24 " wide working rolls of approximately $1100 \mathrm{lb}$. each.

Envelope paper: single supply for all work; procured by USPS/FPL as a $180,000 \mathrm{lb}$. shipment derived from consecutive master rolls from a commercial paper machine, slit into 24" wide working rolls of approximately $1100 \mathrm{lbs}$. each.

Stamp stock face papers: $45 \mathrm{~kg}$. (approximate) supplied by USPS with tie layer, with no printing or adhesive. 3 rolls of paper, one roll from each of three suppliers. 
Linerless (PSA) stamp stock: $50 \mathrm{~kg}$. supplied by USPS. Same stock sample used for Phase 3 study.

Standard PSA stamp laminate: $150 \mathrm{~kg}$. supplied in 3 rolls: conventional construction currently used for stamps (same supply used for phase 3 study)

Experimental PSA stamp laminate, as submitted to FPL through USPS/STR: $20 \mathrm{~kg}$ each adhesive on each face paper (3 preconsumer samples per adhesive) (60 kg total), procured as defect-free production scrap from the stamp preparation process.

Gummed WAG (water-activated glue) stamp stock; 3 rolls each printed by a different printing method: intaglio, offset \& rotogravure.

PSA linerless label stock (color: "canary"), 80\# roll. Current type used by USPS for change-of-address labels

USPS self-sticking PSA Label 11-F (July 1997): EXPRESS MAIL address label. 4000 labels (32 kg.).

III. Other materials

1. Morplas Blue 1003, $0.67 \mathrm{gm} / \mathrm{L}$ in heptane.

2. $\mathrm{pH}$ standards: $4.0,7.0,10.0$

3. Blotters, $20 \mathrm{~cm}$ square, meeting TAPPI specifications.

4. a) Whatman \#4 filter paper or equivalent, $15 \mathrm{~cm}$ diameter.

b) Same, $32 \mathrm{~cm}$ diameter.

5. $10-15 \% \mathrm{NaOH}$ solution.

6. $10-15 \% \mathrm{H}_{2} \mathrm{SO}_{4}$ solution.

7. Flotation aid: HighPoint DI-700A.

8. Soft water: 20 and $80^{\circ} \mathrm{C}$, central supply.

B. Stock Preparation (for each trial)

Throughout the following unit operations flowrates, consistencies, volumes, etc. will be determined in order to establish a mass balance for the processing. Necessary data will be recorded as appropriate.

I. Pulping 
1. Weigh out $112.5 \mathrm{~kg}$, oven-dry basis, of fiber-based material. Measure and record solids content of paper(s).

A. A typical phase 4 pre-consumer loading will be $50.625 \mathrm{~kg}$ copy paper (45\% of total), $50.625 \mathrm{~kg}$ envelope paper ( $45 \%$ of total) and $11.25 \mathrm{~kg}$ total composite stamp stock ( $10 \%$ of total).

B. A typical phase 4 post-consumer loading will be $112.5 \mathrm{~kg}$ of cancelled envelopes each containing one sheet of copy paper.

C. For a post-consumer, non-envelope, trial (phase 3 technique) the $11.25 \mathrm{~kg}$ of total composite stamp stock is weighed out, the release liner is removed and the remaining "stamps" are affixed to envelope paper. The removed release liner is weighed and an equivalent amount of copy/envelope paper ( $1 / 2$ each) is added as make-up. This technique will approximate a $47.5 \%$ copy paper, $47.5 \%$ envelope paper, $5 \%$ stamp stock composition: the actual composition will depend on the basis weight of the release liner.

2. Fill pulper with 780 liters softwater at $46 \pm 2^{\circ} \mathrm{C}\left(115 \pm 5^{\circ} \mathrm{F}\right)$. Adjust $\mathrm{pH}$ to 10.0 with $\mathrm{NaOH}$. Use $\mathrm{H}_{2} \mathrm{SO}_{4}$ to correct overshoots.

Pre-consumer trials

Add copy and envelope papers, with minimal agitation until all paper has been introduced and wetted. Blend for 1 minute, adding only enough water to cause slurry to roll properly. Record total water added.

Stop agitation at end of the one minute; measure $\mathrm{pH}$ and temperature. Restart pulper and immediately start energy-measuring unit. Blend in adhesive-containing stock quickly, while continuing to pulp for a total of 20 minutes. Add just enough water to maintain rolling of the slurry. Collect a consistency sample when rotor has stopped immediately upon shutting off pulper.

Post-consumer trials

Same as (a) except add cancelled envelopes in their entirety as quickly as pulper will take them. Add water only as necessary. Measure temperature and $\mathrm{pH}$. Then start pulper and energy measuring unit.

(Target: total volume $=900$ liters to give a $12.5 \%$ consistency. Actual volume and consistency is determined by producing the proper roll of the slurry at the highest possible consistency (minimum amount of water) to achieve the roll.).

(Note: pulping time was determined in developing the phase 3 portion of this study.) 
3. At end of 20 minutes first shut off energy-measuring unit, then immediately the pulper. Measure final temperature, and $\mathrm{pH}$, and record energy input. Dilute slurry to $1500 \mathrm{~L}$, maintaining temperature at $46 \pm 2^{\circ} \mathrm{C}\left(115 \pm 5^{\circ} \mathrm{F}\right)$.

4. Fill the feedtank with enough water to dilute the slurry to $\underline{\mathbf{2 . 2 6 5 \%}}$ consistency maintaining temperature at $46 \pm 2^{\circ} \mathrm{C},\left(115 \pm 5^{\circ} \mathrm{F}\right)$. Use the feed tank pump to feed the ventri mixer and draw the stock from the pulper. Mix well. Measure actual consistency. Measure temperature. From stock in tank save one 10-L sample (SAMPLE POINT 1).

\section{Pressure Screening}

1. Pre-fill flatscreen, equipped with $0.2 \mathrm{~mm}(0.008$ ") slots, and its $600-\mathrm{L}$ stock tank with $46^{\circ} \mathrm{C}$ water. Record volume of water used. Fill pressure screens with water. Begin pumping flatscreen accepts weir water to 1st pressure screen, equipped with $0.30 \mathrm{~mm}(0.012$ ") slots, at $175 \mathrm{~L} / \mathrm{min}$. Adjust the 0.3 $\mathrm{mm}$ screen rejects flow to $45 \mathrm{~L} / \mathbf{m}$ ( $15 \%$ of total feed) with rejects passing back to flatscreen.

2. Begin pumping feedtank slurry to $0.30 \mathrm{~mm}$ pressure screen at $125 \mathrm{~L} / \mathbf{m i n}$ target rate total flow $=300 \mathrm{~L} / \mathrm{min}$ ), with accepts passing at $255 \mathrm{~L} / \mathrm{min}$ to the second pressure screen, equipped with $0.10 \mathrm{~mm}(0.004$ ") slots. Rejects from the $0.1 \mathrm{~mm}$ pressure screen pass back to the feedtank at $52 \mathrm{~L} / \mathbf{m i n}$

3. Pump the initially clear water from the $600-\mathrm{L}$ stock tank to the flatscreen at $130 \mathrm{~L} / \mathrm{min}$. The $0.1 \mathrm{~mm}$ pressure screen accepts go to the $4000 / 8000-\mathrm{L}$ stock tanks. Immediately begin adding sufficient fresh $46^{\circ} \mathrm{C}$ soft water to $600-\mathrm{L}$ stock tank to maintain the $130 \mathrm{~L} / \mathrm{min}$ flow to the flatscreen. Pressure screen target pressures are to be $115 \mathrm{kPa}(17 \mathrm{psi})$ feed/ $110 \mathrm{kPa}(16 \mathrm{psi})$ accepts for the $0.30 \mathrm{~mm}$ slots and $102 \mathrm{kPa}$ (15 psi) feed/ $96 \mathrm{kPa}$ (14 psi) accepts for the $0.10 \mathrm{~mm}$ slots. Actual values are determined by the nature of the stock and are to be logged and reported. Flowrates are to be maintained.

4. When at equilibrium save a 10-L carboy of accept stock from each pressure screen and a 20-L sample from the flatscreen accepts stock for handsheets (SAMPLE POINTS 3, $5 \&$ 7). Measure consistency of all accepts and (SAMPLE POINTS 2 \& 4) streams. Measure flowrates and total flows of all streams. Measure temperature of final accepts.

5. When $0.1 \mathrm{~mm}$ screening accepts reaches 9000 liters, shut off all flows. Record all volumes. Then pass all remaining flatscreen accepts back to feedtank for disposal. Flush flatscreen with fresh water to remove all fiber.

6. When only adhesive and paper tags remain on flatscreen collect rejected adhesive retained by the flatscreen, dry, and weigh for yield (SAMPLE POINT 6). 
7. Dilute (at $46^{\circ} \mathrm{C}$ ) accepts to $0.65 \%$ consistency, intermixing the slurry in the 4000- and 8000-L tanks until of uniform consistency. Save a 10-L carboy of the uniformly blended accepts slurry for handsheets (SAMPLE POINT 8). Measure consistency.

All of the next operations are performed as a continuous operation

III. Forward Cleaning

1. Slowly open feed valve to 1st primary forward cleaner (Beloit Posiflow 60) until accepts flow is $234 \mathrm{~L} / \mathrm{min}$. Feedrate will be between 240 and $260 \mathrm{~L} / \mathrm{min}$. Accepts flow to a $600-\mathrm{L}$ stock tank and then are pumped to the 2nd primary forward cleaner (Celleco Cleanpac 270) at a feedrate that maintains the level in the $600-\mathrm{L}$ tank.

2. Accepts at $212 \mathrm{~L} / \mathrm{min}$ pass to a second $600-\mathrm{L}$ stock tank. Back pressure of Celleco cleaner must be in the range of $54-136 \mathrm{kPa}(8-20 \mathrm{psi})$. When flow is at equilibrium save a 10-L accepts sample from each cleaner accepts tank (SAMPLE POINTS $9 \&$ 11). Rejects from both primary stages $(56 \mathrm{~L} / \mathrm{min})$ are to be combined in a stock tank, diluted with fresh water $(30 \mathrm{~L} / \mathrm{min})$ at $46^{\circ} \mathrm{C}$, pumped through a secondary fiber recovery forward cleaner (Voith KS60P), with the accepts passing back to the primary forward cleaner feed tank and with the rejects $(7-8 \mathrm{~L} / \mathrm{min})$ being collected in 55-gallon drums (SAMPLE POINT 15). Actual feed/accepts pressures to be set to balance flow. Measure consistency of rejects from each cleaner (SAMPLE POINTS $10,12 \& 15)$. Save two 10 -L samples of secondary cleaner feedstock (SAMPLE POINT 13).

Actual diluted consistency of primary rejects (SAMPLE POINT 13) to be such that the secondary accepts are equal to the initial primary feed consistency.

3. Save a 10-L sample of the secondary forward cleaner accepts for handsheets (SAMPLE POINT 14). Measure flow rates on all primary and secondary accepts and reject streams. Measure consistencies on all streams. Measure accepts temperature in both $600-\mathrm{L}$ tanks and that of the secondary cleaner accepts.

4. As the 8000 -L feedtank empties, continuously transfer contents of $4000-\mathrm{L}$ feedtank to the 8000 -L tank.

IV. Thru-flow Cleaning

1. When the $600-\mathrm{L} 2^{\text {nd }}$ forward cleaner accepts tank is $1 / 2$ full of stock begin feeding slurry to the 1 st through-flow cleaner at $212 \mathrm{~L} / \mathrm{min}$, adjusted slightly 
to maintain level in the feed tank. Target feed pressure is to be $210 \mathrm{kPa}$ ( 30 psi) and back pressure is to be $70 \mathrm{kPa}(10 \mathrm{psi})$. Rejects are fed to a drain at approximately $22 \mathrm{~L} / \mathrm{min}$ while measuring the reject flowrate and total reject volume with an accumulator. Save a 4-L reject sample for consistency (SAMPLE POINT 17).

2. Accepts flow to a $1000-\mathrm{L}$ stock tank at approximately $190 \mathrm{~L} / \mathrm{min}$ When this accepts tank is about $1 / 2$ full turn on pump to feed 2 nd through-flow cleaner (same pressures), with accepts from 2nd stage flowing to its stock accepts tank at approximately $165 \mathrm{~L} / \mathrm{min}$ Balance flows to maintain tank levels. At the same time that the 2nd through-flow cleaner pump is started, begin injecting DI-700A flotation aid ( $0.10 \%$ dry fiber basis) to suction port of the transfer pump. Measure reject flow as for $1^{\text {st }}$ stage, saving a 4-L reject sample for consistency (SAMPLE POINT 19).

3. While maintaining a pressure difference of $140 \mathrm{kPa}(20 \mathrm{psi})$ adjust actual pressures to balance flows. When at system equilibrium save a 10-liter sample of each accepts stream (SAMPLE POINTS $16 \&$ 18). Measure accepts stream temperatures and flowrates.

V. Flotation and Washing

1. When slurry begins to enter flotation cell turn on airflow to $10 \mathrm{~L} / \mathrm{min}$. When outer cell is filled to above return stock injection ports turn on main circulation/transfer pump with stock exit valve shut. When outer cell is nearly filled begin the vacuum removal of foam. When outer cell is full open exit valve sending accepts to the glass-lined tank. Adjust the level controller to give the proper level in the tank. Rejects are sampled and their consistency determined (SAMPLE POINT 21). Reject rate is about 5-7 L/min. When glass-lined tank has received about $1 / 2$ of the total slurry save a 10 -L sample of the flotation cell accepts (SAMPLE POINT 20). Determine its consistency.

2. Begin pumping stock from glass-lined tank to drum washer at $115-125 \mathrm{~L} / \mathrm{min}$ as soon as pump is flooded. Dewater stock using vacuum plus pressure roll, shredding the mat and depositing the resulting crumbed pulp in barrels. Calculate total washer wastewater volume from input volume minus barreled pulp volume. Collect a 4-liter washwater samples after about a 20-minute running time; determine consistencies on these samples (SAMPLE POINT 23).

3. When input to the flotation cell from the through-flow cleaner ceases, shut off the outflow from the flotation cell and let the cell operate batch-style for 10 minutes to strip remaining flotables. Then reopen outflow valve and empty cell to glass-lined tank. 
4. Sample final crumb pulp entering barrels by catching a handful of pulp at each $1 / 3$ barrel level and place the three handfuls in a 12 " x 12 " plastic bag (SAMPLE POINT 22). Mix well and determine consistency on the combined sample. Weigh barrels and calculate total oven-dry pulp. Repeat for each barrel.

5. After consistencies are done, combine the pulps in each bag into one batch, mix well and submit for handsheets.

\section{CLEANING}

1. For stock preparation, after each trial the system is to be thoroughly flushed with water, followed if necessary, by a scrubbing with copy paper, envelope paper and/or virgin lap pulp. The system is again flushed with water and a second copy/ envelope paper scrubbing follows, with a pulp sample taken after shredding (SAMPLE POINT 16). If dirt count exceeds the equivalent to a FPL 15 ppm, an additional scrubbing with copy/envelope paper is made. Target level is below 10 ppm FPL.

2. Baskets from the pressure screen are manually cleaned of the adhering adhesive. The baskets are then cleaned with a pressure washer.

3. The plates from the flatscreen are cleaned with the pressure washer but no effort is made to measure the residual traces of adhesive as it represents only a small trace of the total adhesive removed from the screen previously. The entire flatscreen is pressure washed while the plates are out to maximize the cleanliness of the unit. 


\section{Appendix 3: Hydrophobic Contaminant Identification Method}

DRAFT 3 May 2002

\section{Scope}

1.1 This procedure describes a method for quantifying hydrophobic contaminants in pulp samples. A dye that associates with contaminant particles is used to develop contrast from the pulp background. Computer-based color image analysis can then be used to quantify contamination levels by type based upon color and shade.

1.2 This method is a compliment to TAPPI T 213 "dirt in pulp". It allows for the quantification of hydrophobic contaminants that do not have sufficient contrast with pulp to be identified. Hydrophobic contaminants, i.e., waxes, pressure sensitive adhesives, hot melt adhesives, etc., can contribute to "stickie" problems in recycled fiber mills.

\section{Significance}

2.1 When coupled with automated color image analysis contaminant measurement and classification methods, this method provides a more complete quantification of pulp contaminants.

\section{Apparatus}

3.1 Standard handsheet mold as described in TAPPI T 205 sp-95.

3.2 Standard couch roll.

3.3 Standard blotting paper as described in TAPPI T $205 \mathrm{sp}-95$.

3.4 Handsheet dryer with an operating temperature of $150^{\circ} \mathrm{C}$.

3.5 Image analysis system.

3.6 Plastic or metal tray large enough to hold a blotting paper.

3.7 Foam varnish applicator.

3.8 Laboratory timer

3.9 Standard press as described in TAPPI T $205 \mathrm{sp}-95$

\section{Reagent}

4.1 dye solution $0.67 \mathrm{~g}$ of C.I. solvent blue 36 in 1 liter of $n$-heptane. The dye is also known as Morplas Blue 1003 and can be obtained from Pylam Products Company Inc., 2175 East Cedar Street, Tempe, AZ 85281, (602) 929-0070

\section{Procedure}

5.1 Form handsheets according to TAPPI T 205, except end the procedure after couching. After couching the second wet blotting paper is discarded and a third dry one is placed to protect the handsheet attached to the first blotting paper.

5.2 Stack handsheets and blotters, using care to align sheets in a uniform stack. Place the stack in a press and, over a period of 30 seconds, raise the pressure to $345 \mathrm{kPa}(50 \mathrm{psig})$. Maintain this pressure for 5 minutes. 
5.3 Carefully unstack the sheets and place each pair of blotter papers, with a handsheet between them, on the dryer. The intent is to leave the handsheet firmly attached to the couching blotting paper until it is dyed. Dry for 3 minutes at $150^{\circ} \mathrm{C}$ with gentle restraint.

5.4 Dye the handsheet by applying the dye solution to the back side of the blotter that has a handsheet attached. This allows the dye to uniformly penetrate the handsheet. Furthermore, as the dye solution passes through the blotting paper undissolved dye particles are filtered from the solution. Typically, dying is done by placing the blotting paper/handsheet with the handsheet side down on another blotting paper in a tray, and then painting the blotting paper with a foam brush that has been dipped in the dye solution. This step of the procedure should be carried-out in a ventilation hood to avoid exposure to heptane vapors. Since the dye is a mild sensitizer, heptane-tolerant gloves are also required.

5.5 Let the heptane evaporate from the blotting paper/handsheets without separating the handsheet from the blotter paper by hanging them with clips attached to the blotter paper in the ventilation hood. Typical drying times are 2-3 minutes.

5.6 With a gloved hand, gently peel the dyed handsheet from the blotting paper. Place the side that was towards the blotting paper on the glass of the flat bed scanner. Using a weight with a white surface, hold the sheet flat on the scanner.

5.7 Use the color image analysis software to quantify the number of particles on the sheet. To compensate for sheet to sheet variations in dye intensity, best results are obtained by using a threshold that is automatically set $20 \%$ below the mode of the sheet image picture point luminance value frequency distribution. The software system developed by Verity IA LLC was used in this study. The scanner used was an AGFA Argus II.

\section{Report}

6.1 Results are reported as parts per million of the scanned area. Typically an average and $95 \%$ confidence interval for 10-40 standard $1.2 \mathrm{~g}$ handsheets is calculated.

References

[1] TAPPI Test Method T 213 om-97.

[2] R. Trepanier et al. TAPPI Journal Dec 1989 p. 153.

[3] J. Klungness et al. TAPPI Journal Jan 1989 P. 89.

[4] C. Houtman et al. Proceedings of the TAPPI 2000 Recycling Conference, Vol. 2 p.403.

[5] R. Rosenberger Proceedings of the TAPPI 1999 Recycling Conference p. 669.

[6] G.E.P Box et al. "Statistics for Experimenters" John Wiley and Sons, NY, 1978, p. 323. 


\section{Appendix 4: Datasheets and Image Analysis Results}

\section{Consistencies}

Consistencies for various sample points are shown in Table A4-1.

Table A4-1. Consistencies for various sample points for Trials \#349, \#350, \#371 and \#374.

\begin{tabular}{|c|c|c|c|c|}
\hline Sample Point (ID No.) & $\begin{array}{c}\text { Trial \#349 } \\
\text { Consistency } \\
(\%)\end{array}$ & $\begin{array}{c}\text { Trial \#350 } \\
\text { Consistency } \\
(\%)\end{array}$ & $\begin{array}{c}\text { Trial \#371 } \\
\text { Consistency } \\
(\%)\end{array}$ & $\begin{array}{c}\text { Trial \#374 } \\
\text { Consistency } \\
(\%)\end{array}$ \\
\hline Pulper (I) & 12.79 & 12.95 & 12.72 & 12.65 \\
\hline Screening Feed (1) & 2.19 & 2.23 & 2.15 & 2.24 \\
\hline Screen A (0.3 mm) Rejects (2) & 1.32 & 1.31 & 1.29 & 1.31 \\
\hline Screen A (0.3 mm) Accepts (3) & 0.94 & 0.95 & 0.91 & 0.91 \\
\hline Screen B (0.1 mm) Rejects (4) & 1.92 & 1.80 & 1.86 & 1.96 \\
\hline $\begin{array}{c}\text { Screen B (0.1 mm) Accepts (5) } \\
\text { (Feed to Forward Cleaners) }\end{array}$ & 0.73 & 0.71 & 0.69 & 0.70 \\
\hline Flatscreen $(0.2 \mathrm{~mm})$ Accepts $(7)$ & 0.29 & 0.30 & 0.28 & 0.28 \\
\hline First Forward Cleaner Feed (8) & 0.59 & 0.66 & 0.65 & 0.66 \\
\hline First Forward Cleaner Accepts (9) & 0.51 & 0.52 & 0.52 & 0.51 \\
\hline First Forward Cleaner Rejects (10) & 1.78 & 1.87 & 2.28 & 2.16 \\
\hline Second Forward Cleaner Accepts (11) & 0.49 & 0.49 & 0.51 & 0.49 \\
\hline Second Forward Cleaner Rejects (12) & 0.69 & 0.71 & 0.69 & 0.67 \\
\hline Forward Fiber Recovery Cleaner Feed (13) & 0.70 & 0.71 & 0.76 & 0.74 \\
\hline Forward Fiber Recovery Cleaner Accepts (14) & 0.61 & 0.67 & 0.68 & 0.68 \\
\hline Forward Fiber Recovery Cleaner Rejects (15) & 1.19 & 0.32 & 1.19 & 1.18 \\
\hline First Thru-flow Cleaner Accepts (16) & 0.48 & 0.49 & 0.52 & 0.48 \\
\hline First Thru-flow Cleaner Rejects (17) & 0.11 & 0.11 & 0.12 & 0.11 \\
\hline $\begin{array}{c}\text { Flotation Feed (18) } \\
\text { (Second Thru-Flow Cleaner Accepts) }\end{array}$ & 0.51 & 0.53 & 0.53 & 0.51 \\
\hline Second Thru-flow Cleaner Rejects (19) & 0.11 & 0.12 & 0.09 & 0.12 \\
\hline Flotation Accepts (20) & 0.49 & 0.50 & 0.54 & 0.52 \\
\hline Flotation Rejects (21) & 1.23 & 1.09 & 1.03 & 1.42 \\
\hline Final Pulp (22) & 24.18 & 24.91 & 23.84 & 22.35 \\
\hline Drumwasher Effluent (23) & --- & --- & --- & --- \\
\hline
\end{tabular}


APPENDIX 2: Pilot Scale Testing of F-2001 and 2002.

\author{
Forest Products Laboratory \\ Pilot Plant Recycling Trials with \\ Adhesives on Sized, Wet-Strength Face Stock F-2001, F-2002
}

\author{
Prepared by: Karen Scallon \\ Reviewed by: Carl Houtman \\ USDA Forest Service \\ Forest Products Laboratory \\ One Gifford Pinchot Drive \\ Madison, WI 53705
}

In partial fulfillment of Subcontract No. V4046084002

between University of Minnesota

Department of Wood and Paper Science and

USDA Forest Service

Forest Products Laboratory

September 27, 2002 


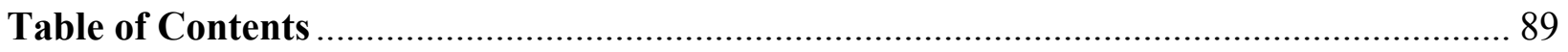

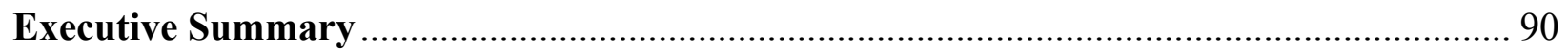

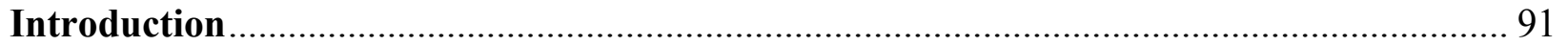

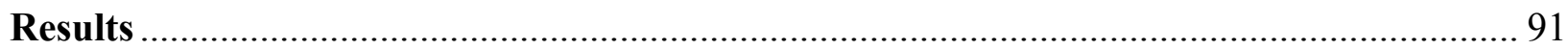

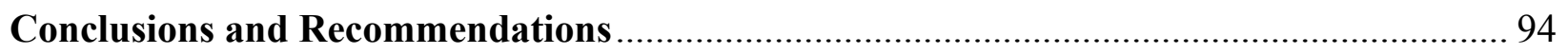

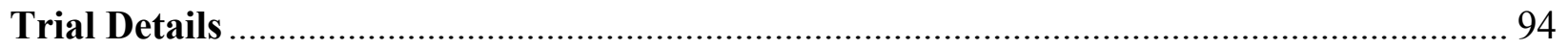

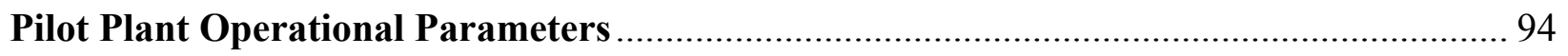

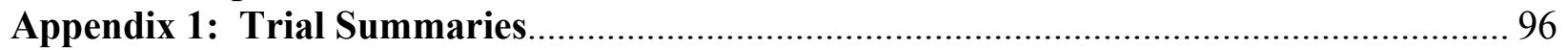

Appendix 2: Phase IV Pilot Plant Recycling Procedure.................................................. 104

Appendix 3: Hydrophobic Contaminant Identification Method...................................... 112

Appendix 4: Datasheets and Image Analysis Results ............................................. 114 
Executive Summary

Two pilot plant recycling trials, \#341 and \#342, using the open-loop configuration were conducted for the University of Minnesota Department of Wood and Paper Science. For Trial \#341, a hot melt adhesive on Boise Cascade facepaper was tested (sample identification number: F-2001). For Trial \#342, the same hot melt adhesive on a wet-strength Western Michigan facepaper was tested (sample identification number: F-2002). Trial results will be used to investigate if combining the adhesive with a wet-strength substrate improves adhesive removal in the system.

The non-wet-strength adhesive material of Trial \#341 was not acceptably removed by screening, cleaning or flotation. The final pulp adhesive content was 1,337 \pm 153 for Trial \#341, indicating an adhesive that is not removable in the recycling system.

The wet-strength adhesive material of Trial \#342 was removed to a marked degree in comparison to Trial \#341 in both the pulper due to the presence of tags that were retained in the pulper and by screening. A comparison of the screening feed adhesive levels for both trials suggests that approximately $85 \%$ of the adhesive remained with the wet-strength substrate in the pulper. In addition, a large quantity of adhesive-coated shredded tags, $3.73 \mathrm{~kg}$, was retained on the $0.2 \mathrm{~mm}$ (8 cut) flat screen in Trial \#342 while virtually no adhesive (only $4.25 \mathrm{~g}$ ) was retained on the flat screen in Trial \#341. The final pulp adhesive content was $121 \pm 10$ for Trial \#342, which is considerably better than in Trial \#341 but still poor compared to the acceptable standard for adhesive recyclability (20 ppm or less in final pulp, USPS specifications). 
Introduction

This report contains information and results obtained for two trials with University of Minnesota Department of Wood and Paper Science hot melt adhesive samples, F-2001, on a non-wet strength facepaper (Trial \#341), and F-2002, on a wet-strength facepaper (Trial \#342). The same hot melt adhesive was used in these trials; the only difference was the facepaper. Trial \#341 was conducted on July 30, 2002 and Trial \#342 was conducted on August 1, 2002. Trial summaries are provided in Appendix 1.

Results

In Trial \#341 the adhesive material pulped with the rest of the paper and no tags were visible after pulping. In Trial \#342 there were many tags pieces visible after pulping, indicating the presence of the wet-strength agent. In both trials, the adhesive particles after pulping were relatively small, less than 0.3 sq. $\mathrm{mm}$ on average. In Trial \#341 the adhesive particles in the pulped sample are free particles. In Trial \#342 the adhesive particles in the pulped sample are a combination of free adhesive as well as adhesive attached to substrate tags, which are present in handsheets for the pulper sample.

Image analysis (IA) results for both trials are shown in Table 1 below. The handsheet adhesive ppm values were subjected to normality plotting analysis; IA data sheets are provided in Appendix 4. This analysis identifies handsheets that appear to be inconsistent with the rest of the handsheets in that group, and also, allows the operator to identify sets of handsheets that displayed inconsistencies in processing. The IA method is presented in Appendix 3.

Table 1: Image analysis results for Trials \#341 and \#342 - adhesive levels and particle sizes.

\begin{tabular}{|l|c|c|c|c|c|c|}
\cline { 2 - 7 } \multicolumn{1}{c|}{} & \multicolumn{3}{c|}{$\begin{array}{c}\text { TRIAL \#341 } \\
\text { (verity software) }\end{array}$} & \multicolumn{2}{c|}{$\begin{array}{c}\text { TRIAL \#342 } \\
\text { (Verity software) }\end{array}$} \\
\cline { 2 - 7 } \multicolumn{1}{c|}{} & \multicolumn{2}{c|}{$\begin{array}{c}\text { Adhesive Level } \\
\text { (ppm) }\end{array}$} & $\begin{array}{c}\text { Particle } \\
\text { Size } \\
\text { (sq. mm) }\end{array}$ & $\begin{array}{c}\text { Adhesive Level } \\
\text { (ppm) }\end{array}$ & $\begin{array}{c}\text { Particle } \\
\text { Size } \\
\text { (sq. mm) }\end{array}$ \\
\hline Sample Point (ID No.) & Average & $95 \%$ CI & Average & Average & $95 \%$ CI & Average \\
\hline Screening Feed (1) & 10,992 & 785 & 0.2901 & 1,662 & 316 & 0.2354 \\
0.3 mm Screen A Accepts (3) & 7,270 & 842 & 0.2284 & 892 & 32 & 0.1277 \\
0.1 mm Screen B Accepts (5) & 483 & 90 & 0.0814 & 228 & 22 & 0.0710 \\
$1^{\text {st }}$ Forward Cleaner Feed (8) & 672 & 106 & 0.0857 & 191 & 23 & 0.0637 \\
$1^{\text {st }}$ Thru-Flow Cleaner Feed (11) & 408 & 29 & 0.0734 & 138 & 14 & 0.0626 \\
Flotation Feed (18) & 460 & 82 & 0.0738 & 217 & 31 & 0.0649 \\
Flotation Accepts (20) & 1,356 & 413 & 0.0968 & 145 & 23 & 0.0647 \\
Final Pulp (22) & 1,337 & 153 & 0.0978 & 121 & 10 & 0.0664 \\
\hline
\end{tabular}

Based on the IA results, neither adhesive was acceptably removed by screening, cleaning or flotation. Figure 1 shows the $0.3 \mathrm{~mm}$ (12 cut) screening efficiency versus pulper particle size for the F-2001 and F-2002 adhesives and other adhesives tested in Phase IV of the USPS project for comparison. F-2001 and F-2002 adhesives are at the lower range of the data set in terms of 0.3. mm screening efficiency at $33.9 \%$ and $46.3 \%$ respectively, which correlates with their smaller pulper particle sizes at 0.2901 and 0.2354 sq. mm, respectively. Similarity in the pulper particle sizes between the two trials suggests that the mechanism of particle formation is not different. 


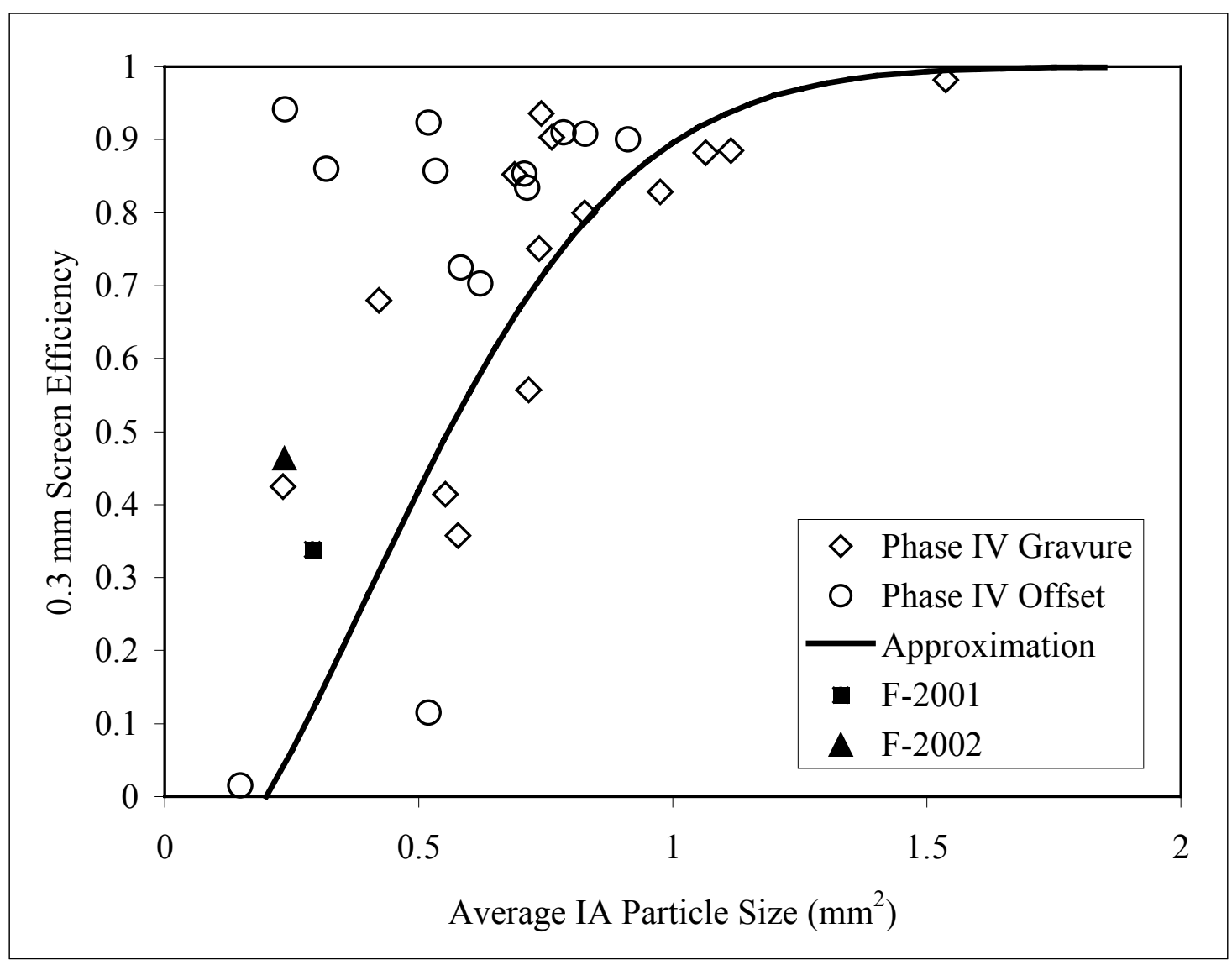

Figure 1. Plot of average adhesive particle size from image analysis versus

$0.3 \mathrm{~mm}$ screen efficiency for adhesives in the Phase IV database and for adhesives F-2001 and F-2002.

The wet strength agent in sample F-2002 did facilitate the retention of adhesive in the pulper. Assuming the F-2002 adhesive loading in Trial \#342 was identical to that of F-2001 in Trial \#341, which is 10,992 ppm in Table 1, and using the screening feed average adhesive level of $1,662 \mathrm{ppm}$ (post-pulper) for F-2002 in Table 1, then by calculation approximately $85 \%$ of the adhesive of the adhesive was retained in the pulper on the shredded paper strips.

There are factors to note that may have influenced the IA results. One factor is the appearance of adhesive particles in the dyed handsheets was different from emulsion polymerized acrylic and rubber adhesives. The dyed areas appeared splotchy as if the material had spread out in the sheet like a drop of oil. It is possible that the heat drying of the sheets caused this hot melt adhesive material to melt and spread out in the sheet, which could potentially result in detection of larger particles. Another factor to note is that adhesive residue adhered to the walls of the dolar tank, which could lead to lower-than-actual handsheet adhesive levels. This may be responsible for the skewed results for Trial \#341, i.e., the flotation accepts having a higher adhesive content than the flotation feed. 
Another potential reason for this anomaly for Trial \#341 is that the flotation surfactant (DI-700) may have agglomerated the smaller adhesive particles, which individually would not have been large enough to be detected by IA, to form a larger particle that would be detected by IA. This is supported by the increase in particle size observed for the flotation accepts compared to the flotation feed for Trial \#341. This occurrence was not observed for the wet-strength sample in Trial \#342 suggesting that the presence of a wet-strength agent prevented the agglomeration.

The weight of the reject material collected by the $0.2 \mathrm{~mm}$ ( 8 cut) flat screen was virtually nonexistent for Trial \#341, only $4.25 \mathrm{~g}$, compared to the $3.73 \mathrm{~kg}$ collected for Trial \#342. Note that the material collected for Trial \#342 consisted of the 1/4"-wide paper shreds, to which the adhesive was coated. For comparison to other open-loop recycling trials, the average for $0.2 \mathrm{~mm}$ flat screen rejects for Phase IV of the USPS project is $520 \mathrm{~g}$ (for post-consumer trials), which typically represents free adhesive. That collected in Trial \#342 is a combination of adhesive, wet-strength agent and face paper. 
Conclusions and Recommendations

Neither of adhesive samples F-2001 (Trial \#341) or F-2002 (Trial \#342) was acceptably removed by pilot plant recycling operations. Neither adhesive met USPS specifications for pulper particle size (greater than 0.32 sq. mm) or final pulp adhesive content ( $20 \mathrm{ppm}$ or less). The wet strength agent in sample F-2002 did facilitate the retention of adhesive in the pulper with results suggesting that up to $85 \%$ of the adhesive in Trial \#342 was retained in the pulper on the shredded paper strips.

Trial Details

The trials were conducted at the USDA Forest Service, Forest Products Laboratory (FPL) Recycling Pilot Plant in Madison, Wisconsin USA. The open-loop recycling procedure is presented in Appendix 2.

For each trial, an adhesive sample equivalent to $1 \%$ by weight was adhered to virgin envelope paper and allowed a 72-hour cure time. Prior to pulping the adhered material was shredded to 1/4"-wide strips, 10 to 20 inches long.

For each trial, a total of $112.5 \mathrm{~kg}$ OD unprinted stock materials was added to the high consistency pulper. The pulper mass percentages and loadings of all stock materials used for the trials are identified in Table 2.

Table 2: Pulper mass loadings of stock materials for recycling trials.

\begin{tabular}{|c|c|c|}
\hline \multicolumn{3}{|c|}{ TRIALS \#341 AND \#342 } \\
\hline $\begin{array}{l}47.5 \% \text { copy paper } \\
53.44 \mathrm{~kg} \text { OD } \\
56.85 \mathrm{~kg} \text { weighed out }\end{array}$ & $\begin{array}{l}47.5 \% \text { envelope paper } \\
53.44 \mathrm{~kg} \text { OD } \\
56.85 \text { weighed out }\end{array}$ & $\begin{array}{l}5 \% \text { facestock }(\sim 1 \% \text { adhesive } \\
\text { content by weight }) \\
5.625 \text { weighed out }\end{array}$ \\
\hline
\end{tabular}

The stock materials were pulped at approximately $12.5 \% \mathrm{csc}$ in alkaline conditions for 20 minutes in $46 \pm 2{ }^{\circ} \mathrm{C}$ soft water. Following pulping, the pulper contents were transferred to the dumpchest and diluted to approximately $2.2 \% \csc$ with $46 \pm 2{ }^{\circ} \mathrm{C}$ soft water. The dumpchest contents, after inline dilution to approximately $1 \% \mathrm{csc}$, were delivered to a screening stage consisting of a $0.3 \mathrm{~mm}$ (12 cut) pressure screen, $0.2 \mathrm{~mm}$ ( 8 cut) flat screen, and a $0.1 \mathrm{~mm}$ (4 cut) pressure screen. The screening accepts were collected in a tank and diluted with $46 \pm 2{ }^{\circ} \mathrm{C}$ soft water to an approximate consistency of $0.65 \%$. The screening accepts were then sent through cleaning, flotation and drum washing/dewatering stages.

Pilot Plant Operational Parameters

Table 3 shows the important pilot plant operational parameters for Trials \#341 and \#342. Also shown, for reference only and not direct comparison to Trials \#341 and \#342, are averages and standard deviations of these parameters for 45 other post-consumer trials in the Phase IV database.

Table 3: Operational parameters for Trials \#341 and \#342. 


\begin{tabular}{|l|c|c|c|c|c|}
\cline { 2 - 6 } \multicolumn{1}{c|}{} & Trial & Trial & \multicolumn{2}{c|}{ Phase IV } & \\
\hline Parameter & $\# 341$ & $\# 342$ & \multicolumn{2}{c|}{ Database } & \\
\hline Temperature after Pulping & Value & Value & Ave & StDev & Unit \\
Consistency in Pulper & 48.0 & 48.4 & 46.6 & 1.3 & ${ }^{\circ} \mathrm{C}$ \\
pH after Pulping & 13.08 & 13.02 & 12.4 & 0.2 & $\%$ \\
Pulper Energy & 9.3 & 9.8 & 9.8 & 0.2 & $\mathrm{pH}$ \\
\hline $0.3 \mathrm{~mm}$ Screen Feed Consistency & 53.1 & 62.5 & 56.3 & 2.4 & $\mathrm{~kW} \mathrm{hr} / \mathrm{MT}$ \\
$0.3 \mathrm{~mm}$ Screen Reject Rate & 1.05 & 1.12 & 1.15 & 0.04 & $\%$ \\
$0.3 \mathrm{~mm}$ Screen Passing Speed & 0.40 & 0.43 & 0.42 & 0.003 & $\mathrm{~m} / \mathrm{s}$ \\
$0.1 \mathrm{~mm}$ Screen Feed Consistency & 0.95 & 0.92 & 1.03 & 0.07 & $\%$ \\
$0.1 \mathrm{~mm}$ Screen Reject Rate & 18.1 & 23.5 & 21 & 1 & $\%$ \\
$0.1 \mathrm{~mm}$ Screen Passing Speed & 0.35 & 0.35 & 0.35 & 0.003 & $\mathrm{~m} / \mathrm{s}$ \\
\hline Forward Cleaner Feed Consistency & 0.63 & 0.65 & 0.64 & 0.04 & $\%$ \\
Forward Cleaner Reject Rate & 10.5 & 10.7 & 10.3 & 0.7 & $\%$ \\
\hline Thru-flow Cleaner Feed & 0.67 & 0.70 & 0.50 & 0.03 & $\%$ \\
Consistency & & & & & \\
Thru-flow Cleaner Reject Rate & 9.0 & 10.1 & 11.6 & 3.4 & $\%$ \\
\hline Flotation Feed Consistency & 0.53 & 0.54 & 0.61 & 0.03 & $\%$ \\
Flotation Residence Time & 10.9 & 11.1 & 11.7 & 0.2 & $\mathrm{~min}$. \\
Flotation Reject Rate & 0.018 & 2.2 & 2.0 & 1.0 & $\%$ \\
\hline Total Yield & 52.6 & 53.8 & 56 & 4 & $\%$ \\
\hline
\end{tabular}

One main goal in conducting Trials \#341 and \#342 was to maintain the operating conditions as consistent as possible between the two trials. From a comparison of values in Table 3, it can be concluded that most of the respective operating parameters for Trials \#341 and \#342 were relatively close to each other. Values of potential concern are the $\mathrm{pH}$ after pulping and $0.3 \mathrm{~mm}$ screen feed consistency for Trial \#341, but the difference of these values from Trial \#342 are not likely great enough to impact trial results. The notably different result for pulper energy between the two trials can be attributed to the presence of wet-strength material in Trial \#342, which required more energy to pulp the materials. 


\section{Appendix 1: Trial Summaries}

\section{Trial \#341 Summary}

Date: July 30, 2002

Purpose: Phase IV configuration testing of Univ. of MN sample F-2001 (Boise Cascade facepaper w/ hot-melt adhesive). Trial results to be compared with Trial \#342.

Materials: Required Mass Loadings: $47.5 \%$ copy paper, $47.5 \%$ envelope paper, 5\% facepaper with adhesive material ( $\sim 1 \%$ adhesive).

Used $56.85 \mathrm{~kg}(53.44 \mathrm{~kg}$ OD) copy paper, $56.85 \mathrm{~kg}(53.44 \mathrm{~kg}$ OD) envelope paper, and $5.625 \mathrm{~kg}$ F-2001 material (weight of facestock only). Total weight of all materials $=119.3 \mathrm{~kg}(112.5 \mathrm{~kg}$ OD). Adhesive material was adhered on July 25, 2002 and shredded into 1/4" strips 10 inches to 16 inches long on July 29, 2002.

\section{Notes:}

- Started pulping at about $\sim 7$ am. Feed to pressure screen started at 8:04 am. End screening 8:50 am. Cleaning stage began at 9:50 am. Overall, the trial ran smoothly.

- $\quad$ Pulping: Dumped some water before pulping due to high temp $\left(52^{\circ} \mathrm{C}\right)$. Temperature after pulping $=48.0^{\circ} \mathrm{C}$. The F-2001 test material pulped, no tags were visible. Pulper consistency $=13.08 \%$ average. Pulper particle size $=0.2901$ sq. $\mathrm{mm}$.

- Screening: Screen A (12 cut), flat screen (8 cut) and Screen B (4 cut) were used. Nothing out the ordinary to report except feed meter to 12 cut screen stopped reading at one point in the trial; flow continued during this outage.

Flat Screen: Adhesive is very small, not all that visible in the flat screen. Occasionally there are very thin, fine worms of adhesive that can be seen in hand samples. The accepts likely contain high adhesive level. At the end of screening a very small amount of adhesive was retained on the flat screen ("chewing gum" size, $4.25 \mathrm{~g}$ ). The postscreening blend tanks are foamy on top, can feel adhesive in foam.

- Cleaning: Nothing out the ordinary to report. Grant reported a lot of very tiny to small bits of adhesive in the $1^{\text {st }}$ and $2^{\text {nd }}$ primary forward cleaner accepts (foam is light bluish gray) and some tiny bits of adhesive in the rejects, but no visible ink/dirt. Same for the $1^{\text {st }}$ through-flow cleaner.

- Flotation: 63 grams of DI-700 surfactant were dissolved in $60 \mathrm{~L}$ of water. The overall average pump rate from start to finish was $0.96 \mathrm{Lpm}(45 \mathrm{~L} / 46$ minutes 56 seconds; target pump rate $=1 \mathrm{Lpm})$. 
There seemed to be a thicker foam layer than in benchmark (STR 34355) trials and a higher rejects rate $(>15 \mathrm{Lpm})$ for a portion of the trial. (The target Lamort rejects rate is 6-8 Lpm. The average rejects rate in the trial was $11.3 \mathrm{Lpm}$.) In order to compensate for this, the airflow rate was dropped from $11 \mathrm{scfm}$ to $9 \mathrm{scfm}$ and the level indicator was reduced so as to lower the level in Lamort. The vacuum shoes were also raised. Dropping the level is not a favorable approach as there must be a minimum level (volume) maintained in the tank, and thus, a minimum residence time.

- Drumwasher: Nothing out of the ordinary to report. Ran well. Final pulp averaged $25.3 \%$ csc.

- Data Acquisition: Nothing out of the ordinary to report.

- Sample Analysis: Handsheet ppm levels are reported using 15\% contrast in scanning software. Normally $20 \%$ contrast is used, but Freya thought this did not provide enough dye resolution. From alternate method (Verity) image analysis results, the 12 cut $(0.3$ $\mathrm{mm})$ screening efficiency was $41.9 \%$ and the overall screening efficiency $(4$ cut $(0.1 \mathrm{~mm})$ screen accepts) was 95.6\%. Final pulp adhesive content was $1,337 \pm 153 \mathrm{ppm}$ (average of values from two bags).

- Cleaning Run: $5 \pm 7 \mathrm{w} / 20 \%$ contrast, $14 \pm 12 \mathrm{w} / 15 \%$ contrast; acceptable.

COMPARISON OF TRIALS \#341 AND \#342:

Table 1 below presents a summary comparison of results for these trials. Note that the ppm data reported below were subjected to normality plotting analysis.

\begin{tabular}{|c|c|c|}
\hline & \multicolumn{2}{|c|}{ Trial No. } \\
(PSA Material Description)
\end{tabular}


Two pilot plant recycling trials, \#341 and \#342, using the open-loop configuration were conducted for the University of Minnesota Department of Wood and Paper Science. For Trial \#341, a hot melt adhesive on Boise Cascade facepaper was tested. For Trial \#342, the same hot melt adhesive on a wet-strength Western Michigan facepaper was tested. Trial results will be used to investigate if combining the adhesive with a wet-strength substrate improves adhesive removal in the system.

In each trial, an adhesive sample equivalent to $1 \%$ by weight was adhered to virgin envelope paper and allowed a 72-hour cure time. Before each trial the adhered material was shredded to $1 / 4$ " wide strips, 10 " to 20 " long. In Trial \#341 the adhesive material pulped with the rest of the paper and no tags were visible after pulping. In Trial \#342 there were many tags pieces visible after pulping, indicating the presence of the wet-strength agent. In both trials, the adhesive particles after pulping were relatively small, less than $0.3 \mathrm{sq}$. $\mathrm{mm}$ on average. In Trial \#341 the adhesive particles in the pulped sample are free particles. In Trial \#342 the adhesive particles in the pulped sample are a combination of free adhesive as well as adhesive attached to substrate tags, which are present in handsheets for the pulper sample.

The non-wet-strength adhesive material of Trial \#341 was not removable by screening, cleaning or flotation. The final pulp adhesive content was $1,337 \pm 153$ for Trial \#341, indicating an adhesive that is not removable in the recycling system.

The wet-strength adhesive material of Trial \#342 was removed to a marked degree in comparison to Trial \#341 in both the pulper due to the presence of tags that were retained in the pulper and by screening. A comparison of the screening feed adhesive levels for both trials suggests that approximately $85 \%$ of the adhesive remained with the wet-strength substrate in the pulper (comparing ppm data subjected to normality plotting analysis). In addition, a large quantity of adhesive-coated shredded tags, $3.73 \mathrm{~kg}$, was retained on the $0.2 \mathrm{~mm}$ ( $8 \mathrm{cut}$ ) flat screen in Trial \#342 while virtually no adhesive (only $4.25 \mathrm{~g}$ ) was retained on the flat screen in Trial \#341. The final pulp adhesive content was $121 \pm 10$ for Trial \#342, which is considerably better than in Trial \#341 but still poor compared to the acceptable standard for adhesive recyclability ( $20 \mathrm{ppm}$ or less in final pulp, USPS specifications).

There are factors to note that may have influenced the IA results. One factor is the appearance of adhesive particles in the dyed handsheets was different from emulsion polymerized acrylic and rubber adhesives. The dyed areas appeared splotchy as if the material had spread out in the sheet like a drop of oil. It is possible that the heat drying of the sheets caused this hot melt adhesive material to melt and spread out in the sheet, which could potentially result in detection of larger particles. Another factor to note is that adhesive residue adhered to the walls of the dolar tank, which could lead to lower-than-actual handsheet adhesive levels. This may be responsible for the skewed results for Trial \#341, i.e., the flotation accepts having a higher adhesive content than the flotation feed.

Another potential reason for this anomaly for Trial \#341 is that the flotation surfactant (DI-700) may have agglomerated the smaller adhesive particles, which individually would not have been large enough to be detected by IA, to form a larger particle that would be detected by IA. This is supported by the increase in particle size observed for the flotation accepts compared to the 
flotation feed for Trial \#341. This occurrence was not observed for the wet-strength sample in Trial \#342 suggesting that the presence of a wet-strength agent prevented the agglomeration. 


\section{Trial \#342 Summary}

Date: August 1, 2002

Purpose: Phase IV configuration testing of Univ. of MN sample F-2002 (Western Michigan wet strength facepaper w/ hot-melt adhesive). Trial results to be compared with Trial \#341.

Materials: Required Mass Loadings: $47.5 \%$ copy paper, $47.5 \%$ envelope paper, $5 \%$ facepaper with adhesive material ( $\sim 1 \%$ adhesive).

Used $56.85 \mathrm{~kg}$ (53.44 kg OD) copy paper, $56.85 \mathrm{~kg}(53.44 \mathrm{~kg}$ OD) envelope paper, and $5.625 \mathrm{~kg}$ F-2002 material (weight of facestock only). Total weight of all materials $=119.3 \mathrm{~kg}(112.5 \mathrm{~kg}$ OD). Adhesive material was adhered on July 25, 2002 and shredded into 1/4" strips 10 inches to 16 inches long on July 29, 2002.

\section{Notes:}

- Three representatives from the Univ. of MN, including Prof. Steve Severtson, were present for the trial. Started pulping at about $\sim 7: 15 \mathrm{am}$. Feed to pressure screen started at 8:30 am. End screening $\sim 9: 20$ am. Cleaning stage began at 10:15 am. There were a few operational issues that had to be dealt with during the trial, 1) transferring pulper contents to feed tank was slow due to shredded strips clogging the pulper plate; 2) secondary forward cleaner feed pump suction line was clogged initially and thus start of this pump was delayed; 3) Lamort reject rate varied a lot during the trial, starting out with a high reject rate $(25 \mathrm{Lpm}$ at first and then $15-18 \mathrm{Lpm})$ and becoming very low $(<1 \mathrm{Lpm})$ near the end of the trial. See Flotation notes below.

- Pulping: Dumped some water before pulping due to high temp $\left(56^{\circ} \mathrm{C}\right)$. Temperature after pulping $=48.4^{\circ} \mathrm{C}$. The F-2002 material did not pulp; the paper strips were torn into shorter strips, the longest 4-5", after the 20-minute pulping period. The transfer of pulp to the feedchest took an extra long time because the drain plate at the bottom of the pulper was plugged with the shredded material. The line had to be periodically backflushed with feedchest contents to get pulper contents to flow from pulper. Pulper consistency $=13.02 \%$ average. Pulper particle size $=0.2354$ sq. $\mathrm{mm}$.

- Screening: Screen A (12 cut), flat screen (8 cut) and Screen B (4 cut) were used. Despite concern that the 12 cut screen would plug with shreds of material, it did not. The shredded material was retained by the flat screen.

Flat Screen: A large quantity of shredded strips (3.734 kg OD) was retained on the flat screen. This material was scooped up in a screen, drained as best as possible and placed in a 5-gallon container to avoid clogging the flat screen. There was a lot of pulp collected along with the shreds, most of which was washed away after screening was complete. The flat screen accepts showed no signs of shreds.

- Cleaning: Nothing out the ordinary to report. 
- Flotation: 63 grams of DI-700 surfactant were dissolved in $60 \mathrm{~L}$ of water. The overall average surfactant pump rate from start to finish was not closely monitored during the trial (not enough eyes to watch it). At the end of cleaning (and thus, feed to the Lamort) there was $\sim 24 \mathrm{~L}$ of surfactant left over. In 47-50 minutes, $\sim 36 \mathrm{~L}$ of surfactant was consumed. This delivery rate is considerably less than the target pump rate of $1 \mathrm{Lpm}$. This may be due to the $2^{\text {nd }}$ through-flow cleaner feed tank having a higher level during the trial (and thus, higher pump head). The $2^{\text {nd }}$ through-flow cleaner feed pump was started later than usual due to the distraction over the secondary forward cleaner feed pump suction line being plugged.

Lamort rejects rate was relatively high and difficult to control in the trial possibly due to the excessive foam. In order to compensate for this, the airflow rate was dropped from $11 \mathrm{scfm}$ to $9 \mathrm{scfm}$ (as in Trial \#341), but the level indicator was kept just above 60. It was noted near the end of the trial the rejects rate was very low $(<1 \mathrm{Lpm})$. There may have been a plug in the rejects line or the tank level was too low/the vacuum shoes were too high. It is likely that this low rejects rate at the end of the trial allowed the trial average to be at a reasonable value $(8.8 \mathrm{Lpm})$. The DAQ graph provides a better picture of the variability observed in the trial.

- Drumwasher: Nothing out of the ordinary to report. Ran well. Final pulp averaged 24.9\% csc. Freya missed the drumwasher washwater sample (\#23) due to making observation handsheets for the trial cooperators.

- Data Acquisition: Nothing out of the ordinary to report.

- Sample Analysis: Handsheet ppm levels are reported using 15\% contrast in scanning software (the same as for Trial \#341). From alternate method (Verity) image analysis results, the 12 cut $(0.3 \mathrm{~mm})$ screening efficiency was $66.9 \%$ and the overall screening efficiency (4 cut $(0.1 \mathrm{~mm})$ screen accepts) was $91.6 \%$. Final pulp adhesive content was $121 \pm 10 \mathrm{ppm}$ (average of values from two bags).

- Cleaning Run: The first cleaning run was $27 \pm 25 \mathrm{w} / 15 \%$ contrast; unacceptable. The second cleaning run was $11 \pm 7 \mathrm{w} / 15 \%$ contrast; acceptable. 
COMPARISON OF TRIALS \#341 AND \#342:

Table 1 below presents a summary comparison of results for these trials.

\begin{tabular}{|c|c|c|}
\hline & \multicolumn{2}{|c|}{$\begin{array}{c}\text { Trial No. } \\
\text { (PSA Material Description) }\end{array}$} \\
\hline $\begin{array}{c}\text { Screening Feed Average } \\
\text { Adhesive Level (i.e., after } \\
\text { pulping) } \\
\text { (ppm) }\end{array}$ & $\begin{array}{c}341 \\
\text { (hot-melt) }\end{array}$ & $\begin{array}{c}342 \\
\text { (wet strength, hot-melt) }\end{array}$ \\
\hline $\begin{array}{c}\text { Screening Feed Particle } \\
\text { Size (sq.mm) }\end{array}$ & $10,992 \pm 785$ & $1,662 \pm 316$ \\
\hline $\begin{array}{c}\text { 12 cut (0.3 mm) Screening } \\
\text { Efficiency }\end{array}$ & $33.9 \%$ & 0.2354 \\
\hline $\begin{array}{c}\text { Overall Screening } \\
\text { Efficiency }\end{array}$ & $95.6 \%$ & $86.3 \%$ \\
\hline $\begin{array}{c}\text { Final Pulp Average Adhesive } \\
\text { Level } \begin{array}{c}\text { (ppm) } \\
\text { (ppong }\end{array}\end{array}$ & $1,337 \pm 153$ & $121 \pm 10$ \\
\hline
\end{tabular}

Two pilot plant recycling trials, \#341 and \#342, using the open-loop configuration were conducted for the University of Minnesota Department of Wood and Paper Science. For Trial \#341, a hot melt adhesive on Boise Cascade facepaper was tested. For Trial \#342, the same hot melt adhesive on a wet-strength Western Michigan facepaper was tested. Trial results will be used to investigate if combining the adhesive with a wet-strength substrate improves adhesive removal in the system.

In each trial, an adhesive sample equivalent to $1 \%$ by weight was adhered to virgin envelope paper and allowed a 72-hour cure time. Before each trial the adhered material was shredded to $1 / 4$ " wide strips, 10 " to 20 " long. In Trial \#341 the adhesive material pulped with the rest of the paper and no tags were visible after pulping. In Trial \#342 there were many tags pieces visible after pulping, indicating the presence of the wet-strength agent. In both trials, the adhesive particles after pulping were relatively small, less than $0.3 \mathrm{sq} . \mathrm{mm}$ on average. In Trial \#341 the adhesive particles in the pulped sample are free particles. In Trial \#342 the adhesive particles in the pulped sample are a combination of free adhesive as well as adhesive attached to substrate tags, which are present in handsheets for the pulper sample.

The non-wet-strength adhesive material of Trial \#341 was not removable by screening, cleaning or flotation. The final pulp adhesive content was $1,337 \pm 153$ for Trial \#341, indicating an adhesive that is not removable in the recycling system.

The wet-strength adhesive material of Trial \#342 was removed to a marked degree in comparison to Trial \#341 in both the pulper due to the presence of tags that were retained in the pulper and by screening. A comparison of the screening feed adhesive levels for both trials suggests that 
approximately $85 \%$ of the adhesive remained with the wet-strength substrate in the pulper (comparing ppm data subjected to normality plotting analysis). In addition, a large quantity of adhesive-coated shredded tags, $3.73 \mathrm{~kg}$, was retained on the $0.2 \mathrm{~mm}$ ( $8 \mathrm{cut}$ ) flat screen in Trial \#342 while virtually no adhesive (only $4.25 \mathrm{~g}$ ) was retained on the flat screen in Trial \#341. The final pulp adhesive content was $121 \pm 10$ for Trial \#342, which is considerably better than in Trial \#341 but still poor compared to the acceptable standard for adhesive recyclability (20 ppm or less in final pulp, USPS specifications).

There are factors to note that may have influenced the IA results. One factor is the appearance of adhesive particles in the dyed handsheets was different from emulsion polymerized acrylic and rubber adhesives. The dyed areas appeared splotchy as if the material had spread out in the sheet like a drop of oil. It is possible that the heat drying of the sheets caused this hot melt adhesive material to melt and spread out in the sheet, which could potentially result in detection of larger particles. Another factor to note is that adhesive residue adhered to the walls of the dolar tank, which could lead to lower-than-actual handsheet adhesive levels. This may be responsible for the skewed results for Trial \#341, i.e., the flotation accepts having a higher adhesive content than the flotation feed.

Another potential reason for this anomaly for Trial \#341 is that the flotation surfactant (DI-700) may have agglomerated the smaller adhesive particles, which individually would not have been large enough to be detected by IA, to form a larger particle that would be detected by IA. This is supported by the increase in particle size observed for the flotation accepts compared to the flotation feed for Trial \#341. This occurrence was not observed for the wet-strength sample in Trial \#342 suggesting that the presence of a wet-strength agent prevented the agglomeration. 


\section{Appendix 2: Phase IV Pilot Plant Recycling Procedure}

These procedures are developed for evaluating the recyclability of environmentally benign postage stamp materials using those conventional unit operations located in the USDA Forest Products Laboratory pilot laboratory paper recycling facility. The process involves high consistency repulping, slot screening, centricleaning with both forward and thru-flow cleaners, flotation, washing, and papermaking using a pilot laboratory machine. Screening and forward cleaning include secondary fiber recovery.

\section{A. Equipment \& Materials}

I. Equipment

1. VOITH high consistency pulper model HC-1.5, $2500 \mathrm{~L}$ total volume, $1500 \mathrm{~L}$ maximum working volume, equipped with OHIO SEMITRONICS model CTX-500S current transducers feeding an OHIO SEMITRONICS model WH3-11195 AC watt-hr meter.

2. VOITH MULTIFRACTOR pressure screen model 00 equipped with a 0.30 $\mathrm{mm}(0.012$ ") slotted basket (1st primary stage). Voith VPS-05 pressure screen equipped with a $0.10 \mathrm{~mm}(0.004$ ") C-bar slotted basket (2nd primary stage).

3. AMINCO 6-plate vat flatscreen w/ $0.2 \mathrm{~mm}(0.008$ ") slotted plates 600 -liter tank plus transfer pump (fiber recovery and adhesive collection stage).

4. Beloit POSIFLOW 60 forward centricleaner (1st primary stage); Celleco CLEANPAC 270 forward centricleaner (2nd primary stage); Voith KSP 60 forward centricleaner with primary reject collection tank and stock pump (secondary fiber recovery stage).

5. Black-Clawson X-clone thru-flow centricleaner, $100 \mathrm{~mm}$ (4") nominal diameter; two primary cleaners in series.

6. LaMort 5000-L, 2-stage laboratory flotation cell.

7. Scales and 200-Liter drums to collect secondary forward cleaner rejects and flotation cell rejects.

8. Stock tanks and pumps, sufficient to store and transfer stock being processed.

9. Foxboro 8000A Magnetic flow tubes and IMT25 Magnetic flow transmitters installed throughout the system. These are the primary units for rate and volume measurements.

10. NALGENE, HDPE containers, or equivalent: 1-L, 4-L, 10-L, and 20-L capacities in sufficient numbers for sample collection. 
11. Self-sealing plastic bags, for sample collection: 4-L plus others as needed.

12. Assorted plastic bags ( $30 \times 60 \mathrm{~cm}, 45 \times 90 \mathrm{~cm}$ minimum sizes) for sample storage. Scales, $150-\mathrm{kg}$ minimum capacity, minimum resolution $0.1 \mathrm{~kg}$. Thermometers, utility knives, glassware, $\mathrm{pH}$ meter, etc. as required.

13. Screen carts, 1 x 1 x 1.5 meter, with 100 - mesh bottom wire (6 needed).

14. Balance, $1-\mathrm{kg}$ capacity, minimum accuracy $0.1 \mathrm{gm}$.

15. Vacuum drum washer, laboratory unit with 100-mesh wire; equipped with press roll and shredder.

16. Barrels, 200-Liter (or equivalent) for storage of cleaned pulp.

17. TAPPI handsheet former and auxiliary equipment

II. Materials

Definitions

Standard (Linered) Pressure Sensitive Adhesive (PSA) Stamp Laminate:

Face Paper/PSA/Release Liner, with or without printing.

Face paper: base paper sheet only, as used to prepare the Standard (Linered) Pressure Sensitive Adhesive Stamp Stock described above.

Linerless Pressure Sensitive Adhesive (PSA) Stamp Stock: Release coating/Printing/Face Paper/PSA.

Papers

Copy paper: single supply for all work; procured by USPS/FPL as a $31,000 \mathrm{lb}$. shipment derived from 2 consecutive master rolls from a commercial paper machine, slit into 24 " wide working rolls of approximately $1100 \mathrm{lb}$. each.

Envelope paper: single supply for all work; procured by USPS/FPL as a $180,000 \mathrm{lb}$. shipment derived from consecutive master rolls from a commercial paper machine, slit into 24" wide working rolls of approximately $1100 \mathrm{lbs}$. each.

Stamp stock face papers: $45 \mathrm{~kg}$. (approximate) supplied by USPS with tie layer, with no printing or adhesive. 3 rolls of paper, one roll from each of three suppliers. 
Linerless (PSA) stamp stock: $50 \mathrm{~kg}$. supplied by USPS. Same stock sample used for Phase 3 study.

Standard PSA stamp laminate: $150 \mathrm{~kg}$. supplied in 3 rolls: conventional construction currently used for stamps (same supply used for phase 3 study)

Experimental PSA stamp laminate, as submitted to FPL through USPS/STR: $20 \mathrm{~kg}$ each adhesive on each face paper (3 preconsumer samples per adhesive) (60 kg total), procured as defect-free production scrap from the stamp preparation process.

Gummed WAG (water-activated glue) stamp stock; 3 rolls each printed by a different printing method: intaglio, offset \& rotogravure.

PSA linerless label stock (color: "canary"), 80\# roll. Current type used by USPS for change-of-address labels

USPS self-sticking PSA Label 11-F (July 1997): EXPRESS MAIL address label. 4000 labels (32 kg.).

III. Other materials

1. Morplas Blue 1003, $0.67 \mathrm{gm} / \mathrm{L}$ in heptane.

2. $\mathrm{pH}$ standards: $4.0,7.0,10.0$

3. Blotters, $20 \mathrm{~cm}$ square, meeting TAPPI specifications.

4. a) Whatman \#4 filter paper or equivalent, $15 \mathrm{~cm}$ diameter.

b) Same, $32 \mathrm{~cm}$ diameter.

5. $10-15 \% \mathrm{NaOH}$ solution.

6. $10-15 \% \mathrm{H}_{2} \mathrm{SO}_{4}$ solution.

7. Flotation aid: HighPoint DI-700A.

8. Soft water: 20 and $80^{\circ} \mathrm{C}$, central supply.

B. Stock Preparation (for each trial)

Throughout the following unit operations flowrates, consistencies, volumes, etc. will be determined in order to establish a mass balance for the processing. Necessary data will be recorded as appropriate.

I. Pulping 
1. Weigh out $112.5 \mathrm{~kg}$, oven-dry basis, of fiber-based material. Measure and record solids content of paper(s).

A. A typical phase 4 pre-consumer loading will be $50.625 \mathrm{~kg}$ copy paper (45\% of total), $50.625 \mathrm{~kg}$ envelope paper ( $45 \%$ of total) and $11.25 \mathrm{~kg}$ total composite stamp stock ( $10 \%$ of total).

B. A typical phase 4 post-consumer loading will be $112.5 \mathrm{~kg}$ of cancelled envelopes each containing one sheet of copy paper.

C. For a post-consumer, non-envelope, trial (phase 3 technique) the $11.25 \mathrm{~kg}$ of total composite stamp stock is weighed out, the release liner is removed and the remaining "stamps" are affixed to envelope paper. The removed release liner is weighed and an equivalent amount of copy/envelope paper ( $1 / 2$ each) is added as make-up. This technique will approximate a $47.5 \%$ copy paper, $47.5 \%$ envelope paper, $5 \%$ stamp stock composition: the actual composition will depend on the basis weight of the release liner.

2. Fill pulper with 780 liters softwater at $46 \pm 2^{\circ} \mathrm{C}\left(115 \pm 5^{\circ} \mathrm{F}\right)$. Adjust $\mathrm{pH}$ to 10.0 with $\mathrm{NaOH}$. Use $\mathrm{H}_{2} \mathrm{SO}_{4}$ to correct overshoots.

Pre-consumer trials

Add copy and envelope papers, with minimal agitation until all paper has been introduced and wetted. Blend for 1 minute, adding only enough water to cause slurry to roll properly. Record total water added.

Stop agitation at end of the one minute; measure $\mathrm{pH}$ and temperature. Restart pulper and immediately start energy-measuring unit. Blend in adhesive-containing stock quickly, while continuing to pulp for a total of 20 minutes. Add just enough water to maintain rolling of the slurry. Collect a consistency sample when rotor has stopped immediately upon shutting off pulper.

Post-consumer trials

Same as (a) except add cancelled envelopes in their entirety as quickly as pulper will take them. Add water only as necessary. Measure temperature and $\mathrm{pH}$. Then start pulper and energy measuring unit.

(Target: total volume $=900$ liters to give a $12.5 \%$ consistency. Actual volume and consistency is determined by producing the proper roll of the slurry at the highest possible consistency (minimum amount of water) to achieve the roll.).

(Note: pulping time was determined in developing the phase 3 portion of this study.) 
3. At end of 20 minutes first shut off energy-measuring unit, then immediately the pulper. Measure final temperature, and $\mathrm{pH}$, and record energy input. Dilute slurry to $1500 \mathrm{~L}$, maintaining temperature at $46 \pm 2^{\circ} \mathrm{C}\left(115 \pm 5^{\circ} \mathrm{F}\right)$.

4. Fill the feedtank with enough water to dilute the slurry to $\underline{\mathbf{2 . 2 6 5 \%}}$ consistency maintaining temperature at $46 \pm 2^{\circ} \mathrm{C},\left(115 \pm 5^{\circ} \mathrm{F}\right)$. Use the feed tank pump to feed the ventri mixer and draw the stock from the pulper. Mix well. Measure actual consistency. Measure temperature. From stock in tank save one 10-L sample (SAMPLE POINT 1).

\section{Pressure Screening}

1. Pre-fill flatscreen, equipped with $0.2 \mathrm{~mm}(0.008$ ") slots, and its $600-\mathrm{L}$ stock tank with $46^{\circ} \mathrm{C}$ water. Record volume of water used. Fill pressure screens with water. Begin pumping flatscreen accepts weir water to 1st pressure screen, equipped with $0.30 \mathrm{~mm}(0.012$ ") slots, at $175 \mathrm{~L} / \mathrm{min}$. Adjust the 0.3 $\mathrm{mm}$ screen rejects flow to $45 \mathrm{~L} / \mathbf{m}$ ( $15 \%$ of total feed) with rejects passing back to flatscreen.

2. Begin pumping feedtank slurry to $0.30 \mathrm{~mm}$ pressure screen at $125 \mathrm{~L} / \mathbf{m i n}$ target rate total flow $=300 \mathrm{~L} / \mathrm{min}$ ), with accepts passing at $255 \mathrm{~L} / \mathrm{min}$ to the second pressure screen, equipped with $0.10 \mathrm{~mm}(0.004$ ") slots. Rejects from the $0.1 \mathrm{~mm}$ pressure screen pass back to the feedtank at $52 \mathrm{~L} / \mathbf{m i n}$

3. Pump the initially clear water from the $600-\mathrm{L}$ stock tank to the flatscreen at $130 \mathrm{~L} / \mathrm{min}$. The $0.1 \mathrm{~mm}$ pressure screen accepts go to the $4000 / 8000-\mathrm{L}$ stock tanks. Immediately begin adding sufficient fresh $46^{\circ} \mathrm{C}$ soft water to $600-\mathrm{L}$ stock tank to maintain the $130 \mathrm{~L} / \mathrm{min}$ flow to the flatscreen. Pressure screen target pressures are to be $115 \mathrm{kPa}(17 \mathrm{psi})$ feed/ $110 \mathrm{kPa}(16 \mathrm{psi})$ accepts for the $0.30 \mathrm{~mm}$ slots and $102 \mathrm{kPa}$ (15 psi) feed/ $96 \mathrm{kPa}$ (14 psi) accepts for the $0.10 \mathrm{~mm}$ slots. Actual values are determined by the nature of the stock and are to be logged and reported. Flowrates are to be maintained.

4. When at equilibrium save a 10-L carboy of accept stock from each pressure screen and a 20-L sample from the flatscreen accepts stock for handsheets (SAMPLE POINTS 3, $5 \&$ 7). Measure consistency of all accepts and (SAMPLE POINTS 2 \& 4) streams. Measure flowrates and total flows of all streams. Measure temperature of final accepts.

5. When $0.1 \mathrm{~mm}$ screening accepts reaches 9000 liters, shut off all flows. Record all volumes. Then pass all remaining flatscreen accepts back to feedtank for disposal. Flush flatscreen with fresh water to remove all fiber.

6. When only adhesive and paper tags remain on flatscreen collect rejected adhesive retained by the flatscreen, dry, and weigh for yield (SAMPLE POINT 6). 
7. Dilute (at $46^{\circ} \mathrm{C}$ ) accepts to $0.65 \%$ consistency, intermixing the slurry in the 4000- and 8000-L tanks until of uniform consistency. Save a 10-L carboy of the uniformly blended accepts slurry for handsheets (SAMPLE POINT 8). Measure consistency.

All of the next operations are performed as a continuous operation

III. Forward Cleaning

1. Slowly open feed valve to 1st primary forward cleaner (Beloit Posiflow 60) until accepts flow is $234 \mathrm{~L} / \mathrm{min}$. Feedrate will be between 240 and $260 \mathrm{~L} / \mathrm{min}$. Accepts flow to a $600-\mathrm{L}$ stock tank and then are pumped to the 2nd primary forward cleaner (Celleco Cleanpac 270) at a feedrate that maintains the level in the $600-\mathrm{L}$ tank.

2. Accepts at $212 \mathrm{~L} / \mathrm{min}$ pass to a second $600-\mathrm{L}$ stock tank. Back pressure of Celleco cleaner must be in the range of $54-136 \mathrm{kPa}(8-20 \mathrm{psi})$. When flow is at equilibrium save a 10-L accepts sample from each cleaner accepts tank (SAMPLE POINTS $9 \&$ 11). Rejects from both primary stages $(56 \mathrm{~L} / \mathrm{min})$ are to be combined in a stock tank, diluted with fresh water $(30 \mathrm{~L} / \mathrm{min})$ at $46^{\circ} \mathrm{C}$, pumped through a secondary fiber recovery forward cleaner (Voith KS60P), with the accepts passing back to the primary forward cleaner feed tank and with the rejects $(7-8 \mathrm{~L} / \mathrm{min})$ being collected in 55-gallon drums (SAMPLE POINT 15). Actual feed/accepts pressures to be set to balance flow. Measure consistency of rejects from each cleaner (SAMPLE POINTS $10,12 \& 15)$. Save two 10 -L samples of secondary cleaner feedstock (SAMPLE POINT 13).

Actual diluted consistency of primary rejects (SAMPLE POINT 13) to be such that the secondary accepts are equal to the initial primary feed consistency.

3. Save a 10-L sample of the secondary forward cleaner accepts for handsheets (SAMPLE POINT 14). Measure flow rates on all primary and secondary accepts and reject streams. Measure consistencies on all streams. Measure accepts temperature in both $600-\mathrm{L}$ tanks and that of the secondary cleaner accepts.

4. As the 8000 -L feedtank empties, continuously transfer contents of $4000-\mathrm{L}$ feedtank to the 8000 -L tank.

IV. Thru-flow Cleaning

1. When the $600-\mathrm{L} 2^{\text {nd }}$ forward cleaner accepts tank is $1 / 2$ full of stock begin feeding slurry to the 1 st through-flow cleaner at $212 \mathrm{~L} / \mathrm{min}$, adjusted slightly 
to maintain level in the feed tank. Target feed pressure is to be $210 \mathrm{kPa}$ ( 30 psi) and back pressure is to be $70 \mathrm{kPa}(10 \mathrm{psi})$. Rejects are fed to a drain at approximately $22 \mathrm{~L} / \mathrm{min}$ while measuring the reject flowrate and total reject volume with an accumulator. Save a 4-L reject sample for consistency (SAMPLE POINT 17).

2. Accepts flow to a $1000-\mathrm{L}$ stock tank at approximately $190 \mathrm{~L} / \mathrm{min}$ When this accepts tank is about $1 / 2$ full turn on pump to feed 2 nd through-flow cleaner (same pressures), with accepts from 2nd stage flowing to its stock accepts tank at approximately $165 \mathrm{~L} / \mathrm{min}$ Balance flows to maintain tank levels. At the same time that the 2nd through-flow cleaner pump is started, begin injecting DI-700A flotation aid ( $0.10 \%$ dry fiber basis) to suction port of the transfer pump. Measure reject flow as for $1^{\text {st }}$ stage, saving a 4-L reject sample for consistency (SAMPLE POINT 19).

3. While maintaining a pressure difference of $140 \mathrm{kPa}(20 \mathrm{psi})$ adjust actual pressures to balance flows. When at system equilibrium save a 10-liter sample of each accepts stream (SAMPLE POINTS $16 \&$ 18). Measure accepts stream temperatures and flowrates.

V. Flotation and Washing

1. When slurry begins to enter flotation cell turn on airflow to $10 \mathrm{~L} / \mathrm{min}$. When outer cell is filled to above return stock injection ports turn on main circulation/transfer pump with stock exit valve shut. When outer cell is nearly filled begin the vacuum removal of foam. When outer cell is full open exit valve sending accepts to the glass-lined tank. Adjust the level controller to give the proper level in the tank. Rejects are sampled and their consistency determined (SAMPLE POINT 21). Reject rate is about 5-7 L/min. When glass-lined tank has received about $1 / 2$ of the total slurry save a 10 -L sample of the flotation cell accepts (SAMPLE POINT 20). Determine its consistency.

2. Begin pumping stock from glass-lined tank to drum washer at $115-125 \mathrm{~L} / \mathrm{min}$ as soon as pump is flooded. Dewater stock using vacuum plus pressure roll, shredding the mat and depositing the resulting crumbed pulp in barrels. Calculate total washer wastewater volume from input volume minus barreled pulp volume. Collect a 4-liter washwater samples after about a 20-minute running time; determine consistencies on these samples (SAMPLE POINT 23).

3. When input to the flotation cell from the through-flow cleaner ceases, shut off the outflow from the flotation cell and let the cell operate batch-style for 10 minutes to strip remaining flotables. Then reopen outflow valve and empty cell to glass-lined tank. 
4. Sample final crumb pulp entering barrels by catching a handful of pulp at each $1 / 3$ barrel level and place the three handfuls in a 12 " x 12 " plastic bag (SAMPLE POINT 22). Mix well and determine consistency on the combined sample. Weigh barrels and calculate total oven-dry pulp. Repeat for each barrel.

5. After consistencies are done, combine the pulps in each bag into one batch, mix well and submit for handsheets.

\section{CLEANING}

1. For stock preparation, after each trial the system is to be thoroughly flushed with water, followed if necessary, by a scrubbing with copy paper, envelope paper and/or virgin lap pulp. The system is again flushed with water and a second copy/ envelope paper scrubbing follows, with a pulp sample taken after shredding (SAMPLE POINT 16). If dirt count exceeds the equivalent to a FPL 15 ppm, an additional scrubbing with copy/envelope paper is made. Target level is below 10 ppm FPL.

2. Baskets from the pressure screen are manually cleaned of the adhering adhesive. The baskets are then cleaned with a pressure washer.

3. The plates from the flatscreen are cleaned with the pressure washer but no effort is made to measure the residual traces of adhesive as it represents only a small trace of the total adhesive removed from the screen previously. The entire flatscreen is pressure washed while the plates are out to maximize the cleanliness of the unit. 


\section{Appendix 3: Hydrophobic Contaminant Identification Method}

DRAFT 3 May 2002

\section{Scope}

1.1 This procedure describes a method for quantifying hydrophobic contaminants in pulp samples. A dye that associates with contaminant particles is used to develop contrast from the pulp background. Computer-based color image analysis can then be used to quantify contamination levels by type based upon color and shade.

1.2 This method is a compliment to TAPPI T 213 "dirt in pulp". It allows for the quantification of hydrophobic contaminants that do not have sufficient contrast with pulp to be identified. Hydrophobic contaminants, i.e., waxes, pressure sensitive adhesives, hot melt adhesives, etc., can contribute to "stickie" problems in recycled fiber mills.

\section{Significance}

2.1 When coupled with automated color image analysis contaminant measurement and classification methods, this method provides a more complete quantification of pulp contaminants.

\section{Apparatus}

3.1 Standard handsheet mold as described in TAPPI T 205 sp-95.

3.2 Standard couch roll.

3.3 Standard blotting paper as described in TAPPI T $205 \mathrm{sp}-95$.

3.4 Handsheet dryer with an operating temperature of $150^{\circ} \mathrm{C}$.

3.5 Image analysis system.

3.6 Plastic or metal tray large enough to hold a blotting paper.

3.7 Foam varnish applicator.

3.8 Laboratory timer

3.9 Standard press as described in TAPPI T $205 \mathrm{sp}-95$

\section{Reagent}

4.1 dye solution $0.67 \mathrm{~g}$ of C.I. solvent blue 36 in 1 liter of $n$-heptane. The dye is also known as Morplas Blue 1003 and can be obtained from Pylam Products Company Inc., 2175 East Cedar Street, Tempe, AZ 85281, (602) 929-0070

\section{Procedure}

5.1 Form handsheets according to TAPPI T 205, except end the procedure after couching. After couching the second wet blotting paper is discarded and a third dry one is placed to protect the handsheet attached to the first blotting paper.

5.2 Stack handsheets and blotters, using care to align sheets in a uniform stack. Place the stack in a press and, over a period of 30 seconds, raise the pressure to $345 \mathrm{kPa}$ (50 psig). Maintain this pressure for 5 minutes. 
5.3 Carefully unstack the sheets and place each pair of blotter papers, with a handsheet between them, on the dryer. The intent is to leave the handsheet firmly attached to the couching blotting paper until it is dyed. Dry for 3 minutes at $150^{\circ} \mathrm{C}$ with gentle restraint.

5.4 Dye the handsheet by applying the dye solution to the back side of the blotter that has a handsheet attached. This allows the dye to uniformly penetrate the handsheet. Furthermore, as the dye solution passes through the blotting paper undissolved dye particles are filtered from the solution. Typically, dying is done by placing the blotting paper/handsheet with the handsheet side down on another blotting paper in a tray, and then painting the blotting paper with a foam brush that has been dipped in the dye solution. This step of the procedure should be carried-out in a ventilation hood to avoid exposure to heptane vapors. Since the dye is a mild sensitizer, heptane-tolerant gloves are also required.

5.5 Let the heptane evaporate from the blotting paper/handsheets without separating the handsheet from the blotter paper by hanging them with clips attached to the blotter paper in the ventilation hood. Typical drying times are 2-3 minutes.

5.6 With a gloved hand, gently peel the dyed handsheet from the blotting paper. Place the side that was towards the blotting paper on the glass of the flat bed scanner. Using a weight with a white surface, hold the sheet flat on the scanner.

5.7 Use the color image analysis software to quantify the number of particles on the sheet. To compensate for sheet to sheet variations in dye intensity, best results are obtained by using a threshold that is automatically set $20 \%$ below the mode of the sheet image picture point luminance value frequency distribution. The software system developed by Verity IA LLC was used in this study. The scanner used was an AGFA Argus II.

\section{Report}

6.1 Results are reported as parts per million of the scanned area. Typically an average and $95 \%$ confidence interval for 10-40 standard $1.2 \mathrm{~g}$ handsheets is calculated.

References

[1] TAPPI Test Method T 213 om-97.

[2] R. Trepanier et al. TAPPI Journal Dec 1989 p. 153.

[3] J. Klungness et al. TAPPI Journal Jan 1989 P. 89.

[4] C. Houtman et al. Proceedings of the TAPPI 2000 Recycling Conference, Vol. 2 p.403.

[5] R. Rosenberger Proceedings of the TAPPI 1999 Recycling Conference p. 669.

[6] G.E.P Box et al. "Statistics for Experimenters" John Wiley and Sons, NY, 1978, p. 323. 


\section{Appendix 4: Datasheets and Image Analysis Results}

\section{Consistencies}

Consistencies for various sample points are shown in Table A4-1.

Table A4-1. Consistencies for various sample points for Trials \#341 and \#342.

\begin{tabular}{|c|c|c|}
\hline Sample Point (ID No.) & $\begin{array}{c}\text { Trial \#341 } \\
\text { Consistency } \\
(\%)\end{array}$ & $\begin{array}{c}\text { Trial \#342 } \\
\text { Consistency } \\
(\%)\end{array}$ \\
\hline Pulper (I) & 13.08 & 13.02 \\
\hline Screening Feed (1) & 2.12 & 2.11 \\
\hline Screen A (0.3 mm) Rejects (2) & 1.35 & 1.93 \\
\hline Screen A $(0.3 \mathrm{~mm})$ Accepts $(3)$ & 0.95 & 0.92 \\
\hline Screen B (0.1 mm) Rejects (4) & 1.78 & 1.70 \\
\hline $\begin{array}{l}\text { Screen B }(0.1 \mathrm{~mm}) \text { Accepts }(5) \\
\text { (Feed to Forward Cleaners) }\end{array}$ & 0.71 & 0.68 \\
\hline Flatscreen $(0.2 \mathrm{~mm})$ Accepts $(7)$ & 0.31 & 0.40 \\
\hline First Forward Cleaner Feed (8) & 0.63 & 0.65 \\
\hline First Forward Cleaner Accepts (9) & 0.51 & 0.53 \\
\hline First Forward Cleaner Rejects (10) & 1.87 & 2.27 \\
\hline Second Forward Cleaner Accepts (11) & 0.49 & 0.50 \\
\hline Second Forward Cleaner Rejects (12) & 0.72 & 0.72 \\
\hline Forward Fiber Recovery Cleaner Feed (13) & 0.69 & 0.81 \\
\hline Forward Fiber Recovery Cleaner Accepts (14) & 0.67 & 0.70 \\
\hline Forward Fiber Recovery Cleaner Rejects (15) & 1.17 & 1.29 \\
\hline First Thru-flow Cleaner Accepts (16) & 0.47 & 0.50 \\
\hline First Thru-flow Cleaner Rejects (17) & 0.12 & 0.12 \\
\hline $\begin{array}{c}\text { Flotation Feed (18) } \\
\text { (Second Thru-Flow Cleaner Accepts) }\end{array}$ & 0.53 & 0.54 \\
\hline Second Thru-flow Cleaner Rejects (19) & 0.11 & 0.16 \\
\hline Flotation Accepts (20) & 0.45 & 0.49 \\
\hline Flotation Rejects (21) & 1.42 & 1.51 \\
\hline Final Pulp (22) & 25.26 & 24.94 \\
\hline Drumwasher Effluent (23) & --- & --- \\
\hline
\end{tabular}


APPENDIX 3: Pilot Scale Testing of F-2006 and 2007

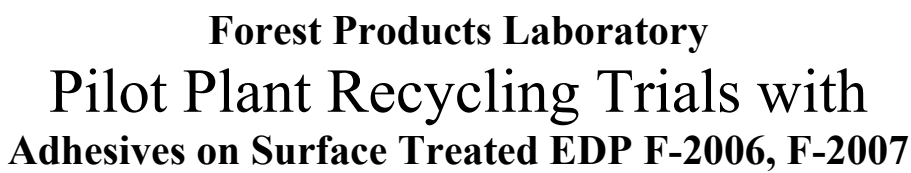

Prepared by: Karen Scallon

Reviewed by: Carl Houtman

USDA Forest Service

Forest Products Laboratory

One Gifford Pinchot Drive

Madison, WI 53705

In partial fulfillment of Subcontract No. V4046084002

between University of Minnesota

Department of Wood and Paper Science and

USDA Forest Service

Forest Products Laboratory

October 16, 2003 


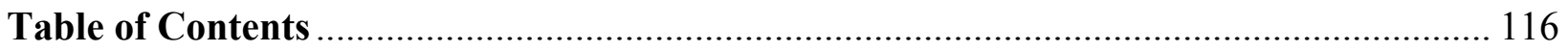

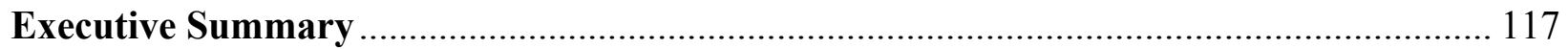

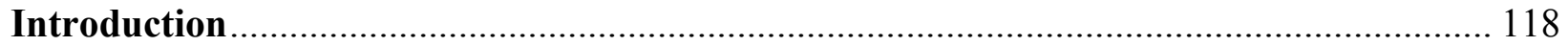

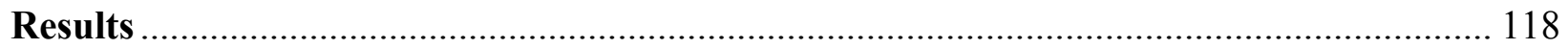

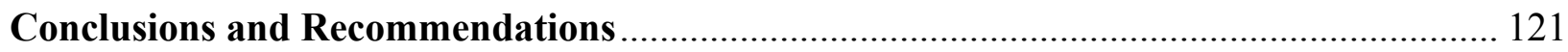

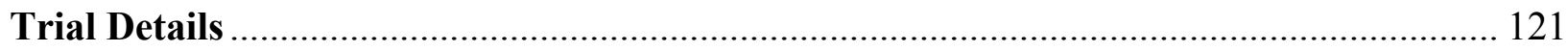

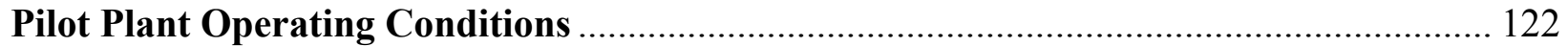

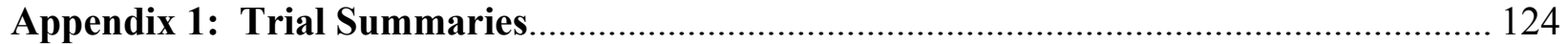

Appendix 2: Phase IV Pilot Plant Recycling Procedure ................................................ 128

Appendix 3: Hydrophobic Contaminant Identification Method..................................... 136

Appendix 4: Datasheets and Image Analysis Results .................................................. 138 
Executive Summary

Two pilot plant recycling trials, \#369 and \#370, using the open-loop configuration were conducted for the University of Minnesota Department of Wood and Paper Science. For Trial \#369, a water-based acrylic pressure sensitive (PSA) adhesive on Boise Cascade standard EDP facepaper was tested (sample identification number: F-2006). For Trial \#370, the same PSA on Boise Cascade modified EDP facepaper was tested (sample identification number: F-2007). Trial results were used to compare the removability/recyclability of PSA laminated on different facepapers.

The PSA of both samples F-2006 and F-2007 was removed to acceptable levels (20 ppm or less) in the recycling system primarily by screening with flotation acting as a polishing stage. The final pulp adhesive content averaged $7 \pm 3$ ppm for F-2006 and $6 \pm 3$ ppm for F-2007.

The PSA pulper particle sizes for both samples was also acceptable ( 0.32 sq. $\mathrm{mm}$ or greater). Sample F-2006 was 0.69 sq. $\mathrm{mm}$ and sample F-2007 was 0.64 sq. $\mathrm{mm}$.

Trial results suggest that there was not a significant difference in overall PSA removability/recyclability as a function of the facepaper type in these two trials. There appeared to be differences, however, in PSA pulper particle sizes and PSA contaminant levels at each screening and cleaning stage, which might or might not be attributable to facepaper type. 
Introduction

This report contains information and results obtained for two trials with University of Minnesota Department of Wood and Paper Science water-based acrylic pressure sensitive adhesive (PSA) samples: sample F-2006 with Boise Cascade standard EDP facepaper (Trial \#369) and sample F-2007 with Boise Cascade modified EDP facepaper (Trial \#370). The same PSA was used in these trials; the only difference was the facepaper. Trial \#369 was conducted on September 2, 2003 and Trial \#370 was conducted on September 4, 2003. Trial summaries are provided in Appendix 1.

Results

Image analysis (IA) adhesive levels and particle sizes are presented in Tables 1 and 2 , respectively, for both trials. These tables present values after statistical analysis of raw data.

Table 1: Adhesive levels for Trials \#369 and \#370.

\begin{tabular}{|c|c|c|c|c|}
\hline \multirow[b]{2}{*}{ Sample Point (ID No.) } & \multicolumn{2}{|c|}{$\begin{array}{c}\text { TRIAL \#369 } \\
\text { SAMPLE F-2006 } \\
\text { Standard EDP } \\
\text { Facepaper }\end{array}$} & \multicolumn{2}{|c|}{$\begin{array}{c}\text { TRIAL \#370 } \\
\text { SAMPLE F-2007 } \\
\text { Modified EDP } \\
\text { Facepaper }\end{array}$} \\
\hline & ppm & $95 \% \mathrm{CI}$ & ppm & $95 \% \mathrm{CI}$ \\
\hline Screening Feed (1) & 10,064 & 796 & 10,909 & 731 \\
\hline $\begin{array}{l}0.3 \mathrm{~mm} \text { Screen A } \\
\text { Accepts (3) }\end{array}$ & 1,663 & 208 & 1,930 & 121 \\
\hline $\begin{array}{l}0.1 \mathrm{~mm} \text { Screen B } \\
\text { Accepts }(5)\end{array}$ & 63 & 8 & 150 & 19 \\
\hline $\begin{array}{l}1^{\text {st }} \text { Forward Cleaner } \\
\text { Feed }(8)\end{array}$ & 38 & 11 & 78 & 8 \\
\hline $\begin{array}{l}1^{\text {st }} \text { Thru-Flow Cleaner } \\
\text { Feed (11) }\end{array}$ & 32 & 9 & 50 & 12 \\
\hline Flotation Feed (18) & 12 & 5 & 27 & 8 \\
\hline Flotation Accepts (20) & 2 & 2 & 7 & 4 \\
\hline Final Pulp (22) & 7 & 3 & 6 & 3 \\
\hline
\end{tabular}


Table 2: Particle sizes for Trials \#369 and \#370.

\begin{tabular}{|c|c|c|c|c|}
\hline \multirow[b]{2}{*}{ Sample Point (ID No.) } & \multicolumn{2}{|c|}{$\begin{array}{c}\text { TRIAL \#369 } \\
\text { SAMPLE F-2006 } \\
\text { Standard EDP } \\
\text { Facepaper }\end{array}$} & \multicolumn{2}{|c|}{$\begin{array}{c}\text { TRIAL \#370 } \\
\text { SAMPLE F-2007 } \\
\text { Modified EDP } \\
\text { Facepaper }\end{array}$} \\
\hline & sq. mm & $95 \% \mathrm{CI}$ & sq. mm & $95 \% \mathrm{CI}$ \\
\hline Screening Feed (1) & 0.6906 & 0.0357 & 0.6431 & 0.0321 \\
\hline $\begin{array}{l}0.3 \mathrm{~mm} \text { Screen A } \\
\text { Accepts }(3)\end{array}$ & 0.3874 & 0.0375 & 0.3217 & 0.0243 \\
\hline $\begin{array}{l}0.1 \mathrm{~mm} \text { Screen B Accepts } \\
(5)\end{array}$ & 0.0861 & 0.0077 & 0.1289 & 0.0145 \\
\hline $\begin{array}{l}1^{\text {st }} \text { Forward Cleaner Feed } \\
(8)\end{array}$ & 0.1015 & 0.0224 & 0.1433 & 0.0245 \\
\hline $\begin{array}{l}1^{\text {st }} \text { Thru-Flow Cleaner Feed } \\
\text { (11) }\end{array}$ & 0.0926 & 0.0166 & 0.1064 & 0.0129 \\
\hline Flotation Feed (18) & 0.0735 & 0.0277 & 0.1103 & 0.0303 \\
\hline Flotation Accepts (20) & 0.0222 & 0.0128 & 0.0400 & 0.0186 \\
\hline Final Pulp (22) & 0.0460 & 0.0213 & 0.0449 & 0.0188 \\
\hline
\end{tabular}

The raw handsheet adhesive level and particle size values were subjected to normality plotting analysis. This analysis identifies handsheets that appear to be inconsistent with the rest of the handsheets in that group and also allows identification of sets of handsheets that display inconsistencies in processing. Typically, IA results can be normalized with the omission of one or two outlier points - or handsheets - out of a total of 16 points or sheets. In certain cases, up to a maximum of 4 points or sheets can be omitted; otherwise the data is left "as is." Fewer sheets, if any, are omitted for the final pulp, which typically (for a removable PSA) has a non-gaussian distribution due to zero/near-zero ppm levels. The IA method is presented in Appendix 3. Raw IA datasheets and results are presented in Appendix 4.

Based on the IA results in Table 1, the PSA of both samples F-2006 and F-2007 was removed to acceptable levels ( $20 \mathrm{ppm}$ or less) in the recycling system primarily by screening with flotation acting as a polishing stage. The final pulp adhesive content averaged $7 \pm 3$ ppm for F-2006 and $6 \pm 3$ ppm for F-2007.

The PSA pulper particle sizes for both samples was also acceptable ( 0.32 sq. $\mathrm{mm}$ or greater). From IA results in Table 2, PSA pulper particles sizes were 0.69 sq. mm for F-2006 and 0.64 sq. $\mathrm{mm}$ for F-2007.

Comparison of individual PSA levels for each screening stage in Table 1 indicates that there is some difference in removal levels at each screening and cleaning stage between the two trials. From Table 1, sample F-2006 (Trial \#369) has consistently lower PSA contaminant levels at each screening and cleaning stage compared to sample F-2007 (Trial \#370). This difference might be due to sample F-2006 having a large PSA pulper particle size and/or more PSA 
particles distributed in larger size ranges compared to sample F-2007, although particle size distributions were not analyzed.

Screening removal efficiencies could be calculated at various stages of screening based on ppm values in Table 1 and are shown in Table 3 below.

Table 3: Screening removal efficiencies for acrylic PSA samples.

\begin{tabular}{|c|c|c|}
\hline Sample ID & $\begin{array}{c}\text { 12 cut (0.3 mm) Screening } \\
\text { Removal Efficiency }\end{array}$ & $\begin{array}{c}\text { Overall Screening Removal } \\
\text { Efficiency }\end{array}$ \\
\hline F-2006 & $83.5 \%$ & $99.4 \%$ \\
\hline F-2007 & $82.3 \%$ & $98.6 \%$ \\
\hline
\end{tabular}

Figure 1 shows the $0.3 \mathrm{~mm}$ (12 cut) screening efficiency versus PSA pulper particle size for samples F-2006 and F-2007 and other PSAs tested in Phase IV of the USPS project for comparison. Both of the samples appear in the upper range of the data set.

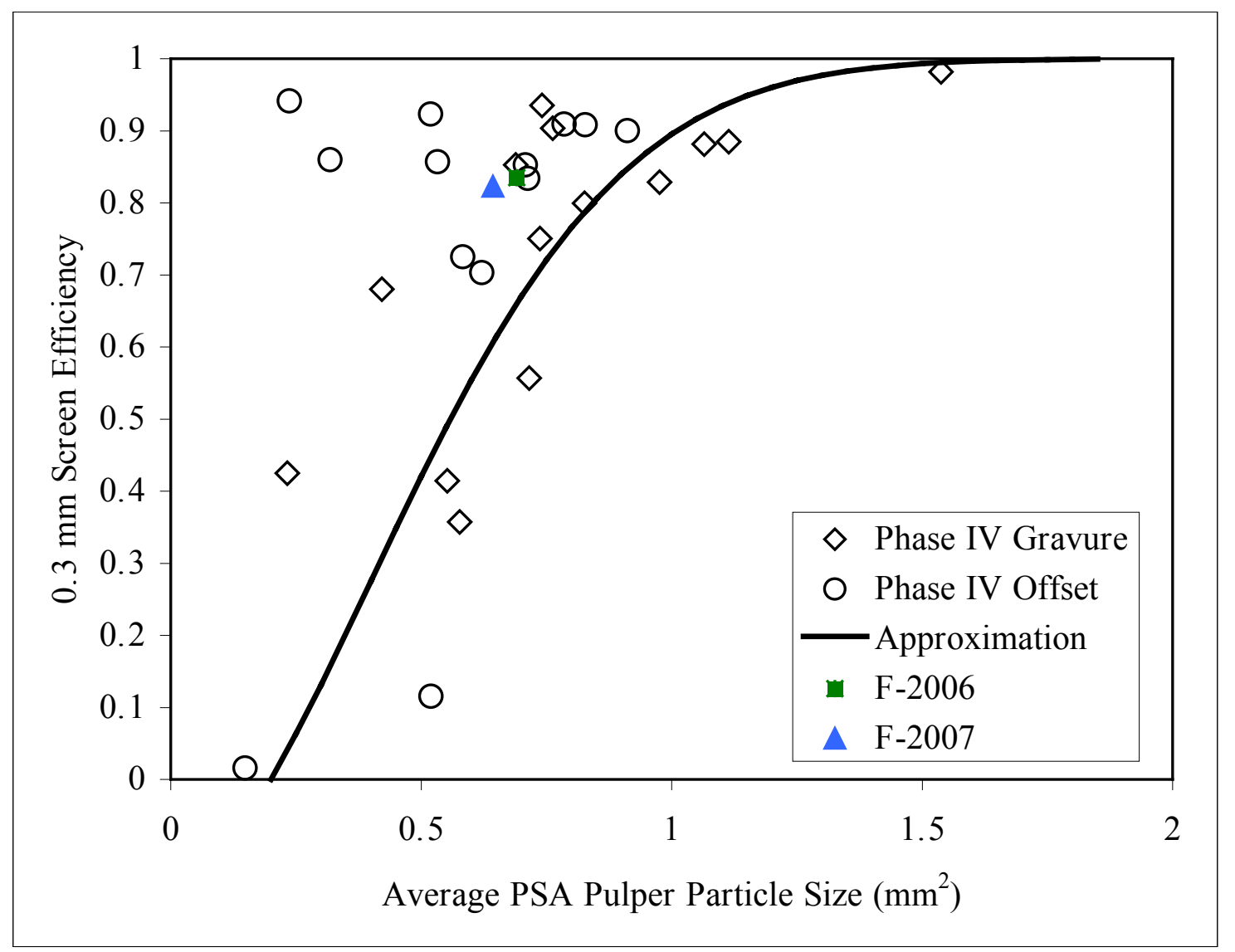

Figure 1. Plot of $0.3 \mathrm{~mm}$ screen efficiency versus average PSA pulper particle size for adhesives in the Phase IV database and for samples F-2006 and F-2007. 
PSA rejects collected on the $0.2 \mathrm{~mm}$ ( 8 cut) flatscreen for each trial were oven dried and weighed. The PSA rejects collected on the 8 cut $(0.2 \mathrm{~mm})$ flatscreen were different for each sample, with $753 \mathrm{~g}$ collected for F-2006 and $434 \mathrm{~g}$ collected for F-2007.

Conclusions and Recommendations

The PSA of both samples F-2006 and F-2007 was removed to acceptable levels (20 ppm or less) in the recycling system primarily by screening with flotation acting as a polishing stage. The final pulp adhesive content averaged $7 \pm 3$ ppm for F-2006 and $6 \pm 3$ ppm for F-2007.

The PSA pulper particle sizes for both samples was also acceptable ( $0.32 \mathrm{sq}$. $\mathrm{mm}$ or greater). Sample F-2006 was 0.69 sq. mm and sample F-2007 was 0.64 sq. mm.

Trial results suggest that there was not a significant difference in overall PSA removability/recyclability as a function of the facepaper type in these two trials. There appeared to be differences, however, in PSA pulper particle sizes and PSA contaminant levels at each screening and cleaning stage, which might or might not be attributable to facepaper type. Trial Details

The trials were conducted at the USDA Forest Service, Forest Products Laboratory (FPL) Recycling Pilot Plant in Madison, Wisconsin USA. The open-loop recycling procedure is presented in Appendix 2.

The stock materials for each trial weighed a total of 112.5 oven-dried (OD) $\mathrm{kg}$ and are identified in Table 4.

Table 4: Pulper mass loadings of stock materials for recycling trials.

\section{TRIAL \#369}

$47.5 \%$ copy paper

$53.44 \mathrm{~kg}$ OD

$56.85 \mathrm{~kg}$ weighed out
$47.5 \%$ envelope paper

$51.94 \mathrm{~kg}$ OD

55.25 weighed out
5\% F-2006 facepaper ( 1\%

adhesive content by weight)

$5.625 \mathrm{~kg}$ OD

$5.984 \mathrm{~kg}$ weighed out

\section{TRIAL \#370}

$47.5 \%$ copy paper

$53.44 \mathrm{~kg}$ OD

$56.85 \mathrm{~kg}$ weighed out
$47.5 \%$ envelope paper $51.97 \mathrm{~kg}$ OD

55.29 weighed out
5\% F-2007 facepaper ( 1\% adhesive content by weight)

$5.625 \mathrm{~kg}$ OD

$6.016 \mathrm{~kg}$ weighed out

The facepaper of both samples had edges that were not coated with adhesive, which was accounted for in the reduced weight of envelope paper. For each trial, FPL personnel manually fixed the PSA facepaper to envelope paper and allowed a minimum of 72 hours before testing for development of adhesive permanence. 
The stock materials were pulped at approximately $12.5 \%$ csc in alkaline conditions for 20 minutes in $46 \pm 2^{\circ} \mathrm{C}$ soft water. Following pulping, the pulper contents were transferred to the dumpchest and diluted to approximately $2.2 \% \csc$ with $46 \pm 2^{\circ} \mathrm{C}$ soft water. The dumpchest contents, after inline dilution to approximately $1 \% \mathrm{csc}$, were delivered to a screening stage consisting of a $0.3 \mathrm{~mm}$ ( $12 \mathrm{cut}$ ) pressure screen, $0.2 \mathrm{~mm}$ ( 8 cut) flat screen, and a $0.1 \mathrm{~mm}$ ( 4 cut) pressure screen. The screening accepts were collected in a tank and diluted with $46 \pm 2{ }^{\circ} \mathrm{C}$ soft water to an approximate consistency of $0.65 \%$. The screening accepts were then sent through cleaning, flotation and drum washing/dewatering stages.

Pilot Plant Operating Conditions

Table 5 shows the important pilot plant operating conditions for Trials \#369 and \#370. Also shown, for reference only and not direct comparison to Trials \#369 and \#370, are averages and standard deviations of these parameters for 45 other USPS post-consumer recycling trials in the Phase IV database. 
Table 5: Operating conditions for recycling trials.

\begin{tabular}{|c|c|c|c|c|c|}
\hline \multirow[b]{2}{*}{ Parameter } & \multirow{2}{*}{$\begin{array}{l}\text { Trial } \\
\# 369 \\
\text { Value }\end{array}$} & \multirow{2}{*}{$\begin{array}{l}\text { Trial } \\
\# 370 \\
\text { Value }\end{array}$} & \multicolumn{2}{|c|}{$\begin{array}{l}\text { Phase IV } \\
\text { Database }\end{array}$} & \multirow[b]{2}{*}{ Unit } \\
\hline & & & Ave & StDev & \\
\hline Temperature after Pulping & 44.3 & 44.5 & 46.6 & 1.3 & ${ }^{\circ} \mathrm{C}$ \\
\hline Consistency in Pulper & 12.7 & 12.6 & 12.4 & 0.2 & $\%$ \\
\hline $\mathrm{pH}$ after Pulping & 9.18 & 9.42 & 9.8 & 0.2 & $\mathrm{pH}$ \\
\hline Pulper Energy & 47.1 & 51.7 & 56.3 & 2.4 & $\mathrm{~kW} \mathrm{hr/MT}$ \\
\hline $0.3 \mathrm{~mm}$ Screen Feed Consistency & 1.10 & 1.13 & 1.15 & 0.04 & $\%$ \\
\hline $0.3 \mathrm{~mm}$ Screen Reject Rate & 14.9 & 15.7 & 14.6 & 1.1 & $\%$ \\
\hline $0.3 \mathrm{~mm}$ Screen Passing Speed & 0.39 & 0.41 & 0.42 & 0.003 & $\mathrm{~m} / \mathrm{s}$ \\
\hline $0.1 \mathrm{~mm}$ Screen Feed Consistency & 0.87 & 0.95 & 1.03 & 0.07 & $\%$ \\
\hline $0.1 \mathrm{~mm}$ Screen Reject Rate & 22.9 & 19.3 & 21 & 1 & $\%$ \\
\hline $0.1 \mathrm{~mm}$ Screen Passing Speed & 0.32 & 0.35 & 0.35 & 0.003 & $\mathrm{~m} / \mathrm{s}$ \\
\hline Forward Cleaner Feed Consistency & 0.68 & 0.66 & 0.64 & 0.04 & $\%$ \\
\hline Forward Cleaner Reject Rate & 10.5 & 10.4 & 10.3 & 0.7 & $\%$ \\
\hline $\begin{array}{l}\text { Thru-flow Cleaner Feed } \\
\text { Consistency }\end{array}$ & 0.51 & 0.51 & 0.50 & 0.03 & $\%$ \\
\hline Thru-flow Cleaner Reject Rate & 9.9 & 10.0 & 11.6 & 3.4 & $\%$ \\
\hline Flotation Feed Consistency & 0.53 & 0.55 & 0.61 & 0.03 & $\%$ \\
\hline Flotation Residence Time & 11.0 & 11.0 & 11.7 & 0.2 & $\min$. \\
\hline Flotation Reject Rate & 5.8 & 0.5 & 2.0 & 1.0 & $\%$ \\
\hline Total Yield & 49.4 & 55.7 & 56 & 4 & $\%$ \\
\hline
\end{tabular}

One main goal in conducting Trials \#369 and \#370 was to maintain the operating conditions as consistent as possible between the two trials. The difference in pulper energy consumption during pulping is attributable to slight differences in pulping times, 18.6 minutes for Trial \#369 versus 20.8 minutes for Trial \#370. The target pulping time is 20 minutes. A procedural error was made in Trial \#369, causing a lower pulping time; however, this is not considered to have adversely impacted results. 


\section{Appendix 1: Trial Summaries}

\section{Trial \#369 Summary}

Date: September 2, 2003

Purpose: Phase IV configuration testing of Univ. of MN sample F-2006 (water-based adhesive). Trial results to be compared with Trial \#370.

Materials: Required Mass Loadings: $47.5 \%$ copy paper, $47.5 \%$ envelope paper, $5 \%$ facepaper with adhesive material ( $\sim 1 \%$ adhesive).

Used $56.85 \mathrm{~kg}$ (53.44 kg OD) copy paper, $55.25 \mathrm{~kg}(51.94 \mathrm{~kg}$ OD) envelope paper, and $5.984 \mathrm{~kg}$ (5.625 kg OD) F-2006 facepaper. The F-2006 facepaper has edges that are not coated with adhesive, which is accounted for in the reduced weight of envelope paper. Total weight of all pulper materials $=118.08 \mathrm{~kg}(112.5 \mathrm{~kg}$ OD). Adhesive material was adhered on envelope paper a minimum of 72 hours prior to the trial.

\section{Notes:}

- Feed to pressure screening stage started at 7:48 am. Screen B plugged initially just after start-up, but the crew got it working properly within a minute or two. Cleaning stage began at 9:30 am. Overall, the trial ran smoothly.

- $\quad$ Pulping: Temperature before pulping $=40.2^{\circ} \mathrm{C}$. Temperature after pulping $=44.3^{\circ} \mathrm{C}$. Pulper consistency $=12.7 \%$. Pulper particle size $=0.6856$ sq. mm. Pulper energy consumption was $47.1 \mathrm{kWhr} / \mathrm{MT}$. According to Grant, PSA actual pulping time was under $20 \mathrm{~min}$ (18.6 min) due to incorrect use of pulping procedure (pulp time button was pressed before PSA was added to the pulper, not after).

- Screening: Screen A (12 cut), flat screen (8 cut) and Screen B (4 cut) were used. Nothing out the ordinary to report except that noted above.

- Flat Screen: Adhesive is visible in the flat screen accepts and rejects as fine white worms. The worms appear somewhat thinner than the benchmark adhesive (STR 34355). The worms agglomerate to each other well. At the end of screening the rejected worms had agglomerated into a rubbery mass (looked like white scrambled eggs). Flat screen rejects $=0.753 \mathrm{~kg}$ OD.

- Cleaning: Nothing out of the ordinary to report.

- Flotation: 63 grams of DI-700 surfactant were dissolved in $60 \mathrm{~L}$ of water. The overall average pump rate from start to finish was $0.96 \mathrm{Lpm}(\sim 45 \mathrm{~L}$ used in $\sim 47$ minutes; target pump rate $=1 \mathrm{Lpm})$. 
The flotation cell was very foamy on top (seemed to be foamier than with the benchmark adhesive STR 34355). The foaminess likely contributed to a higher average reject rate compared to the benchmark adhesive.

- Drumwasher: Nothing out of the ordinary to report. Ran well. Final pulp averaged $22.8 \%$ csc.

- Data Acquisition: Nothing out of the ordinary to report.

- Sample Analysis: Handsheet ppm levels are reported using 20\% contrast in scanning software. From alternate method (Verity) image analysis results, the 12 cut $(0.3 \mathrm{~mm})$ screening efficiency was $83.5 \%$ and the overall screening efficiency (4 cut $(0.1 \mathrm{~mm})$ screen accepts) was $99.4 \%$. Final pulp adhesive content was $7 \pm 3$ ppm (average of values from two bags after statistical analysis of individual handsheet values).

- Cleaning Run: $0 \pm 1 \mathrm{w} / 20 \%$ contrast; acceptable. 


\section{Trial \#370 Summary}

Date: September 4, 2003

Purpose: Phase IV configuration testing of Univ. of MN sample F-2007 (water-based adhesive). Trial results to be compared with Trial \#369.

Materials: Required Mass Loadings: $47.5 \%$ copy paper, $47.5 \%$ envelope paper, $5 \%$ facepaper with adhesive material ( $\sim 1 \%$ adhesive).

Used $56.85 \mathrm{~kg}(53.44 \mathrm{~kg}$ OD) copy paper, $55.29 \mathrm{~kg}(51.97 \mathrm{~kg}$ OD) envelope paper, and $6.016 \mathrm{~kg}$ (5.625 kg OD) F-2007 facepaper. The F-2007 facepaper has edges that are not coated with adhesive, which is accounted for in the reduced weight of envelope paper. Total weight of all pulper materials $=118.16 \mathrm{~kg}(112.5 \mathrm{~kg} \mathrm{OD})$. Adhesive material was adhered on envelope paper a minimum of 72 hours prior to the trial.

\section{Notes:}

- Feed to pressure screening stage started at 7:34 am. Cleaning stage began $\sim 9: 10 \mathrm{am}$. Overall, the trial ran smoothly.

- Pulping: Temperature before pulping $=40.4^{\circ} \mathrm{C}$. Temperature after pulping $=44.5^{\circ} \mathrm{C}$. Pulper consistency $=12.6 \%$. Pulper particle size $=0.6429$ sq. $\mathrm{mm}$. PSA pulping time was 20.8 minutes and pulper energy consumption during this time was $51.7 \mathrm{kWhr} / \mathrm{MT}$.

- Screening: Screen A (12 cut), flat screen (8 cut) and Screen B (4 cut) were used. Nothing out the ordinary to report. Screen B started up smoothly.

- Flat Screen: Adhesive is visible in the flat screen accepts as white worms that appear longer and slightly thicker than in Trial \#369 with F-2006. The worms agglomerate to each other extremely well. At the end of screening the rejected worms had agglomerated into a rubbery mass (looked like white scrambled eggs). By visual inspection, the flat screen rejects collected at the end of the trial appear to be about $1 / 2$ the mass of that collected for Trial \#369 with F-2006. Flat screen rejects $=0.434 \mathrm{~kg} \mathrm{OD}$.

- Cleaning: Nothing out of the ordinary to report, except that the second forward cleaner had a rough startup. Grant flushed the second forward cleaner through the rejects outlet, which seemed to alleviate any problem. Also, the flowmeter for the second thru-flow cleaner need to be checked and possibly recalibrated as it read a total flow volume larger than the feed volume.

- Flotation: 63 grams of DI-700 surfactant were dissolved in $60 \mathrm{~L}$ of water. The overall average pump rate from start to finish was not accurately measured $(\sim 12-15 \mathrm{~L}$ were left over at the end, which is typical; target pump rate $=1 \mathrm{Lpm}$ ). 
- Drumwasher: Ran well, except feed pump would not deliver last 200-300 L, possibly due to recirc. valve being open. Bob tried to keep feed pumping, but ended up getting water in final pulp barrel, making yield calculations inaccurate. For future trials, close recirc. valve when $\sim 500 \mathrm{~L}$ remaining in glass-lined tank . Final pulp averaged $24.1 \%$ csc.

- Data Acquisition: Nothing out of the ordinary to report.

- Sample Analysis: Handsheet ppm levels are reported using 20\% contrast in scanning software. From alternate method (Verity) image analysis results, the 12 cut $(0.3 \mathrm{~mm})$ screening efficiency was $82.3 \%$ and the overall screening efficiency (4 cut $(0.1 \mathrm{~mm})$ screen accepts) was $98.6 \%$. Final pulp adhesive content was $6 \pm 3$ ppm (average of values from two bags after statistical analysis of individual handsheet values).

- Cleaning Run: $3 \pm 3$ w/ 20\% contrast; acceptable. 
Appendix 2: Phase IV Pilot Plant Recycling Procedure

These procedures are developed for evaluating the recyclability of environmentally benign postage stamp materials using those conventional unit operations located in the USDA Forest Products Laboratory pilot laboratory paper recycling facility. The process involves high consistency repulping, slot screening, centricleaning with both forward and thru-flow cleaners, flotation, washing, and papermaking using a pilot laboratory machine. Screening and forward cleaning include secondary fiber recovery.

\section{A. Equipment \& Materials}

I. Equipment

1. VOITH high consistency pulper model HC-1.5, $2500 \mathrm{~L}$ total volume, $1500 \mathrm{~L}$ maximum working volume, equipped with OHIO SEMITRONICS model CTX-500S current transducers feeding an OHIO SEMITRONICS model WH3-11195 AC watt-hr meter.

2. VOITH MULTIFRACTOR pressure screen model 00 equipped with a 0.30 $\mathrm{mm}(0.012$ ”) slotted basket (1st primary stage). Voith VPS-05 pressure screen equipped with a $0.10 \mathrm{~mm}(0.004$ ") C-bar slotted basket (2nd primary stage).

3. AMINCO 6-plate vat flatscreen w/ $0.2 \mathrm{~mm}(0.008$ ") slotted plates 600 -liter tank plus transfer pump (fiber recovery and adhesive collection stage).

4. Beloit POSIFLOW 60 forward centricleaner (1st primary stage); Celleco CLEANPAC 270 forward centricleaner (2nd primary stage); Voith KSP 60 forward centricleaner with primary reject collection tank and stock pump (secondary fiber recovery stage).

5. Black-Clawson X-clone thru-flow centricleaner, $100 \mathrm{~mm}$ (4") nominal diameter; two primary cleaners in series.

6. LaMort 5000-L, 2-stage laboratory flotation cell.

7. Scales and 200-Liter drums to collect secondary forward cleaner rejects and flotation cell rejects.

8. Stock tanks and pumps, sufficient to store and transfer stock being processed.

9. Foxboro 8000A Magnetic flow tubes and IMT25 Magnetic flow transmitters installed throughout the system. These are the primary units for rate and volume measurements.

10. NALGENE, HDPE containers, or equivalent: 1-L, 4-L, 10-L, and 20-L capacities in sufficient numbers for sample collection. 
11. Self-sealing plastic bags, for sample collection: 4-L plus others as needed.

12. Assorted plastic bags ( $30 \times 60 \mathrm{~cm}, 45 \times 90 \mathrm{~cm}$ minimum sizes) for sample storage. Scales, $150-\mathrm{kg}$ minimum capacity, minimum resolution $0.1 \mathrm{~kg}$. Thermometers, utility knives, glassware, $\mathrm{pH}$ meter, etc. as required.

13. Screen carts, 1 x 1 x 1.5 meter, with 100 - mesh bottom wire (6 needed).

14. Balance, $1-\mathrm{kg}$ capacity, minimum accuracy $0.1 \mathrm{gm}$.

15. Vacuum drum washer, laboratory unit with 100-mesh wire; equipped with press roll and shredder.

16. Barrels, 200-Liter (or equivalent) for storage of cleaned pulp.

17. TAPPI handsheet former and auxiliary equipment

II. Materials

Definitions

Standard (Linered) Pressure Sensitive Adhesive (PSA) Stamp Laminate:

Face Paper/PSA/Release Liner, with or without printing.

Face paper: base paper sheet only, as used to prepare the Standard (Linered) Pressure Sensitive Adhesive Stamp Stock described above.

Linerless Pressure Sensitive Adhesive (PSA) Stamp Stock: Release coating/Printing/Face Paper/PSA.

Papers

Copy paper: single supply for all work; procured by USPS/FPL as a $31,000 \mathrm{lb}$. shipment derived from 2 consecutive master rolls from a commercial paper machine, slit into 24 " wide working rolls of approximately $1100 \mathrm{lb}$. each.

Envelope paper: single supply for all work; procured by USPS/FPL as a $180,000 \mathrm{lb}$. shipment derived from consecutive master rolls from a commercial paper machine, slit into 24" wide working rolls of approximately $1100 \mathrm{lbs}$. each.

Stamp stock face papers: $45 \mathrm{~kg}$. (approximate) supplied by USPS with tie layer, with no printing or adhesive. 3 rolls of paper, one roll from each of three suppliers. 
Linerless (PSA) stamp stock: $50 \mathrm{~kg}$. supplied by USPS. Same stock sample used for Phase 3 study.

Standard PSA stamp laminate: $150 \mathrm{~kg}$. supplied in 3 rolls: conventional construction currently used for stamps (same supply used for phase 3 study)

Experimental PSA stamp laminate, as submitted to FPL through USPS/STR: $20 \mathrm{~kg}$ each adhesive on each face paper (3 preconsumer samples per adhesive) (60 kg total), procured as defect-free production scrap from the stamp preparation process.

Gummed WAG (water-activated glue) stamp stock; 3 rolls each printed by a different printing method: intaglio, offset \& rotogravure.

PSA linerless label stock (color: "canary"), 80\# roll. Current type used by USPS for change-of-address labels

USPS self-sticking PSA Label 11-F (July 1997): EXPRESS MAIL address label. 4000 labels (32 kg.).

III. Other materials

1. Morplas Blue 1003, $0.67 \mathrm{gm} / \mathrm{L}$ in heptane.

2. $\mathrm{pH}$ standards: $4.0,7.0,10.0$

3. Blotters, $20 \mathrm{~cm}$ square, meeting TAPPI specifications.

4. a) Whatman \#4 filter paper or equivalent, $15 \mathrm{~cm}$ diameter.

b) Same, $32 \mathrm{~cm}$ diameter.

5. $10-15 \% \mathrm{NaOH}$ solution.

6. $10-15 \% \mathrm{H}_{2} \mathrm{SO}_{4}$ solution.

7. Flotation aid: HighPoint DI-700A.

8. Soft water: 20 and $80^{\circ} \mathrm{C}$, central supply.

B. Stock Preparation (for each trial)

Throughout the following unit operations flowrates, consistencies, volumes, etc. will be determined in order to establish a mass balance for the processing. Necessary data will be recorded as appropriate.

I. Pulping 
1. Weigh out $112.5 \mathrm{~kg}$, oven-dry basis, of fiber-based material. Measure and record solids content of paper(s).

A. A typical phase 4 pre-consumer loading will be $50.625 \mathrm{~kg}$ copy paper (45\% of total), $50.625 \mathrm{~kg}$ envelope paper ( $45 \%$ of total) and $11.25 \mathrm{~kg}$ total composite stamp stock ( $10 \%$ of total).

B. A typical phase 4 post-consumer loading will be $112.5 \mathrm{~kg}$ of cancelled envelopes each containing one sheet of copy paper.

C. For a post-consumer, non-envelope, trial (phase 3 technique) the $11.25 \mathrm{~kg}$ of total composite stamp stock is weighed out, the release liner is removed and the remaining "stamps" are affixed to envelope paper. The removed release liner is weighed and an equivalent amount of copy/envelope paper ( $1 / 2$ each) is added as make-up. This technique will approximate a $47.5 \%$ copy paper, $47.5 \%$ envelope paper, $5 \%$ stamp stock composition: the actual composition will depend on the basis weight of the release liner.

2. Fill pulper with 780 liters softwater at $46 \pm 2^{\circ} \mathrm{C}\left(115 \pm 5^{\circ} \mathrm{F}\right)$. Adjust $\mathrm{pH}$ to 10.0 with $\mathrm{NaOH}$. Use $\mathrm{H}_{2} \mathrm{SO}_{4}$ to correct overshoots.

Pre-consumer trials

Add copy and envelope papers, with minimal agitation until all paper has been introduced and wetted. Blend for 1 minute, adding only enough water to cause slurry to roll properly. Record total water added.

Stop agitation at end of the one minute; measure $\mathrm{pH}$ and temperature. Restart pulper and immediately start energy-measuring unit. Blend in adhesive-containing stock quickly, while continuing to pulp for a total of 20 minutes. Add just enough water to maintain rolling of the slurry. Collect a consistency sample when rotor has stopped immediately upon shutting off pulper.

Post-consumer trials

Same as (a) except add cancelled envelopes in their entirety as quickly as pulper will take them. Add water only as necessary. Measure temperature and $\mathrm{pH}$. Then start pulper and energy measuring unit.

(Target: total volume $=900$ liters to give a $12.5 \%$ consistency. Actual volume and consistency is determined by producing the proper roll of the slurry at the highest possible consistency (minimum amount of water) to achieve the roll.).

(Note: pulping time was determined in developing the phase 3 portion of this study.) 
3. At end of 20 minutes first shut off energy-measuring unit, then immediately the pulper. Measure final temperature, and $\mathrm{pH}$, and record energy input. Dilute slurry to $1500 \mathrm{~L}$, maintaining temperature at $46 \pm 2^{\circ} \mathrm{C}\left(115 \pm 5^{\circ} \mathrm{F}\right)$.

4. Fill the feedtank with enough water to dilute the slurry to $\underline{\mathbf{2 . 2 6 5 \%}}$ consistency maintaining temperature at $46 \pm 2^{\circ} \mathrm{C},\left(115 \pm 5^{\circ} \mathrm{F}\right)$. Use the feed tank pump to feed the ventri mixer and draw the stock from the pulper. Mix well. Measure actual consistency. Measure temperature. From stock in tank save one 10-L sample (SAMPLE POINT 1).

\section{Pressure Screening}

1. Pre-fill flatscreen, equipped with $0.2 \mathrm{~mm}(0.008$ ") slots, and its $600-\mathrm{L}$ stock tank with $46^{\circ} \mathrm{C}$ water. Record volume of water used. Fill pressure screens with water. Begin pumping flatscreen accepts weir water to 1st pressure screen, equipped with $0.30 \mathrm{~mm}(0.012$ ") slots, at $175 \mathrm{~L} / \mathrm{min}$. Adjust the 0.3 $\mathrm{mm}$ screen rejects flow to $45 \mathrm{~L} / \mathbf{m}$ ( $15 \%$ of total feed) with rejects passing back to flatscreen.

2. Begin pumping feedtank slurry to $0.30 \mathrm{~mm}$ pressure screen at $125 \mathrm{~L} / \mathbf{m i n}$ target rate total flow $=300 \mathrm{~L} / \mathrm{min}$ ), with accepts passing at $255 \mathrm{~L} / \mathrm{min}$ to the second pressure screen, equipped with $0.10 \mathrm{~mm}(0.004$ ") slots. Rejects from the $0.1 \mathrm{~mm}$ pressure screen pass back to the feedtank at $52 \mathrm{~L} / \mathbf{m i n}$

3. Pump the initially clear water from the $600-\mathrm{L}$ stock tank to the flatscreen at $130 \mathrm{~L} / \mathrm{min}$. The $0.1 \mathrm{~mm}$ pressure screen accepts go to the $4000 / 8000-\mathrm{L}$ stock tanks. Immediately begin adding sufficient fresh $46^{\circ} \mathrm{C}$ soft water to $600-\mathrm{L}$ stock tank to maintain the $130 \mathrm{~L} / \mathrm{min}$ flow to the flatscreen. Pressure screen target pressures are to be $115 \mathrm{kPa}(17 \mathrm{psi})$ feed/ $110 \mathrm{kPa}(16 \mathrm{psi})$ accepts for the $0.30 \mathrm{~mm}$ slots and $102 \mathrm{kPa}$ (15 psi) feed/ $96 \mathrm{kPa}$ (14 psi) accepts for the $0.10 \mathrm{~mm}$ slots. Actual values are determined by the nature of the stock and are to be logged and reported. Flowrates are to be maintained.

4. When at equilibrium save a 10-L carboy of accept stock from each pressure screen and a 20-L sample from the flatscreen accepts stock for handsheets (SAMPLE POINTS 3, $5 \&$ 7). Measure consistency of all accepts and (SAMPLE POINTS 2 \& 4) streams. Measure flowrates and total flows of all streams. Measure temperature of final accepts.

5. When $0.1 \mathrm{~mm}$ screening accepts reaches 9000 liters, shut off all flows. Record all volumes. Then pass all remaining flatscreen accepts back to feedtank for disposal. Flush flatscreen with fresh water to remove all fiber.

6. When only adhesive and paper tags remain on flatscreen collect rejected adhesive retained by the flatscreen, dry, and weigh for yield (SAMPLE POINT 6). 
7. Dilute (at $46^{\circ} \mathrm{C}$ ) accepts to $0.65 \%$ consistency, intermixing the slurry in the 4000- and 8000-L tanks until of uniform consistency. Save a 10-L carboy of the uniformly blended accepts slurry for handsheets (SAMPLE POINT 8). Measure consistency.

All of the next operations are performed as a continuous operation

III. Forward Cleaning

1. Slowly open feed valve to 1st primary forward cleaner (Beloit Posiflow 60) until accepts flow is $234 \mathrm{~L} / \mathrm{min}$. Feedrate will be between 240 and $260 \mathrm{~L} / \mathrm{min}$. Accepts flow to a $600-\mathrm{L}$ stock tank and then are pumped to the 2nd primary forward cleaner (Celleco Cleanpac 270) at a feedrate that maintains the level in the $600-\mathrm{L}$ tank.

2. Accepts at $212 \mathrm{~L} / \mathrm{min}$ pass to a second $600-\mathrm{L}$ stock tank. Back pressure of Celleco cleaner must be in the range of $54-136 \mathrm{kPa}(8-20 \mathrm{psi})$. When flow is at equilibrium save a 10-L accepts sample from each cleaner accepts tank (SAMPLE POINTS $9 \&$ 11). Rejects from both primary stages $(56 \mathrm{~L} / \mathrm{min})$ are to be combined in a stock tank, diluted with fresh water $(30 \mathrm{~L} / \mathrm{min})$ at $46^{\circ} \mathrm{C}$, pumped through a secondary fiber recovery forward cleaner (Voith KS60P), with the accepts passing back to the primary forward cleaner feed tank and with the rejects $(7-8 \mathrm{~L} / \mathrm{min})$ being collected in 55-gallon drums (SAMPLE POINT 15). Actual feed/accepts pressures to be set to balance flow. Measure consistency of rejects from each cleaner (SAMPLE POINTS $10,12 \& 15)$. Save two 10 -L samples of secondary cleaner feedstock (SAMPLE POINT 13).

Actual diluted consistency of primary rejects (SAMPLE POINT 13) to be such that the secondary accepts are equal to the initial primary feed consistency.

3. Save a 10-L sample of the secondary forward cleaner accepts for handsheets (SAMPLE POINT 14). Measure flow rates on all primary and secondary accepts and reject streams. Measure consistencies on all streams. Measure accepts temperature in both $600-\mathrm{L}$ tanks and that of the secondary cleaner accepts.

4. As the 8000 -L feedtank empties, continuously transfer contents of $4000-\mathrm{L}$ feedtank to the 8000 -L tank.

IV. Thru-flow Cleaning

1. When the $600-\mathrm{L} 2^{\text {nd }}$ forward cleaner accepts tank is $1 / 2$ full of stock begin feeding slurry to the 1 st through-flow cleaner at $212 \mathrm{~L} / \mathrm{min}$, adjusted slightly 
to maintain level in the feed tank. Target feed pressure is to be $210 \mathrm{kPa}$ ( 30 psi) and back pressure is to be $70 \mathrm{kPa}(10 \mathrm{psi})$. Rejects are fed to a drain at approximately $22 \mathrm{~L} / \mathrm{min}$ while measuring the reject flowrate and total reject volume with an accumulator. Save a 4-L reject sample for consistency (SAMPLE POINT 17).

2. Accepts flow to a $1000-\mathrm{L}$ stock tank at approximately $190 \mathrm{~L} / \mathrm{min}$ When this accepts tank is about $1 / 2$ full turn on pump to feed 2 nd through-flow cleaner (same pressures), with accepts from 2nd stage flowing to its stock accepts tank at approximately $165 \mathrm{~L} / \mathrm{min}$ Balance flows to maintain tank levels. At the same time that the 2nd through-flow cleaner pump is started, begin injecting DI-700A flotation aid ( $0.10 \%$ dry fiber basis) to suction port of the transfer pump. Measure reject flow as for $1^{\text {st }}$ stage, saving a 4-L reject sample for consistency (SAMPLE POINT 19).

3. While maintaining a pressure difference of $140 \mathrm{kPa}(20 \mathrm{psi})$ adjust actual pressures to balance flows. When at system equilibrium save a 10-liter sample of each accepts stream (SAMPLE POINTS $16 \&$ 18). Measure accepts stream temperatures and flowrates.

V. Flotation and Washing

1. When slurry begins to enter flotation cell turn on airflow to $10 \mathrm{~L} / \mathrm{min}$. When outer cell is filled to above return stock injection ports turn on main circulation/transfer pump with stock exit valve shut. When outer cell is nearly filled begin the vacuum removal of foam. When outer cell is full open exit valve sending accepts to the glass-lined tank. Adjust the level controller to give the proper level in the tank. Rejects are sampled and their consistency determined (SAMPLE POINT 21). Reject rate is about 5-7 L/min. When glass-lined tank has received about $1 / 2$ of the total slurry save a 10-L sample of the flotation cell accepts (SAMPLE POINT 20). Determine its consistency.

2. Begin pumping stock from glass-lined tank to drum washer at $115-125 \mathrm{~L} / \mathrm{min}$ as soon as pump is flooded. Dewater stock using vacuum plus pressure roll, shredding the mat and depositing the resulting crumbed pulp in barrels. Calculate total washer wastewater volume from input volume minus barreled pulp volume. Collect a 4-liter washwater samples after about a 20-minute running time; determine consistencies on these samples (SAMPLE POINT 23).

3. When input to the flotation cell from the through-flow cleaner ceases, shut off the outflow from the flotation cell and let the cell operate batch-style for 10 minutes to strip remaining flotables. Then reopen outflow valve and empty cell to glass-lined tank. 
4. Sample final crumb pulp entering barrels by catching a handful of pulp at each $1 / 3$ barrel level and place the three handfuls in a 12 " x 12 " plastic bag (SAMPLE POINT 22). Mix well and determine consistency on the combined sample. Weigh barrels and calculate total oven-dry pulp. Repeat for each barrel.

5. After consistencies are done, combine the pulps in each bag into one batch, mix well and submit for handsheets.

\section{CLEANING}

1. For stock preparation, after each trial the system is to be thoroughly flushed with water, followed if necessary, by a scrubbing with copy paper, envelope paper and/or virgin lap pulp. The system is again flushed with water and a second copy/ envelope paper scrubbing follows, with a pulp sample taken after shredding (SAMPLE POINT 16). If dirt count exceeds the equivalent to a FPL 15 ppm, an additional scrubbing with copy/envelope paper is made. Target level is below 10 ppm FPL.

2. Baskets from the pressure screen are manually cleaned of the adhering adhesive. The baskets are then cleaned with a pressure washer.

3. The plates from the flatscreen are cleaned with the pressure washer but no effort is made to measure the residual traces of adhesive as it represents only a small trace of the total adhesive removed from the screen previously. The entire flatscreen is pressure washed while the plates are out to maximize the cleanliness of the unit. 
Appendix 3: Hydrophobic Contaminant Identification Method

DRAFT 3 May 2002

\section{Scope}

1.1 This procedure describes a method for quantifying hydrophobic contaminants in pulp samples. A dye that associates with contaminant particles is used to develop contrast from the pulp background. Computer-based color image analysis can then be used to quantify contamination levels by type based upon color and shade.

1.2 This method is a compliment to TAPPI T 213 "dirt in pulp". It allows for the quantification of hydrophobic contaminants that do not have sufficient contrast with pulp to be identified. Hydrophobic contaminants, i.e., waxes, pressure sensitive adhesives, hot melt adhesives, etc., can contribute to "stickie" problems in recycled fiber mills.

\section{Significance}

2.1 When coupled with automated color image analysis contaminant measurement and classification methods, this method provides a more complete quantification of pulp contaminants.

\section{Apparatus}

3.1 Standard handsheet mold as described in TAPPI T 205 sp-95.

3.2 Standard couch roll.

3.3 Standard blotting paper as described in TAPPI T $205 \mathrm{sp}-95$.

3.4 Handsheet dryer with an operating temperature of $150^{\circ} \mathrm{C}$.

3.5 Image analysis system.

3.6 Plastic or metal tray large enough to hold a blotting paper.

3.7 Foam varnish applicator.

3.8 Laboratory timer

3.9 Standard press as described in TAPPI T $205 \mathrm{sp}-95$

\section{Reagent}

4.1 dye solution $0.67 \mathrm{~g}$ of C.I. solvent blue 36 in 1 liter of $n$-heptane. The dye is also known as Morplas Blue 1003 and can be obtained from Pylam Products Company Inc., 2175 East Cedar Street, Tempe, AZ 85281, (602) 929-0070

\section{Procedure}

5.1 Form handsheets according to TAPPI T 205, except end the procedure after couching. After couching the second wet blotting paper is discarded and a third dry one is placed to protect the handsheet attached to the first blotting paper.

5.2 Stack handsheets and blotters, using care to align sheets in a uniform stack. Place the stack in a press and, over a period of 30 seconds, raise the pressure to $345 \mathrm{kPa}$ (50 psig). Maintain this pressure for 5 minutes. 
5.3 Carefully unstack the sheets and place each pair of blotter papers, with a handsheet between them, on the dryer. The intent is to leave the handsheet firmly attached to the couching blotting paper until it is dyed. Dry for 3 minutes at $150^{\circ} \mathrm{C}$ with gentle restraint.

5.4 Dye the handsheet by applying the dye solution to the back side of the blotter that has a handsheet attached. This allows the dye to uniformly penetrate the handsheet. Furthermore, as the dye solution passes through the blotting paper undissolved dye particles are filtered from the solution. Typically, dying is done by placing the blotting paper/handsheet with the handsheet side down on another blotting paper in a tray, and then painting the blotting paper with a foam brush that has been dipped in the dye solution. This step of the procedure should be carried-out in a ventilation hood to avoid exposure to heptane vapors. Since the dye is a mild sensitizer, heptane-tolerant gloves are also required.

5.5 Let the heptane evaporate from the blotting paper/handsheets without separating the handsheet from the blotter paper by hanging them with clips attached to the blotter paper in the ventilation hood. Typical drying times are 2-3 minutes.

5.6 With a gloved hand, gently peel the dyed handsheet from the blotting paper. Place the side that was towards the blotting paper on the glass of the flat bed scanner. Using a weight with a white surface, hold the sheet flat on the scanner.

5.7 Use the color image analysis software to quantify the number of particles on the sheet. To compensate for sheet to sheet variations in dye intensity, best results are obtained by using a threshold that is automatically set $20 \%$ below the mode of the sheet image picture point luminance value frequency distribution. The software system developed by Verity IA LLC was used in this study. The scanner used was an AGFA Argus II.

\section{Report}

6.1 Results are reported as parts per million of the scanned area. Typically an average and $95 \%$ confidence interval for $10-40$ standard $1.2 \mathrm{~g}$ handsheets is calculated.

\section{References}

[1] TAPPI Test Method T 213 om-97.

[2] R. Trepanier et al. TAPPI Journal Dec 1989 p. 153.

[3] J. Klungness et al. TAPPI Journal Jan 1989 P. 89.

[4] C. Houtman et al. Proceedings of the TAPPI 2000 Recycling Conference, Vol. 2 p.403.

[5] R. Rosenberger Proceedings of the TAPPI 1999 Recycling Conference p. 669.

[6] G.E.P Box et al. "Statistics for Experimenters" John Wiley and Sons, NY, 1978, p. 323. 
Appendix 4: Datasheets and Image Analysis Results

\section{Consistencies}

Consistencies for various sample points are shown in Table A4-1.

Table A4-1. Consistencies for various sample points for Trials \#369 and \#370.

\begin{tabular}{|c|c|c|}
\hline Sample Point (ID No.) & $\begin{array}{c}\text { Trial \#369 } \\
\text { Consistency } \\
(\%)\end{array}$ & $\begin{array}{c}\text { Trial \#370 } \\
\text { Consistency } \\
(\%)\end{array}$ \\
\hline Pulper (I) & 12.69 & 12.57 \\
\hline Screening Feed (1) & 2.17 & 2.21 \\
\hline Screen A (0.3 mm) Rejects $(2)$ & 1.30 & 1.36 \\
\hline Screen A $(0.3 \mathrm{~mm})$ Accepts $(3)$ & 0.87 & 0.95 \\
\hline Screen B (0.1 mm) Rejects (4) & 1.91 & 1.89 \\
\hline $\begin{array}{l}\text { Screen B }(0.1 \mathrm{~mm}) \text { Accepts }(5) \\
\text { (Feed to Forward Cleaners) }\end{array}$ & 0.71 & 0.72 \\
\hline Flatscreen $(0.2 \mathrm{~mm})$ Accepts $(7)$ & 0.31 & 0.36 \\
\hline First Forward Cleaner Feed (8) & 0.68 & 0.66 \\
\hline First Forward Cleaner Accepts (9) & 0.52 & 0.52 \\
\hline First Forward Cleaner Rejects (10) & 2.44 & 2.01 \\
\hline Second Forward Cleaner Accepts (11) & 0.51 & 0.51 \\
\hline Second Forward Cleaner Rejects (12) & 0.69 & 0.69 \\
\hline Forward Fiber Recovery Cleaner Feed (13) & 0.83 & 0.77 \\
\hline Forward Fiber Recovery Cleaner Accepts (14) & 0.74 & 0.73 \\
\hline Forward Fiber Recovery Cleaner Rejects (15) & 1.21 & 1.21 \\
\hline First Thru-flow Cleaner Accepts (16) & 0.52 & 0.52 \\
\hline First Thru-flow Cleaner Rejects (17) & 0.12 & 0.12 \\
\hline $\begin{array}{c}\text { Flotation Feed (18) } \\
\text { (Second Thru-Flow Cleaner Accepts) }\end{array}$ & 0.53 & 0.55 \\
\hline Second Thru-flow Cleaner Rejects (19) & 0.12 & 0.12 \\
\hline Flotation Accepts (20) & 0.51 & 0.51 \\
\hline Flotation Rejects (21) & 1.30 & 1.64 \\
\hline Final Pulp (22) & 22.75 & 24.1 \\
\hline Drumwasher Effluent (23) & --- & --- \\
\hline
\end{tabular}


APPENDIX 4: Final Report Submitted by Dr. Yulin Deng of IPST (Subcontractor)

DEVELOPMENT OF SCREENABLE PRESSURE SENSITIVE ADHESIVES

Final Report to DOE

\author{
Yulin Deng \\ Institute of Paper Science and Technology \\ $50010^{\text {th }}$ Street NW, Atlanta, GA 30318, U.S.A.
}




\section{INTRODUCTION}

In recent years, the world has expressed an increasing interest in the recycling of waste paper to supplement the use of virgin fiber as a way to protect the environment. Statistics show that major countries are increasing their use of recycled paper. For example, in 1991 to 1996, the U.S. increased its recovered paper utilization rate from $31 \%$ to $39 \%$, Germany went from $50 \%$ to $60 \%$, the UK went from $60 \%$ to $70 \%$, France increased from $46 \%$ to $49 \%$, and China went from $32 \%$ to $35 \%$ [1]. As recycled fiber levels and water system closures both increase, recycled product quality will need to improve in order for recycled products to compete with products made from virgin fiber [2]. The use of recycled fiber has introduced an increasing level of metal, plastic, and adhesive contamination into the papermaking process which has added to the complexity of the already overwhelming task of providing a uniform and clean recycle furnish. The most harmful of these contaminates is a mixture of adhesives and polymeric substances that are commonly known as stickies.

Stickies enter the mill with the furnish and are not easily removed from the repulper and become more difficult the further down the system they get. This can be detrimental to the final product quality. Stickies are hydrophobic, tacky, polymeric materials that are introduced into the papermaking system from a mixture of recycled fiber sources. Properties of stickies are very similar to the fibers used in papermaking, viz. size, density, hydrophobicity, and electrokinetic charge. This reduces the probability of their removal by conventional separation processes, such as screening and cleaning, which are based on such properties. Also, their physical and chemical structure allows for them to extrude through screens, attach to fibers, process equipment, wires and felts. Stickies can break down and then reagglomerate and appear at seemingly any place in the mill. When subjected to a number of factors including changes in $\mathrm{pH}$, temperature, concentration, charge, and shear forces, stickies can deposit [3]. These deposits can lead to decreased runnability, productivity and expensive downtime. If the stickie remains in the stock, then machine breaks can be common. Finally, if the stickie is not removed or deposited, it will either leave in the final product causing converting and printing problems or recirculate within the mill.

It has been estimated that stickies cost the paper industry between $\$ 600$ and $\$ 700$ million a year due to the cost of control methods and lost production attributed to stickies [3]. Also, of the seven recycling mills opened in the United States between 1994-1997, four have closed citing stickies as the main reason responsible for the closure [4].

Adhesives are widely used throughout the paper and paperboard industry and are subsequently found in the recycled pulp furnish. Hodgson stated that even the best stock preparation process can only remove $99 \%$ of the contaminants, of which the remaining $1 \%$ is usually adhesives of various types which are usually 10-150 microns in effective diameter [5]. The large particles are removed by mechanical means such as cleaners and screens, and the smaller, colloidal particles can be removed with washing. It is the stickies that pass through the cleaning and screening processes that cause $95 \%$ of the problems associated with recycling [6]. The cleaners will remove most of the stickies that have a density varying from the pulp slurry $\left(\sim 1.0 \mathrm{~g} / \mathrm{cm}^{3}\right)$ and will accept stickies with densities ranging from $0.95-1.05 \mathrm{~g} / \mathrm{cm}^{3}[2]$. The hydrophobicity of the material is also an important characteristic of the stickie [7]. The hydrophobicity causes the stickies to agglomerate with other hydrophobic materials such as other stickies, lignin, and even 
pitch. The tacky and viscous nature of stickies contributes to many product and process problems, negatively affecting the practicality of recycled fiber use.

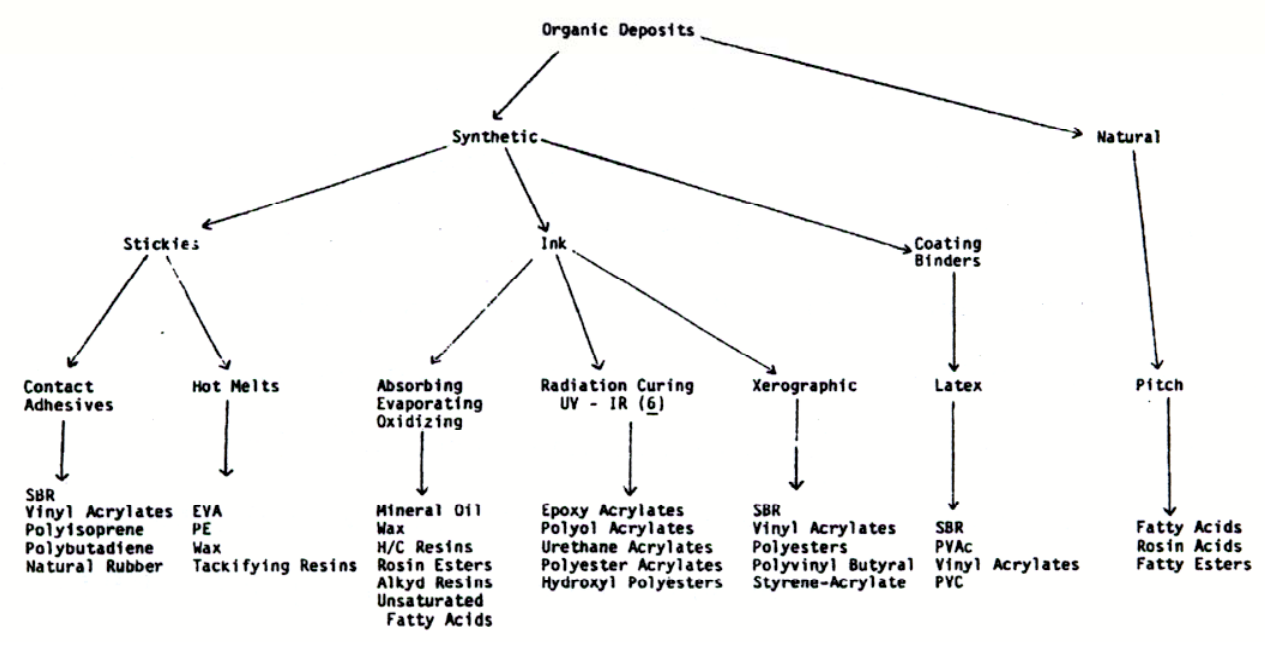

The source of stickies that evade conventional removal techniques are usually synthetic polymers, including acrylates, styrene butadiene rubber, vinyl acetates, and polypropylene [5,6,8-12]. Sources of these adhesives are usually broken down into categories based on application. These categories include contact and pressure sensitive adhesives, hot melts, and binders as Figure 1 illustrates [13].

Figure 1. Adhesive categories.

Pressure sensitive adhesives are primarily made up of a polymer, such as polyacrylate, styrene butadiene rubber (SBR) and a tackifying agent. PSAs are commonly used in self-sealing envelopes, tapes and labels and the tackiness of PSAs is not temperature sensitive. Hot melts commonly contain ethyl vinyl acetate (EVA) or polyvinyl acetate (PVA) as a backbone and a tackifying resin. They are mainly used in book and magazine bindings, boxes, envelopes, bags, and tubes. Hot melts are sensitive to temperature. Waxes are solid at lower temperatures and melt at the temperatures used in mill processing. Waxes also tend to become tacky when in liquid form. They are commonly seen in paper and paperboard coatings, such as cartons [14]. Several studies have collected deposits from mills and have showed the composition of these tacky deposits to commonly be acrylates and polyvinyl acetates [15-20].

The first step to controlling stickies would be to prevent them from entering the mill in the first place. However, this is not an easy task. Problems of stickies can be prevented by careful inspection of the wastepaper entering the mill [21]. Many recycle mills employ people to remove some of the waste paper that has visible stickie contaminants, to avoid process problems [22]. Contaminated waste paper that is removed is sent to the landfill, unused, at the expense of the mill. 
Screening and cleaning currently remove the majority of stickies. Macro stickies are effectively screened out with fine screens, however, as the slots in screens are made smaller, fiber loss occurs. Cleaners separate based on the difference in stickie density and pulp density [6]. After cleaning and screening, stickies are as small as $0.15 \mathrm{~mm}$ and can still be seen in the final product, even if they do not reagglomerate. Dispersion may break up the stickies further, but that is very dependent on consistency, pressure and temperature.

By taking advantage of stickies chemical properties that allow for stickies to elude cleaners and screens, several control strategies have been employed. Talc is a common chemical additive that is used to pacify stickies by covering stickie surfaces, causing them to be less tacky, increasing the specific gravity and allowing for easier removal by cleaners [23.] Talc's surface energy is lower than most adhesives, increasing its attraction to stickies. Other chemicals used for stickies control include dispersants, solvents, cationic polymers, synthetic fibers, zirconium compounds and alum sequestering agent [6]. However, additives are usually very expensive and do not solve the problem, they only temporarily fix it. Talc, zirconium compounds, and synthetic fibers only stabilize stickies by detackifying them, they do not reduce the particle size. These complexes are also shear sensitive, which can cause additional stickie surfaces to be exposed. Dispersants will reduce the particle size and prevent reagllomeration but are temperature and $\mathrm{pH}$ sensitive, which will cause compatibility problems with the existing mill chemistry and raised environmental issues. Anionic stickies are usually countered with low molecular weight, highly charged cationic polymers.

Bruyns et al. have studied problematic stickie deposits at a recycle mill [24]. The mill initially used caustic to clean the wires, which then caused an increase in the use of other chemicals, such as defoamer, sizing and anti-skid agent. It is also known that defoamer is sometimes a component of stickie deposits, thus aiding in stickie deposition on equipment. Other chemical usages were also altered in the mill. Ultimately, the mill returned to manual removal of most contaminated waste paper before pulping to save on further chemical usage.

Hawes [25] has studied a number of machine clothing types to minimize the deposition of stickies. Optimal shower placement and fabric resistance to chemicals that are used to clean off contaminants is where most of this work has been done. However, fabric coating that is resistant to stickie build up frequently wears off within a few days due to usage. Low molecular weight, high cationic charge density polymers are also applied to the machine wire as a barrier to prevent deposition. Cleaning solvents can also be used on machine clothing but cannot be returned to the process due to the high contamination and favorable stickie interaction.

An under explored area of recycling research is stickie deposition and growth on metallic surfaces. Stickies can attach to metallic surfaces, grow, and cause problems when they detach. Understanding the mechanism of attachment and growth of stickies on metallic surfaces will provide new insight into the prevention, interruption or removal of stickies from metallic surfaces of the paper machine. New techniques in image analysis and atomic force microscopy have emerged, allowing for better analysis tools for both quantitative and qualitative analysis of stickie-surface interactions.

In summary, after twenty years of paper recycling experience, stickies remain one of the major issues in recycled paper. Most of the stickie removal techniques are concentrated on physical 
properties of the stickie. Most stickie control strategies concentrated on passivation, by addition of chemicals such as talc, and coagulation and dispersion, by polymers. Stickie-surface interactions have concentrated on felts, fabrics, and rolls. None of these techniques are $100 \%$ efficient at removing stickies from the recycle system. Therefore, there is need to develop new technology to solve the stickies problem. This research is to develop new pressure sensitive adhesives, which can be screened out in paper recycling process.

\section{PROGRESS AND RESULTS}

\section{Part I: Fundamental understanding of the impacts of PSA physical properties on the}

\section{screenability}

Pressure-sensitive adhesives (PSAs) are the major source of stickies in paper recycling. It is desirable that the PSA not break down into very small pieces during repulping so that it can be screened out. However, it is not clear in the literature what mechanical properties of PSAs are required to make PSAs screenable. There are many studies ongoing in this area, but there is no fundamental understanding about the relationship between PSA properties and screenability. Obviously, this understanding is important because it will give PSA producers improved insight into the design of new screenable pressure-sensitive adhesives.

In this study, the screenability of a range of PSAs was evaluated. The hydrophobicity, peel, shear, tack and viscoelastic properties, tensile strength, and contact angle of these PSAs were measured. High tack and peel strength generally increase the screenability of PSAs. The dynamic property of the PSAs also has an effect on screenability. A PSA with a higher stretch index has higher screenability. It is also necessary for a screenable PSA to have a certain degree of hydrophobicity. The optimized PSA properties for a screenable PSA in laboratory repulping settings are reported.

\section{Materials}

Polyacrylate-base pressure-sensitive adhesives: XPD 1811, XPD 1822, XPD 1814, XPD 1988, 26146, 26222, 26171, 26207 were from BF Goodrich. 2077, 2232, 2233, 2431, 3120, 5014, 6072, 6210, 6240, 9110 were from Dyna-Tech Adhesives Inc. Tackifier Snowtack $780 \mathrm{G}$ and 755A were from EKA Chemicals.

\section{Coater}

The coater used was made by ChemInstruments in Fairfield, OH. It consisted of two steel cylinders that could be separated in parallel to known a thickness of 0.0001 ". It had a reservoir filled with either the PSA or the amine. Figure 1 shows a schematic of the coater that was used. The procedure that was used for coatings is as follows: 1) Coated silicone release lined paper was placed between the two cylinders with the release side up. 2) The gauges were then set to zero and the bars set in place. 3) The gauges were set to 0.002". 4) The polymer was then placed in the reservoir. 5) The paper was then drawn at constant speed until the polymer was used up. 


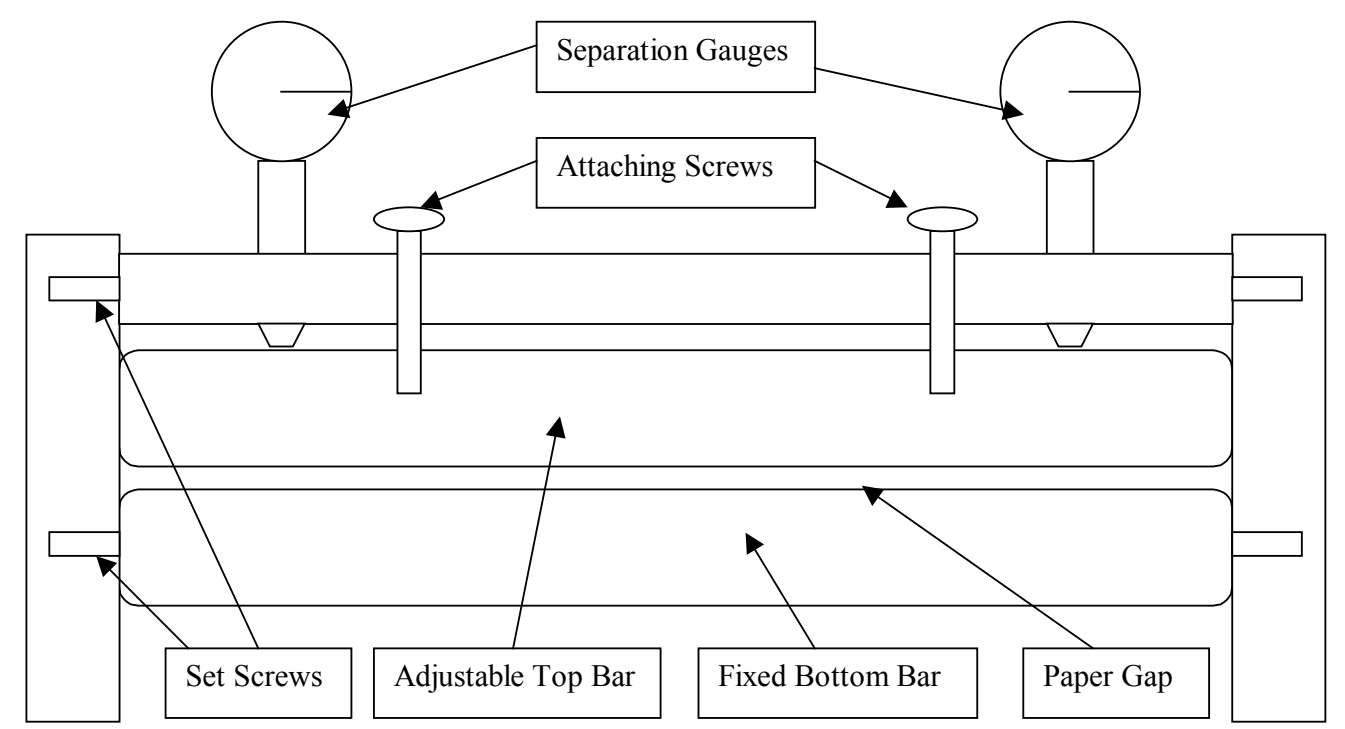

Figure 2. Schematic of Coater

The coated PSA was first air-dried for $15 \mathrm{mins}$, then dried at $110{ }^{\circ} \mathrm{C}$ for 5 mins. The PSA film was transferred to office white copy paper with a lab laminator at 90 psi for repulping and screening test. The PSA was transferred to polyester film with the laminator for PSA property test. All the PSA properties were tested according to the PTSC standard methods.

\section{Pulping and Screening}

Office white copy paper containing $0.3 \%$ of PSA was repulped with a lab LAMORT pulper. Pulping conditions are shown in Table 1. The final pulp freeness was $250 \mathrm{~mL}$. The pulp was screened on a Sommerville vibrating screen with a slot size of $0.2 \mathrm{~mm}$ without pressure.

Table 1. Pulping conditions for screenability tests.

\begin{tabular}{|l|l|l|l|}
\hline Time & Temperature & $\mathrm{pH}$ & Consistency \\
\hline $20 \mathrm{~min}$ & $50^{\circ} \mathrm{C}$ & 10.5 & $10 \%$ \\
\hline
\end{tabular}

Image Analysis

Handsheets for Image Analysis were made according to the standard Buchner funnel methods (PAPTAC Standard C.4U). VWR 415 filter paper with pore size of $25 \mu \mathrm{m}$ was used for filtration. The pad weight was $1.2 \mathrm{~g}$. The pad was pressed according to the standard TAPPI method T205 om-88, air dried, and then dyed. The dyed pad was analyzed with Image Analysis. Screenability was calculated according to: Screenability $=\left(A_{0}-A_{s}\right) \times 100 \% / A_{0}$, where $A_{0}$ is the stickies area of unscreened pulp and $A_{s}$ is the stickies area of screened pulp. 
The contact angle of PSA was measured by FTA200 with PSA coated on a polyester film. The tensile strength and mechanical property of PSA were measured by Instron. The PSA sample for measurement was $0.025 \mathrm{~mm}$ thick, $15 \mathrm{~mm}$ wide, and $5 \mathrm{~mm}$ long. Tensile strength is the maximum torsion force in stretching the PSA film. The stretch index was a measure of the elongation level of the film until a break occurs.

\section{Results and Discussion}

The function of PSAs is to ensure instantaneous adhesion upon application of light pressure. PSAs must possess viscous properties in order to flow and to be able to dissipate energy during the adhesive bonding process. They must also be elastic and be able to store bond rupture energy in order to provide good peel and shear performance. The end-use properties, which are essential in characterizing the nature of PSAs, include tack, peel adhesion, and shear. Tack measures the adhesive's ability to adhere quickly, peel adhesion measures its ability to resist removal through peeling, and shear measures its ability to hold in position when shear force is applied. These PSA end-use properties depend on the nature and composition of the PSA polymer. When papers containing PSAs are repulped in water, the PSA will interact with itself, fibers, water, and other materials during the repulping process. It may break or reagglomerate under shear. For PSAs to be screenable, they must form large particles that do not pass the cleaning screen. The PSA end-use properties and other physical properties should determine the PSA behavior in repulping, and hence the screenability.

Figure 3 shows the effect of PSA tack on screenability. It can be seen that with increased tack, the screenability of the PSA increases.

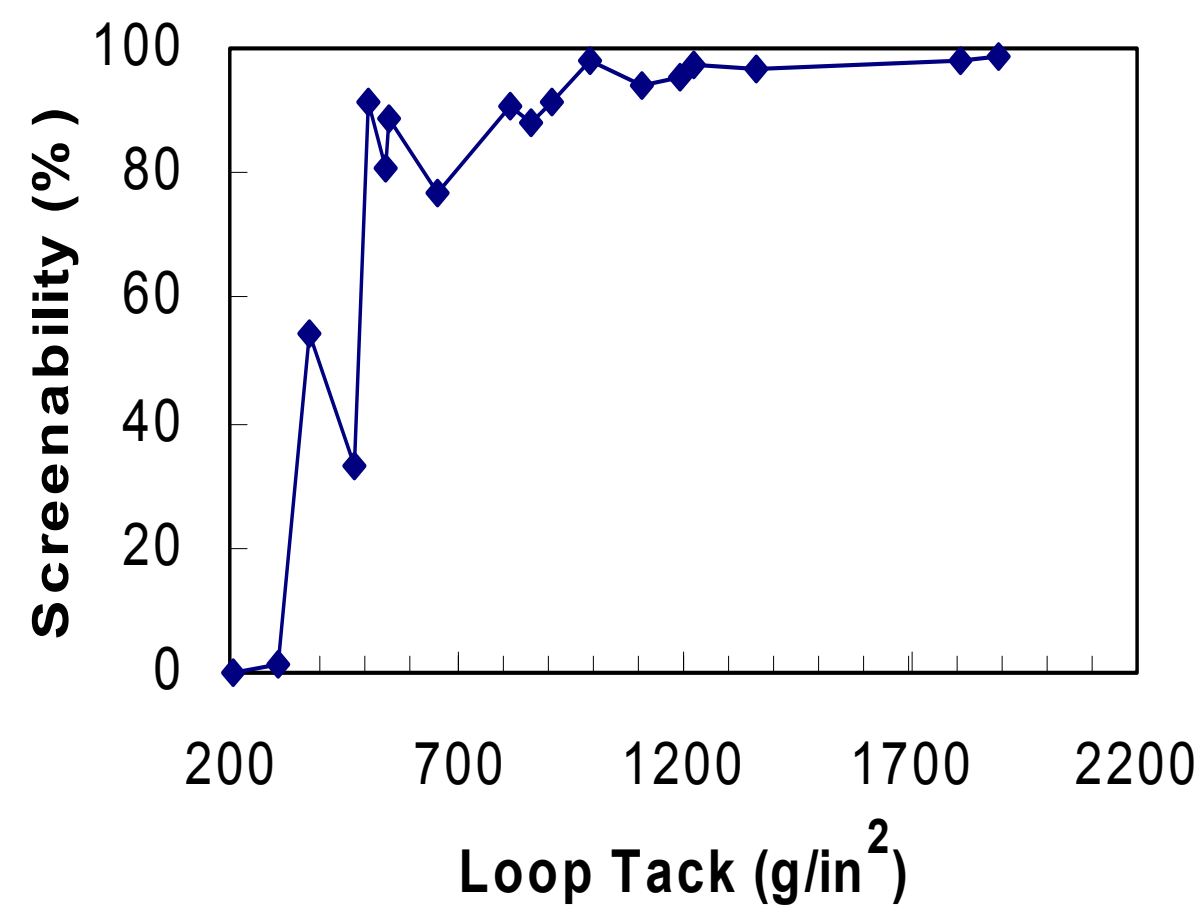

Figure 3. The Relationship between Loop Tack and Screenability. 
Tack is defined as the force required for separating an adherent and an adhesive at the interface shortly after they have been brought rapidly into contact under a light pressure of short duration [26]. It represents the adhesive's ability to adhere quickly. Tack is measured in two steps: the contact step and the separation step [27]. During the first step, contact is made at the geometrical surface points, which increase to a larger area through wetting out, viscous flow, and elastic deformation. In the second step, debonding creates two new surfaces. During debonding, high tack means that the adhesive absorbs a high deformation of energy, which dissipates on the breaking of the bond. Thus PSAs with high tack generally have low bonding viscosity, high debonding viscosity, and high elasticity. During repulping, the PSA is subject to intermittent shear force. A PSA with higher tack would be able to absorb sudden shear force better, and thus would not be easy to break. Also, a PSA with high tack has high fluidity and bonding ability on light pressure. Because normally PSAs are hydrophobic, they tend to agglomerate with each other. PSAs with higher tack should adhere to each other more easily to form large particles during repulping.

Peel adhesion is the force required to remove a PSA-coated film from a specific test surface under standard conditions (specific angle and rate). It gives a measure of adhesive or cohesive strength, depending on the mode of failure [28]. Similar to tack, the measurement of peel adhesion involves a bonding step and a debonding or peeling step. The efficiency of the bonding process is related to the adhesive's ability to exhibit viscous flow. In order to achieve peel adhesion, the bonding stage involves some dwell time. Thus, the flow properties during the bonding step are less critical for peel than for tack. The debonding process involves a rapid deformation of the adhesive mass. Thus, the higher the peel strength, the higher the PSA's ability to resist bond deformation at high strain rates. Thus, PSAs with higher peel strength, on one hand, can form large particles with each other during repulping because of their better viscous flow. Furthermore, higher peel strength has greater ability to resist bond deformation at high shear. As a result, better screenability may be obtained for the PSAs with higher peel strength. In general, the results shown in Figure 4 support the above discussion. However, because the data are scattered, more studies are needed for a concrete conclusion. 


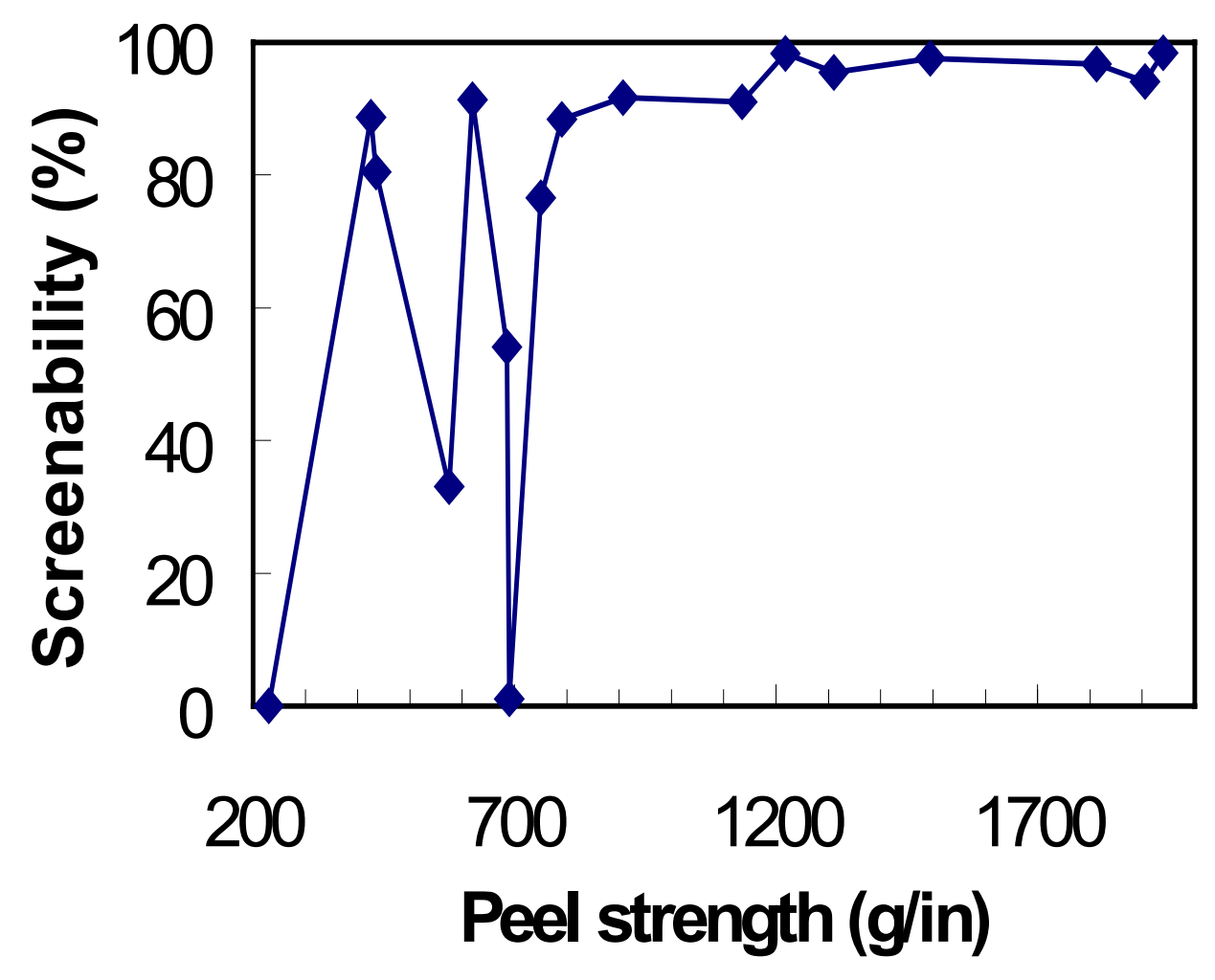

Figure 4. The Relationship between Peel Adhesion and Screenability.

Figure 5 shows the effect of shear strength on screenability. Obviously, no firm conclusion can be drawn from the results for a preferred shear strength range. Shear resistance is measured as a force to pull the PSA material parallel to the surface to which it was affixed with a definite pressure [8]. It measures the cohesion strength of the PSA. PSAs with higher shear strength have higher internal structural resistance; thus, they should be more difficult to break during repulping. On the other hand, PSAs are normally coated on paper as a very thin layer $(\sim 25 \mu \mathrm{m})$; the shear force in repulping is much bigger than the force needed to break the thin film. This may explain why shear strength does not have a determining role in PSA screenability. 


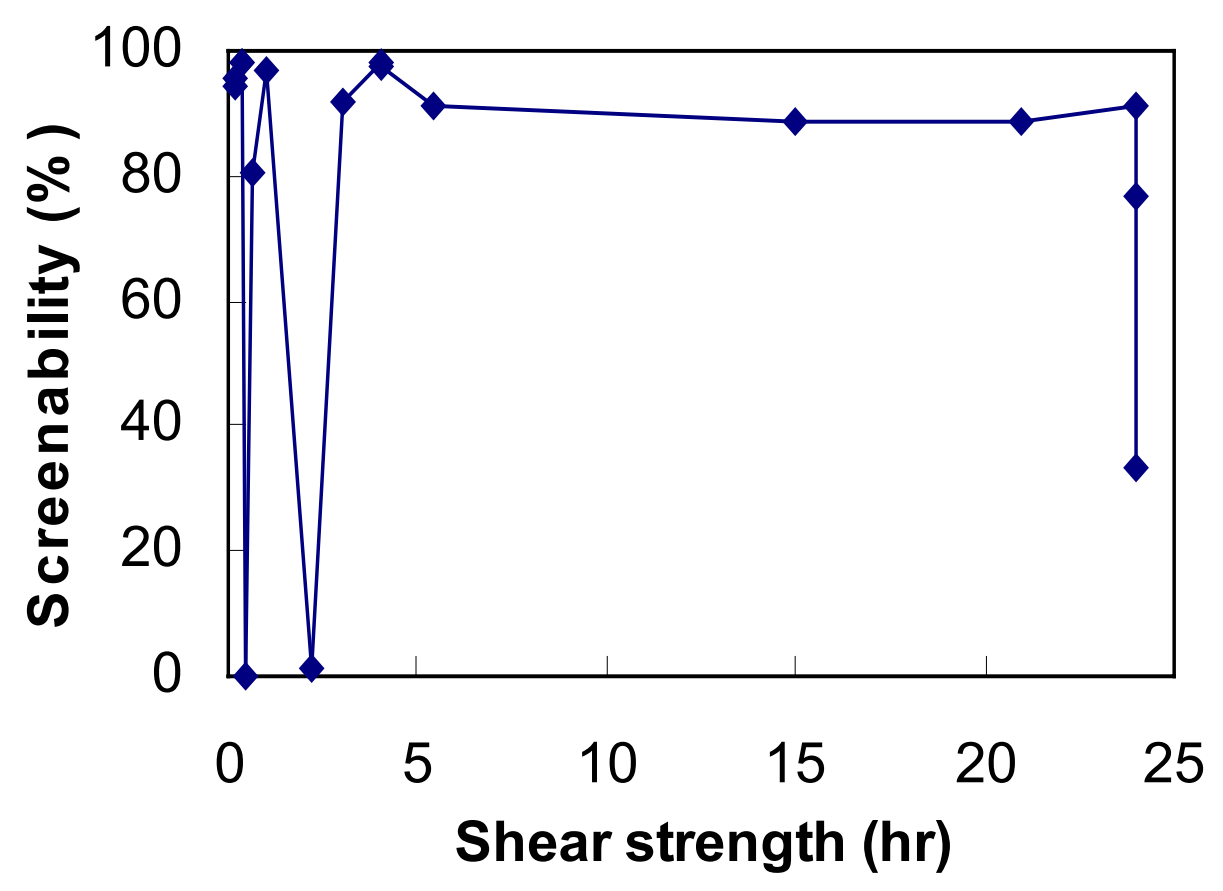

Figure 5. The Relationship between Shear Strength and Screenability

The effect of PSA tensile strength on screenability is shown in Figure 6. It is obvious that tensile strength also does not have a determining effect. Tensile strength is a measure of the PSA internal structural resistance to outside force similar to shear strength. It can be imagined that any PSA film will not break down if it has very high tensile strength. However, the "PSAs" that have very high tensile strength will not be considered real PSAs because they have no tack and peel adhesion. For PSAs coated on paper, tensile strength is so small that it cannot play a significant role in preventing the PSAs from breaking into very small particles, which could pass through the screen. 


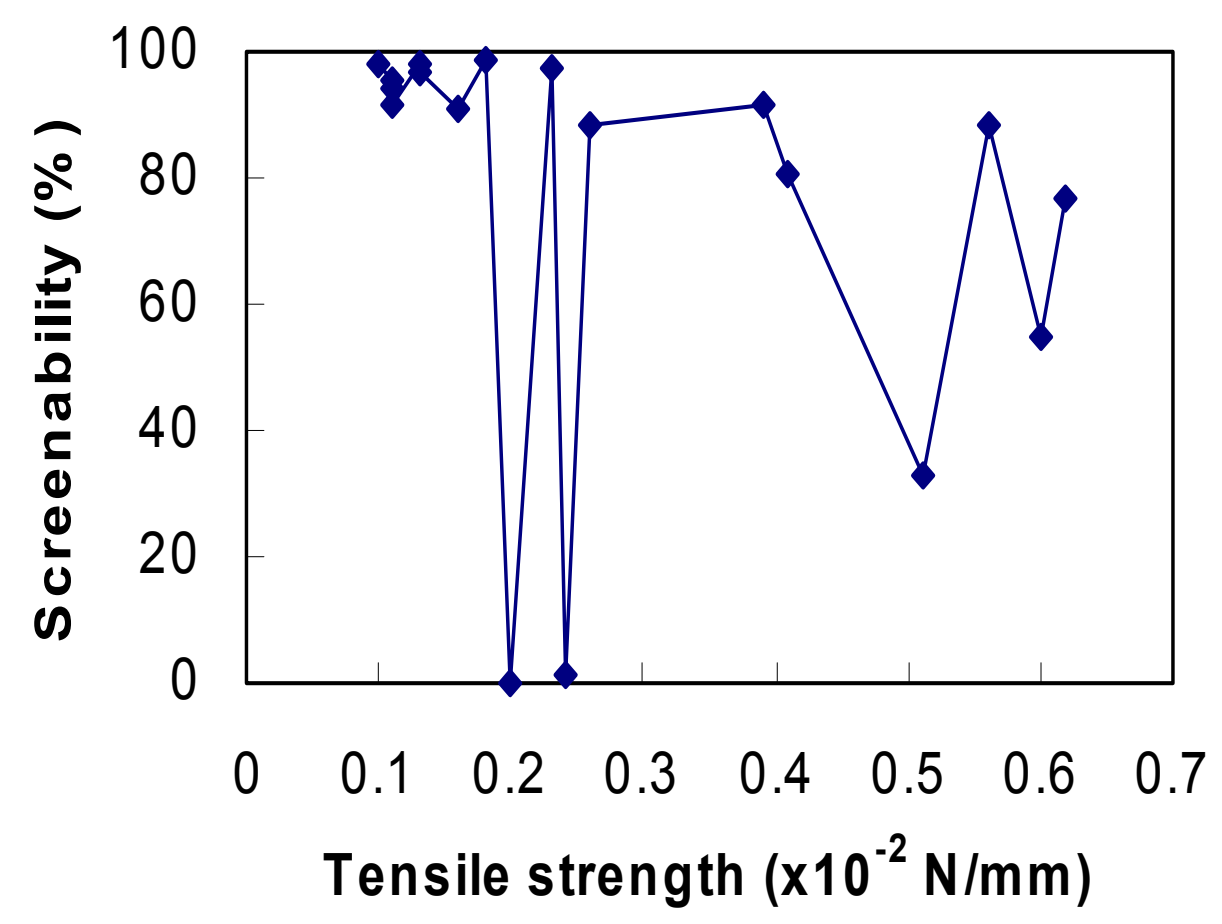

Figure 6. The Relationship between Tensile Strength and Screenability.

Figure 7 shows the Relationship between Distortion Properties and Screenability.

Breaking length divided by the original length gives the stretch index. The stretch index is measure by stretching a certain length $(5 \mathrm{~mm})$ of PSA film under a constant rate until it breaks. It reflects the amplitude of deformation. Thus, a PSA with a higher stretch index generally is more difficult to break under stress because it can stretch under sudden high shear. PSAs have elasticity and also tend to agglomerate together. After the stretch, the PSA may either recover itself or flap over to form PSA particles again. Figure 5 shows that a PSA with a higher stretch index generally has better screenability. 


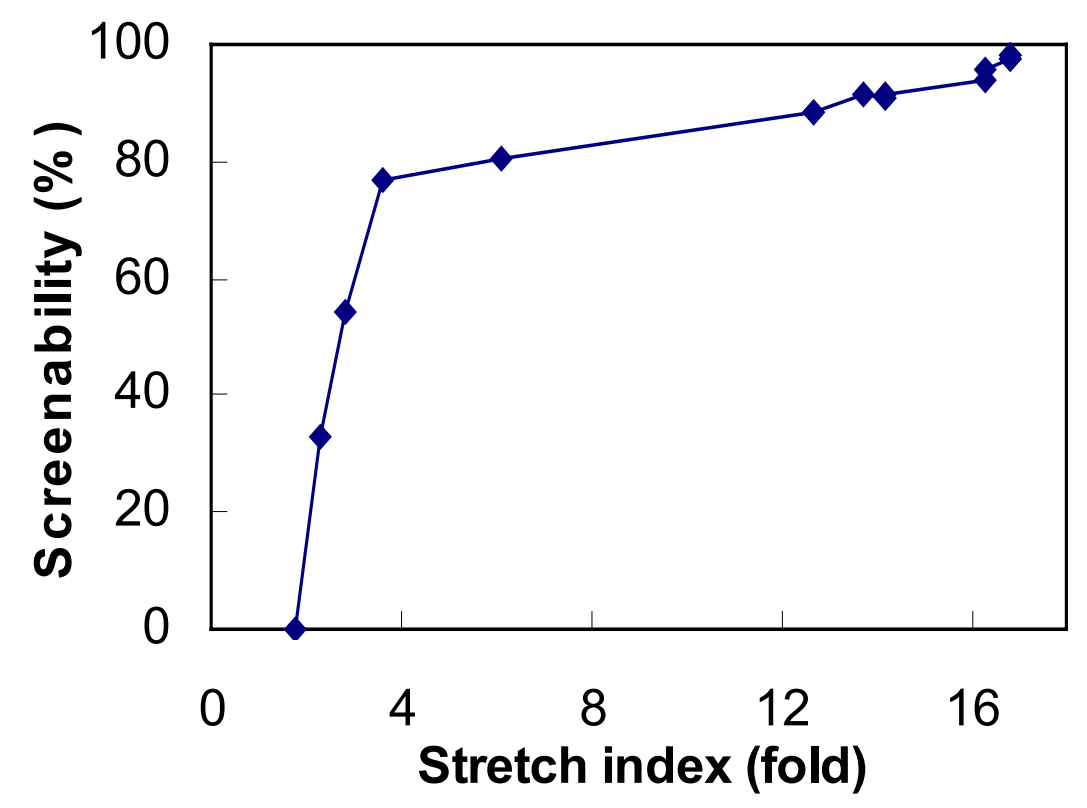

Figure 7. The Relationship between Distortion Properties and Screenability.

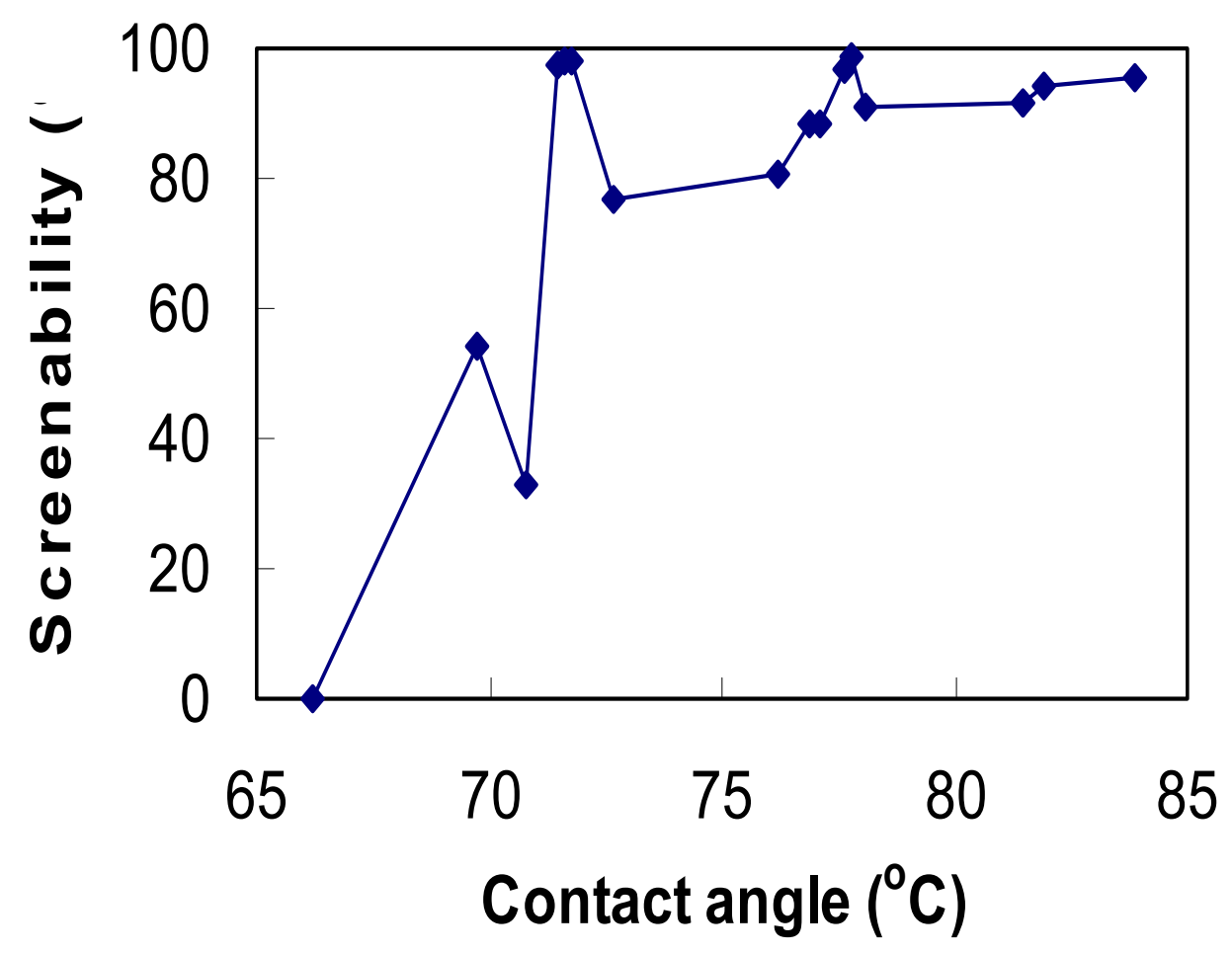

Figure 8. The Relationship between Contact Angle and Screenability.

PSAs with higher contact angles are more hydrophobic. From Figure 8, it can be found that screenability increased as the contact angle increased. The reason for that may be that PSAs with high contact angles have a greater tendency to aggregate during repulping because of their 
high hydrophobicity. However, we are cautious on making this simple conclusion because of the limited data available at this time.

From the above results, it seems the tackier the PSA, the higher is the PSA screenability. Thus, we intended to formulate PSAs with higher tack and to find the screenability of these newly formulated PSAs. Tackifier Snowtack $780 \mathrm{G}$ and 755A from EKA Chemicals were used to formulate different PSAs. Figure 9 shows that with increased tackifier 775A content, the tack of the PSA increased; the screenability first improved slightly and then changed to almost unscreenable. Further study indicated that the tackifier $775 \mathrm{~A}$ used in this study is slightly water soluble under $\mathrm{pH}$ 10.5. Therefore, we believe that some tackifiers were dissolved in the pulping water during the repulping process, resulting in the breakup of PSA film and the poor screenability.

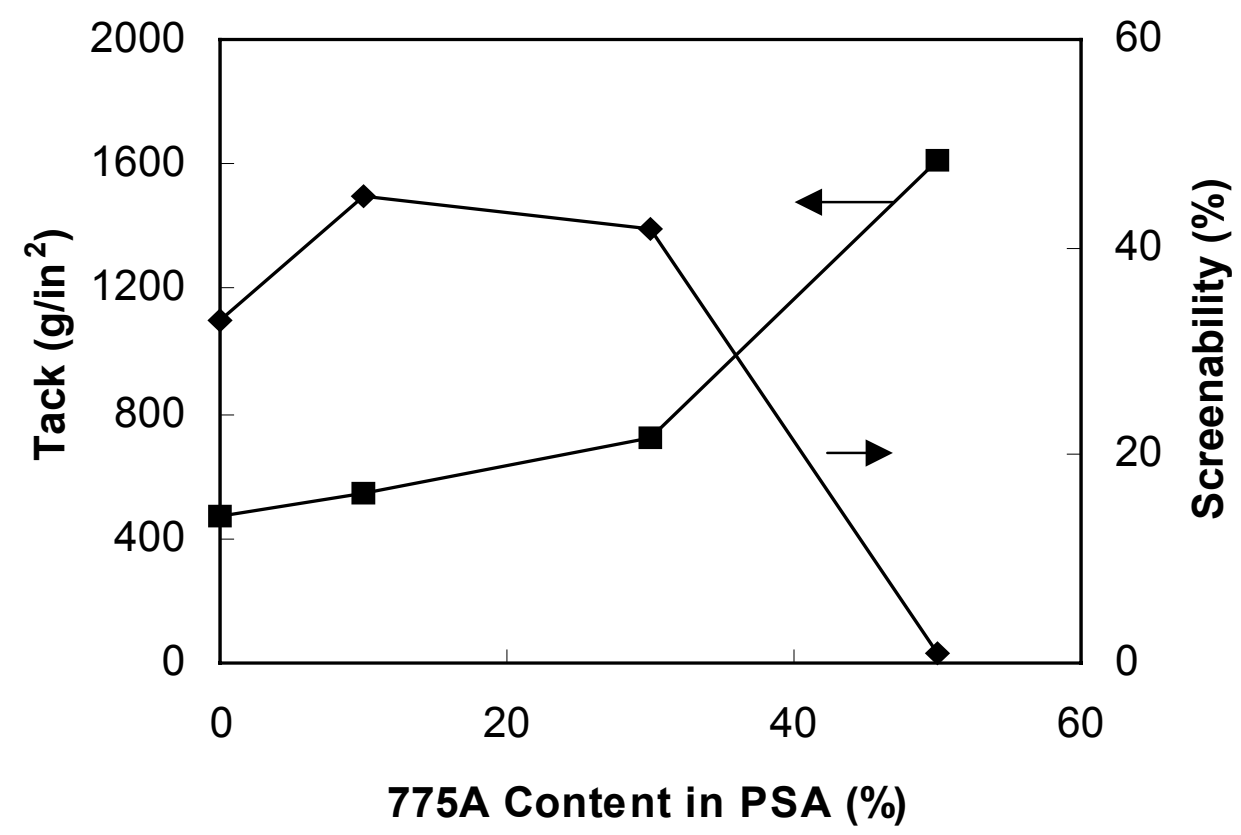

Figure 9. The Effect of Tackifier 775A on PSA Screenability.

We further used a water-insoluble tackifier, Snowtack 780G, to formulate PSA. Figure 10 shows that with increased tackifier content, the tack of the PSA increases and so does the PSA screenability. PSA XPD 1814 was also formulated with 50\% of tackifier $780 \mathrm{G}$. It was found that the loop tack of the PSA increased from $550\left(\mathrm{~g} / \mathrm{in}^{2}\right)$ to $1920\left(\mathrm{~g} / \mathrm{in}^{2}\right)$, and the screenability of the PSA increased from $88.7 \%$ to $98.3 \%$. 


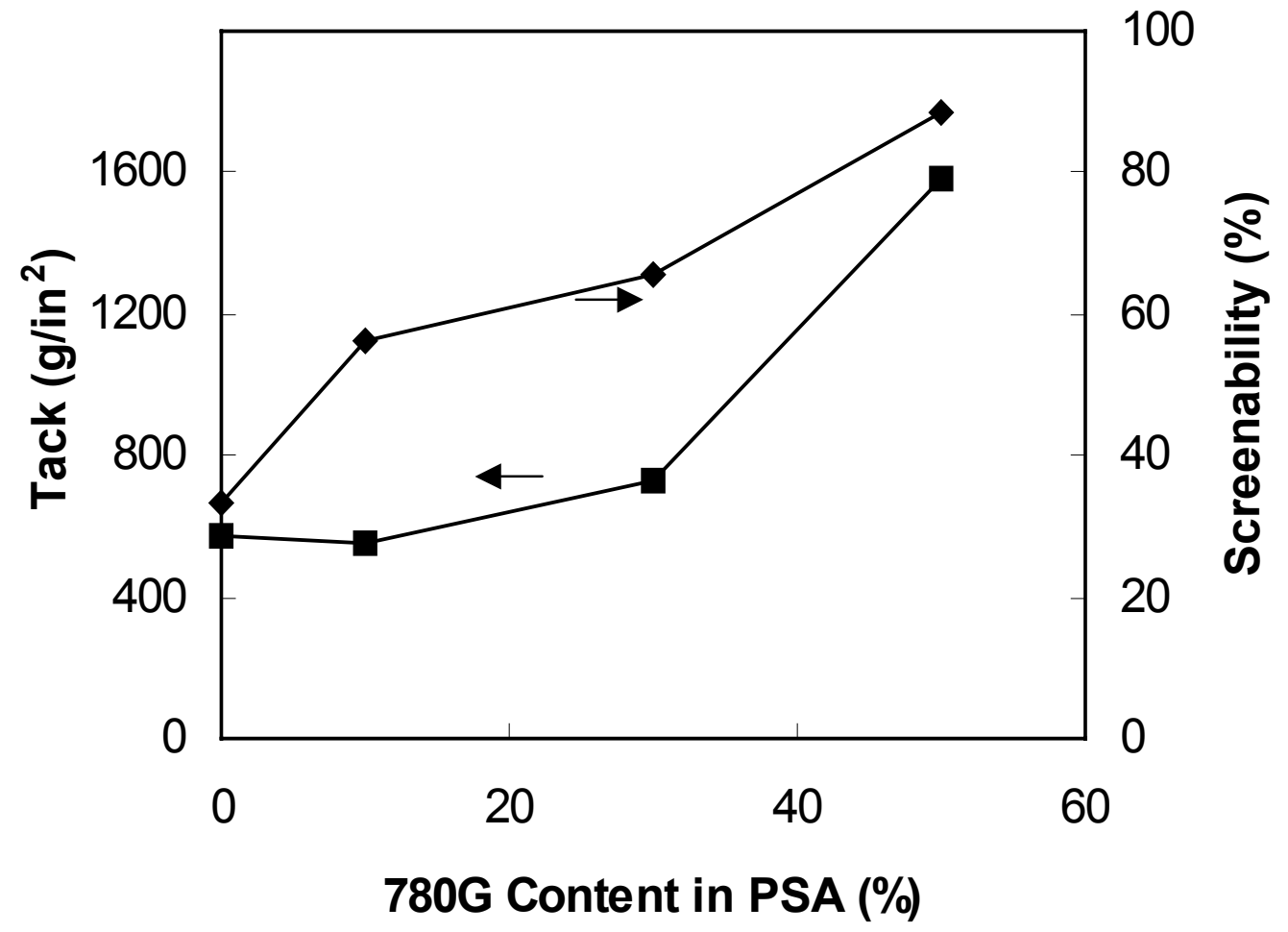

Figure 10. The Effect of Tackifier 780G on PSA Screenability.

The results indicate that PSA screenability can be improved by increasing its tack. But other factors, such as the hydrophobicity of the PSA materials under pulping conditions, should be considered. Higher hydrophobicity would be favorable for PSAs to agglomerate with each other to form large particles.

\section{Conclusions of Part I}

Increased tack generally increases the screenability. The reason for this is that tacky polymer particles adhere together more easily than nontacky particles. Because they strongly stick together, large particles can be obtained during the repulping process. Also, higher tack means the adhesive has higher ability in adsorbing energy in deformation. Therefore, the screenability was improved. Increased peel strength increases the screenability as well. Peel strength reflects the ability of PSAs to stick to other substrates under certain force. PSAs with higher peel strength would be able to form large particles with each other during repulping because of their better viscous flow. They also have higher ability to resist bond deformation at high shear. A PSA with a lower contact angle has higher hydrophilicity and has stronger interaction with water, fibers, and other hydrophilic materials. Thus it may be easier for the PSA to disperse into small particles or to be partially dissolved in water during repulping. A PSA with a hydrophilic surface is difficult to agglomerate to form large particles as well. A PSA with a higher stretch index generally has better screenability because this kind of PSA can absorb more energy during repulping and thus does not easily break down into small particles. Both tensile and shear 
strength, which are the measure of the PSA internal resistance to force, have marginal effect on the screenability. Although higher tensile and shear strength imply the PSA could tolerate higher force in breaking, other factors, such as tack, elongation, and hydrophobicity, are also very important. It should be noted that no vacuum was applied during the screening in our study. If vacuum is applied, the polymer with high tack may distort easily and "swim" through the screen, which will reduce the screenability, while PSAs with high shear and tensile strength may be less likely to deform.

Generally, no single property is enough to determine the PSA screenability. It would be ideal for the PSA to have high tack, peel and shear strength, and reasonable hydrophobicity and elongation ability.

\section{Part II: Development of Screenable PSA through Chemical Crosslinking}

It is known that crosslinking can increase a polymer's internal strength. In this experiment we want to show how cross-linking a pressure sensitive adhesive can increase its screenability in paper recycling. The reason we think this will work is because cross-linking produces a more rigid polymer with stronger internal strength. A PSA film with proper crosslinking may increase its tolerance on high shear, thus making it difficult to breakdown to small particles. Large PSA particles will be able to be screened out in paper recycling. On the other hand, the crosslinking should not have significant affect on the PSA end use properties.

In this study, sheets were double-layer coated with the first layer being a cross-linking agent and the second layer was the PSA. This is illustrated in Figure 11. At the interface between the cross-linker and PSA, cross-linking does occur, but this does not negatively affect the physical properties of the PSA. When repulped the two will cross-link and allow for the larger, more ridged stickie to be screened out. Another study looked at adding the cross-linker directly to the repulper during repulping.

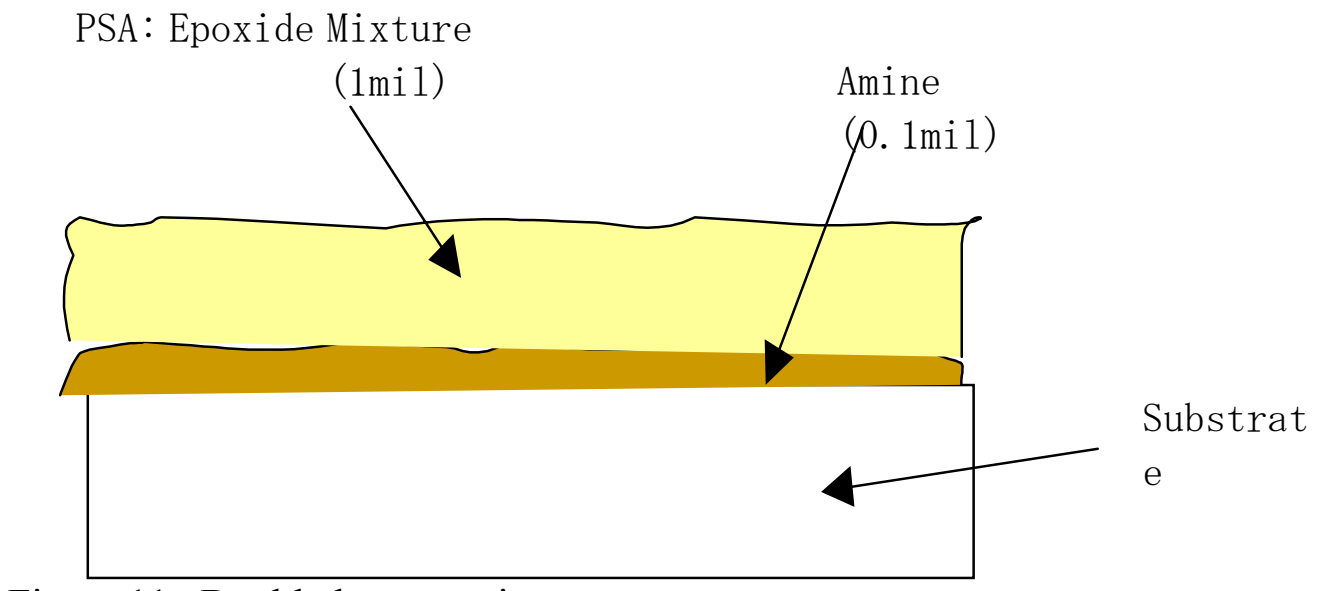

Figure 11. Double layer coating 


\section{Experimental}

The pressure sensitive adhesive used for these experiments was Carbotac ${ }^{\circledR}$ Acrylic Emulsion 26171 made by BF Goodrich. This adhesive was chosen because it provided a good balance of tack, peel and shear. It also contains carboxyl groups that allow for external cross-linking. The emulsion is a $50 \%$ solids, anionically stabilized acrylic emulsion with a $\mathrm{pH}$ of 2.5 . The $\mathrm{pH}$ was adjusted to be slightly basic to thicken the emulsion.

The epoxy resin that was used was Ancarez ${ }^{\circledR}$ AR550 Epoxy Resin from Air Products and Chemicals, Inc. Ancarez AR550 resin is a waterborne solid epoxy resin dispersion delivered at $55 \%$ solids in water with nonionic surfactant. It was chosen because of its fast dry speed and because of its solubility in water.

Air Products and Chemicals, Inc. also made the cross-linking polymer that was used, Anquamine $^{\circledR} 419$ Curing Agent. Anquamine 419 is a waterborne curing agent with modified aliphatic amines supplied at $60 \%$ solids in water and methoxy propanol. This was also chosen because it was water soluble and dried fast. Both the epoxy resin and curing agent were used as received.

Crosslinking with other crosslinkers, such as phenol formaldehyde resin (PFR), has also been studied. It was found those crosslinkers either affected the PSA properties or had no obvious effect on screenability.

\section{Tack}

To test the "tack" of an adhesive, a 2 mil ( 1 mil $=0.001$ inch) layer of the PSA/Epoxy Resin adhesive is coated on to a plastic sheet. Because the solution has $50 \%$ solid content, the dried layer thickness would be 1 mil, e.g., half of the applied thickness. From this sheet 5" x 1" strips were cut. If these strips were to be cross-linked, they were soaked in a given solution of Anquamine 419 at $50{ }^{\circ} \mathrm{C}$ for 30 minutes. These strips were then heat-cured in an oven at $110^{\circ} \mathrm{C}$ for 5 minutes. If the samples were to be cross-linked via a 2-layer adhesive film, a 0.2 mil layer of Anquamine 419 was coated on a plastic sheet. Then a 2 mil layer of the PSA/Epoxy Resin adhesive was coated on silicone release liner. The two were laminated together at 90 psi. The silicone release liner was then removed and the adhesive was heat cured at $110^{\circ} \mathrm{C}$ for 5 minutes. Then 5" x 1" strips were cut. After the strips were cut they were tested.

\section{Tensile}

Tensile tests were done on the Instron Series X tensile tester using a 100-pound weight. A testing frame was hand cut out of copy paper using a razor blade and straight edge to dimensions $15 \mathrm{~mm} \times 20 \mathrm{~mm}$. To place the adhesive on the frame a 2 mil coating of the PSA/Epoxy Resin adhesive is put on silicone release liner. The frame is then pushed into the coating and cut from the rest of the silicone release liner. If the sample is to be cross-linked this cutout is then dip treated in a given concentration of Anquamine 419 for 30 minutes at $50{ }^{\circ} \mathrm{C}$. The sample is then placed in an oven for 5 minutes at $110{ }^{\circ} \mathrm{C}$ to heat cure the film. To test the sample the release liner is peeled from the frame and the sides of the window frame are cut. To make the 2-layer cross-linked film a 2 mil PSA/Epoxy Resin coated silicone release liner and a 0.2 mil Anquamine coated silicone release liner are pressed against opposite sides of the frame and laminated at $90 \mathrm{psi}$. This sample is then heat cured at $110^{\circ} \mathrm{C}$ for 5 minutes. To test this sample 
the release liner is peeled from both sides of the frame and the sides of the window frame are cut. For spray cross-linking of the film the release liner of a prepared film was removed and the cross-linker was sprayed against the film and then heat cured in the same conditions listed above.

\section{Screenablility}

To test the screenability of the adhesives they coated on to office paper and recycled at a $1 \% \mathrm{wt}$ ratio to uncoated office paper. To test the screenability of the uncross-linked adhesive a 2 mil layer of the PSA/Epoxy Resin mixture was coated on office paper. $10 \mathrm{~g}$ total of paper are need to recycle, meaning $0.287 \mathrm{~g}$ of coated paper are added to $9.713 \mathrm{~g}$ of office paper (coating is $34.8 \%$ of coated paper weight for a 2 mil coating). The paper is then soaked at least 4 hours at $50{ }^{\circ} \mathrm{C}$ in $500 \mathrm{~mL}$ of water. After this the slurry is put in the disintegrator and run for 3500 revolutions at $2 \%$ consistency. If unscreened samples are needed they are made from this slurry. The pulp is then screened for 25 minutes at $45{ }^{\circ} \mathrm{C}$ on a Sommerville vibrating screen, with a slot width of 0.006 ". The accepts from this stream are then used to make handsheets. To highlight any "stickies" in the handsheets they are dyed with a solution of Morplas Blue dissolved in hexane. To do this the sheets are dipped into the solution for approximately 15 seconds. To remove dye from the fiber portion of the handsheet rinses with methanol are repeated until the fibers are no longer blue. These handsheets are then dried between blotter paper and analyzed using the image analyzer software. From this the concentration of "stickies" in the sheet can be found.

For a 2-layer cross-linked sample the same procedure as above is followed making a correction for the amount of coating. This is because there is the additional weight of the Anquamine 419. Also these coated paper samples were heat cured at $110{ }^{\circ} \mathrm{C}$ for 5 minutes.

For a cross-linker added during repulping the same amount of PSA/Epoxy Resin used above is coated on the paper. Then $0.0154 \mathrm{~g}$ of Anquamine 419 is added to the paper during the soak period prior to repulping. This amount is the same as the amount coated on the 2-layer samples. Other than these changes the above procedure is used.

\section{Results and discussion}

1. The effect of crosslinking agents on the PSA adhesion properties

The effect of crosslinkers epoxide and polyamine on the PSA properties is shown in Tables 2-3 and Figure 12. Results indicated that epoxide did not have significant effect on PSA's tack when its content is less than $20 \%$. When the PSA film with epoxide was cured in polyamine solution, the tackiness of the film reduced significantly or even reached to zero. This indicates crosslinking occurred at the surface of the PSA film. Thus, direct chemical crosslinking can reduce the PSA's tack, and reduce the stickies problem in paper recycling. The crosslinking may also increase the secreenability. Double layer coating with crosslinking on the interface of the two layers did not affect the PSA's tack. The reason is that the crosslinking only occurred at the bottom interface of the PSA film. 
Table 2. The effect of epoxide on the PSA tackiness.

\begin{tabular}{|l|l|}
\hline PSA:EPX Ratio & Tack $(\mathrm{kg})$ \\
\hline PSA & 0.492 \\
\hline $3: 1$ & 0.315 \\
\hline $4: 1$ & 0.462 \\
\hline $5: 1$ & 0.552 \\
\hline
\end{tabular}

Table 3. The effect of epoxide and polyamine on the PSA tackiness.*

\begin{tabular}{|l|l|}
\hline Aquamine $(\mathrm{ppm})$ & Tack $(\mathrm{kg})$ \\
\hline 100 & 0.108 \\
\hline 500 & 0 \\
\hline 1000 & 0 \\
\hline Two-Layer & 0.502 \\
\hline
\end{tabular}

*The PSA:Epoxide ratio was 5:1.

Figure 12. The effect of crosslinking agents on the strength of the PSA film.

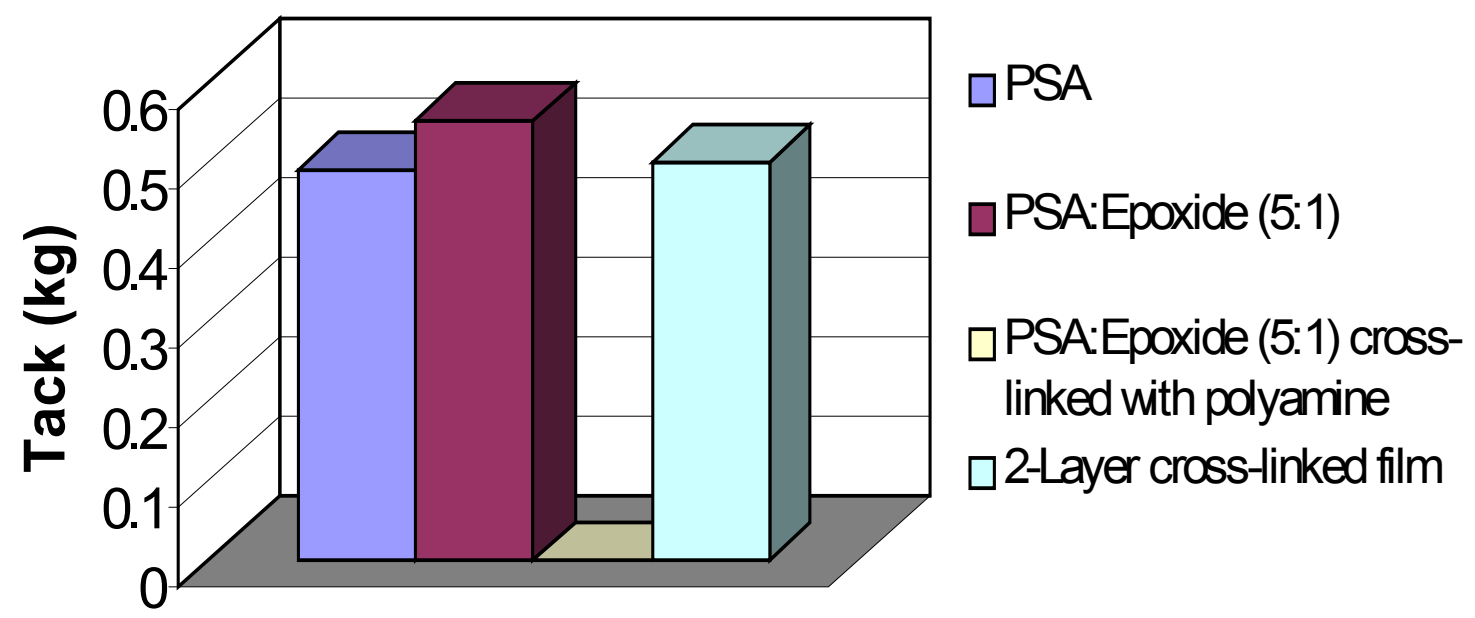

2. The effect of crosslinking on the strength of PSA.

Table 4 and Figure 13 shows the effect of crosslinking on the strength of anionic PSA (Carbotac 26171). This PSA contends carboxylic groups. It was found that polyamine could increase the PSA tensile strength with or without epoxide. It is well known that epoxide can crosslink with polyamine. The reason for polyamine to increase the PSA tensile strength without epoxide may be because the amine group can either react with the carboxylic group to form amide group, or just form ionic bond. We have tried to added polyamine directly to the PSA solution, so that a crosslinking fish net between the polyamine and epoxide could form inside the PSA film. But the cationic charge nature of the polyamine makes it difficult to mix with the anionic PSA. We then tried to use phenol formaldehyde resin (PFR), which is a neutral agent, to crosslink with epoxide. No obvious effect was found on tensile strength. This may indicate that the PFR could not crosslink with the epoxide under the experimental conditions. 
Table 4. The effect of crosslinking agents on the strength of anionic PSA.

\begin{tabular}{|l|l|}
\hline & Tensile $(\mathrm{N} / \mathrm{mm})$ \\
\hline PSA:Epoxide & 0.0026 \\
\hline $\begin{array}{l}\text { PSA:Epoxide 1 side cross-linked in 500 PPM polyamine } \\
\text { solution }\end{array}$ & 0.0066 \\
\hline 2-Layer cross-linked adhesive & 0.0188 \\
\hline 2-Layer PSA:polyamine & 0.0185 \\
\hline 2-Layer PSA:polyamine with water wash & 0.0215 \\
\hline 100 PSA:10 Epoxide:1.7 PFR & 0.0036 \\
\hline 100 PSA:10 Epoxide:2.5 PFR & 0.0046 \\
\hline
\end{tabular}

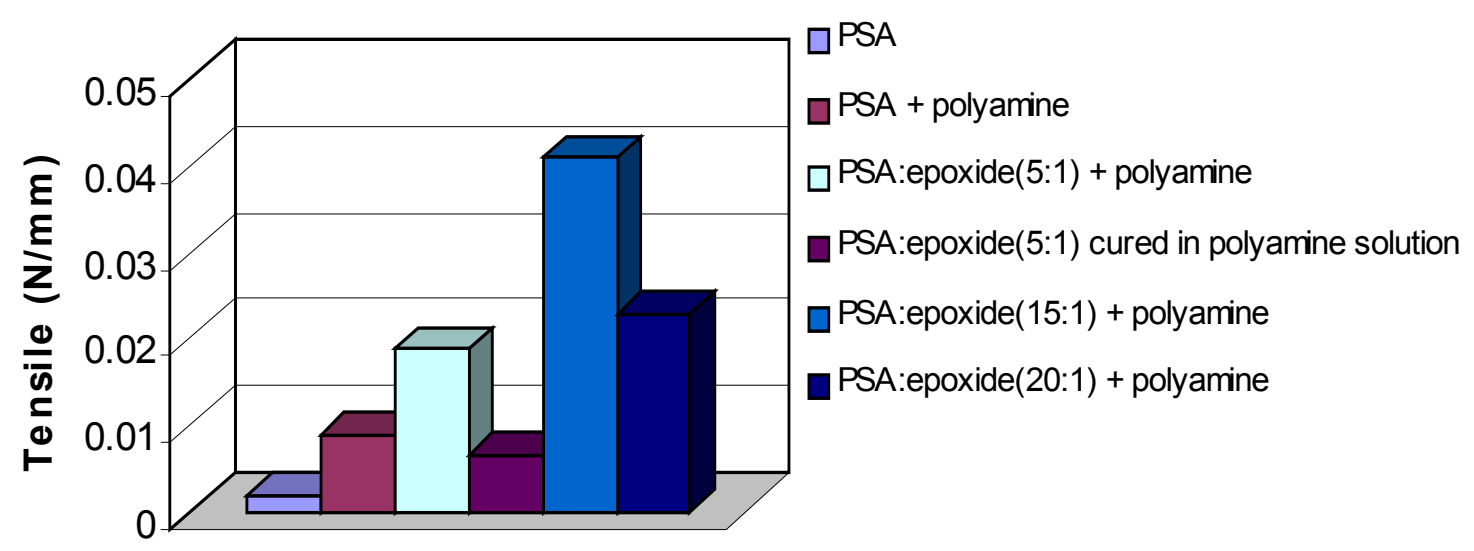

Figure 13. The effect of crosslinking agents on the strength of anionic PSA

We have also tested cationic charged PSA. The cationic PSA was synthesized in our lab by emulsion polymerization of butyl acrylate with a cationic monomer, such as [3(methacryloylamino)propyl]trimethylammonium chloride (MAPTAC) or [2methacryloylethyl]trimethylammonium chloride (MAETAC). We had expected that the cationic PSA would be able to mix with polyamine. Table 5 shows the effect of crosslinking on the tensile strength of cationic PSA. It was found that the crosslinking could increase the tensile strength, but not as high as that for anionic PSA. The reason may be that the polyamine can form extra bonds with anionic PSA directly, but not with cationic PSA. We have not studied the cationic PSA in details because cationic PSA is not yet used in the market, and the strength improvement was not significant.

Table 5. The effect of crosslinking agents on the strength of cationic PSA.

Average Tensile (N/mm) 


\begin{tabular}{|l|l|}
\hline C-PSA & 0.0016 \\
\hline 2-Layer C-PSA:polyamine & 0.0016 \\
\hline 100 C-PSA:10 Epoxide:1 polyamine & 0.0036 \\
\hline 100 C-PSA:10 Epoxide: 2 polyamine & 0.0046 \\
\hline
\end{tabular}

\section{PSA screenability}

The screenability of the PSA during paper recycling was evaluated, and the results are shown in Figure 14 and Table 6. It was found that the addition of polyamine to the repulping solution could increase the PSA screenability significantly from $67 \%$ to $88 \%$. The problem for the addition of polyamine directly to the repulping solution is that the polyamine may adsorb directly on to the negatively charge fiber, and loose its crosslinking efficiency. Double-layer PSAs showed almost totally screenable.

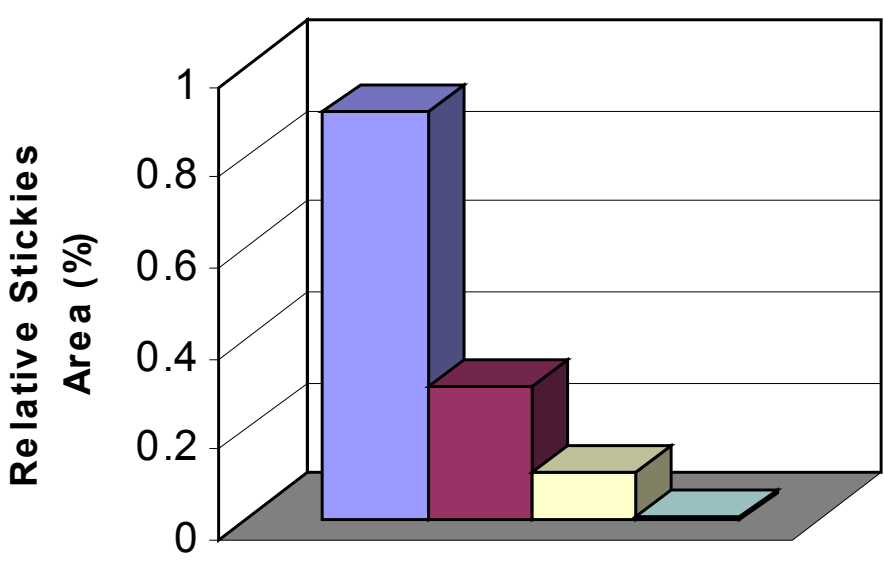

PSA not screened

PSA screened

PSA:epoxide(5:1) + polyamine added during repulping (screened) $\square$ PSA:epoxide (5:1) + polyamine 2-layer (screened)

Figure 14. The screenability of PSA.

Table 6. The screenability of PSA

\begin{tabular}{|l|l|}
\hline PSA composite & Stickies Screened (\%) \\
\hline PSA alone & $67 \%$ \\
\hline Polyamine added during repulping & $88 \%$ \\
\hline 2-Layer crosslinked (PSA:epoxide 5:1) & $>99 \%$ \\
\hline 2-Layer crosslinked (PSA:epoxide 15:1) & $>99 \%$ \\
\hline 2-Layer crosslinked (PSA:epoxide 20:1) & $>99 \%$ \\
\hline
\end{tabular}

Conclusions of Part II 
Screenable PSA was developed through double layer coating. The bottom layer acted as a crosslinker, while the top layer acted as adhesive. The crosslinking increased the PSA's strength to tolerate the high shear during repulping.

\section{Part III: Development of Screenable PSA through UV Crosslinking}

We set out to develop pressure sensitive adhesive (PSA) which can be removed from the pulp as early in the process as possible by screening. Our attempt is to introduce crosslink into PSA, which might act as a network holder to avoid PSA broken into small pieces under pulping condition. At same time, PSA still exhibits high adhesive performance. In Part II, we have discussed using chemical crosslinking. In this part, we will discuss the use of UV radiation polymerization to make PSA with different degree of network. The network we have introduced will improve the screenability of PSA paper during recycling, but it will not affect the PSA end use properties. To achieve this unique property, we carefully designed the PSA film structure. The novel structure of the PSA is that the PSA film contains a polymer network which crosslinked by them self, but not crosslinked with PSA molecules. This structure more like a fish net which spread inside of PSA film, which will improve the screenability, but not affect PSA end use properties.

The possibility of forming this type of network in commercially available PSA was studied using our lab scale UV reactor with or without nitrogen protection. The PSA properties and repulpability were studied.

\section{UV CROSSLINKING WITHOUT NITROGEN PROTECTION}

\section{Materials}

Acrylic emulsion: carbotac 26171, styrene-butadiene emulsion: Good-rite SB-0738 from BF Goodrich Industrial Specialties. Monomer: 2-ethyhexyl acrylate Aldrich Co., Lauryl Acrylate (SR-335) from Sartomer Co.. Photoinitiator: benzoin methyl ether (BME), 99\%, from Aldrich Inc.. Water-borne photoinitiator: Esacure KIP 150 from Abrachem Co.. Oligomer: SR-344, SR349, and CN-972 from Sartomer Co.. Styrene-butadiene (SB) rubber: Kraton DKX-222C, and styrene-isoprene-styrene (SIS) rubber: Kraton D-1117P from Shell Chemicals. Tackifier: Escorez 5600 and Escorez 2520 from ExxonMobile Chemical. Mineral Oil from Aldrich Co..

\section{Instrumentation}

Nicolet 760 FT-IR was used to monitor the curing processes. The curing was performed by Model CL-1000 UV Crosslinker from UVP, Inc.. The morphology was characterized by LEO 982 Field Emission Scanning Electron Microscope.

\section{PSA Preparation and film formation}

Acrylic emulsion: A certain amount of mixture of monomer, oligomer, and photoinitiator was slowly dropped into acrylic emulsion (carbotac-26171) under strong mechanical stirring.

Blend of Acrylic emulsion and SB emulsion: $10 \%$ wt. of SB emulsion was dropped into $90 \%$ wt. of acrylic emulsion, and the mixture was stirred for a while. 
Hot-melt based PSA: SB resin, tackifier, mineral oil, monomer, oligomer, and photoinitiator were solved in toluene. Solid content was controlled to get moderate viscosity for coating. We do not have hot-melt coater, so we used solvent with the PSA.

The films were obtained by coating the above mixture on silicon-release paper with a calibrated wire-wound applicator to obtain a thickness of about $50 \mu \mathrm{m}$. Water was then allowed to evaporate at room temperature and $105{ }^{\circ} \mathrm{C}$ for $5 \mathrm{~min}$. The curing was performed by UV irradiation with $5 \times 8$ watt UV tubes $(\lambda=302 \mathrm{~nm})$. UV energy exposure was set to $400 \mathrm{mj} / \mathrm{cm}^{2}$. The PSA samples were summarized in Table 1-3

\section{Screenability test}

Office white copy paper containing $0.3 \%$ of PSA was repulped with a lab pulp disintegrator at 50 ${ }^{\circ} \mathrm{C}, \mathrm{pH} 10$ and $2 \%$ consistency. Handsheets were made according to the standard Tappi method, and then dyed. The dyed handsheet was analyzed with Image Analysis.

\section{PSA samples prepared}

Acrylic emulsion Carbotac 26171 based PSAs with different crosslinker levels and crosslink degree were prepared. The recipe is shown in Table 7 with totally 27 samples. The recipe for rubber SIS based PSA is shown in Table 8. Totally 6 samples were prepared. The recipe for mixture rubber SBR and SIS based PSA is shown in Table 9. Also 6 samples were prepared. The mixture of polyacrlyic based latex and rubber based latex was studied. It is our intention to prepare a PSA with polyacrylate as PSA base and rubber as crosslinker as well as PSA.

Table 7. Polyacrylic based PSA.

Repulpable, Acrylic Emulsion

\section{A) $10 \%$ Reactive Dilute}

Carbotac 26171

(1)

SR-344

SR-335

Benzoin Methyl Ethyl

B) $20 \%$ Reactive Dilute

Carbotac 26171

SR-344

SR-335

Benzoin Methyl Ethyl

C) 30\% Reactive Dilute

Carbotac 26171
$90 \mathrm{~g}$

$\begin{array}{rrr}90 \mathrm{~g} & 90 \mathrm{~g} & 90 \mathrm{~g} \\ 4.3825 \mathrm{~g} & 4.05 \mathrm{~g} & 2.25 \mathrm{~g} \\ 0.1125 \mathrm{~g} & 0.45 \mathrm{~g} & 2.25 \mathrm{~g} \\ 180 \mathrm{mg} & 180 \mathrm{mg} & 180 \mathrm{mg}\end{array}$

(1)

$90 \mathrm{~g}$

(3)

$90 \mathrm{~g} \quad 90 \mathrm{~g}$

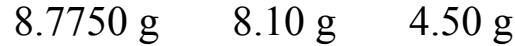

$\begin{array}{lll}0.2250 \mathrm{~g} & 0.90 \mathrm{~g} \quad 4.50 \mathrm{~g}\end{array}$

$360 \mathrm{mg} \quad 360 \mathrm{mg} \quad 360 \mathrm{mg}$
(3)

(2)

$90 \mathrm{~g} \quad 90 \mathrm{~g}$ 
SR-344

SR-335

$13.1625 \mathrm{~g}$

$12.15 \mathrm{~g}$

$6.75 \mathrm{~g}$

Benzoin Methyl Ethyl

$0.3375 \mathrm{~g} \quad 1.35 \mathrm{~g} \quad 6.75 \mathrm{~g}$

$540 \mathrm{mg} \quad 540 \mathrm{mg} \quad 540 \mathrm{mg}$

UV Exposure Dosage: $400 \mathrm{mj} / \mathrm{cm}^{2}$, Exposure Time $1 \mathrm{~min}, 5 \mathrm{~min}, 15 \mathrm{~min}$.

Table 8. Rubber (SIS) based PSA

\section{Solvent-borne PSA (SIS)}

3) $10 \%$ Reactive Dilute

3)

Rubber-I*

SR-344

SR-335

Benzoin Methyl Ethyl

B) $30 \%$ Reactive Dilute

3)

Rubber-I

SR-344

SR-335

Benzoin Methyl Ethyl

C) Reference 1

Rubber-I

Benzoin Methyl Ethyl

D) Reference 2
(2)

$22.5 \mathrm{~g} \quad 22.5 \mathrm{~g}$

$47.8 \mathrm{mg} \quad 0.3339 \mathrm{~g}$

$0.4521 \mathrm{~g} \quad 0.1661 \mathrm{mg}$

$0.5170 \mathrm{~g} \quad 0.5170 \mathrm{~g}$

(2)

$22.5 \mathrm{~g} \quad 22.5 \mathrm{~g}$

$0.1436 \mathrm{~g} \quad 1.0018 \mathrm{~g}$

$1.3564 \mathrm{~g} \quad 0.4982 \mathrm{~g}$

$0.5570 \mathrm{~g} \quad 0.5570 \mathrm{~g}$

$22.5 \mathrm{~g}$

$0.4970 \mathrm{~g}$

Rubber-I

UV Exposure Dosage: $900 \mathrm{mj} / \mathrm{cm}^{2}$, Exposure Time $30 \mathrm{~min}$.

*Rubber-I: Mixture of $30 \mathrm{~g}$ of Kraton D-1117P, $30 \mathrm{~g}$ of Escorez 5600, $15 \mathrm{~g}$ of Mineral Oil, and $60.8 \mathrm{~g}$ of Toluene.

Table 9. Rubber mixture (SBR and SIS) based PSA.

Solvent-borne PSA (SIS+SB)

A) $10 \%$ Reactive Dilute 


$\begin{array}{lrl}\text { Rubber-II* } & 21.99 \mathrm{~g} & 21.99 \mathrm{~g} \\ \text { SR-344 } & 47.8 \mathrm{mg} & 0.3339 \mathrm{~g} \\ \text { SR-335 } & 0.4521 \mathrm{~g} & 0.1661 \mathrm{mg} \\ \text { Benzoin Methyl Ethyl } & 0.4986 \mathrm{~g} & 0.4986 \mathrm{~g}\end{array}$

B) $30 \%$ Reactive Dilute

$\begin{array}{lrr} & & (1) \\ \text { Rubber-II } & 21.99 \mathrm{~g} & 21.99 \mathrm{~g} \\ \text { SR-344 } & 0.1436 \mathrm{~g} & 1.0018 \mathrm{~g} \\ \text { SR-335 } & 1.3564 \mathrm{~g} & 0.4982 \mathrm{~g} \\ \text { Benzoin Methyl Ethyl } & 0.5386 \mathrm{~g} & 0.5386 \mathrm{~g}\end{array}$

\section{C) Reference 1}

Rubber-II

$21.99 \mathrm{~g}$

Benzoin Methyl Ethyl $\quad 0.4786 \mathrm{~g}$

D) Reference 2

Rubber-II

UV Exposure Dosage: $900 \mathrm{mj} / \mathrm{cm}^{2}$, Exposure Time $30 \mathrm{~min}$.

*Rubber-II: Mixture of $20.9 \mathrm{~g}$ of Kraton D-1117P, $20.9 \mathrm{~g}$ of Kraton DKX-222C, $10 \mathrm{~g}$ of Rosin, $23.2 \mathrm{~g}$ of Escorez 5600, 25.0 $\mathrm{g}$ of Escorez 2520, and 83.8 $\mathrm{g}$ of Toluene.

\section{Emulsion compatibility}

During the mixing, the emulsion of SB-0738 was dropped to the emulsion of carbotac 26171 under strong mechanical stirring. The blend emulsion was relatively stable. FT-IR showed no difference could be found from the upper and lower layers after emulsion mixed. However, when a film having a dry thickness of about $0.5 \mathrm{~mm}$ was prepared on watch glass at $50{ }^{\circ} \mathrm{C}$ in vacuum, the film showed an asymmetric surface property. FT-IR indicated that the bottom-side surface was rich in SB-0738, and air-side surface rich in Carbotac 26171. Tackiness was also different for both surfaces. The bottom-side surface exhibited high tack, whereas the air-side exhibited low tackiness. This might be the reason that emulsifier molecules, especially the free molecules unabsorbed onto particles, were localized at the air-side surface during the film formation and resulted in the marked reduction of tackiness at the air-side surface. We also assumed that macroscopical phase separation happened during the film formation due to different molecular polarity. The results was also confirmed by SEM. From SEM, the layered interface could be obviously seen.

The results indicated that the polyacrylic latex tended to separate from the rubber-based latex in the mixture. Further research is needed in this area.

Different ratios of reactive dilute (monomer and oligomer) to acrylic emulsion had been tried. When reactive dilute reached $30 \%$ wt., the final emulsion is not proper to form PSA films. 


\section{Mixture in toluene}

All components could be solved in toluene. The PSA comprised SIS rubber, and a mixture of SB and SIS. The mixture was very good to form PSA film.

\section{PSA properties and screenability}

When the crosslinker level is less than $10 \%$, the crosslinker has no effect PSA properties. When the level reached $30 \%$, PSA almost lost its tackiness. Thus it is desirable to keep the crosslinker level less than $10 \%$. Rubber based PSA can form crosslinking itself under UV, thus the added crosslinker level is low.

Screenability test showed that all the polyacrylic (Carbotac 26171) based PSAs were not totally screenable, while all rubber based PSAs were screenable.

\section{UV CROSSLINKING WITH NITROGEN PROTECTION}

\section{Materials}

Acrylic emulsion: carbotac 26171, carbotac XPD-1811, from BF Goodrich Industrial Specialties. Monomer: 2-ethyhexyl acrylate Aldrich Co., Lauryl Acrylate (SR-335) from Sartomer Co.. Photoinitiator: benzoin methyl ether (BME), 99\%, from Aldrich Inc.. Water-borne photoinitiator: Esacure KIP 150 from Abrachem Co.. Oligomer: SR-344, SR-349, and CN-972 from Sartomer Co.. Styrene-butadiene (SB) rubber: Kraton DKX-222C from Shell Chemicals. Tackifier: Escorez 5600 and Escorez 2520 from ExxonMobile Chemical. Mineral Oil from Aldrich Co..

\section{PSA samples prepared}

Atmospheric oxygen exerts a detrimental effect on photopolymerizations. It quenches excited triplet state of photoinnitiators reducing the quantum yields of initiating radicals, thereby reducing the efficiency of initiation. This generally leads to significant reduction (or even inhibition) of the polymerization. We prepared a mixture sample of Carbotac 26171 with $30 \%$ of 2-ethylhexyl acrylate (EHA) and $2.5 \%$ crosslink degree. This sample was exposed under UV for $3 \mathrm{~h}$ (dosage: $900 \mathrm{mj} / \mathrm{cm}^{2}$ ) under atmospheric oxygen condition and examined with FT-IR. Results showed that the peak of double bond at $810 \mathrm{~cm}^{-1}$ was not completely disappeared. Neither were EHA and SR-344, which suggests the polymerization under oxygen is not complete.

In order to increase polymerization degree, a box with quartz cover was designed to keep UV radiation in nitrogen atmosphere. As a result, A complete double bond conversion for EHA and SR-344 was found in just a few seconds. This results suggests that we can make a network in PSA by UV radiation under nitrogen condition. Thus we prepared a series of following PSA samples in the quartz cell and crosslinked them with UV under nitrogen. The samples include acrylic based PSAs, rubber based (SBR) based PSA with different crosslinkers and different curing conditions.

$\begin{array}{lr}\text { Carbotac XPD-1811 (55\% solid) } & 100 \mathrm{~g} \\ \text { SR-335 (Lauryl Acrylate) } & 5.51 \mathrm{~g} \\ \text { SR-344 (Polyethylene Glycol } 400 \text { Diacrylate) } & 592 \mathrm{mg} \\ \text { Benzoin Methyl Ether } & 243 \mathrm{mg}\end{array}$

\begin{tabular}{|l|l|l|l|}
\hline Sample & Light Dose $(\mathrm{mj} / \mathrm{cm} 2)$ & UV Cured $(\mathrm{min})$ & Crosslinkage \\
\hline
\end{tabular}




\begin{tabular}{|l|l|l|l|}
\hline CSS-20-10 & 200 & 10 & $5 \%$ \\
\hline CSS-20-2 & 200 & 1 & $5 \%$ \\
\hline
\end{tabular}

Carbotac XPD-1811 (55\% solid)

$100 \mathrm{~g}$

SR-335 (Lauryl Acrylate) $\quad 5.50 \mathrm{~g}$

SR-344 (Polyethylene Glycol 400 Diacrylate) $123 \mathrm{mg}$

Benzoin Methyl Ether

$224 \mathrm{mg}$

\begin{tabular}{|l|l|l|l|}
\hline Sample & Light Dose $(\mathrm{mj} / \mathrm{cm} 2)$ & UV Cured $(\mathrm{min})$ & Crosslinkage \\
\hline CSS-20-1 & 100 & 1 & $1 \%$ \\
\hline CSS-20-4 & 400 & 1 & $1 \%$ \\
\hline
\end{tabular}

Carbotac XPD-1811 (55\% solid) $\quad 100 \mathrm{~g}$

SR-335 (Lauryl Acrylate) $\quad 5.50 \mathrm{~g}$

SR-349 (Ehoxylate Bisphenol Diacrylate) $536 \mathrm{mg}$

Benzoin Methyl Ether

\begin{tabular}{|l|l|l|l|}
\hline Sample & Light Dose $(\mathrm{mj} / \mathrm{cm} 2)$ & $\begin{array}{l}\text { UV } \\
\text { Cured (min) }\end{array}$ & Crosslinkage \\
\hline CSS-349-1 & 100 & 1 & $5 \%$ \\
\hline CSS-349-10 & 400 & 1 & $5 \%$ \\
\hline
\end{tabular}

Carbotac XPD-1811 (55\% solid) $\quad 100 \mathrm{~g}$

SR-335 (Lauryl Acrylate) $\quad 5.53 \mathrm{~g}$

CN-972 (Urethane Acrylate) $925 \mathrm{mg}$

Benzoin Methyl Ether

\begin{tabular}{|l|l|l|l|}
\hline & Light Dose (mj/cm2) & UV Cured (min) & Crosslinkage \\
\hline CSU-20-1 & 100 & 1 & $5 \%$ \\
\hline CSS-20-4 & 400 & 1 & $5 \%$ \\
\hline
\end{tabular}

Carbotac 26171 (50\% solid) $\quad 55 \mathrm{~g}$

SR-335 (Lauryl Acrylate) $\quad 2.77 \mathrm{~g}$

SR-344 (Polyethylene Glycol 400 Diacrylate) 299 mg

Benzoin Methyl Ether $123 \mathrm{mg}$

\begin{tabular}{|l|l|l|l|}
\hline Sample & Light Dose $(\mathrm{mj} / \mathrm{cm} 2)$ & UV Cured $(\mathrm{min})$ & Crosslinkage \\
\hline CSS-5-100 & 100 & 1 & $5 \%$ \\
\hline CSS-5-400 & 400 & 1 & $5 \%$ \\
\hline
\end{tabular}

Carbotac $26171 \quad$ (50\% solid) $\quad 55 \mathrm{~g}$

SR-335 (Lauryl Acrylate) $\quad 2.77 \mathrm{~g}$

SR-344 (Polyethylene Glycol 400 Diacrylate) $131 \mathrm{mg}$

Benzoin Methyl Ether $115 \mathrm{mg}$ 


\begin{tabular}{|l|l|l|l|}
\hline Sample & Light Dose $(\mathrm{mj} / \mathrm{cm} 2)$ & $\begin{array}{l}\text { UV } \\
\text { Cured (min) }\end{array}$ & Crosslinkage \\
\hline CSS-1-100 & 100 & 1 & $1 \%$ \\
\hline CSS-1-400 & 400 & 1 & $1 \%$ \\
\hline
\end{tabular}

Carbotac 26171 (50\% solid)

SR-335 (Lauryl Acrylate)

SR-349 (Ehoxylate Bisphenol Diacrylate)

Benzoin Methyl Ether
$55 \mathrm{~g}$

$2.75 \mathrm{~g}$

$265 \mathrm{mg}$

$120 \mathrm{mg}$

\begin{tabular}{|l|l|l|l|}
\hline Sample & Light Dose $(\mathrm{mj} / \mathrm{cm} 2)$ & UV Cured $(\mathrm{min})$ & Crosslinkage \\
\hline CSS349-5-100 & 100 & 1 & $5 \%$ \\
\hline CSS349-5-400 & 400 & 1 & $5 \%$ \\
\hline
\end{tabular}

Carbotac $26171 \quad$ (50\% solid)

SR-335 (Lauryl Acrylate)

CN-972 (Urethane Acrylate)

Benzoin Methyl Ether
$55 \mathrm{~g}$

$5.57 \mathrm{~g}$

$965 \mathrm{mg}$

$255 \mathrm{mg}$

\begin{tabular}{|l|l|l|l|}
\hline & Light Dose $(\mathrm{mj} / \mathrm{cm} 2)$ & UV Cured $(\mathrm{min})$ & Crosslinkage \\
\hline CSC-5-100 & 100 & 1 & $5 \%$ \\
\hline CSC-5-400 & 400 & 1 & $5 \%$ \\
\hline
\end{tabular}

Rubber based PSAs

\begin{tabular}{|l|l|l|l|l|l|l|l|l|}
\hline & $\begin{array}{l}\text { KD- } \\
222 \mathrm{C} \\
(\mathrm{g})\end{array}$ & $\begin{array}{l}\text { ES- } \\
5600 \\
(\mathrm{~g})\end{array}$ & $\begin{array}{l}\text { Min. } \\
\text { Oil } \\
(\mathrm{g})\end{array}$ & $\begin{array}{l}\text { SR- } \\
335 \\
(\mathrm{~g})\end{array}$ & $\begin{array}{l}\text { SR- } \\
344 \\
(\mathrm{mg})\end{array}$ & $\begin{array}{l}\text { BME } \\
(\mathrm{mg})\end{array}$ & $\begin{array}{l}\text { UV } \\
\left(\mathrm{mj} / \mathrm{cm}^{2}\right)\end{array}$ & $\begin{array}{l}\text { Cross- } \\
\text { linkage }\end{array}$ \\
\hline $\begin{array}{l}\text { SB-SS-5- } \\
100\end{array}$ & $5 \mathrm{~g}$ & $5 \mathrm{~g}$ & $25 \mathrm{~g}$ & $1 \mathrm{~g}$ & 106 & 44 & 100 & $5 \%$ \\
\hline $\begin{array}{l}\text { SB-SS-5- } \\
400\end{array}$ & $5 \mathrm{~g}$ & $5 \mathrm{~g}$ & $25 \mathrm{~g}$ & $1 \mathrm{~g}$ & 106 & 44 & 400 & $5 \%$ \\
\hline $\begin{array}{l}\text { SB-SS-2- } \\
100\end{array}$ & $5 \mathrm{~g}$ & $5 \mathrm{~g}$ & $25 \mathrm{~g}$ & $1 \mathrm{~g}$ & 42 & 42 & 100 & $2 \%$ \\
\hline $\begin{array}{l}\text { SB-SS-2- } \\
400\end{array}$ & $5 \mathrm{~g}$ & $5 \mathrm{~g}$ & $25 \mathrm{~g}$ & $1 \mathrm{~g}$ & 42 & 42 & 400 & $2 \%$ \\
\hline $\begin{array}{l}\text { SB-SS-20- } \\
100\end{array}$ & $5 \mathrm{~g}$ & $5 \mathrm{~g}$ & $25 \mathrm{~g}$ & $1 \mathrm{~g}$ & 423 & 57 & 100 & $20 \%$ \\
\hline $\begin{array}{l}\text { SB-SS-20- } \\
400\end{array}$ & $5 \mathrm{~g}$ & $5 \mathrm{~g}$ & $25 \mathrm{~g}$ & $1 \mathrm{~g}$ & 423 & 57 & 400 & $20 \%$ \\
\hline & $\begin{array}{l}\text { KD- } \\
222 \mathrm{C} \\
(\mathrm{g})\end{array}$ & $\begin{array}{l}\text { ES- } \\
5600 \\
(\mathrm{~g})\end{array}$ & $\begin{array}{l}\text { Min. } \\
\text { Oil } \\
(\mathrm{g})\end{array}$ & $\begin{array}{l}\text { SR- } \\
335 \\
(\mathrm{~g})\end{array}$ & $\begin{array}{l}\text { SR- } \\
349 \\
(\mathrm{mg})\end{array}$ & $\begin{array}{l}\text { BME } \\
(\mathrm{mg})\end{array}$ & $\begin{array}{l}\mathrm{UV} \\
\left(\mathrm{mj} / \mathrm{cm}^{2}\right)\end{array}$ & $\begin{array}{l}\text { Cross- } \\
\text { linkage }\end{array}$ \\
\hline & $5 \mathrm{~g}$ & $5 \mathrm{~g}$ & $25 \mathrm{~g}$ & $1 \mathrm{~g}$ & 97.5 & $44 \mathrm{mg}$ & 100 & $5 \%$ \\
\hline SB-SR349- & $5 \mathrm{~g}$ & & & & & \\
\hline
\end{tabular}




\begin{tabular}{|c|c|c|c|c|c|c|c|c|}
\hline \multirow{2}{*}{$\begin{array}{l}5-100 \\
\text { SB-SR349- } \\
4100\end{array}$} & \multirow[b]{2}{*}{$5 \mathrm{~g}$} & \multirow[b]{2}{*}{$5 \mathrm{~g}$} & \multirow[b]{2}{*}{$25 \mathrm{~g}$} & \multirow[b]{2}{*}{$1 \mathrm{~g}$} & & \multirow[b]{2}{*}{$44 \mathrm{mg}$} & \multirow[b]{2}{*}{400} & \multirow[b]{2}{*}{$5 \%$} \\
\hline & & & & & & & & \\
\hline & $\begin{array}{l}\text { KD- } \\
222 \mathrm{C} \\
(\mathrm{g})\end{array}$ & $\begin{array}{l}\text { ES- } \\
5600 \\
(\mathrm{~g})\end{array}$ & $\begin{array}{l}\text { Min. } \\
\text { Oil } \\
\text { (g) }\end{array}$ & $\begin{array}{l}\text { SR- } \\
335 \\
(\mathrm{~g})\end{array}$ & $\begin{array}{l}\text { CN- } \\
972 \\
(\mathrm{mg})\end{array}$ & $\begin{array}{l}\text { BME } \\
(\mathrm{mg})\end{array}$ & $\begin{array}{l}\mathrm{UV} \\
\left(\mathrm{mj} / \mathrm{cm}^{2}\right)\end{array}$ & $\begin{array}{l}\text { Cross- } \\
\text { linkage }\end{array}$ \\
\hline $\begin{array}{l}\text { SB-CN972- } \\
5-100\end{array}$ & $5 \mathrm{~g}$ & $5 \mathrm{~g}$ & $25 \mathrm{~g}$ & $1 \mathrm{~g}$ & 167 & $44 \mathrm{mg}$ & 100 & $5 \%$ \\
\hline $\begin{array}{l}\text { SB-CN972- } \\
5-400\end{array}$ & $5 \mathrm{~g}$ & $5 \mathrm{~g}$ & $25 \mathrm{~g}$ & $1 \mathrm{~g}$ & $\begin{array}{l}167 \\
\mathrm{mg}\end{array}$ & $44 \mathrm{mg}$ & 400 & $5 \%$ \\
\hline & $\begin{array}{l}\text { KD- } \\
222 \mathrm{C} \\
(\mathrm{g})\end{array}$ & $\begin{array}{l}\text { ES- } \\
5600 \\
(\mathrm{~g})\end{array}$ & $\begin{array}{l}\text { Min. } \\
\text { Oil } \\
\text { (g) }\end{array}$ & & & $\begin{array}{l}\text { BME } \\
(\mathrm{mg})\end{array}$ & $\begin{array}{l}\mathrm{UV} \\
\left(\mathrm{mj} / \mathrm{cm}^{2}\right)\end{array}$ & $\begin{array}{l}\text { Cross- } \\
\text { linkage }\end{array}$ \\
\hline SB-0-100 & 15 & 5 & 2.5 & - & - & 46 & 100 & - \\
\hline SB-0-400 & 15 & 5 & 2.5 & - & - & 46 & 400 & - \\
\hline KD-222C & 25 & - & - & - & - & - & - & - \\
\hline
\end{tabular}

Note: BME: Benzoin Methyl Ether. UV time exposure was set to $1 \mathrm{~min}$.

\section{Conclusions of Part III}

For acrylic based PSA, when the crosslinker level is less than $10 \%$, the crosslinker has no effect PSA properties. When the level reached 30\%, PSA almost lost its tackiness. Thus it is desirable to keep the crosslinker level less than 10\%. Rubber based PSA can form crosslinking itself under UV, thus the added crosslinker level is low. Screenability test showed that all the polyacrylic (Carbotac 26171) based PSAs were not totally screenable, while all rubber based PSAs were screenable. Without nitrogent protection, crosslinking reaction was slow. The screenability of UV crosslinked PSA has been fully studied by University of Minnesota and H.B. Fuller company.

\section{References}

1. Sasaki, H., Shibano, T., and Yamakage, M. "Repulpable Pressure-sensitive Adhesive Tapes and Labels. Packaging Technology and Science 11, pp. 205-215. (1998).

2. Heise, O., Kemper, M., Wiese, H., Krauthauf, E. "Removal of Residual Stickies at Haindl Paper Using New Flotation Technology.” Tappi J. 83(3): 73-79 (2000).

3. Friberg, T. "Cost Impact of Stickies." Progress in Paper Recycling, pp. 70-72. November (1996)

4. Cauchon, D. "Paper Recyclers Unable to Lick Stickies Problem.” USA Today, Oct. 7, 1997. P.3A. 
5. Hodgson, K. "Surface Science and Process Factors Affecting Removal of Sticky Contaminants." Paper Recycling Challenge- Stickies Vol. 1. pp. 71-75. (1997).

6. Fogarty, T. "Cost Effective, Common Sense Approach to Stickies Control." Pulping Conference Proceedings, Book 2, Boston, MA: 429-438 (1992).

7. Alison, P. "Problem Solving Using Specialty Chemicals for Recycled-Fiber Processing." Paper South Africa. 12(5): 47-52 (1992).

8. Diaz, R. "Measurements of Interactions Between Fibers and Styrene Butadiene Rubber Based Pressure Sensitive Adhesives.” IPST Master's Thesis. Atlanta, GA. (June 1995).

9. Scholz, W. "Recycling Pressure Sensitive Adhesives." Pulping Conference Proceedings, Atlanta. Book 2: 501-506 (1993).

10. Hsu, N., Schroeck, J., Errigo, L. "Identification of the Origins of Stickies in Deinked Pulp." Recycling Symposium Proceedings. Chicago, IL: 331-339 (1997).

11. Douek, M. "Stickies." Paper Recycling Challenge- Stickies Vol. 1. pp. 15-21. (1997).

12. Ling, T. "Stickies Control by Chemical Modification of Stickies Surface." Proceedings of the 1991 TAPPI Pulping Conference. pp. 1039-1045.

13. Moreland, R.D. "Stickies Control by Detackification." 1986 TAPPI Pulping Conference Proceedings. TAPPI Press, Atlanta, GA. pp. 193-196. (1986).

14. Olsen, C.R., Letscher, M.K. "Increasing the Use of Secondary Fiber: An Overview of Deinking Chemistyr and Stickies Control.” Appita Journal 45(2). pp. 125-130. (1992).

15. Hsu, N. "Stickies- the Importance of Their Chemical and Physical Properties." Paper Recycling Challenge- Stickies Vol. 1. pp. 256-258. (1997).

16. Latimer, J. “Predicting 'white pitch' Problems.” Tappi J. 62(5): 29-31 (1979).

17. Wilhelm, D., Makris, S., Banerjee, S. "Signature of Recalcitrant Stickies in Recycled Newsprint.” Tappi J. 82(12): 63-66 (1999).

18. Patel, S., Banerjee, S. "Deposition of Hot Melt and Wax on Surfaces." Tappi J. 82(11): 99103 (1999).

19. Venditti, R., Chang, H., Jameel, H. "Overview of Stickies Research at NCSU.” Paper Age. pp. 18-20. (Nov 1999).

20. Cathie, K., Haydock, R, Dias, I. "Understanding the Fundamental Factors Influencing Stickies Formation and Depostition.” Pulp and Paper Canada. 93(12): 157-160 (1992). 
21. Doshi, M. R. "Properties and Control of Stickies.” Progress in Paper Recycling. pp. 54-63. (November 1991).

22. Bryuns, M., Rajan, K., Dayliss, R., Van Doren, S. "Contaminant Control by OCC Grading System.” Paper Recycling Challenge- Stickies. Vol. 1. pp. 292-295. (1997).

23. Yordan, J., Williams, G. "Talc for Contaminant Control in Recycled Fiber." Paper Recycling Challenge- Stickies. Vol. 1. pp. 76-80. (1997).

24. Bryuns, M., Rajan, K., Dayliss, R., Van Doren, S. "Contamination Control by OCC Grading System.” Paper Recycling Challenge-Stickies. Vol. 1. pp. 292-295. (1997).

25. Hawes, J. "Design Considerations for Paper Machine Clothing in Secondary Fiber." Paper Recycling Challenge-Stickies. Vol. 1. pp. 76-80. (1997).

26. ASTM, D-1878-61T; Pressure Sensitive Tack of Adhesives, American Society for Testing and Materials, Philadelphia.

27. Zosel, A., Adhesion, 3, 17 (1966).

28. Caton, P., European Adhesives and Sealants, 12, 18 (1990).

29. Benedek, I. and Heymans, L.J., Pressure Sensitive Adhesive Technology, Marcel Dekker, Inc, New York, 214 (1997). 